University of Louisville

ThinkIR: The University of Louisville's Institutional Repository

Electronic Theses and Dissertations

$12-2017$

\title{
Artificial olfactory system for multi-component analysis of gas mixtures.
}

Alexander Aleksandrovich Larin

University of Louisville

Follow this and additional works at: https://ir.library.louisville.edu/etd

Part of the Condensed Matter Physics Commons, Engineering Physics Commons, Materials

Chemistry Commons, Membrane Science Commons, Physical Chemistry Commons, Semiconductor and

Optical Materials Commons, and the Systems Engineering Commons

\section{Recommended Citation}

Larin, Alexander Aleksandrovich, "Artificial olfactory system for multi-component analysis of gas mixtures." (2017). Electronic Theses and Dissertations. Paper 2866.

https://doi.org/10.18297/etd/2866

This Doctoral Dissertation is brought to you for free and open access by ThinkIR: The University of Louisville's Institutional Repository. It has been accepted for inclusion in Electronic Theses and Dissertations by an authorized administrator of ThinkIR: The University of Louisville's Institutional Repository. This title appears here courtesy of the author, who has retained all other copyrights. For more information, please contact thinkir@louisville.edu. 


\title{
ARTIFICIAL OLFACTORY SYSTEM FOR MULTI-COMPONENT ANALYSIS OF GAS MIXTURES
}

\section{By}

Alexander Aleksandrovich Larin

B.S. Western Kentucky University, 2012

\author{
A Dissertation \\ Submitted to the Faculty of the \\ College of Art and Sciences of the University of Louisville \\ In Partial Fulfillment of the Requirements \\ for the Degree of
}

Doctor of Philosophy

in Physics

Department of Physics and Astronomy

University of Louisville

Louisville, Kentucky

December 2017 
Copyright 2017 by Alexander Aleksandrovich Larin

All rights reserved 



\title{
ARTIFICIAL OLFACTORY SYSTEM FOR MULTI-COMPONENT ANALYSIS OF GAS MIXTURES
}

\author{
By
}

Alexander Aleksandrovich Larin

B.S. Western Kentucky University, 2012

A Dissertation Approved on

November 1, 2017

By the following Dissertation Committee:

Dr. Gamini Sumanasekera

Dr. Vladimir Dobrokhotov

Dr. Sergio B. Mendes

Dr. Chakram S. Jayanthi 


\section{ACKNOWLEDGMENT}

I would like to express my deepest appreciation to both of my advisors Dr. Vladimir Dobrokhotov and Dr. Gamini Sumanasekera who supported me throughout my PhD program. I am very thankful to Dr. Vladimir Dobrokhotov for providing me with opportunity to achieve my long-term research and academic goals. His exceptional knowledge and outstanding experience have a great impact on my career and he is an inspiration to me. It was a pleasure of being a part of his research group at WKUAPI for many years. I am also especially grateful to Dr. Gamini Sumanasekera who provided me with a great experience and the benefit of his exceptional knowledge throughout my $\mathrm{PhD}$ program. His outstanding experience in experimental physics in combination with theoretical knowledge provided great support for my research. I would like to say special thank you to Dr. Chakram S. Jayanthi, Chair of the Department of Physics and Astronomy at University of Louisville, for understanding and full support during the entire $\mathrm{PhD}$ program. I would like to express my appreciation and gratitude to Dr. Chris Davis, Graduate Program Director at University of Louisville who supervised me during the entire graduate school. His brilliant advice saved me a great deal of time and minimized the amount of paper work that had to be done. I would like to acknowledge all the members of my Ph.D. committee Dr. Gamini Sumanasekera, Dr. Vladimir Dobrokhotov, Dr. Sergio B. Mendes, Dr. Chakram S. Jayanthi for their significant input toward my work including 
important comments, suggestions and questions. I also would like to say thank you to Dr. Julia Aebersold, Director of the Clean Room facility at University of Louisville and all the support engineers for providing an exceptional service. I am also fully appreciating for the help provided by Dr. Phillip Womble a chief scientist at Vaon LLC. He dedicated the best of his experience and knowledge to revise the dissertation. 


\begin{abstract}
ARTIFICIAL OLFACTORY SYSTEM FOR MULTI-COMPONENT ANALYSIS OF GAS MIXTURES

Alexander Aleksandrovich Larin

November 1, 2017
\end{abstract}

Gas analysis is an important part of our world and gas sensing technology is becoming more essential for various aspects of our life. A novel approach for gas mixture analysis by using portable gas chromatography in combination with an array of highly integrated and selective metal oxide (MOX) sensors has been studied. We developed a system with small size ( $7 \times 13 \times 16$ inches), low power consumption $(\sim 10 \mathrm{~W})$ and absence of special carrier gases designed for portable field analysis (assuming apriori calibration). Low ppb and even sub-ppb level of detection for some VOCs was achieved during the analysis of $50 \mathrm{ml}$ of gas samples. A detailed description of our innovative design of multisensory platforms based on MOX sensors for multidimensional portable gas chromatography is provided in detail in this work. As a part of this effort, we successfully synthesized nanocomposite gas sensors based on $\mathrm{SnO}_{2}$ for selective detection of hydrogen sulfide, mercaptans, alcohols, ketones and heavy hydrocarbons. The morphology of the prepared sensors was closely studied by scanning electron microscopy (SEM), atomic force 
microscopy (AFM), transition electron microscopy (TEM) and X-Ray diffraction (XRD). Optical and electrical properties of polycrystalline $\mathrm{SnO}_{2}$ were investigated by using UVVis spectroscopy, transmission line measurement (TLM) and four probe resistance measurement techniques. Furthermore, more advanced gas sensing performance for detection of benzene, toluene, ethylbenzene, and O-xylene (BTEX) of polycrystalline $\mathrm{SnO}_{2}$ film $(30 \mathrm{~nm})$ coated with bimetal Au:Pd (9:1 molar ratio) nanoclusters was measured. Finally, besides the experimental result, the theoretical validation of the detector's performance was provided based on high catalytic activity of nanocomposite materials and its superior electronic structure for gas detection compared to the polycrystalline $\mathrm{SnO}_{2}$. The theoretical background of gas chemisorption process at the surface of polycrystalline $\mathrm{SnO}_{2}$ was reviewed in this work. Furthermore, one dimensional Poisson equation relates surface energy states $\left(E_{c,}^{s} E_{v}^{s} E_{b . g}^{S}\right.$ and $\left.E_{f}^{s}\right)$ and the bulk electronic structure $\left(E_{c,}^{b} E_{v}^{b} E_{b . g}^{b}\right.$ and $\left.E_{f}^{b}\right)$ of polycrystalline $\mathrm{SnO}_{2}$. The main theory of electronic processes on the surface of semiconductors during the gas chemisorption was further applied in a case of nanocomposite materials. 


\section{TABLE OF CONTENTS}

ACKNOWLEDGMENT...................................................................................... ii

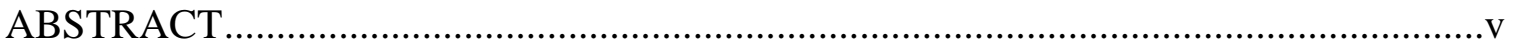

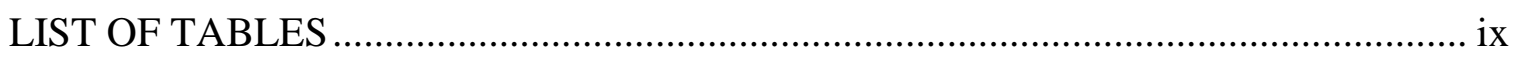

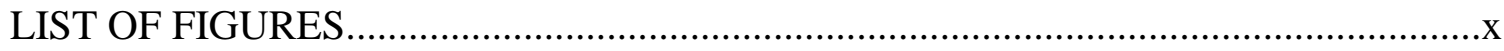

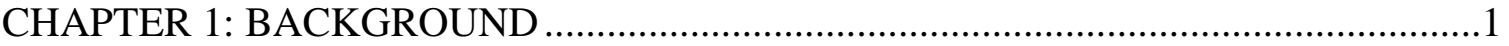

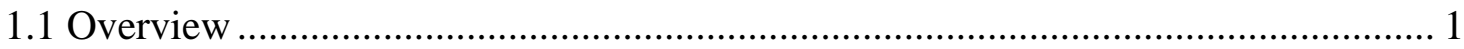

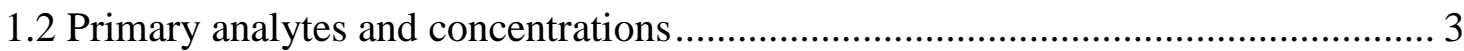

1.3 Overview of different methods and instruments for gas mixture analysis ................ 5

1.4 Physical principles and methods of gas detection................................................ 11

1.4.1 Electrical methods ……………………………..........................................11

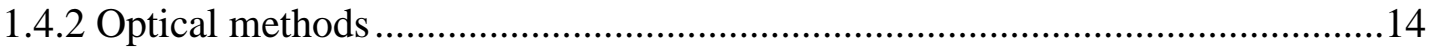

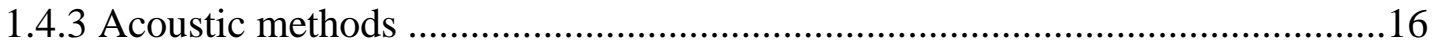

1.4.4 Calorimetric methods ..............................................................................

1.4.5 Comparative analysis of gas sensing methods ................................................18

1.5 Solid-state semiconductor gas sensors ............................................................... 23

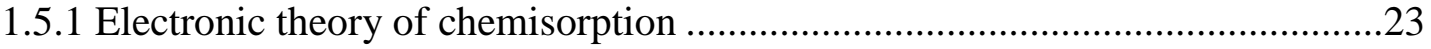

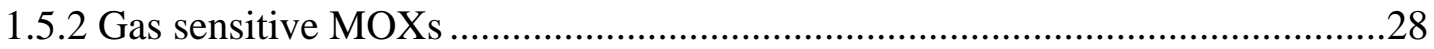

1.5.3 Synthesis and deposition methods of $\mathrm{SnO}_{2}$ gas sensing layer...........................30

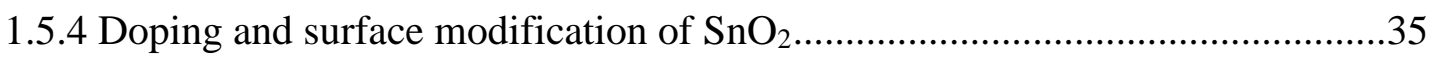

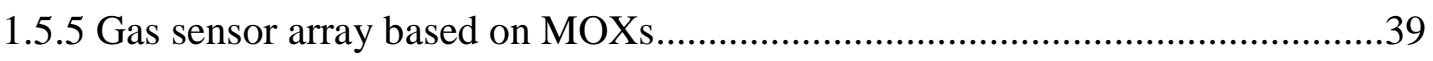

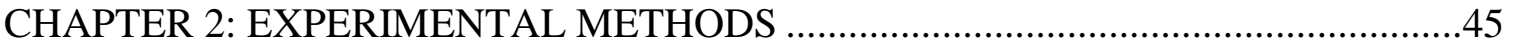

2.1 Design, modeling and fabrication of multi-sensor platform ................................... 45

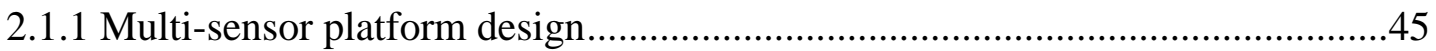

2.1.2 Modeling and simulation of the multi-sensor platform ....................................50

2.1.3 Multi-sensor platform fabrication...................................................................52

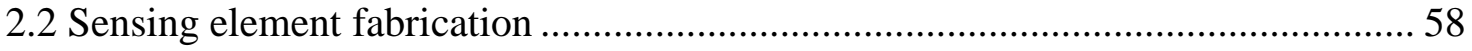

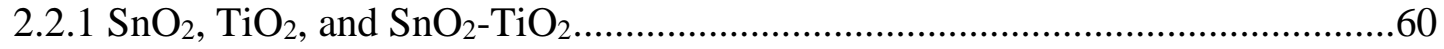

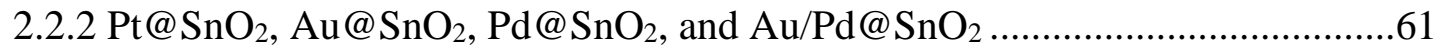


2.2.3 Multiple sensing element fabrication on a single platform 62

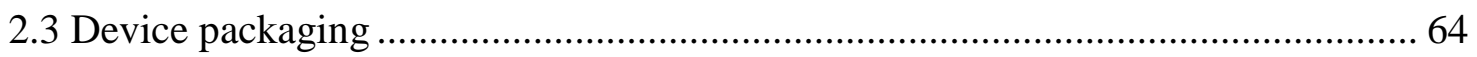

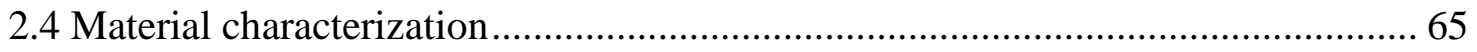

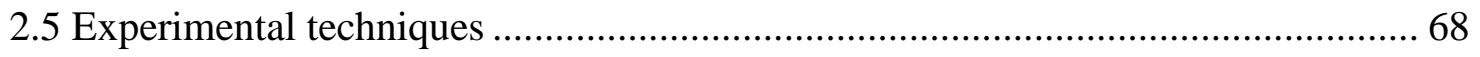

2.6 Gas sampling and delivery systems ........................................................... 70

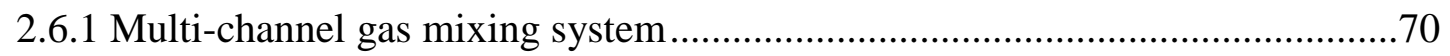

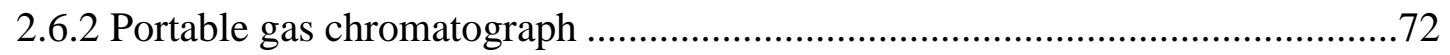

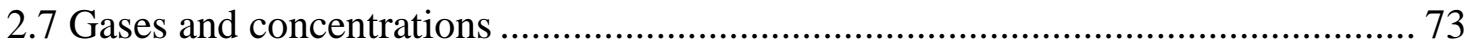

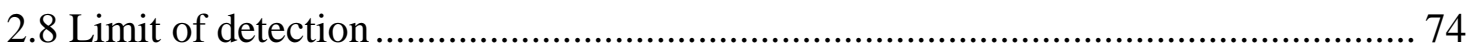

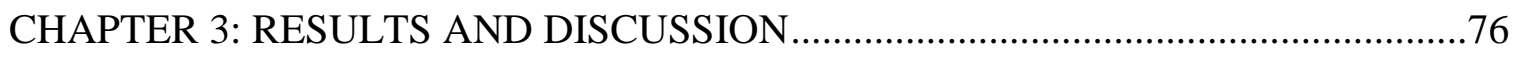

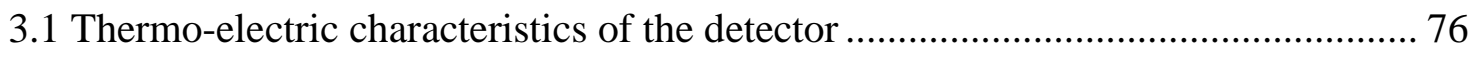

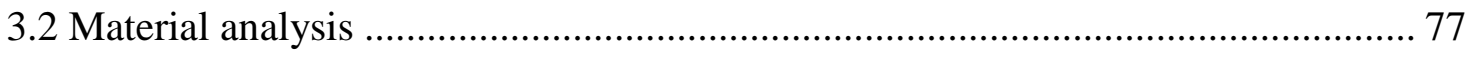

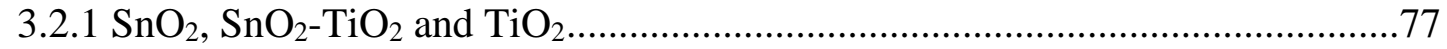

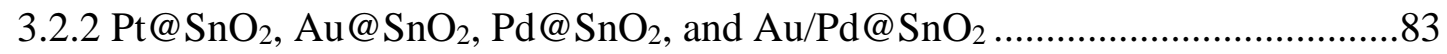

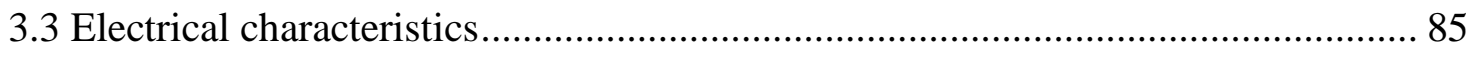

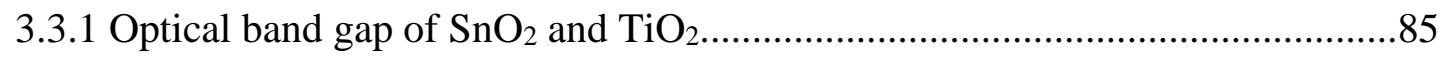

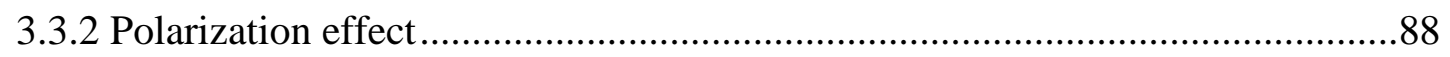

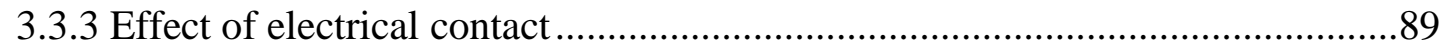

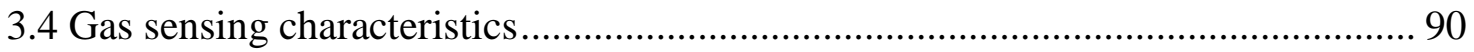

3.4.1 $\mathrm{H}_{2} \mathrm{~S}$ detection with $\mathrm{SnO}_{2}, \mathrm{TiO}_{2}$ and $\mathrm{SnO}_{2}-\mathrm{TiO}_{2}$ gas sensors .......................... 91

3.4.2 Detection of BTEX compounds with $\mathrm{Au}, \mathrm{Pd}$ and $\mathrm{Au} / \mathrm{Pd}-\mathrm{doped} \mathrm{SnO}_{2}$ gas

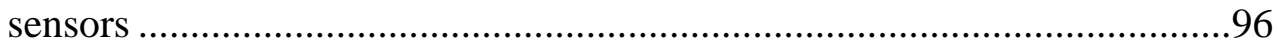

3.4.3 Multi-component analysis of complex gas mixtures ...................................104

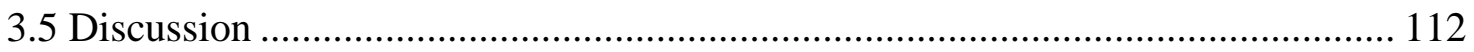

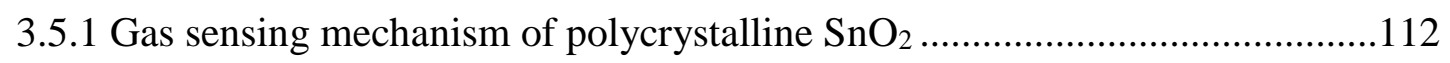

3.5.2 Gas sensing mechanism of $\mathrm{TiO}_{2}-\mathrm{SnO}_{2}$ hybrid sensor ................................114

3.5.3 Noble metal nanoparticles and gas sensing mechanism of $\mathrm{Pt}, \mathrm{Au}, \mathrm{Pd}$ and $\mathrm{Au} / \mathrm{Pd}$-doped $\mathrm{SnO}_{2}$ gas sensors ..........................................................120

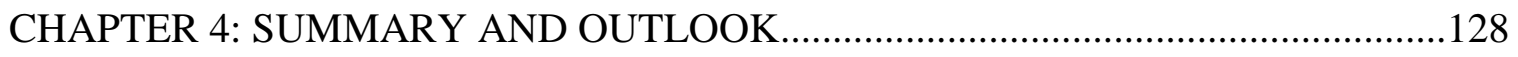

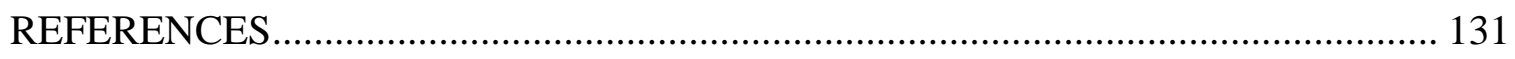

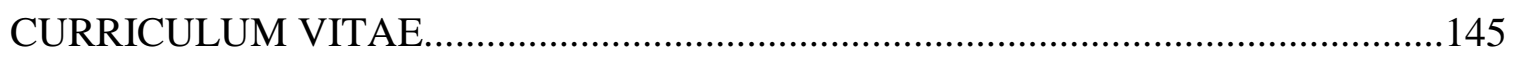




\section{LIST OF TABLES}

Table 1.1 Major characteristics of some portable GCs with different detectors. ............. 10

Table 1.2 Comparative analysis of gas sensing methods and techniques...................... 20

Table 1.3 Different methods of $\mathrm{SnO}_{2}$ synthesis and deposition.................................. 31

Table 1.4 Different type of $\mathrm{SnO}_{2}$ doping for selective detection of specific gases. ......... 38

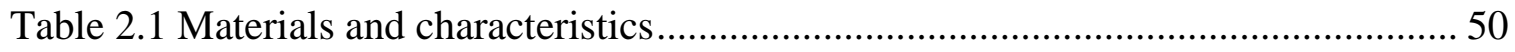

Table 2.2 Results from thermo-electric simulation of the multi-sensory platform.......... 52

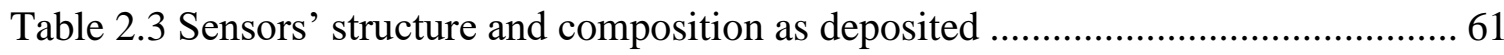

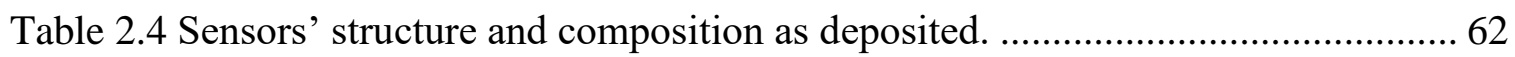

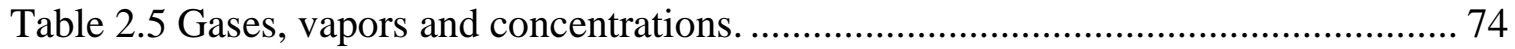

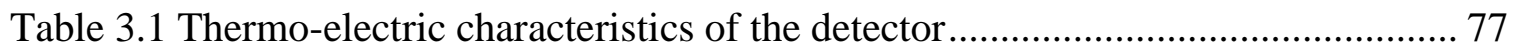

Table 3.2 Some important characteristics of the metal nanoparticles. .......................... 85

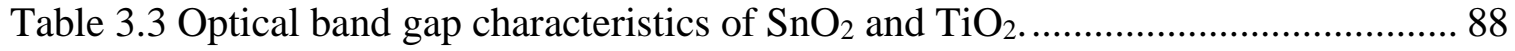

Table 3.4 Optimal operational temperature of the sensors S.1.0-S.1.6 ........................ 92

Table 3.5 Response and recovery time of the sensors S.1.0-S.1.6. ............................ 93

Table 3.6 Some important reports on $\mathrm{SnO} 2$ and $\mathrm{SnO} 2$ doped $\mathrm{MOX}$ gas sensors for

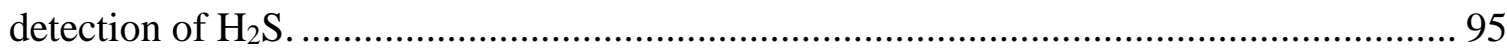

Table 3.7 Performance characteristics of the sensors S.1.0, S.2.1-S.2.3 under detection of

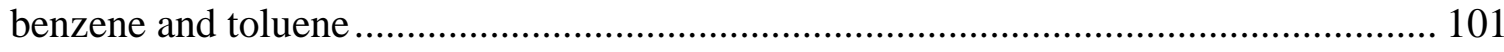

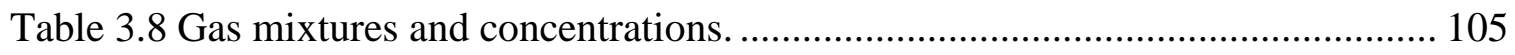




\section{LIST OF FIGURES}

Figure 1.1 Some important applications of gas analysis......................................... 2

Figure 1.2 The target gases for detection and analysis by revenue (left) in 2014 and

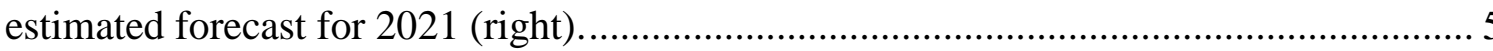

Figure 1.3 A diagram of some important methods for gas mixture analysis. .................. 6

Figure 1.4 A diagram of general algorithm for gas mixture analysis. ........................... 7

Figure 1.5 A schematic diagram of classical gas chromatograph................................. 9

Figure 1.6 A classification diagram of major gas sensing methods. ............................ 11

Figure 1.7 (a) Different types of gas sensors, detectors and analyzers,(b) market analysis by revenue from 2014 for gas sensors, detectors and analyzers and (c) revenue analysis by the different types of gas detectors.

Figure 1.8 (a) Flat band structure and (b) band bending after oxygen ion sorption at the surface of n-type semiconductor, where $\phi$ is the work function inside (bulk) the MOX and $\phi$ ' is the work function at the surface of the MOX due to the chemisorption process, $\chi$ is the electron affinity, $\mu$ is the electrochemical potential, $q V_{s}$ is the band bending and $\mathrm{z}_{0}$ is the depth of depleted layer. $\mathrm{E}_{\mathrm{vac}}, \mathrm{E}_{\mathrm{cb}}, \mathrm{E}_{\mathrm{vb}}, \mathrm{E}_{\mathrm{f}}, \mathrm{E}_{\mathrm{g}}$ are the vacuum energy level, bottom of the conductive band, top of the valence band, Fermi level and band gap respectively. $\mathrm{E}_{\mathrm{cs}}$, $E_{\mathrm{vs}}$ are the values of conductive and valence band borders at the surface, $E_{d}$ and $E_{s s}$ are the levels of donors and surface states.

Figure 1.9 A schematic diagram of (a) porous layer and (b) compact layer approximation model with corresponding electronic band structure. 28

Figure 1.10 The most studied (a) n- and (b) p-type MOX semiconductors for gas sensing applications (internet search Web knowledge).

Figure 1.11 So-called "radar diagrams" of simultaneous response ( $\mathrm{R}_{\text {air }} / \mathrm{R}_{\text {gas }}$ ) of multisensory system of 24 sensors to different chemicals can be the basis of a pattern recognition algorithm. Note that each shape is reproducibly (within statistics) different from the others and thus rules for pattern recognition algorithms can be determined. ... 40 
Figure 1.12 An image of (a) portable KAMINA device with electronics and the detection chamber, (b) the amplified image of the KAMINA multi-sensory chip and (c) thermal imaging of the temperature distribution across the chip.

Figure 1.13 An image of (a) the array of four sensors based on micro hot plates, (b) the single micro hot plate with metal contacts on the top, and (c) the main layout of MOX gas detector based on micro hot plate technology.

Figure 2.1 A schematic diagram of MEMS based MOX gas sensors including main components and outline for (a) stacked structure and (b) planar structure.

Figure 2.2 An image of thermo-electric simulation of multi-sensor MOX detector by using finite element analysis with $\mathrm{COMSOL}^{\mathrm{TM}}$ Multiphysics.

Figure 2.3 Calculated (a) temperature distribution and (b) average temperature over sensing element as a function of membrane thickness and total activation power. 52

Figure 2.4 An image of multiple photo-masks for step by step fabrication of multi-sensor MOX detector: (a) mask 1, (b) mask 2, (c) mask 3, and (d) mask 4 with white color corresponds to transparent glass and the dark area is protected by thin chromium layer. 53

Figure 2.5 The multi-sensor platform step by step micro-fabrication process. 57

Figure 2.6 An image of the $\mathrm{Si} / \mathrm{SiO} 2$ wafer with multiple sensing platforms. 58

Figure 2.7 An image of multi-source magnetron sputtering deposition system for sensing element fabrication.

Figure 2.8 A zoomed image of the sensing element (a) before the MOX deposition, (b) after the deposition and (c) after the lift off process.

Figure 2.9 A schematics diagram of (a) mono-oxide single-layer, (b) bilayer and (c) multilayer structure.|

Figure 2.10 A zoomed image of a sensing element (a) before and (b) after sensing element deposition and (c) different sensing elements integrated onto one platform by using hard contact shadow mask technique.

Figure 2.11 A magnified image of the detector with (a) electrical and mechanical connections between the sensing platform and the modified transistor outline package and (b) optical image of the detector with passive air intake structure and small detector's volume $\left(<1 \mathrm{~cm}^{3}\right)$. 
Figure 2.12 Schematics diagrams of (a) four probe resistance measurement, (b) transmission line measurement, and (c) V-I characteristics of the sensing element. 70

Figure 2.13 A schematic diagram of (a) multi-channel gas mixing system with (b) total six different gases and (c) detector's chamber.

Figure 2.14 A schematic diagram of (a) portable GC unit with optical images of the (b) detector, (c) GC protection case, and (c) internal architecture of the unit. 73

Figure 2.15 The schematic diagram of the detection limit with sensor's noise (blue) and minimum detectable sensor's signal (red). 75

Figure $3.1(a, b)$ Optical images of the detector, (c) a temperature profile obtained with QFI thermal imaging station, (d) corresponding relation between average surface temperature of a sensing element and the total power dissipation across the micro-heater for both simulated and actual device and (e) the temperature distribution across a single

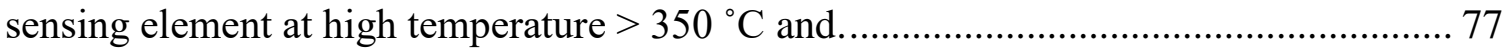

Figure 3.2 (a) SEM, (b) TEM and (c) AFM analysis of $\mathrm{SnO}_{2}$ thin film.......................... 78

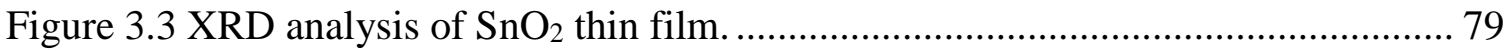

Figure 3.4 SEM images of the samples S.1.1-S.1.6: (a) $\mathrm{SnO}_{2} / \mathrm{TiO}_{2}$ bilayer structure $30 \mathrm{~nm}$ $+5 \mathrm{~nm}$ (S.1.1), (b) $\mathrm{SnO}_{2} / \mathrm{TiO}_{2}$ bilayer structure $30 \mathrm{~nm}+10 \mathrm{~nm}$ (S.1.2), (c) $\mathrm{SnO}_{2} / \mathrm{TiO}_{2}$ bilayer structure $30 \mathrm{~nm}+20 \mathrm{~nm}$ (S.1.3), (d) $\mathrm{SnO}_{2} / \mathrm{TiO}_{2}$ multilayer $5 \mathrm{vol} \%$ of $\mathrm{TiO}_{2}$ (S.1.4), (e) $\mathrm{SnO}_{2} / \mathrm{TiO}_{2}$ multilayer $20 \mathrm{vol} \%$ of $\mathrm{TiO}_{2}$ (S.1.5), (f) $\mathrm{SnO}_{2} / \mathrm{TiO}_{2}$ multilayer

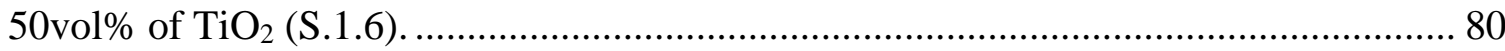

Figure 3.5 XRD analysis of (a) the samples S.1.0 - S.1.3 and (b) samples S.1.4 - S.1.6. 81

Figure 3.6 (a) SEM, (b) TEM and (c) AFM analysis of $\mathrm{TiO}_{2}$ thin film........................... 82

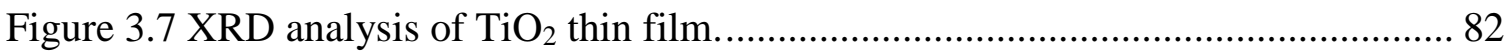

Figure 3.8 (a, d, g and j) SEM surface images of the samples S.2.0 - S.2.3, (b, e, h and k) TEM images of the simplified samples S.2.0 - S.2.3, and (c, f, i and l) nanoparticle size distribution calculated from the TEM analysis.

Figure 3.9 (a) UV-Vis spectroscopy of $\mathrm{SnO}_{2}, \mathrm{TiO}_{2}$ thin films and intensity of incoming light (blue) with no coating, (b) the calculated Tauc plot for the thin films with direct allowed transitions. 
Figure 3.10 A schematic representation of the process for (a) direct and (b) indirect allowed transitions inside semiconductors by using energy-momentum diagram, where $E_{p}$ is the energy of a phonon and $E_{g}$ is the band gap energy.

Figure 3.11 Tauc plots of (a) $\mathrm{SnO}_{2}$ and (b) $\mathrm{TiO}_{2}$ thin films for indirect allowed transitions

Figure 3.12 (a) V-I characteristics of thin $\mathrm{SnO}_{2}$ film at $300{ }^{\circ} \mathrm{C}$ and (b) resistance of the sensor as a function of polarization voltage across the platinum contacts under zero grade air and $300 \mathrm{ppm}$ of $\mathrm{CO}$.

Figure 3.13 (a) An image of fabricated device for TLM experiment and (b) $\mathrm{SnO}_{2}$ film resistance at $300{ }^{\circ} \mathrm{C}$ as a function of the distance between electronic contacts under zero grade air and $300 \mathrm{ppm}$ of $\mathrm{CO}$.

Figure 3.14 (a) Sensors resistance (zero grade air) under different temperature conditions $100-350{ }^{\circ} \mathrm{C}$, (b) resistance of the sensors in the present of $10 \mathrm{ppm}$ of $\mathrm{H}_{2} \mathrm{~S}$ as a function of temperature and (c) various response of the sensors toward $10 \mathrm{ppm}$ of $\mathrm{H}_{2} \mathrm{~S}$ over the temperature range.

Figure 3.15 (a) A response of the sensor (a) (S.1.5) multilayer and (b) (S.1.2) bilayer structure to different concentrations of $\mathrm{H}_{2} \mathrm{~S}(2-20 \mathrm{ppm})$ and (c) sensor response vs. concentration for all the sensors.

Figure 3.16 A response of the sensor (a) S.1.5 (multilayer structure) and S.1.2 (bilayer structure) to various gases and (b) response of sensor S.1.5 to sub-ppm concentrations of $\mathrm{H}_{2} \mathrm{~S}$ diluted in pure methane.

Figure 3.17 (a) Baseline resistance of the sensors S.1.0, S.2.1-S.2.3 in ultra-zero grade air, (b) the corresponding resistance of the sensors in pure nitrogen, and (c) calculated response of the sensors to presence of oxygen over the temperature range from 25 to 400 ${ }^{\circ} \mathrm{C}$

Figure 3.18 (a) The resistance of sensors S.1.0, S.2.1-S.2.3 in the presence of $0.5 \mathrm{ppm}$ of benzene, and (b) the calculated response of sensors S.1.0, S.2.1-S.2.3 to $0.5 \mathrm{ppm}$ of benzene over the temperature range from 25 to $400{ }^{\circ} \mathrm{C}$.

Figure 3.19 The average response of the sensors S.1.0, S.2.1-S.2.3 to different concentrations of (a) benzene and (b) toluene in a range between 12.5 and $500 \mathrm{ppb}$ under optimal operational temperature conditions (Table 3.6) were obtain from multiple experiments over a two week period. The error bars on the graphs correspond to statistical errors equal to three times the standard deviation. 100 
Figure 3.20 (a) A response of sensors S.1.0, S.2.1-S.2.3 to different relative humidity levels and (b) the response of the sensors to $0.5 \mathrm{ppb}$ of benzene under different humidity conditions.

Figure 3.21 (a) A response of the sensors S.1.0 and S.2.1-S.2.3 to $0.5 \mathrm{ppm}$ of $\mathrm{CO}, \mathrm{H}_{2} \mathrm{~S}$, acetone, ethanol, benzene and toluene, and (b) normalized response of the sensors. .... 103

Figure 3.22 Gas chromatogram of Mix. 1: (a) zoomed image of light compounds and (b) the full gas chromatogram. 106

Figure 3.23 (a) Gas chromatogram of 0.3 ppb of BTEX mixture, (b) integrated detector's response to $0.3 \mathrm{ppb}$ of BTEX mixture and integrated GC background signal. 107

Figure 3.24 Gas chromatogram of Mix. 2: (a) zoomed image of light compounds and (b) the full gas chromatogram. (1. Methane 99.99\%, 2. $\mathrm{H}_{2} \mathrm{~S} 100 \mathrm{ppb}$, 3. Ethyl-Mercaptan 50 $\mathrm{ppb}, 4$. Benzene $10 \mathrm{ppb}, 5$. Toluene $10 \mathrm{ppb}, 6$. Water, 7. Ethylbenzene $10 \mathrm{ppb}, 8$. OXylene $10 \mathrm{ppb})$.. 108

Figure 3.25 Gas chromatogram of Mix. 3 by using conventional non selective MOX detector (a) zoomed image of light compounds and (b) the full gas chromatogram. (1. CO $10 \mathrm{ppm}, 2 . \mathrm{H}_{2} \mathrm{~S} 100 \mathrm{ppb}, 3$. Ethyl-Mercaptan $50 \mathrm{ppb}$, 4. Acetone $50 \mathrm{ppb}$, 5. Ethanol 50 ppb, 6. Benzene $10 \mathrm{ppb}, 7$. Unknown, 8. Toluene $10 \mathrm{ppb}, 9$. Water, 10. Ethylbenzene 10 ppb, 11. O-Xylene $10 \mathrm{ppb}$ ).

Figure 3.26 Gas chromatogram of Mix. 3: (a) zoomed image of light compounds and (b) the full gas chromatogram. (1. CO $10 \mathrm{ppm}, 2 . \mathrm{H}_{2} \mathrm{~S} 100 \mathrm{ppb}$, 3. Ethyl-Mercaptan $50 \mathrm{ppb}$, 4. Acetone $50 \mathrm{ppb}$,5. Ethanol $50 \mathrm{ppb}, 6$. Benzene $10 \mathrm{ppb}$, 7. Unknown, 8. Toluene 10 ppb, 9. Water, 10. Ethylbenzene $10 \mathrm{ppb}, 11$. O-Xylene $10 \mathrm{ppb}$ ).

Figure 3.27 The calibration curves for (a) $\mathrm{SnO}_{2}$, (b) $\mathrm{TiO}_{2}-\mathrm{SnO}_{2}$, (c) $\mathrm{Au} / \mathrm{Pd} @ \mathrm{SnO}_{2}$ and (d) $\mathrm{Pt} @ \mathrm{SnO}_{2}$ obtained by integrating the total area under the sensor's response curve over

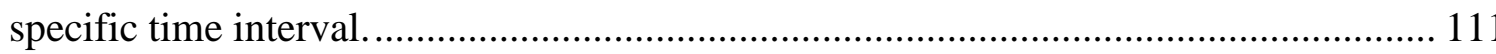

Figure 3.28 A simplified diagram of the conduction mechanism in polycrystalline $\mathrm{SnO}_{2}$ in the case of (a) depletion layer, (b) flat band, and (c) accumulation layer model. ...... 114

Figure 3.29 A schematic diagrams of flat energy band approximation of (a) $\mathrm{SnO}_{2}$ and $\mathrm{TiO}_{2}$ and (b) the $\mathrm{TiO}_{2}-\mathrm{SnO}_{2}$ heterojunction in vacuum.

Figure 3.30 (a) Electronic grain structure of a hybrid $\mathrm{SnO} / \mathrm{TiO} 2$ layer in ambient atmosphere and (b) upon exposure to $\mathrm{H}_{2} \mathrm{~S}$ 120

Figure 3.31 A schematic diagram of the gas sensing mechanism of polycrystalline $\mathrm{SnO}_{2}$ functionalized with (a) gold nanoparticles with the primarily chemical (spill-over) type of 
sensitization, and (b) palladium nanoparticles with the primarily electric (Fermi level) sensitization type.

Figure 3.32 A schematic diagram of the gas sensing mechanism of polycrystalline $\mathrm{SnO}_{2}$ functionalized with bimetal nanoparticles with a hybrid sensitization type, when spillover and electric mechanisms complement and amplify each other.............................. 126 


\section{CHAPTER 1: BACKGROUND}

\subsection{Overview}

The detection and analysis of gases and vapors is an important part of the modern world where gas sensing technology is becoming increasingly important for various aspects of our life. Gas sensing technologies improve the self-sustainability of our society and quality of everyday life. A variety of gas analysis techniques and gas detectors are regularly used to improve safety, establish more precise product quality control and process control $[1,2]$. Some industrial sectors such as food/medicine, automotive, heavy industry, environmental, security and home appliances have utilized gas analysis for a wide range of applications (Figure 1.1).

In the security sector, for example, indoor smoke and fire alarm detectors and alcohol and drugs intoxication analyzers are household items. However, more complex medical breath analysis, forensic analysis, and explosive trace detectors (e.g. airports) are an important part of public safety [3-6] . In addition, safety protection is one of the most important among end users, especially related to the increasing number of accidents connected to gas leakage and explosions of hazardous gases. High gas related security of production plants and workplaces is a necessary requirement from insurance companies that increase the demand for gas sensors, detectors and analyzers.

In heavy industry and food/medicine sector, air, water, food, or natural gas analysis with analytical instruments provides more reliable data for everyday product quality control [7-9]. Specifically, quality control and responsibility for industrial products have 
been gaining much attention since the enforcement of IS0 9000 standard certification.

Presently, the control of food quality is based on hand operated manual tests ran by special food experts. An automated method to replace the manual analysis is necessary to improve the speed and reliability of food quality monitoring [10]. The automated product quality control systems based on different types of gas sensors, detectors and analyzers are highly demanded by various industries. Finally, the gas analysis by using different instruments and techniques provides the essential data output to control some industrial processes. The system and process control by using gas analysis techniques is widely accepted in automotive and aircraft industry, air filtration systems, industrial plants, refineries, fumigation facilities, and waste-water treatment plants [11-14]. The gas sensors provide on-line measurement and feedback for real-time process control. For example, some new vehicle diagnostic and control processes include monitoring of a wide range of emission gases, including $\mathrm{NO}, \mathrm{NO} 2, \mathrm{CO}, \mathrm{CO} 2, \mathrm{HC}$, and $\mathrm{O} 2$ etc. in order to eliminate a high level of pollution [15].

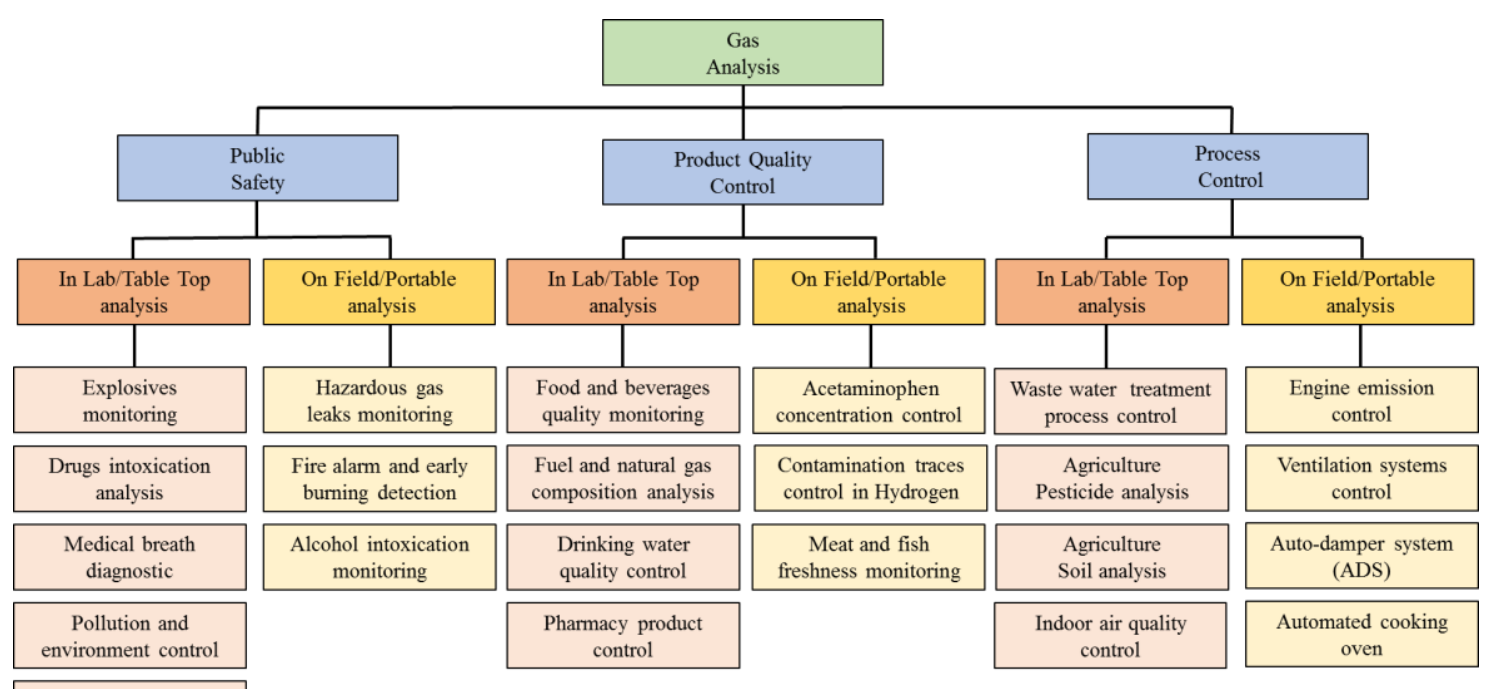

Figure 1.1 Some important applications of gas analysis. 
The minimum requirements for analysis of gas samples such as detection range and precision are the most important parameters that determine the type of gas analysis technique utilized in a system. The ongoing process of developing new gas sensing methods in parallel with improving the conventional state-of-the-art gas sensors, is primarily governed by modern technological processes and ecological standards that require better sensitivity, faster response and recovery time, better selectivity and improved stability from gas sensors. In this chapter we provide a broad overview of main target analytes, and gas analysis techniques involving state-of-the-art gas sensors, detectors along with complex analytical instruments.

\subsection{Primary analytes and concentrations}

Based on historic data from 2014 and the forecast analysis for the 2021 [16] , the gas analytes in highest demand are methane $\left(\mathrm{CH}_{4}\right)$, hydrogen sulfide $\left(\mathrm{H}_{2} \mathrm{~S}\right)$, carbon monoxide $(\mathrm{CO})$, oxygen $\left(\mathrm{O}_{2}\right)$, carbon-dioxide $\left(\mathrm{CO}_{2}\right)$, other hydrocarbons $\left(\mathrm{C}_{\mathrm{x}} \mathrm{H}_{\mathrm{y}}\right)$, sulfurdioxide $\left(\mathrm{SO}_{2}\right)$, nitrous oxide $(\mathrm{NO})$, nitrogen-dioxide $\left(\mathrm{NO}_{2}\right)$, ammonia $\left(\mathrm{NH}_{3}\right)$, chlorinedioxide $\left(\mathrm{ClO}_{2}\right)$ and volatile organic compounds (VOC) (Figure 1.2a,b) a. The demand for methane detection is the highest with a market share to be equal to $22.4 \%$ in 2014 . The importance of methane detection is related to a broad range of its applications, including oil and gas transportation, mining and gas turbines, domestic cooking and heating.

The second highest demand for detection with the market share equal to $20.3 \%$ was indicated for $\mathrm{H}_{2} \mathrm{~S}$. The dangerous level of $\mathrm{H}_{2} \mathrm{~S}$ concentration above 100 parts per million (ppm) makes its detection and intoxication prevention at early stages very important. Due to high toxicity the concentration of $\mathrm{H}_{2} \mathrm{~S}$ must be monitored across various industrial 
processes that involve natural gas, oil, sulfur production (Claus process) as well as water treatment and paper mills.

Carbon monoxide and $\mathrm{CO}_{2}$ are the other two important gases that account for $19.7 \%$ and $7.1 \%$ of total gas sensors market revenue in 2014, correspondingly. CO is a toxic gas that is generated by burning fuel inside car engines, stoves, lanterns, grills, fireplaces, gas ranges, or furnaces. The concentration level of $\mathrm{CO}$ in indoor air has to be constantly monitored to prevent human poisoning. The exposure limit for $\mathrm{CO}$, according to Occupational Safety and Health Administration (OSHA) is only 50ppm. Similarly, with concern about indoor air quality control, energy efficiency of industrial processes and outdoor air pollution, monitoring of $\mathrm{CO}_{2}$ became very important. The climate change and global warming seem to be correlated with the amount of carbon in the atmosphere. The tendency to reduce carbon emission from different manufacturing processes require to equip factories with $\mathrm{CO}_{2}$ detectors. At the same time, both gases $\mathrm{CO}_{2}$ and $\mathrm{CO}$ in combination with oxygen $\left(\mathrm{O}_{2}\right)$ have been widely monitored for indoor air quality, cryogenic suppliers, and medical breath analysis.

The detection of VOC's and other toxic and combustible gases such as hydrocarbons, sulfur-dioxide, ammonia, chlorine and etc. is an important part of modern gas sensors, detectors and analyzers market accounted for approximately 17.9\% in 2014 . 
PERCENT REVENUE BY TYPE OF GAS, GLOBAL 2014

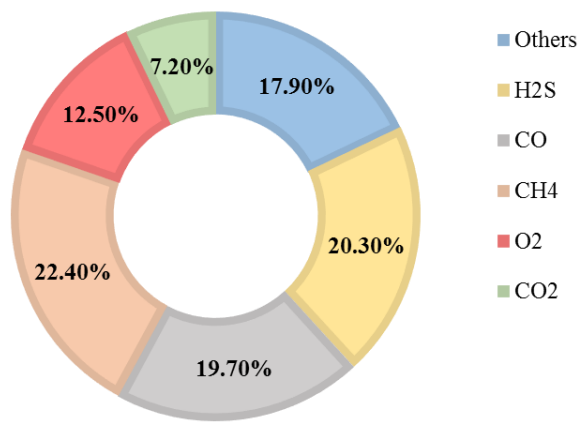

PERCENT REVENUE BY TYPE OF GAS, GLOBAL 2021

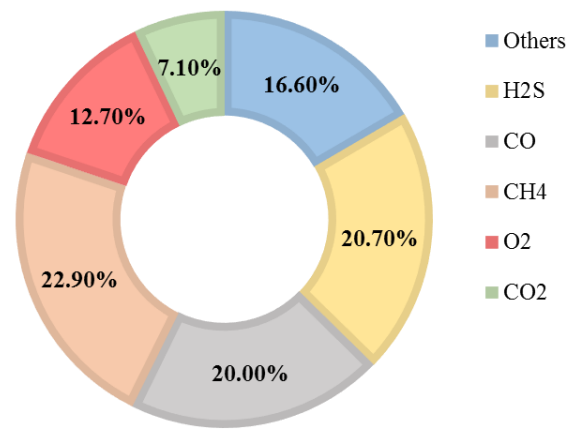

Others includes VOC's, hydrocarbons, sulfur-di-oxide, nitrous oxide, nitrogen-di-oxide, ammonia, chlorine, and chlorine-di-oxide.

Figure 1.2 The target gases for detection and analysis by revenue (left) in 2014 and estimated forecast for 2021 (right).

The application of gas sensors, detectors and analyzers in the area of public safety, quality control or system control show the importance of detection of some VOC's components such as alcohols (ethanol, propanol, and methanol), ketones (acetone), light hydrocarbons (methane, propane, and butane), and heavy hydrocarbons (benzene, toluene, ethylbenzene, xylene), sulfur components $\left(\mathrm{H}_{2} \mathrm{~S}\right.$, sulfur dioxide, and mercaptans) and others (CO, nitric oxide, ammonia). The detection of some specific gases in complex backgrounds as well as multi-component analysis of gas mixtures was determined to be critically important for field applications.

1.3 Overview of different methods and instruments for gas mixture analysis

Analytical instrumentation for gas sample analysis can be divided into three main categories: portable handheld devices that are based on selective gas sensors or an array of partially orthogonal sensors, semiportable gas analytical instruments with primitive gas sample preconditioning system and stationary devices for laboratory analysis with advanced gas sampling, conditioning and delivery systems (Figure 1.3). 


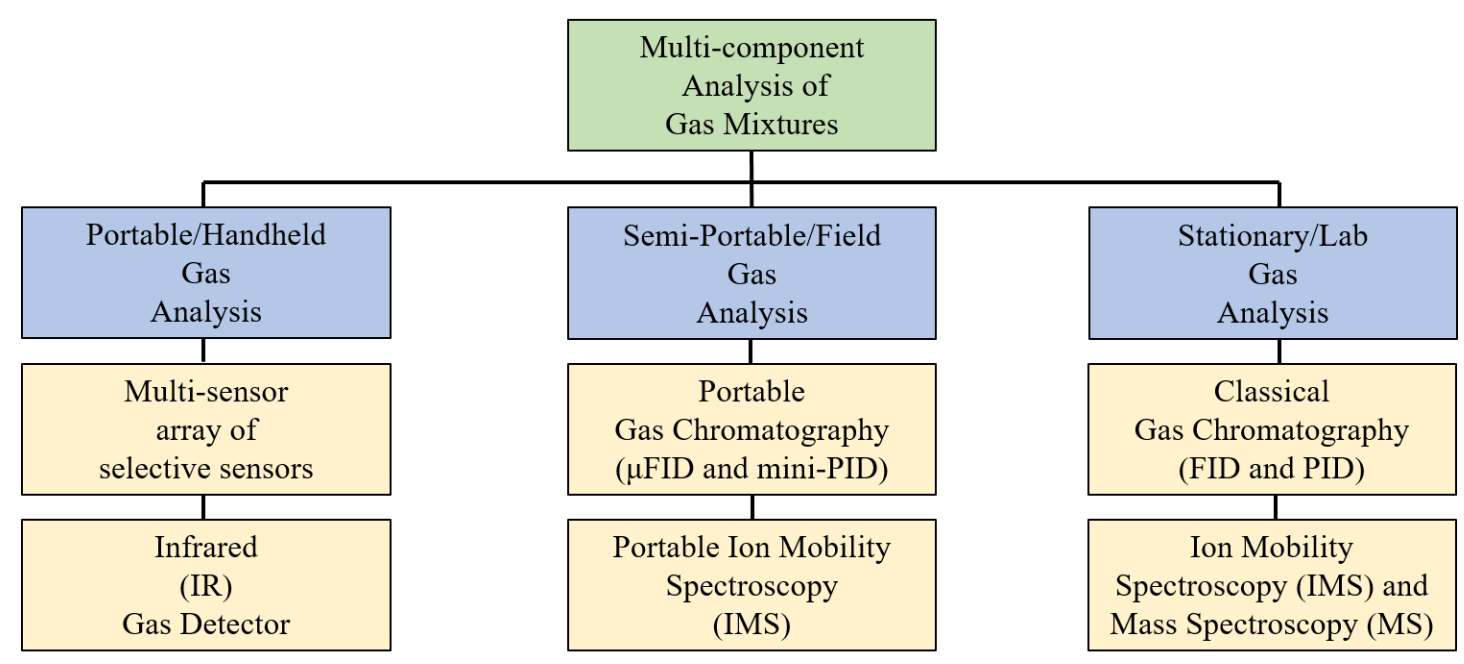

Figure 1.3 A diagram of some important methods for gas mixture analysis.

The first category of portable gas analyzers utilizes selective sensors (semiconductor, electrochemical, catalytic, infrared, etc.) in order to identify specific components in gas mixtures. Selective detection of target gases in the mixture is an essential part of portable gas analysis. The ability of passive detectors with selective sensors to detect signatures of some chemical components in gas mixtures has been previously reported [17-19]. The capability of those system to perform a real-time analysis is always a significant advantage. However, many gas sensing methods, which successfully detect individual gases in the ambient air, fail when employed in complex gas mixtures due to high cross-sensitivity. Additional filters such as optical/mechanical filters or protective membranes are necessary to solve the selectivity problem $[20,21]$. Also, the number of detectable gases is limited by the number of sensors in the array.

In contrast to the handheld devices, the stationary analytical instruments for laboratory analysis of gas mixtures can detect and measure concentrations of hundreds of 
different components in complex blends. Advanced sampling system, which includes collection, preconditioning and delivery of gas samples is the major difference between the laboratory instruments and portable/handheld devices. The most common analytical instruments based on mass spectroscopy, gas chromatography, or ion mobility spectroscopy have similar algorithms for gas mixture analysis (Figure 1.4).

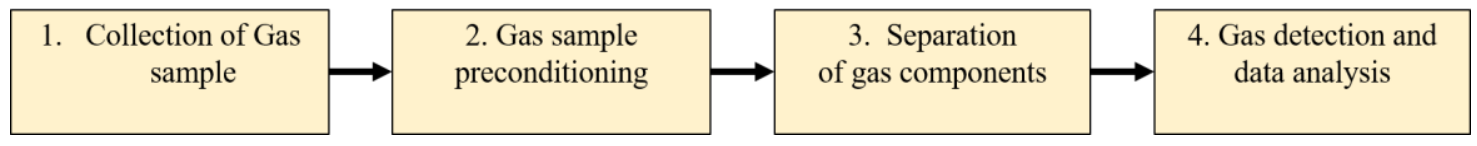

Figure 1.4 A diagram of general algorithm for gas mixture analysis.

The injection of fixed volume of gas sample is followed by sample preconditioning and separation of gas components prior to the detection. Despite a complex gas delivery system in the laboratory analytical instruments, the detectors utilized in them are rather basic. High accuracy of selective detection of gas components is primarily achieved through specific separation methods. A combination of two or more gas separation techniques in one instrument was determined to be very effective. For example, a combination of mass spectroscopy and gas chromatography (GC - MS) results in a very accurate analysis of gas mixtures. However, high complexity of analytical instruments allowed one to perform gas sample analysis under laboratory conditions only. Pressure control, special carrier gases, high power requirements, and excessive size make it impossible to utilize laboratory gas analyzers in the field. Also, the analysis time that takes from several minutes to half an hour, is another drawback of this method.

The new generation of gas analytical equipment is intended to provide a close to real-time sample analysis for fast and reliable on-site implementation. A novel highly 
integrated detector together with the advanced miniaturized sampling and separation system, are the key components for the novel portable gas analyzer. Recently, some portable gas analyzers were developed based on miniaturized ion mobility spectroscopy, portable infrared spectroscopy and portable gas chromatography [22-24]. Those instruments established a first step toward high quality field analysis of gas, liquid and solid samples at low cost. However, many problems in semi-portable gas analysis remain unsolved. Real time, non-destructive, direct, field analysis at low power consumption, with no special carrier gases, that provides wide detection range for variety of different chemicals is still unavailable for the general public.

In order to overcome some current limitations of semi-portable gas analytical instruments an optimal gas sample preconditioning system has to be integrated with powerful analytical detector into one system. For example, the analysis of gas samples by using gas chromatography (GC) in combination with a variety of detectors, such as flame ionization detector (FID), photo ionization detector (PID), pulse discharge detector (PDD) and thermal conductivity detector (TCD) or IR and UV spectroscopy is one of the most common techniques for gas mixture analysis. The gas separation method based on gas chromatography has some important advantages compare to the other methods. First of all, the separation of gas species inside the GC column can be done without ionizing the gas sample. Nondestructive separation of gasses is an advantage of the GC method compared to the separation of gasses done by MS and IMS methods. In addition, possible miniaturization of GC columns makes the separation technique available for portable devices. Finally, cost advantage of the GC gas analysis compare to mass spectroscopy is significant. The separation of the most common VOC compounds, sulfur compounds and 
etc. inside narrow tube with inner diameter of $10-50 \mu \mathrm{m}$, is related to specific chemical and physical properties of different chemicals. The chemicals from the gas sample are interacting with filling material inside the column under constant temperature and switching between solid (stationary phase) and gaseous (mobile phase) state. The main function of the stationary phase is to separate gas components with different time of retention prior the detection (Figure 1.5).

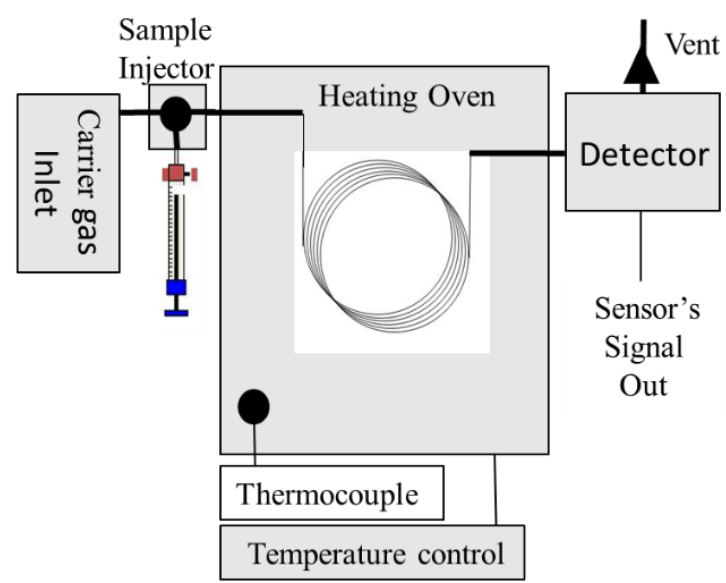

Figure 1.5 A schematic diagram of classical gas chromatograph.

Semi-portable miniaturized GCs with various kinds of detectors including mini PIDs, micro FIDs ( $\mu$ FID), surface acoustic wave (SAW) and on chip thermal conductivity ( $\mu$ SC-TCD) detectors have been recently developed (Table 1). The new sensors exhibit high sensitivity and selectivity toward VOCs at sub-ppm level in combination with compact size and low power consumption. However, the major drawback of the portable gas analyzers such as requirement of special carrier gases still has not been resolved.

Currently, novel types of sensors and detectors, such as surface modified quartz crystal micro-balance system (QCM), miniaturized molecularly imprinted polymers quartz 
crystal tuning forks (MIP-TF), and novel metal oxide (MOX) sensors have been investigated as detectors for real time portable gas analysis (Table 1.1). The weight, size and power consumption of miniaturized GC with the novel sensors has been drastically reduced making them suitable for portable field analysis using filtered air as a carrier gas. However, the sensitivity of such sensors without a long term pre-concentration procedure is extremely low and does not allow to perform the analysis of gas mixtures at ppb level.

Table 1.1 Major characteristics of some portable GCs with different detectors.

\begin{tabular}{|c|c|c|c|c|c|}
\hline $\begin{array}{l}\text { GC detectors for } \\
\text { portable field } \\
\text { analysis }\end{array}$ & $\begin{array}{l}\text { Carrier gas } \\
\text { and flow rate } \\
\left(\mathbf{m L ~} \mathbf{m i n}^{-1}\right)\end{array}$ & $\begin{array}{c}\text { Sampling } \\
\text { technique and } \\
\text { injecting } \\
\text { volume }(\mathrm{mL})\end{array}$ & $\begin{array}{c}\text { Limit of } \\
\text { detection } \\
\text { (LOD) } \\
\text { VOCs (ppb) } \\
\end{array}$ & $\begin{array}{c}\text { Time of one } \\
\text { cycle } \\
\text { analysis } \\
\text { (min) }\end{array}$ & References \\
\hline $\begin{array}{c}\text { Micro Flame } \\
\text { Ionization Detector } \\
(\mu \mathrm{FID})\end{array}$ & $\begin{array}{c}\text { Oxyhydrogen } \\
\text { (35) }\end{array}$ & N/A & $\begin{array}{l}\text { VOS's } \\
(100)\end{array}$ & N/A & {$[25]$} \\
\hline $\begin{array}{l}\text { Mini Photo } \\
\text { Ionization Detector } \\
\text { (mini PID) }\end{array}$ & $\begin{array}{c}\mathrm{N}_{2} / \mathrm{H}_{2} \\
(2.5-3.5)\end{array}$ & $\begin{array}{c}6 \text { port valve } \\
(0.2)\end{array}$ & $\begin{array}{l}\text { Benzene } \\
(<1)\end{array}$ & 10 & [26] \\
\hline $\begin{array}{c}\text { On chip Thermal } \\
\text { Conductivity } \\
\text { Detector }(\mu \mathrm{SC}- \\
\text { TCD) }\end{array}$ & $\begin{array}{c}\mathrm{He} \\
(1-5)\end{array}$ & $\begin{array}{c}\text { Pre- concentrator } \\
(10)\end{array}$ & $\begin{array}{l}\text { Benzene } \\
(<100)\end{array}$ & 14.5 & [27] \\
\hline $\begin{array}{l}\text { Surface Acoustic } \\
\text { Wave Detector } \\
\text { (SAW) }\end{array}$ & $\begin{array}{l}\mathrm{He} \\
(1-5)\end{array}$ & $\begin{array}{c}\text { 6-port valve }+ \\
\text { Pre-concentrator } \\
(30)\end{array}$ & $\begin{array}{l}\text { Benzene } \\
(<1)\end{array}$ & 1.3 & [28] \\
\hline $\begin{array}{c}\text { Micro Quartz } \\
\text { Crystal Tuning } \\
\text { Forks } \\
\text { (MIP-TF) }\end{array}$ & $\begin{array}{l}\text { filtered ambient } \\
\text { air } \\
(8)\end{array}$ & $\begin{array}{c}3 \text { way valve } \\
\text { Online sampling }\end{array}$ & $\begin{array}{l}\text { Benzene } \\
(10000)\end{array}$ & 4 & [29] \\
\hline $\begin{array}{l}\text { Metal Oxide } \\
\text { MEMS sensor } \\
\text { array }(\mathrm{MOX})\end{array}$ & $\begin{array}{l}\text { filtered ambient } \\
\text { air } \\
(15)\end{array}$ & $\begin{array}{c}3 \text { way valve }+ \\
\text { Pre-concentrator } \\
(2700)\end{array}$ & $\begin{array}{l}\text { Benzene } \\
(0.1)\end{array}$ & 60 & [30] \\
\hline
\end{tabular}

The desirable detector for portable GC should operate under standard atmospheric conditions (pressure and temperature) without special carrier gases and also provide enough sensitivity for selective analysis of gas components at low ppb level. The miniature 
size, low power consumption, low fabrication cost, and low maintenance are also important requirements of the detector. In order to meet all of the requirements, an overview of gas sensing methods has to be performed and natural limitations of each sensing method have to be underlined.

1.4 Physical principles and methods of gas detection

Different types of gas sensors and detectors have been developed in the past based on different gas sensing mechanisms. Electrical, optical, acoustic and thermal gas sensing methods were successfully utilized. These methods are based on converting the gas concentration into a corresponding measurable physical quantity. Some of those mechanisms and quantities are listed in the Figure 1.6.

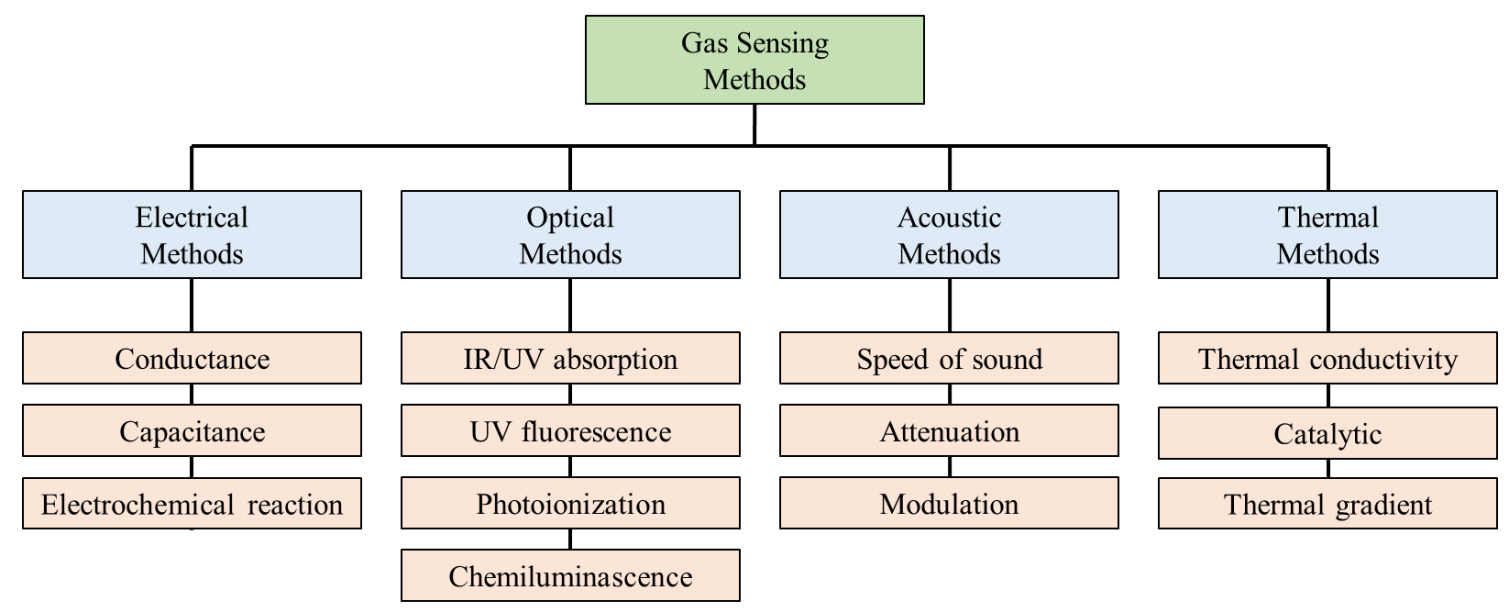

Figure 1.6 A classification diagram of major gas sensing methods.

\subsubsection{Electrical methods}

The most common gas sensing method is based on variations in electrical properties of sensing material upon exposure to target gases. The conductometric technique is related to the change in conductance/resistivity of sensing element when exposed to different gas 
environment [31]. The electronic interaction between gas molecules and sensor's surface governed by the density of electronic states and the total energy available for the interaction. Good examples of chemo-resistive sensing elements are different transitional and non-transitional MOXs $\left(\mathrm{SnO}_{2}, \mathrm{ZnO}, \mathrm{V}_{2} \mathrm{O}_{5}\right.$, and $\left.\mathrm{WO}_{3}\right)$, or carbon nano-structure (graphene and graphene oxide, carbon nanotubes (CNT)). Conductometric sensors (chemiresistors) typically are simple in design, have high sensitivity and fast response at low power consumption. However, a substantial long-term drift of these sensors complicates their utilization in analytical instruments. Also, most of the conductometric sensors are broadly tuned and non-specific. At the same time, some reports claim that the surface modification of chemiresistors can make them selective to specific chemical groups. It was shown that highly integrated array of conductometric sensors can be successfully utilized for analysis of simple gas mixtures [32-35].

Another gas sensing method, which is based on capacitance change, is widely used in the process of gas detection [36]. Capacitive humidity sensors were successfully commercialized in the past. The technique is based on monitoring the change in dielectric constant or/and the change in dielectric layer thickness upon exposure to gas. A miniaturized stable and reliable chemicapacitor was reported by Zamani et al. [37]. The selective detection of $\mathrm{CO}_{2}$ and $\mathrm{NO}$ is the key feature of chemicapasitors. However, their sensitivity is relatively poor and allows for detection of only parts per millions (ppm) with a special amplifier circuit. Also, slow time of response and recovery of chemicapasitors is another drawback of the method.

Electrochemical sensors, utilizing electrochemical reactions between target gas and ionic liquids, currently have the largest market share globally. The electrochemical sensing 
method is based on electroactive gaseous species, which react within the electrochemical cell by either producing or consuming electrons [38]. The reaction rate is sensitive to environmental changes. The electrochemical techniques are categorized as being either potentiometric or amperomentric. The potentiometric approach based on increase in potential difference between the working and counter electrodes inside the electrochemical cell according to the Nernst equation $[39,40]$. The amperometric gas sensing technique is related to the change in electric current between working and counter electrodes at fixed potential inside the electrochemical cell [41, 42]. The electrochemical technique of detection has shown significant advantages compared to other detection methods. Modern electrochemical sensors provide high sensitivity at relatively low cost and compact size in combination with low power consumption. Selective detection of specific gaseous compounds $\left(\mathrm{O}_{2}, \mathrm{CO}_{2}, \mathrm{CO}, \mathrm{PH}_{3}, \mathrm{C}_{\mathrm{x}} \mathrm{H}_{\mathrm{y}}, \mathrm{NH}_{3}, \mathrm{H}_{2} \mathrm{~S}, \mathrm{SO}_{2}, \mathrm{ClO}_{2}, \mathrm{NO}_{\mathrm{x}}, \mathrm{O}_{3}, \mathrm{H}_{2} \mathrm{O}_{2}, \mathrm{H}_{2}\right.$ and etc.) inside the electrochemical cell is the strength of the method which allowed to develop very selective gas sensors. Electrochemical sensors were proven to be very robust under standard sensing environment $\left(-40\right.$ to $\left.50{ }^{\circ} \mathrm{C}, 20-90 \% \mathrm{RH}, \sim 1 \mathrm{~atm}\right)$. The drawback of electrochemical sensors is their relatively short lifetime from 6 months to one year. Also, high cross sensitivity to gaseous compounds within the same chemical group, such as hydrocarbons, and small (2-10\%) cross sensitivity between different chemical groups $\left(\mathrm{O}_{2}\right.$ and $\mathrm{CO}_{2}$ ) is a limitation of the method. Another drawback of the technique is very long time of response. The delay between gas exposure and gas detection is limited by the diffusion time through the sensors' membrane. According to some recent reports on amperometric gas sensors, the time of response for different commercial sensors is varying between 11 and $25 \mathrm{sec}$ [42]. High selectivity and stability, low detection limit (sub-ppm) 
and simplicity are the key components of the global success of the electrochemical method. However, the multi-component analysis of gaseous mixtures by using electrochemical sensors is hard to accomplish with a single detector. An integrated sensor array can be much more comprehensive for multi-component analysis. Currently, the size limitations of electrochemical sensors make it impossible to build a highly-integrated array of sensors for synchronized analysis of gas mixtures. Also, the amount of sensors needed for gas mixture analysis should be equal to the amount of detectable gases.

\subsubsection{Optical methods}

Optical methods are mainly based on IR and UV spectroscopy, photoionization, and chemiluminescence $[43,44]$. They provide higher sensitivity down to sub-ppm level in combination with long lifetime and operational stability. Short response and recovery time is another advantage of optical sensors, which is important for real-time gas analysis. However, the main disadvantage of optical methods is relatively high cost and complexity of optical detectors. Several different optical techniques based on absorption and emission spectroscopy have been developed in the past. The theory of photon absorption by gas at specific wavelengths (i.e., Beer-Lambert law) determines the working principle of absorption spectroscopy. Some well-known specific absorption spectroscopic approaches includes Differential Absorption LIDAR (DIAL) [45, 46], Differential Optical Absorption Spectroscopy (DOAS) [47], Raman Light Detection and Ranging (LIDAL) [48], Tunable Diode Laser Absorption Spectroscopy (TDLAS) [49], and Intra-Cavity Absorption Spectrometry (ICAS) $[50,51]$ etc. The gas analysis based on emission spectroscopy enable to detect specific photons emitted by excited atoms while returning to their ground state. The emission spectroscopy techniques such as Laser-Induced Breakdown Spectroscopy 
(LIBS) [52] , and Fourier Transform Infrared Spectroscopy (FTIR) provide very accurate and reliable result in gas analysis [53].

Photoionization is another well-known optical gas detection technique [54]. The technique relies on gas ionization. The ionization is applied to gases by using deep ultraviolet (DUV) light source with short wavelength inside a closed chamber with two to three electrodes and a polarization voltage across it. The photon energy of light ionizes gas molecules; whose ionization potential is lower than the photon energy of the light source energy ( $\sim 10 \mathrm{eV}$ for $\lambda=120 \mathrm{~nm})$. After the gas is ionized, the electric current is generated between the electrodes. The recorded current is proportional to the gas concentration. The photoionization technique has several advantages, such as: excellent sensitivity, long term stability and accuracy. However, the technique is not selective and cannot be utilized for analysis of gas mixtures. Also, the gases with ionization energy lower than the energy of DUV source cannot be detected. In order to overcome selectivity limitations, the photoionization detectors have been widely used in analytical gas chromatography. The fast time of response in combination with GC gas separation technique provide selective detection of specific chemical compounds in gas mixtures. However, analysis of gas species that are poorly separated by the GC column is limited by using single, non-selective photoionization detector.

Chemiluminescence is unique gas detection technique that is based on emission of photons as a result of chemical reaction [55]. The optical methods based on chemiluminescence are extremely selective. For example, chemiluminescence technique is used as the industrial standard for detection of $\mathrm{NO}_{\mathrm{x}}$. During the reaction between $\mathrm{NO}$ and ozone $\left(\mathrm{O}_{3}\right)$, photons with specific wavelength are produced. The amount of light generated 
during the reaction is proportional to the gas concentration. The detection of photons is performed by using a photo multiplier tube (PMT). The chemiluminescence technique enables instant and selective detection of specific gases in low concentrations. However, only a few gases can be detected by this technique.

\subsubsection{Acoustic methods}

Acoustic methods for gas detection have been widely investigated [56]. Acoustic sensing methods have shown some advantages such as longer life time and robustness compared to the sensors based on chemical principals. Acoustic gas sensing methods are mainly based on the speed of sound, attenuation and acoustic impedance. Monitoring sound velocity is the most robust method for gas detection [57]. The method is based on variations in sound propagation velocity obtained for different gas environments. The gas sensing method demonstrated high precision, stability and long sensor life under laboratory conditions, but the impact of the environment, large power consumption and miniaturization problems makes it problematic to utilize the technique for portable field testing.

Another type of gas detection using acoustic method is based on sound attenuation [58]. The loss of energy due to different kinds of interactions (thermal, scattering) between sound waves and gaseous environment during the sound propagation can be measured. The gas analysis method by using attenuation technique was determined to be less robust due to the particle contamination and the presence of turbulence in the gas sample. The technique can be utilized in combination with speed of sound method to improve the reliability of the detector. 
In addition, acoustic impedance technique for determination of gas density was utilized in the gas analysis [59]. The acoustic impedance technique is related to the gas density calculation by using the equation: $Z=C^{*} \rho$, where $C$ is the speed of sound, $Z$ is impedance and $\rho$ is the gas density. It is important to note; that impedance measurement is complicated procedure especially under complex environmental conditions. Both, attenuation and acoustic impedance techniques have not been utilized in commercial gas sensors for mass production.

A surface acoustic wave (SAW) gas detection technique is based on modulation of acoustic signal which can be generated and recorded by using single MEMS device [60, 61]. The system transducer generates an output in terms of mechanical wave which can be disturbed by a physical phenomenon such as gas adsorption. The generated signal is then transduced back into the receiving part of the MEMS device and converted into an electrical signal. Phase, frequency, amplitude modulation of the signal or time delay between transducer and receiver can be detected and used to measure the gas concentration. The detector is very sensitive to the background gases and signal conditioning.

\subsubsection{Calorimetric methods}

Calorimetric methods for gas detection have shown some promising result [62, 63]. There are commercially available gas sensors based on catalytic, thermal conductivity and enthalpy methods. The catalytic method is based on sensing heat from gas catalytic oxidation reaction on the surface of special catalytic pellistor. The catalytic type of detectors enable to detect high concentrations (low ppth) of combustible gases and provide fast sensing response [64]. The main disadvantage of the method is related to catalyst poisoning problem by gases other than the combustible, which significantly affects the 
sensitivity. Also, poor selectivity within the group of combustible gases prevents using the method in analytical instruments.

The detection of gasses with different thermal conductivity was successfully utilized by using thermal conductivity pellistors. The gas sensing method based on thermal conductivity measurements do not rely on the flammability of the detectable gases. The technique can be used to provide the information about two gases present and that the two gases have significantly different thermal conductivities [65-67]. The resistive change in preheated sensing element upon exposure to target gases provides information about the thermal conductivity of the environment around the sensor. Later the detector was miniaturized, keeping stable and reliable result for a wide range of gas concentrations from part per thousands (ppth) to $100 \%$. However, the sensitivity of the thermal conductivity method is very poor and need to be significantly improved to address ppm level of detection. Also, thermal conductivity method cannot be used for gas mixture analysis where the thermal conductivities of the two gases are very similar.

Some other types of sensors based on calorimetric methods were also investigated by utilizing temperature gradient created by active chemical reactions. The temperature difference can be measured by a thermocouple (Seebeck-effect) [66]. Apart from low sensitivity of the temperature gradient method, poor selectivity is another important limitation of the technique. In general, all calorimetric methods based on catalytic, thermal conductivity, or temperature gradient (enthalpy) methods experience the lack of selectivity toward similar gases.

1.4.5 Comparative analysis of gas sensing methods 
The classification and characterization of gas sensing methods has been accomplished in order to identify the best type of detector for portable analytical instrument for analysis of gas mixtures. The evaluation of different gas sensing techniques was performed based on several important sensor characteristics, such as: (1) sensitivity, (2) selectivity, (3) stability (4) time of response, (5) size, (6) power consumption, and (7) fabrication cost (Table 1.2). 
$\underline{\text { Table } 1.2}$ Comparative analysis of gas sensing methods and techniques

\begin{tabular}{|c|c|c|c|c|c|c|c|c|}
\hline $\begin{array}{l}\text { Gas Detec- } \\
\text { tion } \\
\text { Methods }\end{array}$ & $\begin{array}{c}\text { Gas } \\
\text { Detection } \\
\text { Technique }\end{array}$ & $\begin{array}{l}\text { Sensi- } \\
\text { tivity }\end{array}$ & $\begin{array}{l}\text { Selec- } \\
\text { tivity }\end{array}$ & Stability & $\begin{array}{l}\text { Time of } \\
\text { Response }\end{array}$ & $\begin{array}{c}\text { Detector } \\
\text { Size }\end{array}$ & $\begin{array}{l}\text { Power } \\
\text { Consu } \\
\text { mption }\end{array}$ & $\begin{array}{c}\text { Fabrication } \\
\text { cost and } \\
\text { mainte- } \\
\text { nance }\end{array}$ \\
\hline \multirow{3}{*}{ Electrical } & Conductance & 0 & (0) & () & 0 & 0 & ○ & 0 \\
\hline & Capacitance & $\otimes$ & () & 0 & (?) & () & (0) & () \\
\hline & $\begin{array}{c}\text { Electro- } \\
\text { chemical }\end{array}$ & 0 & () & (0) & (?) & (?) & (0) & () \\
\hline \multirow{4}{*}{ Optical } & $\begin{array}{l}\text { IR/UV ab- } \\
\text { sorption }\end{array}$ & (?) & () & () & (2) & () & () & (?) \\
\hline & $\begin{array}{c}\text { UV } \\
\text { Fluorescence }\end{array}$ & () & 0 & (O) & 0 & () & () & $\otimes$ \\
\hline & $\begin{array}{c}\text { Photoionizati } \\
\text { on }\end{array}$ & () & $\otimes$ & () & 0 & () & (?) & () \\
\hline & $\begin{array}{c}\text { Lumines- } \\
\text { cence }\end{array}$ & () & 0 & 0 & 0 & () & $\otimes$ & $\otimes$ \\
\hline \multirow{3}{*}{ Acoustic } & $\begin{array}{l}\text { Speed of } \\
\text { sound }\end{array}$ & $\otimes$ & () & 0 & () & $\otimes$ & $\otimes$ & () \\
\hline & Attenuation & $\otimes$ & () & () & () & $\otimes$ & $\otimes$ & $\varnothing$ \\
\hline & Modulation & () & () & () & ○ & () & 0 & (-) \\
\hline \multirow{3}{*}{ Calorimetric } & $\begin{array}{c}\text { Thermal } \\
\text { conductivity }\end{array}$ & $\otimes$ & () & 0 & () & 0 & () & () \\
\hline & Catalytic & $\otimes$ & 0 & (0) & 0 & () & (0) & 0 \\
\hline & $\begin{array}{l}\text { Thermal } \\
\text { gradient }\end{array}$ & $\otimes$ & $\otimes$ & () & (0) & ○ & ○ & ○ \\
\hline
\end{tabular}

$\bigotimes$ poor, @ good, $\bigcirc$ excellent

The comparative analysis of different gas sensing mechanisms has shown that only optical and electrical methods provide satisfactory sensitivity at low concentrations. The low limit of detection at least at sub-ppm level is necessary to address some important problems of gas analysis. Gas detection techniques based on modulation of conductance, electrochemical reactions, and photoionization were determined to be the most suitable for fast and reliable detection of gas components at low concentrations. Miniaturization of sensing elements, low power requirements, and low maintenance are also the key advantages of conductometric, electrochemical, and photoionization gas sensors.

Selectivity is another important characteristic of sensor's performance. Excellent selectivity of electrochemical sensors is determined by unique electrochemical reactions 
occurring with specific gas components in complex gas mixtures. The conductometric gas sensors based on MOXs were determined to be less selective. However, temperature modulation in combination with sensor's surface modification improved the selectivity of conductomentric gas sensors and minimized cross sensitivity between some important chemical groups: hydrocarbons, ketones, sulfur compounds, alcohols and etc. In contrast to electrochemical and conductometric sensors, the photoionization detector does not provide any selectivity and cannot be tuned for selective detection of specific gases.

A variety of gas sensors and detectors were developed lately based on the gas sensing techniques described above. The characterization of gas sensing methods, was determined to be in a good agreement with recent market analysis of gas sensors and detectors by its revenue (Figure 1.7a-c). In the report from 2014 [16] the major part of the gas sensors and detectors is based on photoionization (Photoionization detectors, PID), catalytic reaction (Catalytic sensors, CA), conductance variation (Semiconductor sensors, SS), infrared absorption (IR detectors, IR) and electrochemical reactions (Electrochemical sensors, EC). 


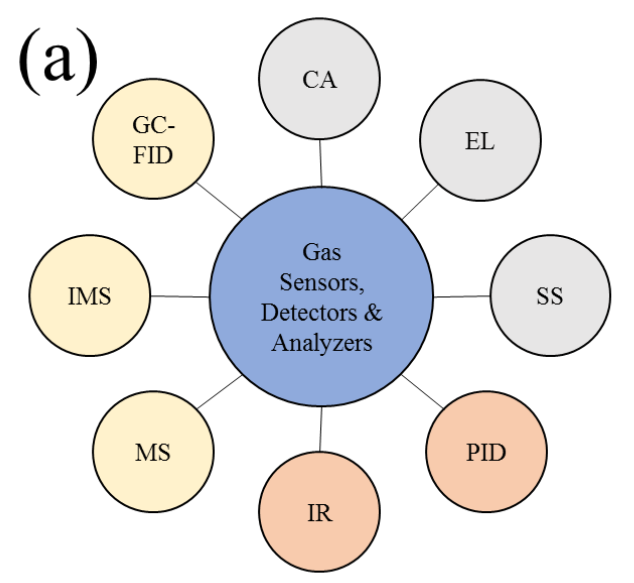

Sensors, Detectors, \& Analyzers

1. Catalytic gas sensors (CA)

2. Electrochemical gas sensors (EL)

3. Semiconductor gas sensors (SS)

4. Photoionization detector (PID)

5. Infrared gas detector (IR)

6. Mass spectroscopy (MS)

7. Ion mobility spectroscopy (IMS)

8. Gas chromatography with Flame Ionization detector (GC-FID)
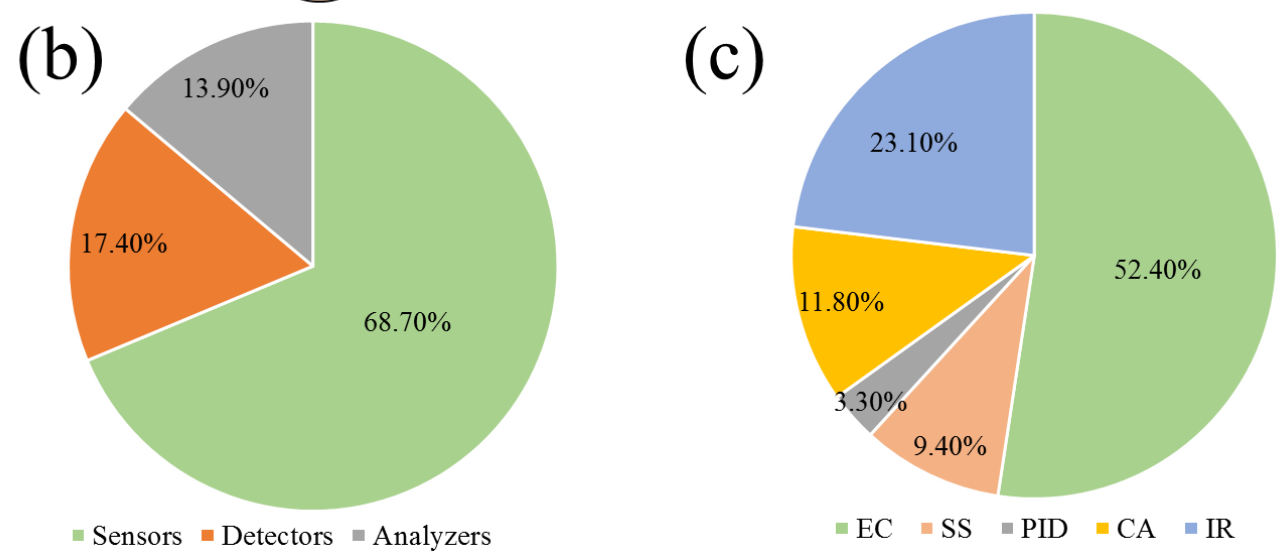

Figure 1.7 (a) Different types of gas sensors, detectors and analyzers,(b) market analysis by revenue from 2014 for gas sensors, detectors and analyzers and (c) revenue analysis by the different types of gas detectors.

From all of the above, novel gas sensors and detectors based on different sensing mechanisms have to meet very strict requirements in order to be utilized in portable analytical gas instruments. The demand for innovative gas sensors with better sensing performance, low power consumption, low cost, miniature size, and low maintenance in combination with simple circuitry, versatility and robustness make semiconductor gas sensors the best choice. Also, the manufacturing process of semiconductor gas sensors and sensing arrays is compatible with CMOS processes, which brings precise control into manufacturing process. It is important to note that semiconductor gas sensors do not require special environmental conditions and can operate under standard room temperature and 
pressure with ambient air as a background gas. At the same time, the new generation of semiconductor gas sensors based on novel nanocomposite materials show significant progress toward much higher stability and sensitivity.

\subsection{Solid-state semiconductor gas sensors}

The conductomentric gas sensors based on MOXs semiconductors have been widely studied for the last fifty years [68-71]. The industrial application of semiconductor gas sensors attracted much attention due to some advantages compared to other sensing techniques $[72,73]$. Many commercial options of MOX sensors are now offered by different companies around the world such as Figaro, CityTech, Applied-Sensors, FIS, TGS, SGX and etc. Gas detection under atmospheric conditions is one of the main advantages of semiconductor gas sensors. Also, several factors such as real time detection of large number of gases, long lifetime (2-3 years), good reliability, low cost, low maintenance and associated production simplicity make semiconductor gas sensors very attractive for a variety of gas sensing applications.

\subsubsection{Electronic theory of chemisorption}

The main working principles of MOX sensors are based on the theory of gas chemisorption. According to Wolkenstein [74], the change in surface electronic structure of metal-oxides upon exposure to oxidizing or reductive gases has a noticeable impact on the bulk electronic structure inside the material. It has to be noted that not all the gases have direct impact on the sensor's resistance. Some inert gaseous species are not involved in free carrier exchange with the surface of MOX. Instead, different type of gas adsorption (physisorption) is based on surface dipole formation (Figure 1.8a). In a case of chemisorption, the conduction of semiconductor sensing element is primarily determined 
by the rate and amplitude of the reactions at the surface. For example, it is well accepted that chemisorption of oxygen species $\mathrm{O}_{2}^{-}$and $\mathrm{O}^{-}, \mathrm{O}^{2-}$ under elevated temperature (200-400 $\left.{ }^{\circ} \mathrm{C}\right)$ generate negative charge at the surface of MOX nanocrystals and change the surface electronic band structure (Figure 1.8b). The molecular form of surface oxygen is dominant at low temperature $(\sim 150 \mathrm{C})$ and chemisorption of ionized oxygen species $\mathrm{O}^{-}$and $\mathrm{O}^{2-}$ happen at higher temperatures $\left(\sim 250{ }^{\circ} \mathrm{C}\right)$. It is important to note that, gas chemisorption process is strongly influenced by physical and chemical properties of MOXs such as electronic band structure, concentration of free carriers, amount of surface and bulk defect, doping and morphology of the material. The schematic diagram of n-type semiconductor band structure is presented for both cases: flat band structure and surface band bending under chemisorption of oxygen (Figure 1.8).

(a)

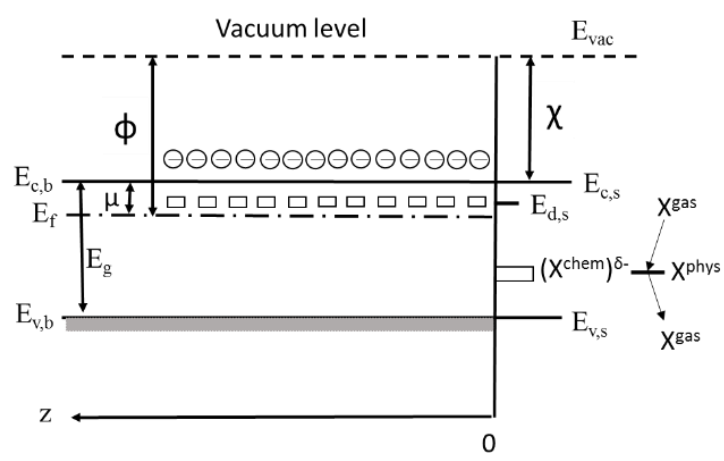

(b)

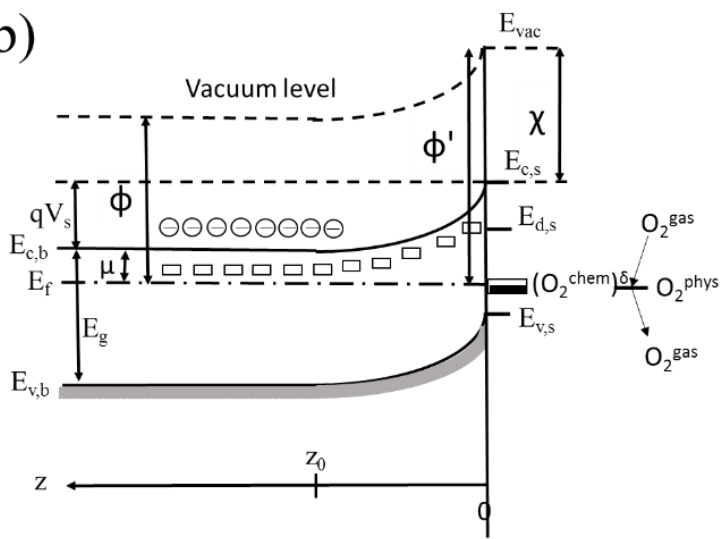

Figure 1.8 (a) Flat band structure and (b) band bending after oxygen ion sorption at the surface of n-type semiconductor, where $\phi$ is the work function inside (bulk) the MOX and $\phi$ ' is the work function at the surface of the MOX due to the chemisorption process, $\chi$ is the electron affinity, $\mu$ is the electrochemical potential, $\mathrm{qVs}$ is the band bending and $\mathrm{z}_{0}$ is the depth of depleted layer. $\mathrm{E}_{\mathrm{vac}}, \mathrm{E}_{\mathrm{cb}}, \mathrm{E}_{\mathrm{vb}}, \mathrm{E}_{\mathrm{f}}, \mathrm{E}_{\mathrm{g}}$ are the vacuum energy level, bottom of the conductive band, top of the valence band, Fermi level and band gap respectively. $\mathrm{E}_{\mathrm{cs}}, \mathrm{E}_{\mathrm{vs}}$ are the values of conductive and valence band borders at the surface, $E_{\mathrm{d}}$ and $\mathrm{E}_{\mathrm{ss}}$ are the levels of donors and surface states.

The charge transfer mechanism from the bulk to the surface of nanocrystals due to additional low energy surface states available is very similar to the metal-semiconductor 
Schottky contact $[75,76]$. The connection between surface and bulk electronic structure can be established by solving one dimensional Poisson equation with specific boundary conditions:

$$
\begin{aligned}
\left.\left(\frac{d V}{d z}\right)\right|_{z=z_{0}} & =0 ; \quad V(0)=V_{s} \\
\frac{d^{2} V}{d z^{2}} & =-\frac{\rho(z)}{\varepsilon}
\end{aligned}
$$

where $\rho(z)=q\left(p-n+N_{d}^{-}+N_{a}^{+}\right)$is the total charge density, $\varepsilon$ is the semiconductor dielectric constant, $q$ is the absolute value of the electron elementary charge, $n$ and $p$ are the electrons and holes concentrations and $N_{d}^{-}$and $N_{a}^{+}$are the ionized donors and acceptors concentrations. The analytical solution of the equation (1.2) can be obtained with some approximations: the charge density outside the depletion region $\left(\mathrm{z}>\mathrm{z}_{0}\right)$ is $\mathrm{zero}$, the concentration of free carriers inside the depletion region $\left(0<\mathrm{z}<\mathrm{z}_{0}\right)$ is negligible $(\mathrm{n}=\mathrm{p}=0)$, and ionized donors concentration is equal to the doping concentration $\left(N_{d}=N_{d}^{-}\right)$. The equation 1.2 can be rewritten in another form:

$$
\frac{d^{2} V}{d z^{2}}=-\frac{q N_{d}}{\varepsilon}
$$

Integration the equation 1.2 with the boundary condition $\left.\left(\frac{d V}{d z}\right)\right|_{z=z_{0}}=0$, gives the function of the electric field along $\mathrm{z}$ axis inside the depletion region $0<\mathrm{z}<\mathrm{z}_{0}$ :

$$
\begin{gathered}
\frac{d V}{d z}=-\frac{q N_{d}}{\varepsilon} z+C_{1} \\
\left.\left(\frac{d V}{d z}\right)\right|_{z=z_{0}}=-\frac{q N_{d}}{\varepsilon} z_{0}+C_{1}=0 \\
C_{1}=\frac{q N_{d}}{\varepsilon} z_{0}
\end{gathered}
$$




$$
E(z)=-\frac{d V}{d z}=\frac{q N_{d}}{\varepsilon}\left(z-z_{0}\right)
$$

Further integration of the electric field function (equation 1.3) and setting $\mathrm{V}\left(\mathrm{z}_{0}\right)=0$, gives the function of the potential inside the depletion layer (equation 1.4):

$$
\begin{gathered}
\frac{d V}{d z}=\frac{q N_{d}}{\varepsilon} z_{0}-\frac{q N_{d}}{\varepsilon} z \\
V(z)=\frac{q N_{d}}{\varepsilon} z z_{0}-\frac{q N_{d}}{2 \varepsilon} z^{2}+C_{2} \\
V\left(z_{0}\right)=\frac{q N_{d}}{2 \varepsilon} z_{0}^{2}+C_{2}=0 \\
C_{2}=\frac{q N_{d}}{2 \varepsilon} z_{0}^{2} \\
V(z)=\frac{q N_{d}}{\varepsilon} z z_{0}-\frac{q N_{d}}{\varepsilon} z^{2}+\frac{q N_{d}}{2 \varepsilon} z_{0}^{2}
\end{gathered}
$$

Setting $\mathrm{V}(0)=\mathrm{V}_{\mathrm{s}}$ provides useful connection between surface potential due to gas chemisorption process and the width of depletion region inside the semiconductor (equation 1.5):

$$
V(0)=V_{s}=-\frac{q N_{d} z_{0}^{2}}{2 \varepsilon}
$$

The equation 1.5 can be rewritten by using the expression (equation 1.6) for Debye length $\left(L_{D}\right)$ which provides the relation between the surface potential and the depletion depth under different temperature conditions and impurity concentrations for different MOXs (equation 1.7):

$$
\begin{aligned}
& L_{D}=\sqrt{\frac{\varepsilon_{r} k_{b} T}{q^{2} N_{d}}} \\
& z_{0}=L_{D} \sqrt{\frac{2 q V_{s}^{2}}{k_{b} T}}
\end{aligned}
$$


where $k_{b}$ is the Boltzmann's constant and T is the temperature of MOX.

In case of partially ionized impurities, when the concentration of free charge carriers cannot be easily approximated or simplified, a numerical solution to Poisson equation can be obtained to describe interaction between surface and bulk electronic band structure as well as free charge carrier distribution inside the semiconductor [77]. Also, the calculation of the surface potential and depletion depth for other geometrical shapes different than flat surface approximation, was done in Cartesian, spherical and cylindrical coordinate system by other research groups $[78,79]$.

A general theory of gas chemisorption at the surface of MOXs is applicable to some real world materials and devices with specific morphology (thin and thick polycrystalline films, nanowires, and etc.) and chemical composition. For example, the chemoresistive gas sensor consists of a pair of metal electrodes and a sensing layer usually transitional or post transitional MOXs operating at elevated temperature $200-400{ }^{\circ} \mathrm{C}$. The MOX sensing layer can be described by two simple models: compact layer model and porous layer model (Figure 1.9a, b) [80] . In a case of the compact layer model (Figure 1.9b), only surface of the sensing element can be exposed to an ambient atmosphere due to very high material density. As a result of high material density, no grain-grain Schottky barriers within the layer are formed. The compact layer model can be applied in a case of monocrystalline MOX nanowires. On another side, porous sensing layer model (Figure 1.9a) enable interaction between gas species and polycrystalline sensing layer all the way through the volume. Most of thick and thin MOX gas sensing films can use the porous layer model for approximation. 


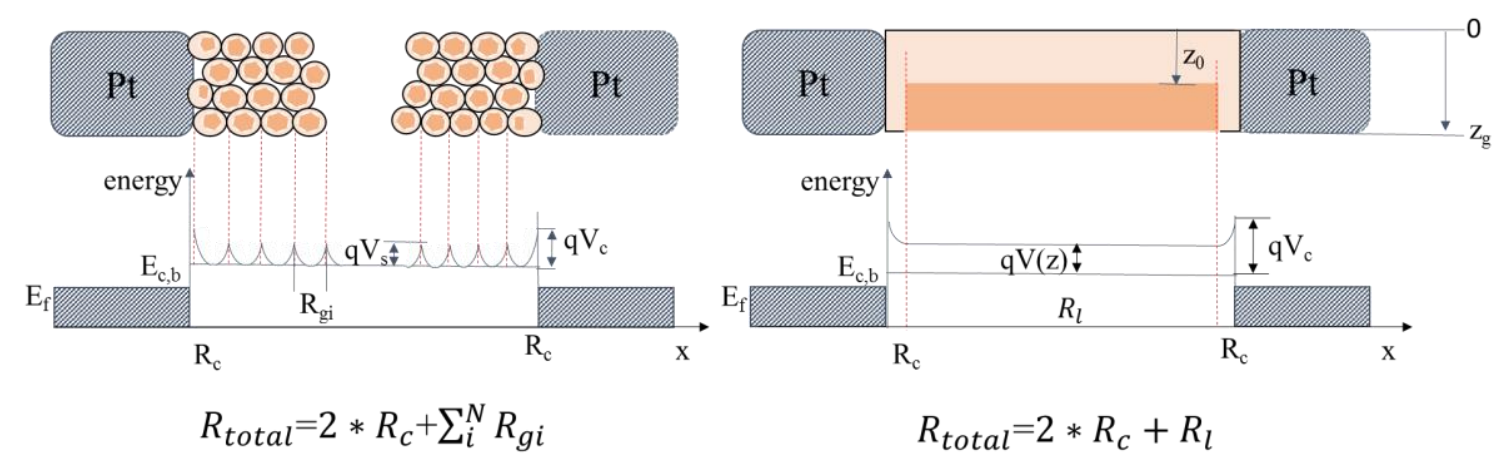

Figure 1.9 A schematic diagram of (a) porous layer and (b) compact layer approximation model with corresponding electronic band structure.

The generalized theory of conductometric gas sensors provides the necessary background for further investigation and optimization of MOX gas sensors performance. High surface to volume ratio of the sensing material in combination with high density of active surface sites and easy ionized bulk impurities, provides preferable conditions for converting gas-solid interaction into a noticeable electrical signal. The gas sensing characteristics of different MOXs as well as its thermal and chemical stability are primarily determined by its electronic and crystal structure, concentration of surface defects, amount of bulk impurities and basic morphology and geometry the sensing layer.

\subsubsection{Gas sensitive MOXs}

A variety of MOXs exhibit significant change in conductance up on exposure to reducing and oxidizing gases [70-72, 81]. Different $\mathrm{MOXs}$ including $\mathrm{SnO}_{2}, \mathrm{ZnO}, \mathrm{WO}_{3}$, $\mathrm{In}_{2} \mathrm{O}_{3}, \mathrm{~V}_{2} \mathrm{O}_{5}, \mathrm{TiO}_{2}, \mathrm{Cr}_{2} \mathrm{O}_{3}, \mathrm{Mn}_{2} \mathrm{O}_{3}, \mathrm{NiO}, \mathrm{CuO}, \mathrm{Co}_{3} \mathrm{O}_{4}, \mathrm{SrO}, \mathrm{GeO}_{2}, \mathrm{Fe}_{2} \mathrm{O}_{3}, \mathrm{Nb}_{2} \mathrm{O}_{5}, \mathrm{MoO}_{3}$, $\mathrm{Ta}_{2} \mathrm{O}_{5}, \mathrm{La}_{2} \mathrm{O}_{3}, \mathrm{CeO}_{2}, \mathrm{Nd}_{2} \mathrm{O}_{3}$ were reported to be gas sensitive. The wide range of MOXs can be divided into two categories: transitional and non-transitional (pre-transitional and post transitional). The first category of consists of oxides formed from transitional metals 
such as iron $(\mathrm{Fe})$, nickel $(\mathrm{Ni})$, titanium $(\mathrm{Ti})$, vanadium $(\mathrm{V})$ and etc. The insignificant energy variations between $d_{n}$ and $d_{n+1}, d_{n-1}$ configurations, allowed different kinds of oxides to be formed. The transitional MOXs have high sensitivity. However, high instability makes it difficult to use the transitional MOXs as gas sensors [82]. Only, transitional MOXs with an electronic structure $d_{0}$ and $d_{10}$ was determined to be stable enough for gas sensing applications (TiO2, V2O5, and WO3). In contrast, pre-transitional MOXs (MgO, $\mathrm{AlO} 3$ etc.) are chemically stable and inert. The large band gap of pre-transitional MOXs is another obstacle that limits the formation of electron-holes pairs and make it very difficult to measure conductivity of the sensing element even at elevated temperatures (150-500 $\left.{ }^{\circ} \mathrm{C}\right)$. The post-transitional MOXs were determined to be the most proper material for gas sensors. In particular, the post-transitional MOXs with electronic configuration of $\mathrm{d}_{10}$ such as $\mathrm{SnO}_{2}$ and $\mathrm{ZnO}$ were studied the most $[81,83,84]$. Both oxides have high sensitivity to variety of oxidizing and reducing gases (VOCs, $\mathrm{H}_{2} \mathrm{~S}, \mathrm{NO}, \mathrm{NH}_{4}$ etc.). Also, thermal and mechanical properties of $\mathrm{SnO}_{2}$ and $\mathrm{ZnO}$ provide long term operational stability.

Both $\mathrm{n}$ - and p-type semiconductors have been determined to be gas sensitive [8588]. The conductivity of n-type semiconductors (Figure 1.10a), where major carries are electrons, increase upon exposure to reducing gases (VOCs, $\mathrm{H}_{2} \mathrm{~S}, \mathrm{NO}_{\mathrm{x}}, \mathrm{NH}_{3}$, etc.) and decrease upon exposure to oxidizing gases $\left(\mathrm{O}_{2}, \mathrm{O}_{3}, \mathrm{H}_{2} \mathrm{O}_{2}\right.$, etc.). In contrast, opposite effect was observed for p-type semiconductors (Figure 1.10b), where the major carriers are holes. The conductivity of p-type semiconductors decreases upon exposure to reductive gases and increases upon exposure to oxidizing gases. It is important to note that conductivity of both $\mathrm{n}$ and $\mathrm{p}$ type semiconductors is also highly depend on internal crystal structure of MOXs. Presence of crystal defects and impurities plays an important role in conduction mechanism 
of semiconductors and determine total free carrier concentration. For example, both MOXs such as $\mathrm{SnO}_{2}$ and $\mathrm{ZnO}$ with a wide-band gap $(>3.5 \mathrm{eV})$ were determined to be n-type semiconductors due to some internal crystal defect.
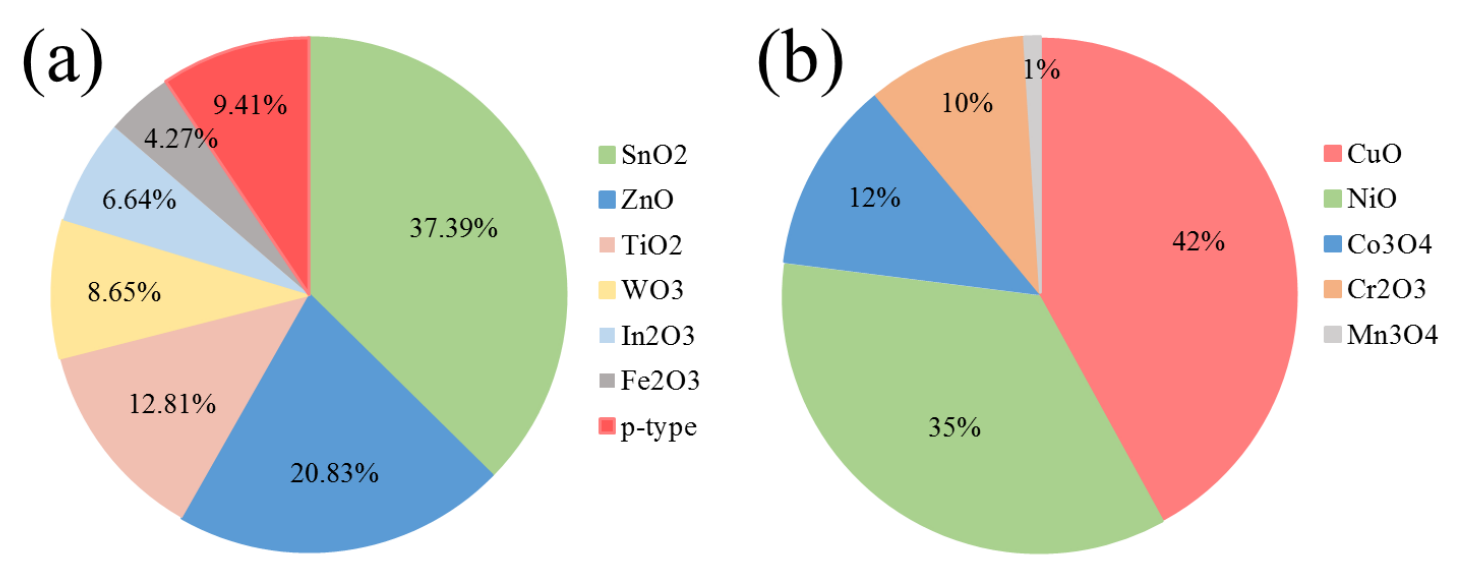

Figure 1.10 The most studied (a) n- and (b) p-type MOX semiconductors for gas sensing applications (internet search Web knowledge).

In most cases, choice of $\mathrm{SnO}_{2}$ as a main gas sensing material is determined by its advanced physical and chemical properties compared to the other oxides. High thermal stability of polycrystalline $\mathrm{SnO}_{2}$ even at $900{ }^{\circ} \mathrm{C}$ and wide spectrum of surface energy sites for chemisorption processes has been previously shown [89, 90]. Also, moderate resistance of the material under ambient air allowed to perform accurate conductance measurement of $\mathrm{SnO}_{2}$ with a simple electric circuit. Currently, different types of $\mathrm{SnO}_{2}$ gas sensing materials has been developed based on various synthesis methods.

\subsubsection{Synthesis and deposition methods of $\mathrm{SnO}_{2}$ gas sensing layer}

Gas sensing properties of $\mathrm{SnO}_{2}$ strongly depend on material morphology, crystal structure including stoichiometry and coordination, internal microstructural features and defects, geometry, size of $\mathrm{SnO}_{2}$ nanocrystals, and interaction between them. In the context 
of reliable and repeatable device fabrication, the method of gas sensing material synthesis and deposition plays a very important role. Different $\mathrm{SnO}_{2}$ synthesis techniques for gas sensing applications $[91,92]$ mainly focus on the production of nanoscale materials with tightly controlled morphological, structural and electronic properties (Table 1.3).

Table 1.3 Different methods of $\mathrm{SnO}_{2}$ synthesis and deposition

\begin{tabular}{|c|c|c|c|c|c|}
\hline Methods & $\begin{array}{l}\text { Synthesis } \\
\text { technique }\end{array}$ & Morphology & Advantages & Disadvantages & Ref. \\
\hline \multirow{3}{*}{$\begin{array}{l}\text { Liquid - } \\
\text { solid }\end{array}$} & Sol-gel & $\begin{array}{l}\text { Polycrystalline/ } \\
\text { Thick film }\end{array}$ & $\begin{array}{l}\text { - High chemical homogeneity } \\
\text { - Low processing temperature } \\
\text { - Control over size and } \\
\text { morphology of nanoparticles } \\
\text { - Mechanical stability }\end{array}$ & $\begin{array}{l}\text { - Poor control over coating } \\
\text { and deposition } \\
\text { - Fabrication cost } \\
\text { - High carbon content }\end{array}$ & {$[93,94]$} \\
\hline & Co-precipitation & $\begin{array}{l}\text { Polycrystalline/ } \\
\text { Thick film }\end{array}$ & $\begin{array}{l}\text { - Low processing temperature } \\
\text { - Fine powder production } \\
\text { - Control over size and } \\
\text { morphology of nanoparticles } \\
\text { - Homogeneity on microscale }\end{array}$ & $\begin{array}{l}\text { - Collecting and purifying } \\
\text { the particles is complicated } \\
\text { - Not universal for various } \\
\text { MOXs } \\
\text { - Poor control over coating } \\
\text { and deposition }\end{array}$ & [95] \\
\hline & Micro-emulsion & $\begin{array}{l}\text { Polycrystalline/ } \\
\text { Thick film }\end{array}$ & $\begin{array}{l}\text { - Homogeneous on microscale } \\
\text { - Thermodynamically stable } \\
\text { - High surface to volume ratio } \\
\text { - Control over size and } \\
\text { morphology of nanoparticles }\end{array}$ & $\begin{array}{l}\text { - Not universal for various } \\
\text { MOXs } \\
\text { - Poor control over coating } \\
\text { and deposition }\end{array}$ & [96] \\
\hline \multirow{4}{*}{$\begin{array}{l}\text { Gas - } \\
\text { solid }\end{array}$} & $\begin{array}{c}\text { Chemical vapor } \\
\text { deposition }\end{array}$ & $\begin{array}{l}\text { Polycrystalline/ } \\
\text { Thin film }\end{array}$ & $\begin{array}{l}\text { - Homogeneous on microscale } \\
\text { - Diverse crystal morphology } \\
\text { - Control over size and } \\
\text { morphology of nanoparticles } \\
\text { - Good control over coating } \\
\text { thickness } \\
\text { - Universal techniques for } \\
\text { variety of MOXs } \\
\text { - High yield and low cost } \\
\text { - High thermal stability }\end{array}$ & $\begin{array}{l}\text { - High temperature and low } \\
\text { vacuum process } \\
\text { - Poor control other device } \\
\text { morphology at nanoscale }\end{array}$ & {$[97,98]$} \\
\hline & $\begin{array}{l}\text { Physical vapor } \\
\text { deposition/ } \\
\text { Magnetron } \\
\text { Sputtering }\end{array}$ & $\begin{array}{l}\text { Polycrystalline/ } \\
\text { Thin film }\end{array}$ & $\begin{array}{l}\text { - Low temperature process } \\
\text { - Excellent control over } \\
\text { deposition thickness and } \\
\text { surface homogeneity } \\
\text { - Universal for MOXs, } \\
\text { metals and nanocomposite } \\
\text { materials } \\
\text { - Highly reproducible } \\
\text { technique } \\
\text { - Fine nanocrystal structure }\end{array}$ & $\begin{array}{l}\text { - Low pressure process } \\
\text { - Expensive operational } \\
\text { equipment and maintains }\end{array}$ & [99] \\
\hline & $\begin{array}{c}\text { Thermal } \\
\text { Evaporation }\end{array}$ & $\begin{array}{l}\text { Polycrystalline/ } \\
\text { Thin film }\end{array}$ & $\begin{array}{l}\text { - High control over deposition } \\
\text { rates } \\
\text { - High purity of fabricated } \\
\text { films } \\
\text { - Flexibility over deposited } \\
\text { materials } \\
\text { - Least expensive PVD system }\end{array}$ & $\begin{array}{l}\text { - Ultra- low pressure } \\
\text { process } \\
\text { - Low control over film } \\
\text { properties } \\
\text { - Poor film thickness } \\
\text { uniformity and surface } \\
\text { coverage }\end{array}$ & {$[100]$} \\
\hline & & & - High purity thin films can be & - High cost of equipment & \\
\hline
\end{tabular}




\begin{tabular}{|c|c|c|c|c|c|}
\hline Methods & $\begin{array}{l}\text { Synthesis } \\
\text { technique }\end{array}$ & Morphology & Advantages & Disadvantages & Ref. \\
\hline & $\begin{array}{l}\text { Atomic layer } \\
\text { deposition }\end{array}$ & $\begin{array}{l}\text { Polycrystalline/ } \\
\text { Thin film }\end{array}$ & $\begin{array}{l}\text { obtained } \\
\text { - High control over film } \\
\text { thickness } \\
\text { - High control over film } \\
\text { morphology } \\
\text { - Ultra-fine crystal structure }\end{array}$ & $\begin{array}{l}\text { deposition and precursors } \\
\text { - Low vacuum system } \\
\text { - Not universal for various } \\
\text { materials }\end{array}$ & {$[101]$} \\
\hline \multirow{4}{*}{$\begin{array}{l}\text { Other } \\
\text { novel } \\
\text { composite } \\
\text { Methods }\end{array}$} & $\begin{array}{c}\text { Thermal } \\
\text { evaporation } \\
\text { Condensation }\end{array}$ & $\begin{array}{c}\text { Singles crystal/ } \\
\text { Nanobelts }\end{array}$ & $\begin{array}{l}\text { - Excellent chemical, thermal } \\
\text { and mechanical stability } \\
\text { - Low fabrication cost } \\
\text { - Advanced catalytic, optical } \\
\text { and } \\
\text { electronic properties }\end{array}$ & $\begin{array}{l}\text { - High temperature of } \\
\text { material temperature } \\
>800{ }^{\circ} \mathrm{C} \\
\text { - Poor control over device } \\
\text { manufacturing by using } \\
\text { single or multiple } \mathrm{SnO}_{2} \\
\text { the nanobelts }\end{array}$ & [102] \\
\hline & Electrospinning & $\begin{array}{l}\text { Polycrystalline/ } \\
\text { Nanofibers }\end{array}$ & $\begin{array}{l}\text { - High surface to volume ratio } \\
\text { of } \\
\text { 1D nanofiber } \\
\text { - Low fabrication cost and } \\
\text { simplicity } \\
\text { - Low fabrication temperature } \\
< \\
300{ }^{\circ} \mathrm{C}\end{array}$ & $\begin{array}{l}\text { - Poor flexibility for } \\
\text { nanocomposite material } \\
\text { fabrication } \\
\text { - Wet chemistry processes } \\
\text { are involved } \\
\text { - Not reproducible at } \\
\text { Nanoscale }\end{array}$ & {$[103]$} \\
\hline & $\begin{array}{l}\text { Vapor liquid } \\
\text { Solid }\end{array}$ & $\begin{array}{l}\text { Single crystal/ } \\
\text { Nanowires }\end{array}$ & $\begin{array}{l}\text { - Excellent chemical, thermal } \\
\text { and mechanical stability } \\
\text { - Advanced catalytic, optical } \\
\text { and } \\
\text { electronic properties }\end{array}$ & $\begin{array}{l}\text { - Require high temperature } \\
>800{ }^{\circ} \mathrm{C} \text { and low pressure } \\
\text { during the material } \\
\text { synthesis } \\
\text { - Require additional } \\
\text { Catalyst (gold, nickel, } \\
\text { platinum) }\end{array}$ & [104] \\
\hline & Solvothermal & $\begin{array}{l}\text { Polycrystalline/ } \\
\text { Microspheres }\end{array}$ & $\begin{array}{l}\text { - Unique morphology, optical } \\
\text { and catalytic properties of } \\
\text { solid } \\
\text { and hollow spheres fabricated } \\
\text { by the method } \\
\text { - Well controlled process for } \\
\text { nanomaterial fabrication } \\
\text { - Relatively inexpensive and } \\
\text { simple }\end{array}$ & $\begin{array}{l}\text { - Wet chemistry processes } \\
\text { are involved } \\
\text { - Require high temperature } \\
\text { and pressure during the } \\
\text { material synthesis }\end{array}$ & {$[105]$} \\
\hline
\end{tabular}

The variety of $\mathrm{SnO}_{2}$ preparation methods can be grouped into two main categories:

liquid-solid and gas-solid. The preparation methods based on liquid-solid techniques such as co-precipitation, sol-gel, micro-emulsion, provide tight control over morphological properties with a "bottom-up" approach. However, creating a uniform coating with the sensing material in a specific area using liquid-solid methods is problematic. The $\mathrm{SnO}_{2}$ sensing layers manufactured by using co-precipitation, sol-gel and micro-emulsion are usually referred to as "thick film" methods. Conversely, the synthesis of MOXs by using gas-solid techniques (such as chemical vapor deposition (CVD) and plasma assisted 
chemical vapor deposition (PECVD), physical vapor deposition/sputtering (PVD), thermal evaporation, atomic layer deposition (ALD)) are usually used for generation of ultra-thin and ultra-fine nano-crystalline MOX films. The gas-solid deposition methods enable to control physical parameters of sensing element in combination with morphological, chemical, and electrical properties of the $\mathrm{SnO}_{2}$ layer.

Recently there is much interest in a new generation of MOX gas sensors with high surface to volume ratios using so-called "one-dimensional" (1D) structures. Several new methods were developed for synthesis of $1 \mathrm{D} \mathrm{SnO}_{2}$ nanostructures: nanowires, nanotubes, nanorods and nanosprings. These methods include: metal-organic chemical vapor deposition (MOCVD), vapor liquid solid (VLS), pulse laser deposition (PLD), hydrothermal decomposition, solvothermal, electrospinning, thermal evaporationcondensation (TEC) and controllable oxidation/ anodic oxidation. However, repeatable synthesis of 1D materials with highly controllable structure, morphology and electrical properties is still a challenge. Also, the lack of control over the product of synthesis is another drawback of self-assembly methods. Finally, the technique of making electrical connection to nanowires and nanotubes is unreliable and has a significant impact on over all sensors performance.

An analysis of different methods for synthesis and fabrication of $\mathrm{SnO}_{2}$ sensing layer shows some important advantages of the physical vapor deposition technique (PVD). Exacting control over film thickness, the uniformity of the coating across the sensing element without particle agglomeration as well as excellent adhesive properties, make the sputtering technique one of the most reliable methods for production of reproducible sensing elements according to the industrial standard. This type of fabrication method open 
an opportunity for comparative analysis of different samples. Furthermore, high gas sensitivity of ultra-thin $(10-100 \mathrm{~nm})$ films produced by magnetron sputtering technique is primarily determined by high catalytic activity of ultra-fine crystal structure of the deposited oxide in combination with high surface to volume ratio of the sensing material. In addition, the deposition and synthesis of the sensing layers are closely combined in the fabrication process which bring much more stability and repeatability than using PVD methods. In particular, magnetron sputtering technique is one of the most reliable methods in electronic industry allowing for production of identical sensing elements with high reproducibility in contrast to the other deposition methods, such as: spraying, dipping, dropping or spinning technique by utilizing sol-gel materials. The simplicity of the sputtering method in combination with a variety of available materials for deposition including insulators, semiconductors and metals, makes it very attractive compared to the other industrial deposition methods such as atomic layer deposition (ALD), high temperature and e-beam evaporation or electroplating. Also, the multi-source magnetron sputtering technique brings more flexibility to the process of complex material fabrication and makes it possible to control the material surface or volume doping.

The material deposition technique has one of the most significant impacts on the MOX gas sensing performance. It is well known that electronic and catalytic properties of the MOXs are tightly related to the imperfection and defects in the periodic crystal structure of the MOX lattice. Different deposition techniques can significantly change the morphology, electronic and lattice crystal structure of MOXs. On the other hand, it is important not only design and manufacture highly gas sensitive materials but also being able to reproduce them. The problem of repeatability and reproducibility of MOX gas 
sensors is one of the most important in the industry of MOX sensors. The control of crystal defects at the atomic level is impossible by using magnetron sputtering technique due to the complexity of the problem. However, reproduction of MOX thin film with similar electronic, mechanical, and morphological properties was proven to be possible at micro and even nanoscale level. The combination of the precise deposition technique and photolithography process provides a tool for identical sensing element fabrication.

\subsubsection{Doping and surface modification of $\mathrm{SnO}_{2}$}

Surface modification and bulk doping of $\mathrm{SnO}_{2}$ is one of the major methods to optimize stability, sensitivity and selectivity of MOX sensors. Several research groups previously reported that small $1 \%$ to $5 \%$ volume doping of $\mathrm{SnO}_{2}$ with $\mathrm{In}, \mathrm{V}, \mathrm{Cu}, \mathrm{Pt}, \mathrm{Ce}$, or Re can improve the overall stability of the sensor's response and minimize sensor's baseline drift [106-108]. Different types of $\mathrm{SnO}_{2}$ volume and surface doping were reported in order to stabilize structural and face transition of $\mathrm{SnO} 2$ under long term of use. Unfortunately high poisoning resistance of $\mathrm{SnO} 2$ - Pt were also reported [109] as well as improvement in its surface catalytic properties.

Noble metals ( $\mathrm{Au}, \mathrm{Pt}, \mathrm{Pd}$ and $\mathrm{Ag}$ ) were determined to be extremely effective oxidation catalysts for enhancing surface catalytic reactions at low temperatures by decreasing the energy barrier for chemical reactions [110]. Also, reactivity and catalytic activity of noble metal nanoclusters is strongly related to the size of the nanoparticles. Small metal nanoclusters of $\mathrm{Au}, \mathrm{Pd}$, and $\mathrm{Pt}(2-5 \mathrm{~nm})$ have recorded the highest catalytic activity under interaction with tested gases and produced the highest sensor's response [111-115]. The main theory of advance sensing mechanism of MOX sensors modified with noble metal nanoclusters is based on two different mechanisms. The first is "electronic 
mechanism" which is related to the depletion zone formation around metal nanoclusters and nano-Schottky barriers modulation upon exposure to different gases. The "chemical mechanism" of enhanced gas sensation is related to the advanced catalytic activity of noble metal nanoparticles and their enhanced dissociative ability. The "chemical" and "electronic" sensing mechanisms will be discussed in details in Chapter 3. Previous research $[32,82]$ has shown that $\mathrm{SnO}_{2}$ gas sensors modified with noble metal ( $\mathrm{Au}, \mathrm{Pt}$, and Pd) nanoparticles allowed one to detect ultra-low concentration of VOC's in the ambient air. However, the stability of such a fine nanostructure under elevated temperature was ascertained to be very poor. High particle migration, agglomeration, sublimation, poor particles surface density and chemical deactivation are common problems of ultra-fine noble metal nanoparticles. Synthesis of highly stable and ultra-small nanoparticles is another important step toward novel MOX detectors.

Low selectivity of $\mathrm{SnO}_{2}$ due to its wide energy range of surface adsorption sites is a significant drawback for selective analysis of gas mixtures. The modification of $\mathrm{SnO}_{2}$ surface in order to improve its selectivity is one of the focus areas. The sensitivity of MOX conductometric gas sensors is primarily determined by the magnitude of surface catalytic activity and electronic interaction between the surface of $\mathrm{SnO}_{2}$ and the bulk of the material. Both the bulk doping and the surface modification of MOX has been widely used to increase sensing characteristics and improve selectivity of the semiconductor gas sensors. Some dopants/additives behave as "accelerators" while others serve as "inhibitors", depending on the chemical reaction. Noble metals ( $\mathrm{Au}, \mathrm{Pd}, \mathrm{Pt}$, and $\mathrm{Ag}$ ), transitional metals $(\mathrm{Fe}, \mathrm{Co}, \mathrm{Cu})$, non- metallic $(\mathrm{Se})$, earth metals $(\mathrm{Ca}, \mathrm{Ba}, \mathrm{Sr}, \mathrm{Mg})$, metalloids $(\mathrm{B}, \mathrm{Si})$ have been widely used for modifications of tin oxide polycrystalline surface [33] . Surface 
modifications by noble metal nanoclusters or transitional MOXs are the most commonly used techniques to modify the catalytic properties of the original oxide. MOX detectors have been shown to be able to be tuned toward detection of specific chemical groups (Table 1.4). For example, selective MOX sensors for hydrocarbons, ketones, alcohols, sulfur compounds and other gases have been previously reported (Table 1.4). 
Table 1.4 Different type of $\mathrm{SnO}_{2}$ doping for selective detection of specific gases.

\begin{tabular}{|c|c|c|c|c|c|}
\hline \multicolumn{2}{|c|}{ Gases and Vapors } & $\begin{array}{l}\text { Nanocomposite } \\
\text { material }\end{array}$ & $\begin{array}{l}\text { Preparation method/ } \\
\text { sensing material }\end{array}$ & $\begin{array}{l}\text { Operational } \\
\text { temperature } \\
\left({ }^{\circ} \mathrm{C}\right)\end{array}$ & References \\
\hline \multirow{3}{*}{$\begin{array}{l}\text { Oxidant } \\
\text { gases }\end{array}$} & $\mathrm{H}_{2} \mathrm{O}, \mathrm{O}_{2}$ & $\mathrm{SnO}_{2}-\mathrm{Sb}$ & $\begin{array}{c}\text { Pulse Laser Deposition/ } \\
\text { nanowires }\end{array}$ & $\sim 300$ & {$[33,34]$} \\
\hline & $\mathrm{O}_{3}$, & $\mathrm{SnO}_{2}-\mathrm{In}_{2} \mathrm{O}_{3}$ & $\begin{array}{l}\text { Sputtering/ } \\
\text { thin film }\end{array}$ & $\sim 200-300$ & [35] \\
\hline & $\mathrm{NO}_{\mathrm{x}}$ & $\mathrm{SnO}_{2}-\mathrm{WO}_{3}$ & $\begin{array}{l}\text { Short Pulse Laser } \\
\text { Deposition/thin film }\end{array}$ & $\sim 25$ & [116] \\
\hline \multirow{3}{*}{ Toxic gases } & $\mathrm{H}_{2} \mathrm{~S}$ & $\mathrm{SnO}_{2}-\mathrm{CuO}$ & $\begin{array}{l}\text { RF sputtering/ } \\
\text { thin film }\end{array}$ & $\sim 140$ & [117-119] \\
\hline & $\mathrm{NH}_{3}$ & $\mathrm{SnO}_{2}-\mathrm{WO}_{3}$ & $\begin{array}{l}\text { Glassing angle } \\
\text { deposition/ } \\
\text { thin film }\end{array}$ & $\sim 450$ & {$[33,120]$} \\
\hline & $\mathrm{SO}_{2}$ & $\mathrm{SnO}_{2}-\mathrm{NiO}$ & $\begin{array}{l}\text { RF sputtering/ } \\
\text { thin film }\end{array}$ & $\sim 180$ & [121] \\
\hline \multirow{3}{*}{ Alcohols } & Ethanol & $\mathrm{SnO}_{2}-\mathrm{Fe}_{2} \mathrm{O}_{2}$ & $\begin{array}{l}\text { Chemical Precipitation/ } \\
\text { thick film }\end{array}$ & $\sim 250$ & [122] \\
\hline & Methanol & $\begin{array}{l}\mathrm{SnO} 2-\mathrm{Pt}- \\
\mathrm{Pd}-\mathrm{In}_{2} \mathrm{O}_{3}\end{array}$ & $\begin{array}{l}\text { Facile hydrothermal/ } \\
\text { thick film }\end{array}$ & $\sim 150-200$ & [123] \\
\hline & Propanol & $\begin{array}{c}\mathrm{SnO} 2-\mathrm{Ag} \\
\mathrm{Au}\end{array}$ & $\begin{array}{l}\text { Co-precipitation/ } \\
\text { thick film }\end{array}$ & $\sim 300$ & [124] \\
\hline \multirow{3}{*}{ Hydrocarbons } & Methane & $\mathrm{SnO}_{2}-\mathrm{RuO}_{2}$ & $\begin{array}{l}\text { Impregnation method/ } \\
\text { thick film }\end{array}$ & $\begin{array}{l}\sim 150- \\
250\end{array}$ & [125] \\
\hline & Propane & $\mathrm{SnO}_{2}-\mathrm{Pt}$ & $\begin{array}{l}\text { Sol-gel// } \\
\text { thick film }\end{array}$ & $\sim 300$ & [126] \\
\hline & BTEX & $\mathrm{SnO}_{2}-\mathrm{Pt}, \mathrm{Pd}$ & $\begin{array}{l}\text { Selective growth/ } \\
\text { Nanowires }\end{array}$ & $\sim 300$ & [127] \\
\hline $\begin{array}{l}\text { Carbon } \\
\text { monoxide }\end{array}$ & $\mathrm{CO}$ & $\mathrm{SnO}_{2}-\mathrm{Pt}, \mathrm{Pd}$ & $\begin{array}{l}\text { Selective growth/ } \\
\text { Nanowires }\end{array}$ & $\sim 250$ & {$[128]$} \\
\hline
\end{tabular}


Furthermore, recent reports on MOXs modified with bimetal noble nanoclusters indicated even more enhanced gas sensing performance compare to monometallic metal clusters [129]. In addition, selective catalytic properties of bimetal nanoparticles was shown to be highly dependent on nanoparticles composition. For example, Au-Pd nanoparticles were determined to be extremely catalytically active toward toluene when its molar ratio is 10:1 [130, 131]. Also, bimetal particles $\mathrm{Pt}-\mathrm{Pd}, \mathrm{Au}-\mathrm{Pd}, \mathrm{Cu}-\mathrm{Pd}$ were identified to be much more stable compared to pure $\mathrm{Pt}, \mathrm{Au}$, or $\mathrm{Cu}$ nanoparticles under elevated temperature $\left(>400{ }^{\circ} \mathrm{C}\right)[132,133]$. However, the catalytic effect of bimetal nanoparticles as well as its electronic interaction with support layer has not been studied well and many question remain unanswered. The improvement of gas sensing characteristics of pure $\mathrm{SnO}_{2}$ by using noble bimetal nanoclusters can significantly improve the detection level of next generation MOX gas sensors and sensors arrays, bring more selectivity for multi-component analysis of gas mixtures and provide long term stability for MOX detectors.

\subsubsection{Gas sensor array based on MOXs}

The major advantage of multi-sensory systems is the ability to provide unique fingerprints for different chemicals, chemical groups or specific gas mixtures. Unlike many other analytical techniques, a multi-sensory systems do not try to separate all the chemical components within a sample, but it perceives a sample as a whole, creating a global fingerprint. The devices for the gas analysis by using multiple sensors is usually called electronic nose. In an electronic nose, the headspace from a sample (i.e. the gases emanating from a sample) are delivered to an array of chemical sensors. As each sensor is different in some way, (usually broadly tuned to a different chemical group) each sensors 
response to a sample is different. These responses can then be used to form a chemical fingerprint of a sample. The response is seen as a change in electrical properties (normally resistance) of the sensor. Specialized software then identifies the sample from this fingerprint. Pattern recognition algorithms and/or neural network hardware are used on the output signals arising from the multi-sensory system to classify, identify, and where necessary quantify, the vapor or odors of concern. This response is much like the way the mammalian olfactory sense produces diagnostic patterns and then transmits them to the brain for processing and analysis. This approach does not require development of highly specific recognition chemistries. Instead, this approach requires a broadly responsive array of sensors that is trainable to the target signature of interest and then can recognize this signature and deliver it to the sensing electronics in a robust fashion for subsequent processing by pattern recognition algorithms (Figure 1.11).

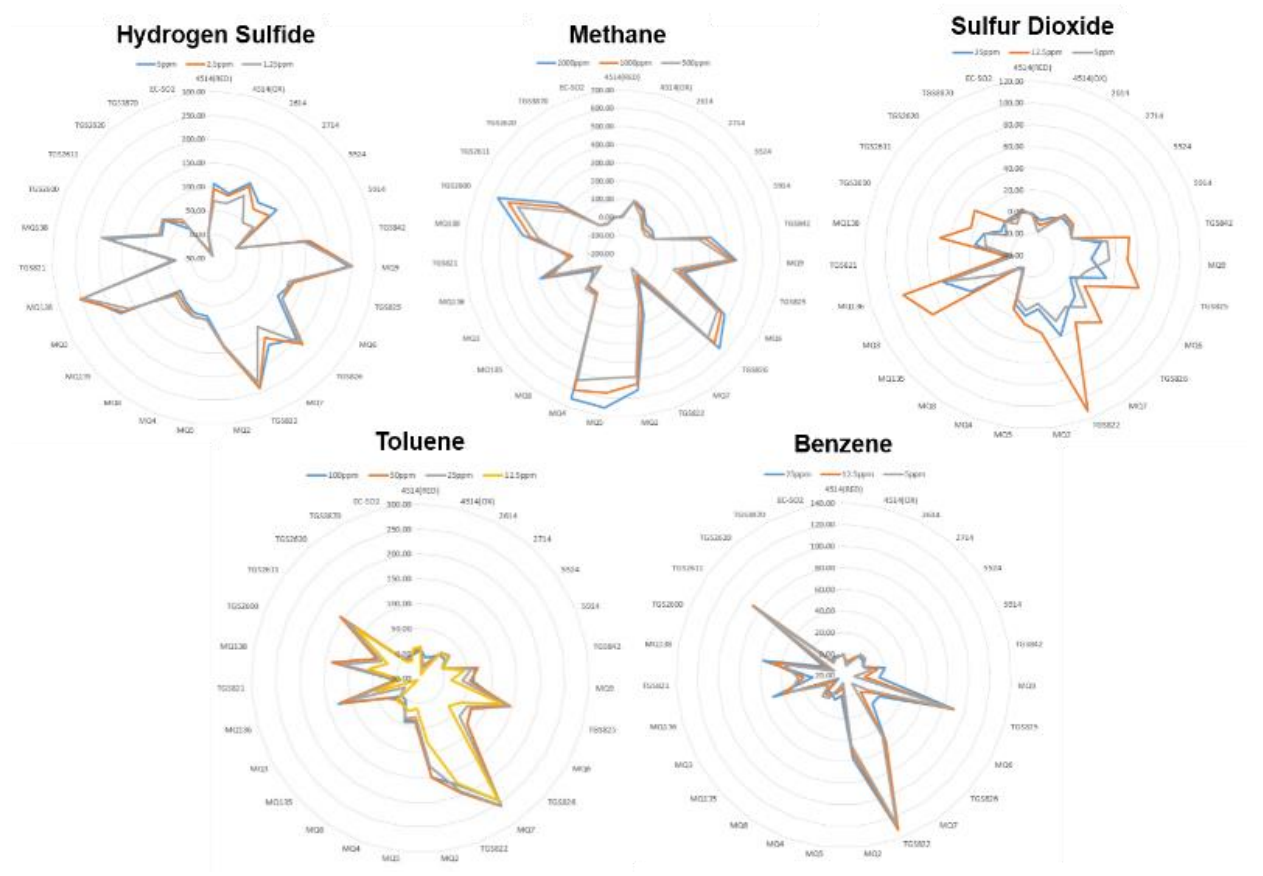

Figure 1.11 So-called "radar diagrams" of simultaneous response $\left(\mathrm{R}_{\text {air }} / \mathrm{R}_{\text {gas }}\right)$ of multi-sensory system of 24 sensors to different chemicals can be the basis of a pattern recognition algorithm. Note that each shape is reproducibly (within statistics) different from the others and thus rules for pattern recognition algorithms can be determined. 
A variety of multisensory systems based on MOXs have been developed and are continuing to be developed. The low cost of MOX devices is the main advantage of the method. There are two main approaches for the development MOX multisensory systems for gas mixture analysis. The first approach was developed around multiple identical sensing elements on the same chip. The variation of internal parameters of each sensor such as operational temperature and bias voltage, has an impact on the sensor's response toward different chemical groups. One of the first multisensory systems based on single layer of MOX was proposed and developed in Germany by J. Goschnick (Figure 1.12) $[134,135]$. The Karlsruhe Micro Nase (KAMINA) chip is based on monolayer metal-oxide film deposited over multiple parallel metal electrodes. The multi-sensory system is formed as a result of sensing layer fragmentation. The response of each segment is recorded based on resistance change upon exposure to detectable gases. The short time of gas analysis between 1 to 10 seconds allowed to analyze gas mixtures in real time. Also, simple design and low cost of the device are the main advantages of the KAMINA system.

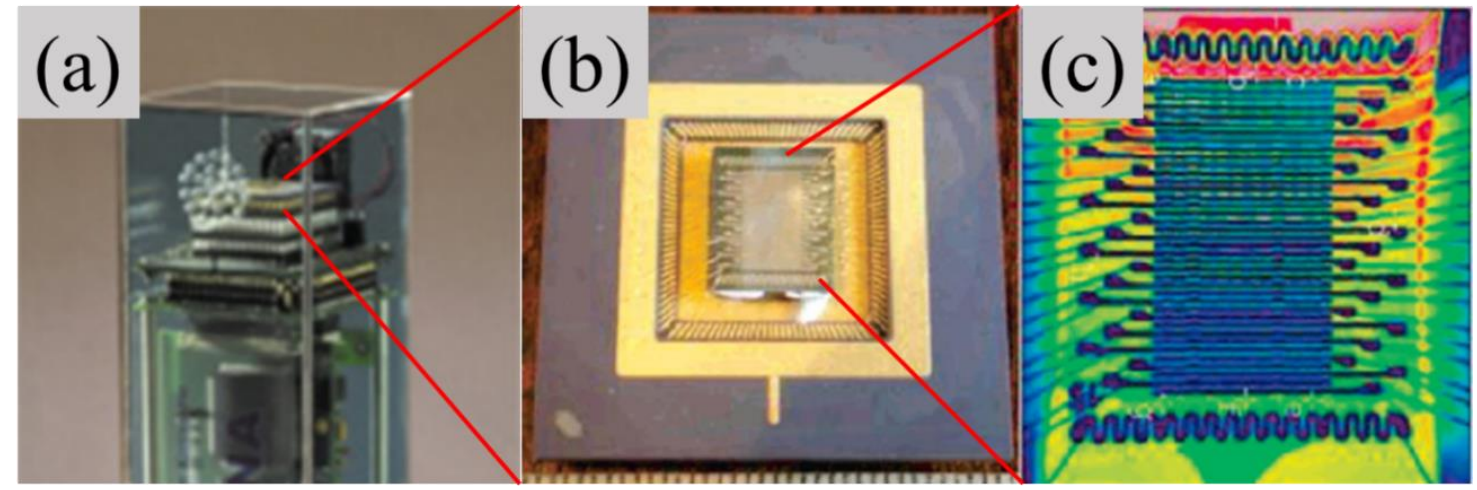

Figure 1.12 An image of (a) portable KAMINA device with electronics and the detection chamber, (b) the amplified image of the KAMINA multi-sensory chip and (c) thermal imaging of the temperature distribution across the chip. 
The second approach is mainly based on manufacturing of chemically different sensing elements which are thermally and electrically independent from each other. The pioneers of this approach is Sweden group, Baltes [136, 137]. Another integrated multisensory system based on different types of chemo-resistors, was designed by S. Semancik $[138,139]$. In this work, a new approach toward multi-sensor gas analysis based on micro-hot plates was developed and an array of micro gas sensors $\left(100 \times 100 \mu \mathrm{m}^{2}\right)$ was constructed on a single chip [140]. The proposed structure is based on gas mixture analysis by using thermally and electrically independent sensing elements where each sensor has its own heating element and a pair of electrodes (Figure 1.13a-c). The miniaturization of sensing elements brings great flexibility in operational temperature control and minimized energy consumption down to $30 \mathrm{~mW}$ per sensing element.
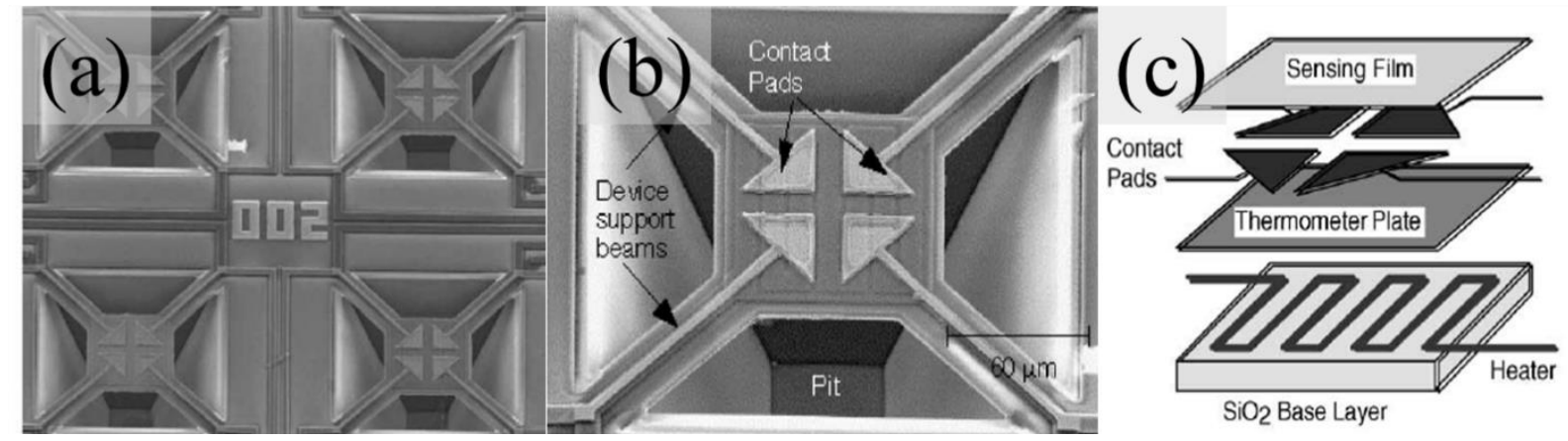

Figure 1.13 An image of (a) the array of four sensors based on micro hot plates, (b) the single micro hot plate with metal contacts on the top, and (c) the main layout of MOX gas detector based on micro hot plate technology.

The development of multi-sensor platforms for gas analysis based on chemoresistors has attracted much attention in the United States. An important work was done by C. Zhou $[141,142]$. In his work, different types of monocrystalline nanofiber $\left(\mathrm{SnO}_{2}, \mathrm{ZnO}\right.$, and $\mathrm{In}_{2} \mathrm{O}_{3}$ ) were used as sensing elements, instead of thin film MOXs. Lately, many other multi-sensory systems based on chemo-resistors were developed and commercialized such 
as Cyranose (Cyrano Sciences, USA), JPL Enose (NASA, USA), Sam Detect (Daimler Chrysler Aerospace, USA-Germany), i-PEN (WMA Airsense Analysentechnik, Germany) [143-146].

The review of different methods and instrumentations for gas mixture analysis has shown that multidimensional analysis of gas mixtures by using multisensory systems based on chemo-resistors has some obvious advantages: low detection limit, low power consumption, miniaturization of the device, simplicity, low cost and variety of gases and vapors that can be detected.

However, using those sensory systems in analytical instruments is still a big challenge. The main drawback of the technology is cross sensitivity of different sensors to variety of gases and vapors which affects multicomponent analysis of gas mixtures with the sensing array. Also, long term instability of sensing elements as well as poor reproducibility during the fabrication process makes it impossible to utilize the state of art MOX detectors in analytical instruments.

In order to develop an analytical instrumentation based on MOX chemo-resistors, a complex approach has to be taken. First, new types of MOX gas sensors has to be developed for highly selective detection of specific gaseous compounds and provide gas sensitivity at ppb level. Second, the fabrication process of the sensing elements has to be highly controllable in order to be able to reproduce repeatable sensors and sensors arrays. Third, a special preconditioning system including gas sampling, gas separation and gas delivery has to be integrated into the final device.

In this work, we developed gas analytical instrumentation based on novel MOX sensors array in combination with portable gas chromatography. A multisensory detector 
was manufactured for detection of specific gases such as sulfur compounds $\left(\mathrm{H}_{2} \mathrm{~S}\right.$, Mercaptans), heavy hydrocarbons (BTEX), ketones (acetone) and alcohols (ethanol, propanol, methanol). The nanocomposite sensing materials which were chosen, had outstanding performance for multidimensional analysis of gas mixtures at ultra-low concentrations. We will also present research that the multidimensional portable chromatography is able to analyze complex gas mixtures such as natural gas and human breath. 


\section{CHAPTER 2: EXPERIMENTAL METHODS}

In this chapter, the design and fabrication of novel multi-sensor platforms is discussed as well as synthesis of nanocomposite thin films based on multi-source magnetron sputtering technique. The description of main instruments and procedures for analysis of gas sensing materials is an important part of the chapter. Also, the detailed explanation of gas delivery instruments and the process of gas sample preparation is provided.

2.1 Design, modeling and fabrication of multi-sensor platform

2.1.1 Multi-sensor platform design

The fabrication of the multi-sensor MOX detector requires high precision manufacturing methods in combination with specific materials that are long term mechanically and electrically stable under elevated temperature. The standard CMOS microfabrication processes for machining bulk silicon such as photolithography, sputtering, reactive ion etching (RIE) and deep reactive ion etching (DRIE) allowed us to achieve high quality control over device dimensions down to a few microns and produce hundreds of identical devices simultaneously. At the same time, the MEMS made out of $\mathrm{Si} / \mathrm{SiO} 2$ were proven to be very robust over an extensive period of time even at highly elevated temperatures (>400C), which is a necessary condition for activation of MOX sensors $[140,147]$. There are two types of micro-machined Si-based thermally insulated structures that have been mostly used in the process of making micro gas sensors: front 
side etched micro-bridge and backside etched membrane [148-151]. The combination of both methods by using the DRIE technique provided more control over the membrane final thickness and total mechanical stability of the device over the fabrication process.

The fabrication methods to produce thermally activated sensing elements at the surface of the thin membrane can be divided into two main categories: stacked and planar. The stacked structure (Figure 2.1a) where the sensing material, sensing electrodes, insulating layers and the heating element are stacked successively is considered to be a conventional way to build semiconductor type gas sensors [140]. However, the stacked approach is fairly complicated. First of all, during the manufacturing process several (5-6) photolithographic masks are necessary to develop many layer structure, which increase the complexity of the fabrication process. Second, the temperature distribution over the sensing element is hard to control due to the temperature difference between the heating paths and the area between them. Third, the stability of the stacked structure over long period of time is poor. Any changes in the stacked structure have a significant impact on the resistive signal from the sensing element especially in a case of ultra-thin film MOX gas sensors.

The 'planar-type' structure in contrast to the 'stacked-type' structure is much simpler to manufacture and it demonstrated higher stability and temperature control over sensing element area [152]. The proposed planar structure in which heating element, electrodes and sensing element are located on the same plane (Figure 2.1b), demonstrated the ability to integrate multiple sensing elements at the surface of the membrane and control the activation temperature of the sensors by a single micro-heater. The main advantage of the planar structure with the single micro-heater and multiple sensing elements is maximum time and space synchronization of multiple sensor response in combination with 
identical temperature conditions. In addition, the total power consumption of the multisensor planar structure gas detector is much less than the total power consumption across the array of individual sensors activated independently from each other.

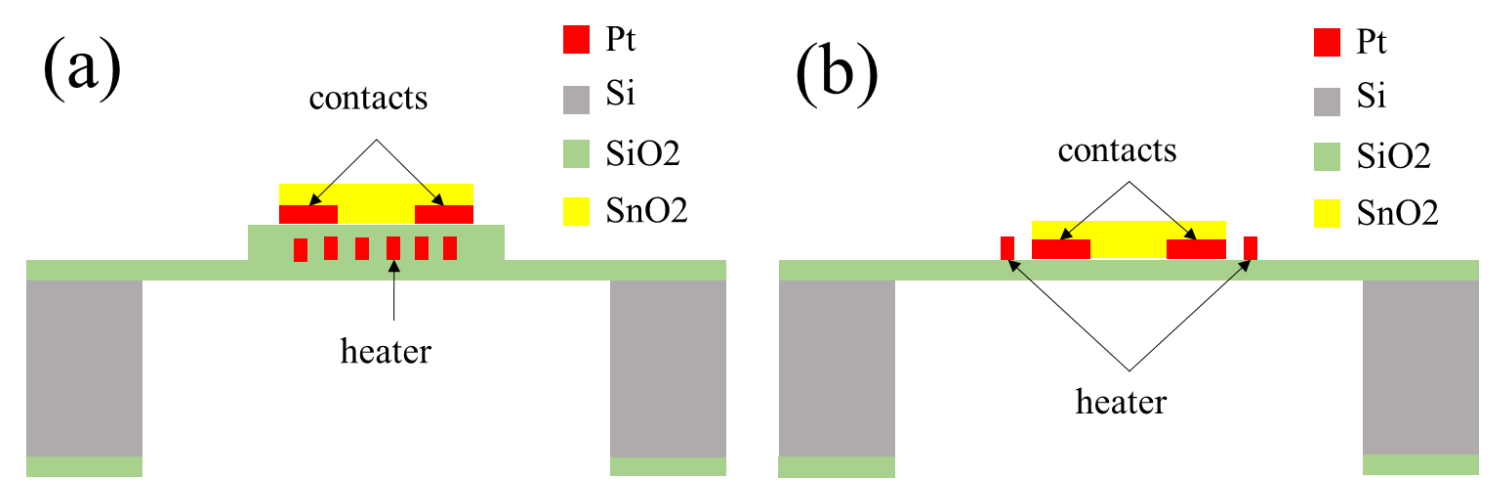

Figure 2.1 A schematic diagram of MEMS based MOX gas sensors including main components and outline for (a) stacked structure and (b) planar structure.

The multi-sensor MOX detector consists of several major components such as main support structure, thermally insulated suspended membrane, a micro heater, multiple pair of electronic contacts and sensing elements. The choice of silicon as a main building block and support material for the device was predetermined by several factors. First of all, the material properties of silicon crystal such as thermal expansion, thermal conductivity and mechanical stability under elevated temperature $\left(>400^{\circ} \mathrm{C}\right)$ allowed us to fabricate thermally insulated membrane structure suspended in the middle of the device $[153,154]$. In addition, the advanced silicon micromachining CMOS techniques allowed to manufacture microscale devices and significantly decrease the necessary power consumption of the detector. Also, a thin layer of thermally stable electrical insulator (SiO2) can naturally be formed by using dry or wet oxidation of silicon on the surface of the device. Among the possible solutions, silicon based systems for metal-oxide (MOX) sensors seem to be the 
best candidates for miniaturized, low-cost, highly stable devices, compatible with integrated microsystems $[155,156]$.

The design and choice of material for the main membrane structure is one of the most important steps during the fabrication process that determines total power consumption of the device, the temperature distribution across sensing elements, and the mechanical and thermal stability of the micro-system. The membranes made out of dielectric materials such as silicon dioxide or silicon nitride were well investigated and have shown great performance in terms of low power consumption and thermal insulation [157]. However, the mechanical stability and elasticity of the thin membranes made out of the dielectric materials is very poor which increases the complexity of fabrication process. Different types of polymer material such as polyimide (PI) were recently used to increase the mechanical stability and flexibility of the membrane and bring the advantage by simplifying the manufacturing process $[158,159]$. However, low thermal conductivity of the material (PI) does its use in a planar structure without creating a wide temperature gradient across the sensing elements. Also, the temperatures on ultra-thin membranes (13um) are very dependent on total gas flow rate across the device. Instant change in gas flow can significantly affect the membrane temperature and be a cause of unpredictable behavior of the detector. In this work, the planar structure of multi-sensor MOX detector was proposed in combination with $\mathrm{Si} / \mathrm{SiO} 2$ membrane (50um) in order to simplify the fabrication process, increase thermal and mechanical stability of the device and reach low level power consumption ( $<20 \mathrm{~mW}$ ) per sensing element.

Another important part of the multi-sensory MOX detector is an onboard microheater. Using micro-heaters is necessary in most MOX gas detectors because the detection 
of different chemicals by the sensing layer takes places at high temperatures (100-300C). The temperature of the sensing layer must be held constant in order to be able to detect a change in resistance across the sensing elements upon gas exposure. The micro-heater generates heat by running electric current through a resistive element and keeps the suspended membrane structure of the multi-sensor device at stable elevated temperature. The choice of the proper material for the micro-heater fabrication is extremely important to create a low power and long term stable micro-heating element. Some important properties of the material for micro-heater fabrication such as thermal conductivity, thermal expansion $(\alpha)$, melting point $(T)$, material density $(\rho)$, electrical conductivity $(\sigma)$ and geometrical shape of the micro-heater have major impact on the micro-heater performance characteristics. For example, thermal conductivity of the material can affect the response time of the micro-heater. At the same time, the thermal expansion of the material is related to the physical size of the micro-heater and the overall mechanical stability of the system. Finally, the total power consumption by the device depends on the electrical conductivity and geometrical shape of the micro-heater through the Joule heating law. It is a challenge to choose the right material for micro-heater and meet the criteria for the desirable temperature requirements of the multi-sensor MOX detector. A variety of different materials such as $\mathrm{SiC}$ [160], Pt [148-150], poly-silicon [161], single crystal silicon [162] and TiN [163] were proposed by different research groups for fabrication of different micro-heaters. In this research, platinum was used to fabricate micro-heating element. Platinum is a well-known metal with well-known characteristics, which makes it easy to build a simulated model of the device. The parameters of the platinum micro-heater satisfied all the necessary conditions by providing thermal stability due to the high melting 
point of platinum and very low thermal expansion at high temperature. Also, the excellent thermal conductivity of platinum creates an isothermal distribution across the micro-heater and thus an instant response to the temperature ramping. Finally, using platinum as the material for micro-heater allows the simultaneous fabrication of platinum contacts for multiple sensing elements by utilizing the simplicity of the planar structure. Some important materials and its characteristics for multi-sensory platform fabrication are shown in Table 2.1.

Table 2.1 Materials and characteristics

\begin{tabular}{ccccc}
\hline Material properties & $\begin{array}{c}\text { Silicon } \\
(\mathrm{Si}) \mathrm{n} \text {-type }(100)\end{array}$ & $\begin{array}{c}\text { Silicon dioxide } \\
(\mathrm{SiO} 2)\end{array}$ & $\begin{array}{c}\text { Platinum } \\
(\mathrm{Pt})\end{array}$ & $\begin{array}{c}\mathrm{SI} \\
\text { Units }\end{array}$ \\
\hline Specific heat capacity $(\mathrm{Cp})$ & 710 & 720 & 133 & $\mathrm{~J} /(\mathrm{Kg} * \mathrm{~K})$ \\
Young module $(\mathrm{E})$ & 130 & 66 & 168 & $\mathrm{GPa}$ \\
Thermal expansion $(\alpha)$ & $2.59^{*} 10^{-6}$ & $5.6^{*} 10^{-7}$ & $8.80^{*} 10^{-6}$ & $1 / \mathrm{K}$ \\
Thermal conductivity $(\mathrm{k})$ & 150 & 1.4 & 72 & $\mathrm{~W} /(\mathrm{m} * \mathrm{~K})$ \\
Density $(\rho)$ & 2.57 & 2.2 & 21.09 & $\mathrm{~g} / \mathrm{cm} 3$ \\
Electrical resistivity $(\rho)$ & 100 & $10^{16}$ & $10.5 * 10^{-8}$ & $\Omega^{*} \mathrm{~m}$ \\
Melting point $(\mathrm{t})$ & 1412 & 1700 & 1768 & ${ }^{\circ} \mathrm{C}$ \\
\hline
\end{tabular}

2.1.2 Modeling and simulation of the multi-sensor platform

A computer simulation model of the multi-sensor MOX detector was performed with COMSOL ${ }^{\mathrm{TM}} 5.2$ Multiphysics. The simulation of the device prior to the actual fabrication allowed us to optimize some physical parameters and main geometries of the device in order to minimize power consumption and optimize temperature distribution across the sensing elements. The model of the simulated device consists of four pairs of platinum contacts and a cross-shaped micro-heater, with the total thickness of $350 \mathrm{~nm}$, all located at a thin suspended membrane in the middle of the multi-sensor platform (Figure 2.2). The platform is mechanically and electronically connected to a modified transistor 
outline package (TO8). The total meshing of the model was obtained for finite element analysis prior to thermo-electric simulation of the device.

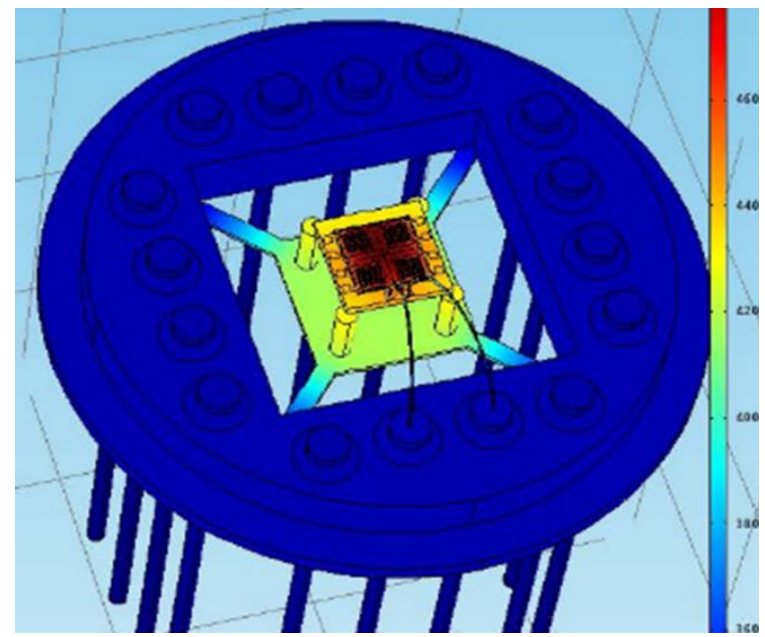

Figure 2.2 An image of thermo-electric simulation of multi-sensor MOX detector by using finite element analysis with $\mathrm{COMSOL}^{\mathrm{TM}}$ Multiphysics.

Thermo-electric characteristics of the detector was obtained by using Joule heating and thermal expansion model with $\mathrm{COMSOL}^{\mathrm{TM}}$ Multiphysics. The results from the thermo-electric simulation of the device were obtained in a case of steady state conditions for different membrane thicknesses (Figure 2.3a, b and Table 2.2). The geometry of the micro-heater at the surface of the main membrane was ascertained to be very important especially in a case of 'planar-structure' of multi-sensor platform. A cross shaped microheater at the center of the suspended membrane was designed to provide uniform temperature distribution across all four sensing elements. Another important parameter such as thickness of the main membrane has a great impact on the temperature distribution across the sensing area. In order to optimize the performance of the detector, the balance between low power consumption and uniform temperature distribution was determined in the case of the four sensor platform. In this work, we optimized the power consumption of 
the multi-sensor MOX detector and minimized the temperature gradient across the sensing elements by varying the thickness of the $\mathrm{Si} / \mathrm{SiO}_{2}$ membrane. The ultra-thin membrane 2.5 $\mu \mathrm{m}$ thickness recorded the lowest power consumption for the fixed average temperature across the sensing area. However, poor temperature uniformity across the sensing element was identified in the case of ultra-thin $\mathrm{SiO}_{2} / \mathrm{Si}$ membrane. The balance between low power consumption and acceptable temperature distribution within $10{ }^{\circ} \mathrm{C}$ (FWHM) was determined for the membrane thickness of $50 \mu \mathrm{m}$.
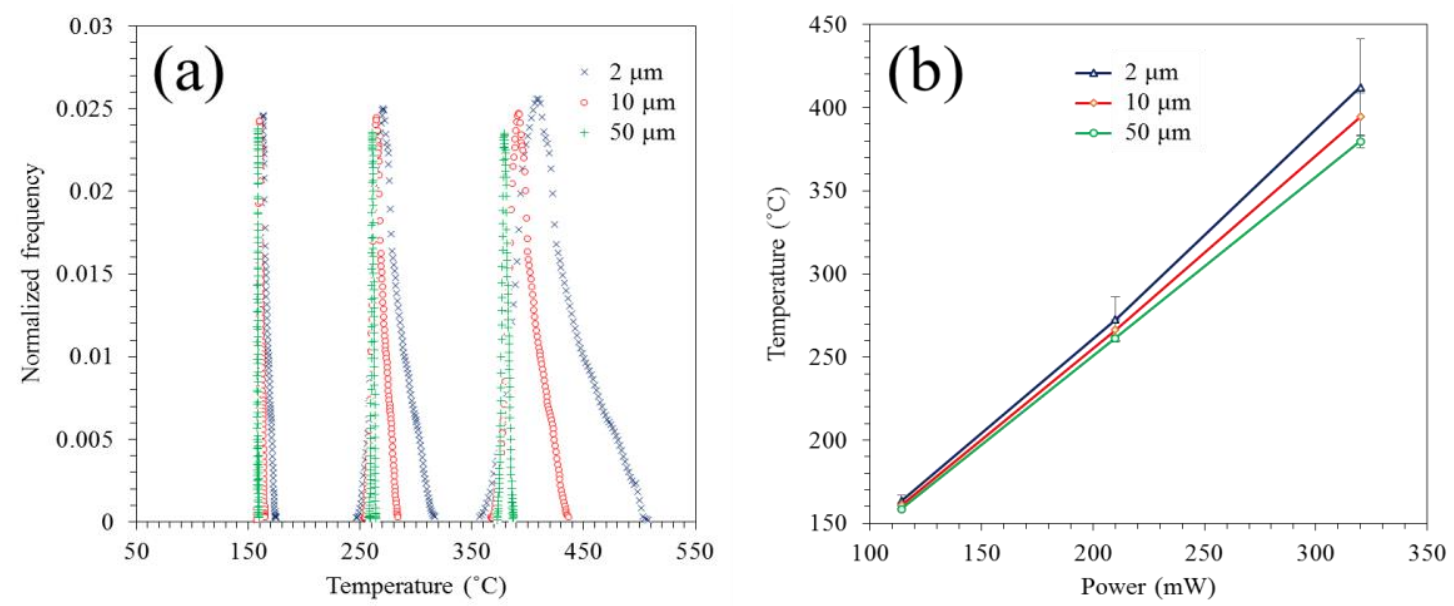

Figure 2.3 Calculated (a) temperature distribution and (b) average temperature over sensing element as a function of membrane thickness and total activation power.

Table 2.2 Results from thermo-electric simulation of the multi-sensory platform

\begin{tabular}{ccccccccc}
\hline \multirow{2}{*}{$\begin{array}{c}\text { Voltage } \\
(\mathrm{V})\end{array}$} & Current & Power & \multicolumn{2}{c}{2 um } & \multicolumn{2}{c}{10 um } & \multicolumn{2}{c}{50 um } \\
\cline { 4 - 9 } & $(\mathrm{mA})$ & $(\mathrm{mW})$ & $\mathrm{T}_{\text {avg }}\left({ }^{\circ} \mathrm{C}\right)$ & $\mathrm{FWHM}$ & $\mathrm{T}_{\text {avg }}\left({ }^{\circ} \mathrm{C}\right)$ & $\mathrm{FWHM}$ & $\mathrm{T}_{\text {avg }}\left({ }^{\circ} \mathrm{C}\right)$ & $\mathrm{FWHM}$ \\
\hline 2 & 57 & 114 & 163.5 & 6.98 & 160.85 & 3.11 & 158.61 & 0.64 \\
3 & 71 & 210 & 272.5 & 27.46 & 266.19 & 12.66 & 261.36 & 3.11 \\
4 & 82 & 320 & 412.2 & 58.61 & 394.48 & 28.41 & 379.71 & 7.52 \\
\hline
\end{tabular}

\subsubsection{Multi-sensor platform fabrication}

The fabrication process of the multi-sensor metal-oxide detector can be divided into three main steps: fabrication of the micro-heater, contacts and suspended membrane, sensing elements deposition and final device packaging. The step by step process requires 
total four photomasks (Figure 2.4 a-d) to pattern the parts of thin films or the bulk of the $\mathrm{Si} / \mathrm{SiO}_{2}$ substrate. During the fabrication process several hundred identical devices were fabricated on a single 4-inch wafer.

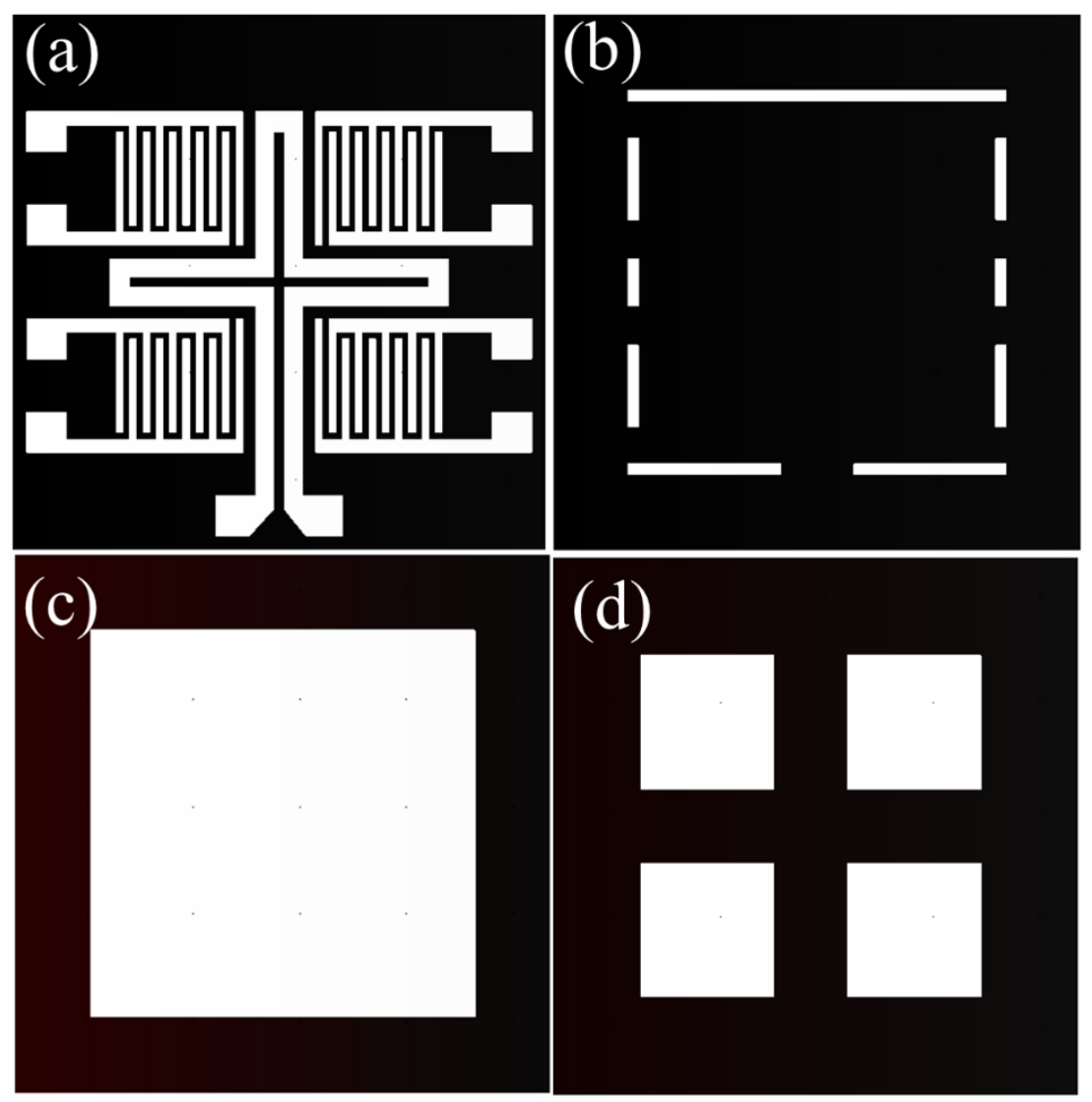

Figure 2.4 An image of multiple photo-masks for step by step fabrication of multi-sensor MOX detector: (a) mask 1, (b) mask 2, (c) mask 3, and (d) mask 4 with white color corresponds to transparent glass and the dark area is protected by thin chromium layer.

During the first fabrication step, front side Pt contacts and Pt micro-heater were deposited on a surface of oxidized silicon (100), 4 inch wafer. The patterns for the contacts and the micro-heater (Mask 1) were transfer on the surface of the device by using photolithography process. After the pattern of the front side contacts and the micro-heater was transferred, the quality of photolithography was verified by optical microscopy to match the desirable percent of defects, right geometry and the photoresist free area. The deposition of metal layer Ti/Pt (5-10 nm / $350 \mathrm{~nm})$ over the patterned photoresists layer 
was achieved by utilizing a DC multi-source magnetron sputtering technique (Lesker PVD 75). The deposition of titanium layer prior the main platinum deposition is necessary to create stable adhesive layer between $\mathrm{SiO} 2$ substrate and the $\mathrm{Pt}$ layer. The consecutive deposition of both metals was done under an inert argon environment in order to avoid oxidation of the adhesive (Ti) layer. After the deposition of metal layer, the lift off process was applied to the wafer in order to dissolve the sacrificial layer (PMMA). During the lift off process only the materials that have direct contact with the substrate stay in place and the rest of the sacrificial layer is washed away. After the lift off process the optical revision of the device surface was done by using optical microscopy and the total thickness of the deposited metal layer was verified by contact profilometer to be $350 \mathrm{~nm}+/-10 \mathrm{~nm}$. The step by step process for deposition of front side Pt contacts and Pt micro-heater is described below:

1. Wafer cleaning and drying (acetone bath $1 \mathrm{~min}$, deionized water, drying with N2 )

2. Spin coating of photoresist (PMMA 1827, $0.2 \mathrm{sec}-500 \mathrm{rpm}, 10 \mathrm{sec}-4000$ rpm)

3. Soft bake (temperature $90^{\circ} \mathrm{C}$, time $70-75 \mathrm{sec}$ )

4. Exposure to UV light (front side, mask 1, power $325 \mathrm{~W}$, time $22 \mathrm{sec}$ )

5. Toluene bath (time $60 \mathrm{sec}$ )

6. Blow dry and soft bake (gas $\mathrm{N} 2$, temperature $90^{\circ} \mathrm{C}$, time $15 \mathrm{sec}$ )

7. Develop photoresist MF-24A (time $90 \mathrm{sec}$ )

8. Quick dump rinse (QDR) (time 3x1 min)

9. Spin rinse dryer (SRD) (30 sec $500 \mathrm{rpm}$ water spray, 3 min $2000 \mathrm{rpm} \mathrm{N}_{2}$ flow, and 3 min 4000 rpm dry)

10. Sputtering parameters( based pressure $5 * 10^{-6}$ mTorr, temperature $25 \mathrm{C}$, substrate rotation $10 \mathrm{rpm}$,)

11. Ti layer deposition ( $5 \mathrm{mT}$ Torr (Ar), DC power $300 \mathrm{~W}$, time $60 \mathrm{sec}$ ) 
12. Pt layer deposition ( $5 \mathrm{mT}$ Torr (Ar), DC power $200 \mathrm{~W}$ DC, time $15 \mathrm{~min}$ )

13. Acetone bath (time 2 hours, temperature 60-70C)

14. Ultra-sonicated acetone bath (time 5-10 min, temperature 25C)

15. QDR, SRD

16. Optical microscopy

17. Contact profilometer

The next step in the fabrication of multi-sensor platform is to manufacture the $\mathrm{Si} / \mathrm{SiO}_{2}$ encapsulated membrane at the center of the device by using the RIE and DRIE techniques. The formation of the membrane structure was divided into two parts. During the first phase the encapsulation pattern (Mask 2) was transferred on the front side of the multi-sensor platform by using photolithography process following by machining the $\mathrm{SiO}_{2} / \mathrm{Si}$ surface with $\mathrm{RIE}$ and DRIE. The second part of the process is the membrane fabrication. During the second step the backside of the multi-sensor platform was processed by using photolithography (Mask 3), RIE and DRIE to form the encapsulated SiO2/Si membrane structure with a total thickness of $50 \mathrm{um}$. The consecutive machining of the front and then back side of the platform was done by protecting the other side of the platform with silicon wafer. The step by step procedure for suspended $\mathrm{Si} / \mathrm{SiO}_{2}$ membrane fabrication is described below:

1. Wafer cleaning and drying (acetone bath $1 \mathrm{~min}$, deionized water, drying with N2 )

2. Spin coating of photoresist (PMMA SPR $220-7,0.2 \mathrm{sec}-500 \mathrm{rpm}, 30 \mathrm{sec}-$ $4000 \mathrm{rpm})$

3. Soft bake (temperature $90^{\circ} \mathrm{C}$ for $30 \mathrm{sec}$, and temperature $115^{\circ} \mathrm{C}$, time $70 \mathrm{sec}$ )

4. Exposure to UV light (front side, mask 2, power $325 \mathrm{~W}$, time $55 \mathrm{sec}$ )

5. Wait time (time 30min)

6. Hard bake (temperature $120^{\circ} \mathrm{C}$, time $75 \mathrm{sec}$ )

7. Develop photoresist MF-24A (time $120 \mathrm{sec}$ )

8. QDR, SRD 
9. RIE ( time $10 \mathrm{~min}, \mathrm{H}_{2}+\mathrm{CH}_{4}(5+5 \mathrm{sccm})$, Pressure (500mTorr), RF power $(80 \mathrm{~W})$ )

10. DRIE (50 cycles, passivated phase: C4F8 flow rate $200 \mathrm{sccm}$ for $5 \mathrm{sec}$, and etching phase: SF6 flow rate $400 \mathrm{sccm}$ for $15 \mathrm{sec}$ )

11. Acetone bath (time $2 \mathrm{~min}$, temperature $60-70^{\circ} \mathrm{C}$ )

12. QDR, SRD

13. Optical microscopy

14. Contact profilometer

15. Wafer cleaning and drying (acetone bath $1 \mathrm{~min}$, deionized water, drying with $\mathrm{N}_{2}$ )

16. Spin coating of photoresist (PMMA SPR 220 - 7, $0.2 \mathrm{sec}-500 \mathrm{rpm}, 30 \mathrm{sec}-$ $4000 \mathrm{rpm})$

17. Soft bake (temperature $90^{\circ} \mathrm{C}$ for $30 \mathrm{sec}$, and temperature $115^{\circ} \mathrm{C}$, time $70 \mathrm{sec}$ )

18. Exposure to UV light (back side, mask 3, power $325 \mathrm{~W}$, time $55 \mathrm{sec}$ )

19. Wait time (time 30min)

20. Hard bake (temperature $120^{\circ} \mathrm{C}$, time $75 \mathrm{sec}$ )

21. Develop photoresist MF-24A (time $120 \mathrm{sec}$ )

22. QDR, SRD

23. RIE ( time $10 \mathrm{~min}, \mathrm{H}_{2}+\mathrm{CH}_{4}(5+5 \mathrm{sccm})$, Pressure (500mTorr), RF power $(80 \mathrm{~W})$ )

24. DRIE (250 cycles, passivated phase: C4F8 flow rate $200 \mathrm{sccm}$ for $5 \mathrm{sec}$, and etching phase: SF6 flow rate 400sccm for $15 \mathrm{sec}$ )

25. Acetone bath (time $2 \mathrm{~min}$, temperature 60-70C)

26. QDR, SRD

27. Optical microscopy

28. Contact profilometer

The final pattern of multiple sensing elements (Mask 4) with areas free of PMMA across four pair of metallic electrodes was transfered on the surface of the encapsulated membrane by using photolithography process. It is important to note that masks 1-4 have specific marks that allowed to match all features of the platform at each step of the fabrication process. During the platform fabrication hundreds of identical devices were manufactured on the same 4 inch wafer. The separation of multiple platforms from each 
other was done by using dicing procedure. The step by step process of pattern (Mask 4) transfer and device separation is described below:

1. Wafer cleaning and drying (acetone bath $1 \mathrm{~min}$, deionized water, drying with $\mathrm{N}_{2}$ )

2. Spin coating of photoresist (PMMA 1827, $0.2 \mathrm{sec}-500 \mathrm{rpm}, 10 \mathrm{sec}-4000 \mathrm{rpm}$ )

3. Soft bake (temperature $90^{0} \mathrm{C}$, time $70-75 \mathrm{sec}$ )

4. Exposure to UV light (front side, mask 4, power $325 \mathrm{~W}$, time $22 \mathrm{sec}$ )

5. Toluene bath (time $60 \mathrm{sec}$ )

6. Blow dry and soft bake (gas $\mathrm{N} 2$, temperature $90^{\circ} \mathrm{C}$, time $15 \mathrm{sec}$ )

7. Develop photoresist MF-24A (time $90 \mathrm{sec}$ )

8. Quick dump rinse (QDR) (time 3x1 min)

9. Spin rinse dryer (SRD) (30 sec at $500 \mathrm{rpm}$ water spray, $3 \mathrm{~min}$ at $2000 \mathrm{rpm} \mathrm{N}$ flow, and $3 \mathrm{~min} 4000 \mathrm{rpm}$ dry)

10. Dicing (road width 100um)

The original 15 step fabrication process (Figure 2.5) was applied to manufacture the multi-sensor platform with a total amount of sensors equal to four (4X platform).

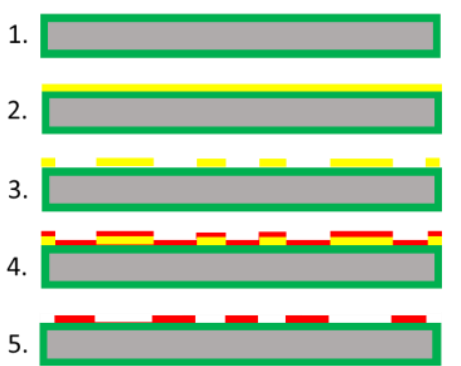

1. Substrate oxidation

2. Front side spin coating of PMMA

3. Front side photolithography process

4. Front side Metal deposition

5. Lift Off process and PMMA removing

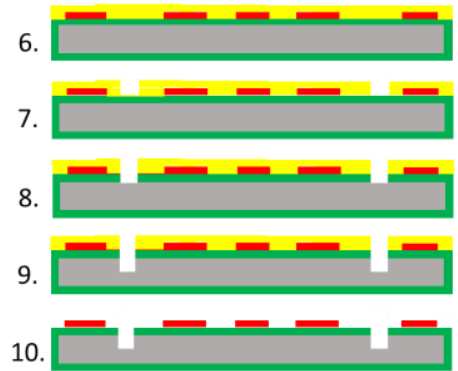

6. Front side spin coating of PMMA

7. Front side photolithography process

8. Front side silicon oxide etching

9. Front side silicon substrate etching

10. PMMA removing

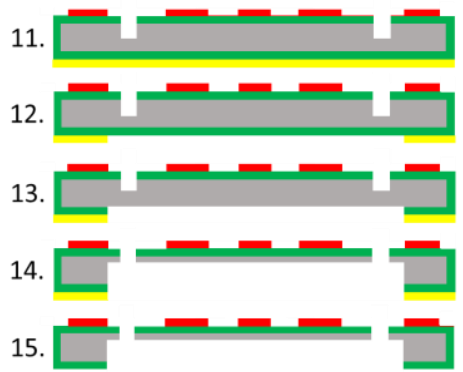

11. Backside spin coating of PMMA

12. Backside photolithography process 13. Backside silicon oxide etching

14. Backside silicon substrate etching 15. Backside PMMA removing

Figure 2.5 The multi-sensor platform step by step micro-fabrication process.

The $4 \mathrm{X}$ platform provides the ability to analyze gas samples by using four highly integrated distinct sensing elements under identical temperature condition. Also, the simultaneous fabrication of multiple sensing platforms (Figure 2.6) on the same 
substrate/wafer provides necessary conditions for comparative analysis of different sensing elements and minimize possible errors from device variations.

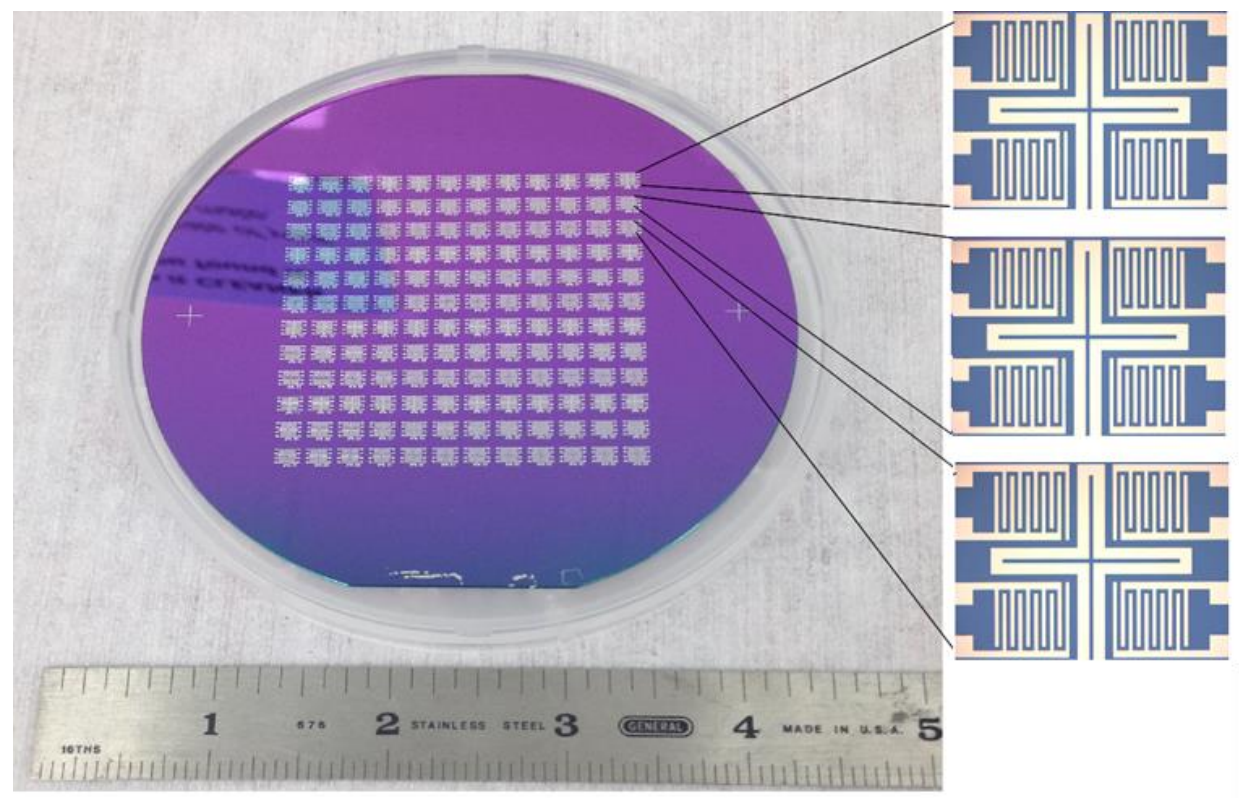

Figure 2.6 An image of the $\mathrm{Si} / \mathrm{SiO} 2$ wafer with multiple sensing platforms.

\subsection{Sensing element fabrication}

In this section, we present sensing element manufacturing process by using multi source magnetron sputtering technique in combination with photolithography and shadow mask process. The deposition chamber contains three sputtering source that can operate simultaneously: 4 inch RF sputtering source and two DC sputtering sources with 2 inch in diameter. The chamber has a sample holder located 5 inches above the sputtering sources. The sample holder undergoes a constant rotation of 10 revolutions per minute. The shadow on/off protection bellow the sample holder provide the ability to precisely control the deposition time. The thicknesses of all the layers were monitored during the deposition process by using quartz crystal sensor (Inficon, Gold, $6 \mathrm{Mhz}$ ) and verified by surface profile meter (Alpha Step 500) after the fabrication. The base chamber pressure prior any deposition process is required to be set below $5.5 \times 10^{-5}$ Torr. The major components and 
schematic diagram of the deposition chamber for sensing element fabrication is presented in Figure 2.7.

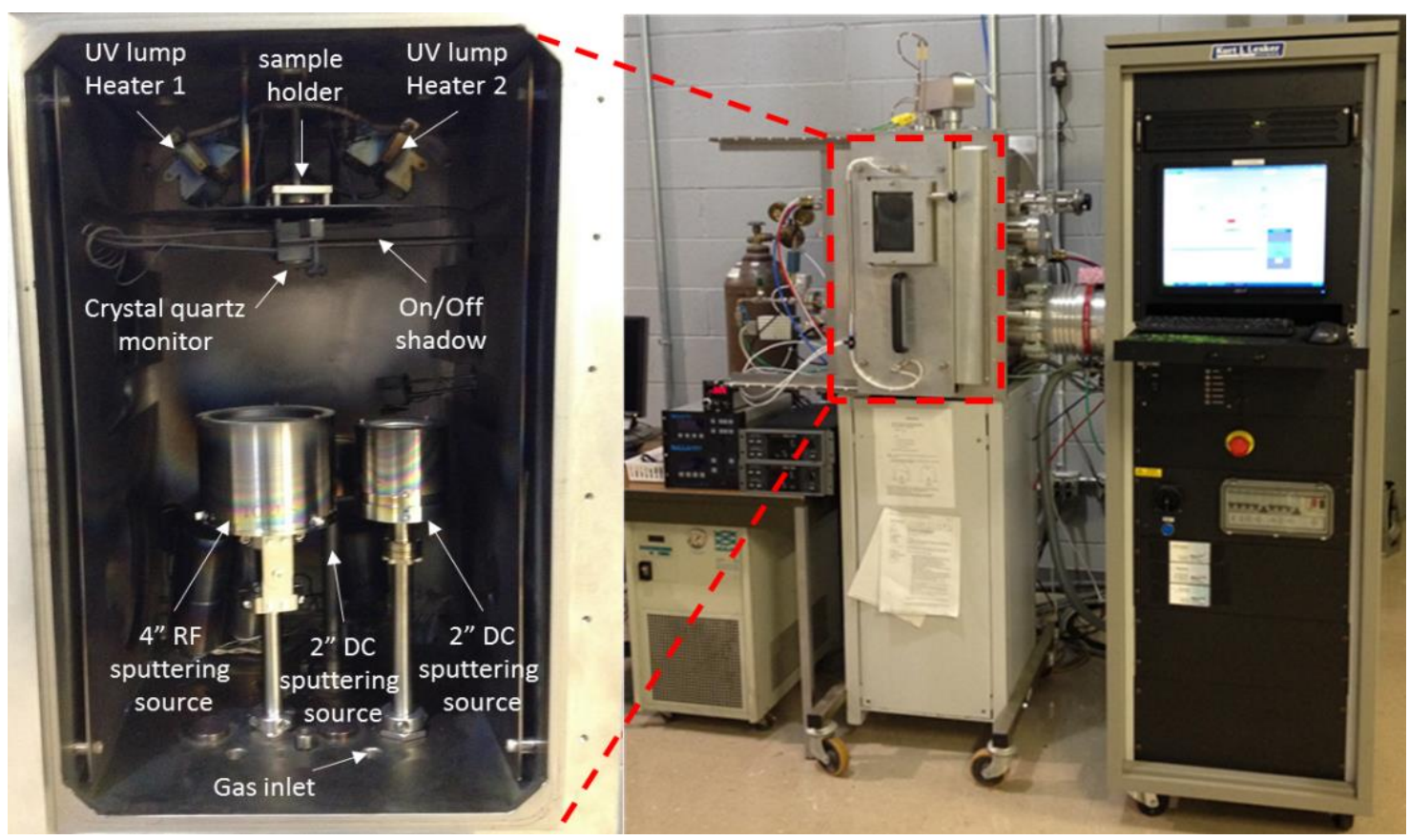

Figure 2.7 An image of multi-source magnetron sputtering deposition system for sensing element fabrication.

The deposition of sensing elements over a pair of platinum electrodes was performed by utilizing photolithography technique by depositing the gas sensing material over the area free of PMMA and protecting the rest of the device with a thin layer $(2.7 \mathrm{um})$ of polymer (Figure 2.8a and b). The photolithography approach was used to precisely control the dimensions (width and length) of the sensing element down to a couple of microns. Such a high precision of the photolithographic technique allowed us to fabricate sensing elements over extremely small surface area of only hundred square microns. After the sensing layer was deposited, the lift off process was applied to the device in order to remove the rest of the PMMA. During the lift off process the sensing platform was washed 
inside a warm $\left(50^{\circ} \mathrm{C}\right)$ ultrasonic acetone bath over a period of time $15 \mathrm{~min}$ followed by cleaning the sample in deionized water and drying it with nitrogen gun (Figure 2.8c).

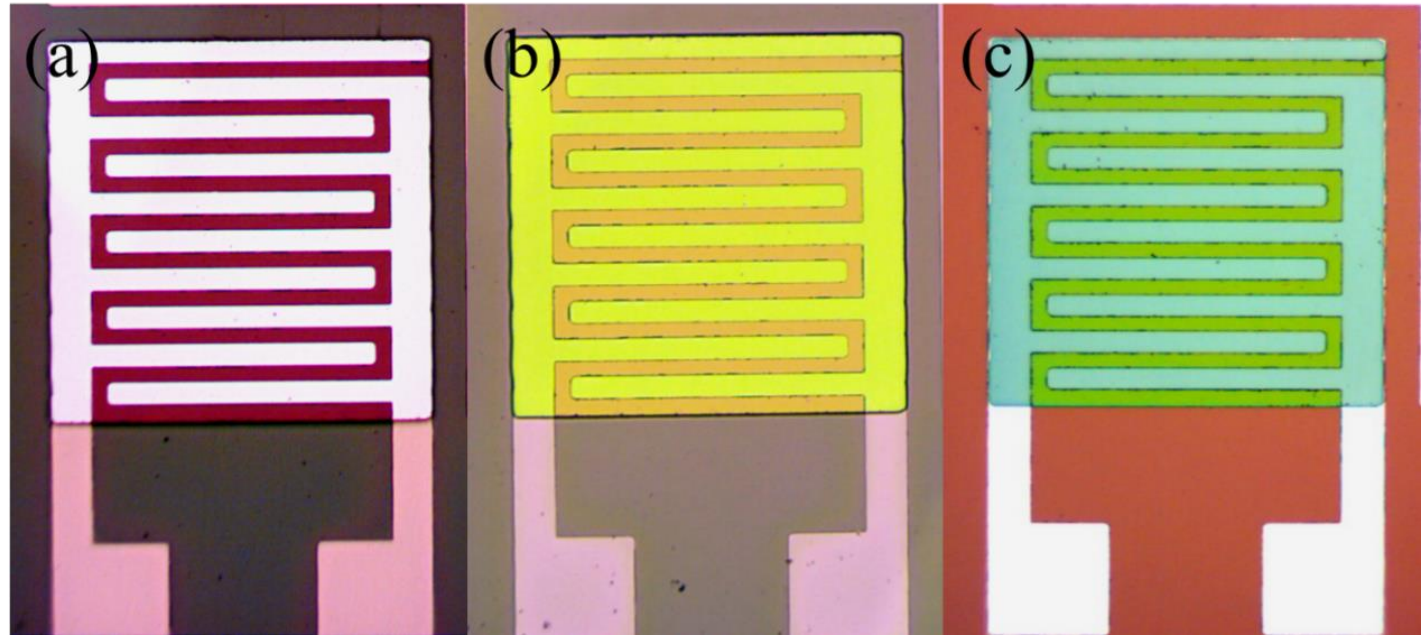

Figure 2.8 A zoomed image of the sensing element (a) before the MOX deposition, (b) after the deposition and (c) after the lift off process.

\subsection{1 $\mathrm{SnO}_{2}, \mathrm{TiO}_{2}$, and $\mathrm{SnO}_{2}-\mathrm{TiO}_{2}$}

Thin films of $\mathrm{TiO}_{2}, \mathrm{SnO}_{2}, \mathrm{SnO}_{2}-\mathrm{TiO}_{2}$ bilayer and multilayer structures were synthesized by using multisource RF magnetron sputtering technique. The material deposition was done by using $\mathrm{SnO}_{2}$ and $\mathrm{TiO}_{2}$ four inch sputtering targets with purity of $99.99 \%$ and $99.998 \%$, respectively. The deposition was conducted at room temperature and no special bias voltage was applied to the sample during the deposition. The schematics of a single-layer, a bilayer and a multilayer structure are shown in Figure $2.9 \mathrm{a}-\mathrm{c}$, respectively.

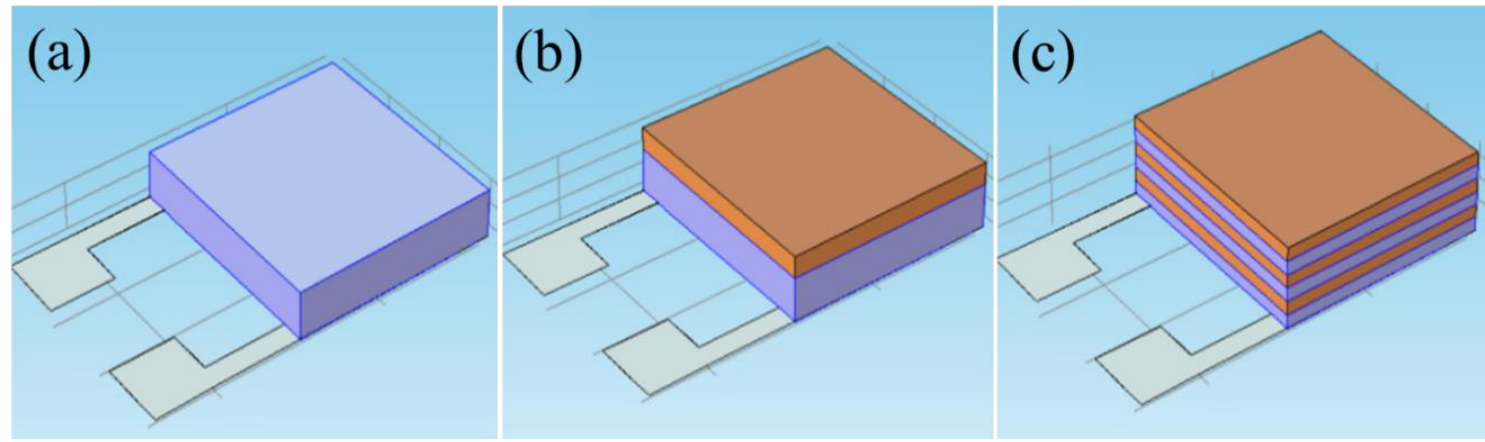

Figure 2.9 A schematics diagram of (a) mono-oxide single-layer, (b) bilayer and (c) multilayer structure.| 
The pure oxide layers of $\mathrm{SnO}_{2}$ and $\mathrm{TiO}_{2}$ were sputtered under 12 mTorr of argon (Ar) pressure and total RF power of $200 \mathrm{~W}$. The bilayer structure of $\mathrm{SnO}_{2}-\mathrm{TiO}_{2}$ were fabricated under identical conditions over two step process: deposition of main layer of $\mathrm{SnO}_{2}$ and then deposition of surface modified layer of $\mathrm{TiO}_{2}$. The multilayer $\mathrm{SnO}_{2}-\mathrm{TiO}_{2}$ structures were prepared by multiple consecutive depositions of two MOXs. Different volume fraction (vol\%) of $\mathrm{TiO}_{2}$ in $\mathrm{SnO}_{2}$ were obtained by varying the deposition rate of $\mathrm{TiO}_{2}$. The multilayer structure was constructed out of six layers: three layers of $\mathrm{SnO}_{2}$ and three layers of $\mathrm{TiO}_{2}$. During the sample preparation eight different sensors were prepared for detection of $\mathrm{H}_{2} \mathrm{~S}$ (Table 2.3). After the deposition, all the samples were annealed in a tube furnace (MKS OTF 1200x, MTI Corporation, Richmond, CA, USA) under $500^{\circ} \mathrm{C}$ for 48 hours in ultra-zero grade air (UZ300 Airgas, flow rate $100 \mathrm{sccm}$ ).

Table 2.3 Sensors' structure and composition as deposited

\begin{tabular}{cccc}
\hline Sample \# & Sensing material & Composition & Total thickness \\
\hline $\mathrm{S} .1 .0$ & $\mathrm{SnO}_{2}$ & $100 \%$ & $30 \mathrm{~nm}$ \\
$\mathrm{~S} .1 .1$ & $\mathrm{SnO}_{2}-\mathrm{TiO}_{2}$ bi-layer & $30 \mathrm{~nm}+5 \mathrm{~nm}$ & $35 \mathrm{~nm}$ \\
$\mathrm{~S} .1 .2$ & $\mathrm{SnO}_{2}-\mathrm{TiO}_{2}$ bi-layer & $30 \mathrm{~nm}+8 \mathrm{~nm}$ & $38 \mathrm{~nm}$ \\
$\mathrm{~S} .1 .3$ & $\mathrm{SnO}_{2}-\mathrm{TiO}_{2}$ bi-layer & $30 \mathrm{~nm}+20 \mathrm{~nm}$ & $50 \mathrm{~nm}$ \\
$\mathrm{~S} .1 .4$ & $\mathrm{SnO}_{2}-\mathrm{TiO}_{2}$ multilayer & $5 \mathrm{vol} \% \mathrm{TiO}_{2}$ & $31.5 \mathrm{~nm}$ \\
$\mathrm{~S} .1 .5$ & $\mathrm{SnO}_{2}-\mathrm{TiO}_{2}$ multilayer & $10 \mathrm{vol} \% \mathrm{TiO}_{2}$ & $33 \mathrm{~nm}$ \\
$\mathrm{~S} .1 .6$ & $\mathrm{SnO}_{2}-\mathrm{TiO}_{2}$ multilayer & $20 \mathrm{vol} \% \mathrm{TiO}_{2}$ & $36 \mathrm{~nm}$ \\
$\mathrm{~S} .1 .7$ & $\mathrm{TiO}_{2}$ & $100 \%$ & $30 \mathrm{~nm}$ \\
\hline
\end{tabular}

\subsubsection{Pt@ $\mathrm{SnO}_{2}, \mathrm{Au} @ \mathrm{SnO}_{2}, \mathrm{Pd} @ \mathrm{SnO}_{2}$, and $\mathrm{Au} / \mathrm{Pd} @ \mathrm{SnO}_{2}$}

Four different types of $\mathrm{SnO}_{2}$ based nanocomposite thin films (Table 2.4) were prepared for detection of VOCs. A thin layer of $\mathrm{SnO}_{2}(30 \mathrm{~nm}+/-2 \mathrm{~nm})$ was first deposited over all four sensors S.2.0 - S.2.3. During the $\mathrm{SnO}_{2}$ sputtering, the deposition rate was kept constant at $0.6 \mathrm{~A} / \mathrm{s}$ by applying $200 \mathrm{~W}$ RF power to 4-inch tin oxide $\left(\mathrm{SnO}_{2} 99.99 \%\right)$ target under 12 mTorr of Argon pressure. A thin layer $(1.5 \mathrm{~nm})$ of platinum was then deposited 
on the surface of $\mathrm{SnO}_{2}$ sensor S.2.0 by using 2-inch $\mathrm{Pt}(99.995 \%)$ sputtering target under 5 mTorr of argon pressure with constant deposition rate of $1 \mathrm{~A} / \mathrm{s}$. The surface of sensor S.2.1 was then modified with $1.5 \mathrm{~nm}+/-.2 \mathrm{~nm}$ of gold (Au 99.99\%) deposited over the $\mathrm{SnO}_{2}$ layer. Similarly, the $\mathrm{SnO}_{2}$ surface of S.2.2 sensor was coated with $1.5 \mathrm{~nm}+/-0.2 \mathrm{~nm}$ of palladium (Pd 99.95\%). The Au and Pd depositions were performed by applying DC power to a 2-inch metal target under 5 mTorr of argon pressure. The deposition rates of Au and $\mathrm{Pd}$ remained constant at $1 \mathrm{~A} / \mathrm{s}$ and $0.5 \mathrm{~A} / \mathrm{s}$ respectively over the deposition process. The surface of sensor S.2.3 was then modified with a thin $\mathrm{Au} / \mathrm{Pd}$ (9:1) alloy layer by simultaneous sputtering from both $\mathrm{Au}$ and Pd targets. The DC power for the Pd target was adjusted in order to decrease the deposition rate of Pd down to $0.1 \mathrm{~A} / \mathrm{s}$ and the deposition rate of the gold target was left unchanged.

Table 2.4 Sensors' structure and composition as deposited.

\begin{tabular}{ccc}
\hline Sensor \# & Sensor's bulk material & Sensor's surface modification \\
\hline $\mathrm{S} .2 .0$ & $\mathrm{SnO}_{2}(30 \mathrm{~nm}+/-2 \mathrm{~nm})$ & $\mathrm{Pt}(1.5 \mathrm{~nm}+/-0.2 \mathrm{~nm})$ \\
$\mathrm{S} .2 .1$ & $\mathrm{SnO}_{2}(30 \mathrm{~nm}+/-2 \mathrm{~nm})$ & $\mathrm{Au}(1.5 \mathrm{~nm}+/-0.2 \mathrm{~nm})$ \\
$\mathrm{S} .2 .2$ & $\mathrm{SnO}_{2}(30 \mathrm{~nm}+/-2 \mathrm{~nm})$ & $\mathrm{Pd}(1.5 \mathrm{~nm}+/-0.2 \mathrm{~nm})$ \\
$\mathrm{S} .2 .3$ & $\mathrm{SnO}_{2}(30 \mathrm{~nm}+/-2 \mathrm{~nm})$ & $\mathrm{Au} / \mathrm{Pd}(9: 1)(1.5 \mathrm{~nm}+/-.+/-0.2 \mathrm{~nm})$ \\
\hline
\end{tabular}

The sensors S.2.0-S.2.3 had an amorphous structure right after the deposition. The synthesis of metal nanoparticles and the formation of $\mathrm{SnO}_{2}$ nanocrystals from the amorphous pre-deposited layers was achieved via high-temperature calcination process. The samples were calcined in a tube furnace (MTI) at $500{ }^{\circ} \mathrm{C}$ for 48 hours under a flow rate of $100 \mathrm{sccm}$ of ultra-zero grade air from AirGas. During the heating and cooling stage of the annealing process, the furnace was pre-programmed for slow temperature ramping at the constant rate of $10{ }^{\circ} \mathrm{C}$ per minute.

2.2.3 Multiple sensing element fabrication on a single platform 
The placing of different sensing elements onto one multi-sensor platform is an important part of the detector fabrication. The sensing elements deposition process is the last step of multi-sensory platform fabrication in order to avoid any further modification of the sensing element surface. The multi-sensory platform with four different sensing elements was fabricated by using combination of photolithographic process and hardcontact shadow mask approach. The combination of both (photolithography and hard contact shadow masks) techniques allowed us to preserve high precision over the deposited sensing area, introduce some flexibility to the process of multiple sensing element fabrication onto a single sensing platform and avoid the deposition of PMMA over existing sensing elements. It is important to remember that any wet chemical process applied to the sensor's surface after it was deposited might affect the surface properties of the sensing material and change its future performance. In order to avoid the multiple use of the PMMA material per sensor fabrication, an additional glass and silicon shadow mask was used over the existing photolithographic pattern on the surface of the multi-sensory platform to specify the deposition area and protect the rest of the device (Figure 2.10a and b). The rotation of the shadow mask over all the sensing elements allowed us to avoid multiple photolithographic processes and protect the sensing elements. After the deposition of all the sensors on the single platform, the similar lift off process was applied. The multisensory system with four different sensing elements (S1.0, S.1.5, S.2.3 and S.2.0) was fabricated for multi-component analysis of complex gas mixtures such as indoor air, natural gas and human breath (Figure 2.10c). 


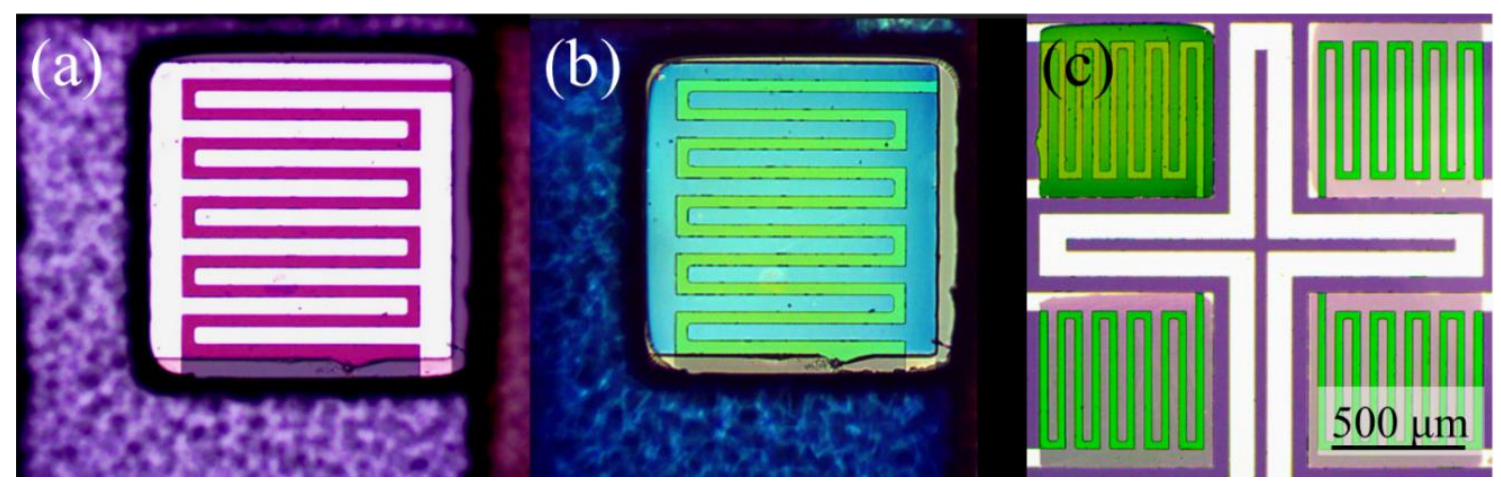

Figure 2.10 A zoomed image of a sensing element (a) before and (b) after sensing element deposition and (c) different sensing elements integrated onto one platform by using hard contact shadow mask technique.

\subsection{Device packaging}

The interconnection of microelectronic devices with the main electronic circuit board is an important step. The packaging technique provides the necessary connection and maintain the necessary mechanical and electrical stability of the device over a long term. Additionally, the electronic package plays an important role in developing a long term use gas detector by applying laminar flow of gas samples over the sensor's surface and removing dust particles from the stream of gas prior the detection process.

High thermal insulation of the sensing platform under elevated temperature in combination with high mechanical stability of the device was preserved by attaching the platform to a modified transistor outline package (TO8) through additional supporting structure at the corners of the platform. The supporting structure was manufactured by modifying the surface of the metal package (TO8) with a high precision milling machine and producing four identical thin and long legs. The mechanical stability of the point like contacts at the four corners of the device was achieved by using ultra-high temperature adhesive paste. Thermally stable electronic interconnection between the multi-sensor platform and the electronic package was performed by using a wire bonding technique. All 
the connections between the platinum pads at the surface of the multi-sensor platform and the TO package pins were done by using 1 mil gold wire. (Figure 2.11a). Finally, a small detector's volume $\left(<0.5 \mathrm{~cm}^{3}\right)$ was obtained by using a cap for the TO package with active gas intake structure (Figure 2.11b).
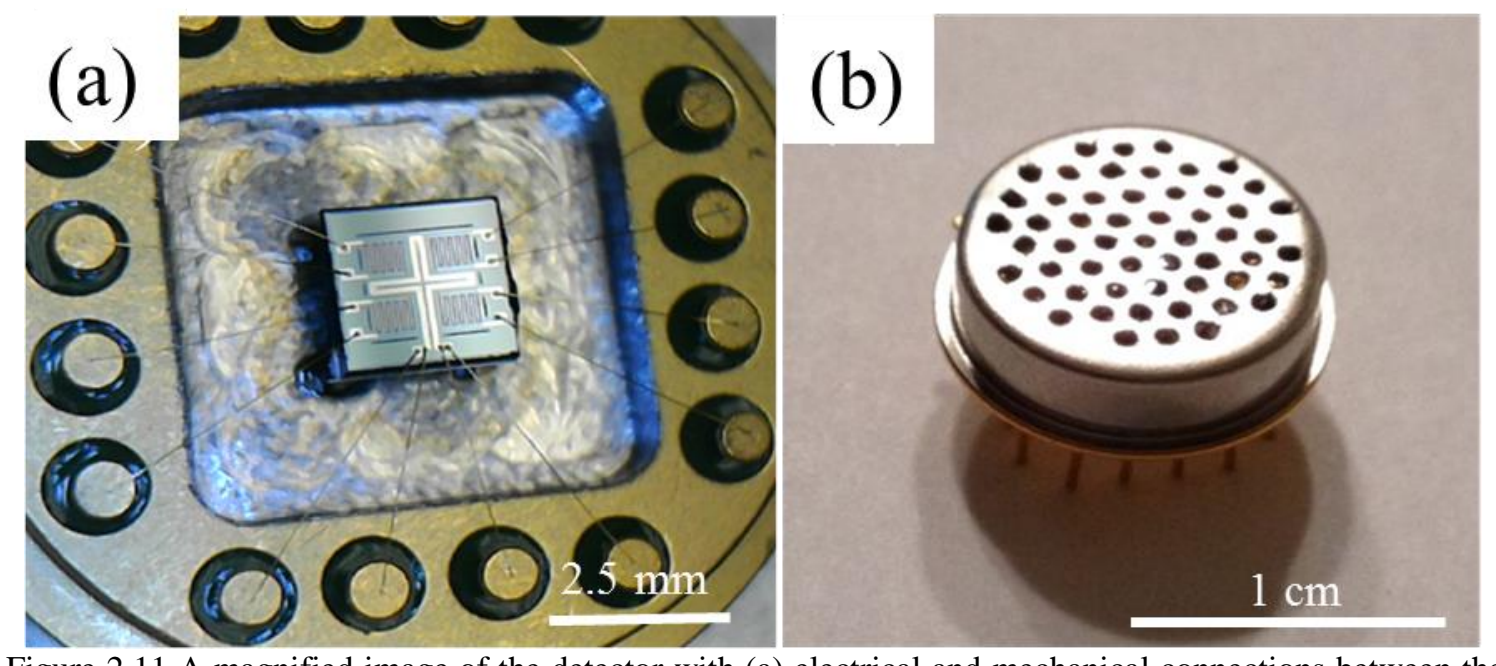

Figure 2.11 A magnified image of the detector with (a) electrical and mechanical connections between the sensing platform and the modified transistor outline package and (b) optical image of the detector with passive air intake structure and small detector's volume $\left(<1 \mathrm{~cm}^{3}\right)$.

\subsection{Material characterization}

In this work the material characterization techniques for analysis of ultra-thin films can be divided into two categories: direct analysis of the sensing layers on the surface of the device and analysis of simplified samples. Some techniques such as Scanning Electron Microscopy (SEM), Atomic Force Microscopy (AFM), Energy Dispersive Analysis by XRay (EDAX) and surface contact profilometry directly characterize the sensing materials on the actual device. Other techniques such as Transmission Electron Microscopy (TEM) and X-Ray Diffraction (XRD) are very important for material characterization but cannot be applied on the device. In such cases, the analysis is performed on simplified samples. 
Ultra-thin nanocomposite MOX gas sensing films are the main priority of this research. The total thickness of each sample was monitored during the deposition by using quartz crystal thickness sensor (6MHz INFICON Crystal, part number 008-010-G10). The verification of the deposited layer thickness was done by using surface contact profilometer (KLA-Tencor 500 AlphaStep IQ, (TENCOR Instruments, Mountain View, CA, USA). Further analysis of atomic and molecular crystal structure, surface and bulk morphology, chemical composition of each sample was performed by using XRD, SEM, TEM and AFM.

The crystal structure of the samples was evaluated by the XRD method. The XRD spectrum of samples was collected by a Thermo ARL (model XTRA, Thermo Fisher Scientific Waltham, MA, USA) X-ray diffraction machine $(\mathrm{Cu} \mathrm{K} \alpha$ radiation wavelength was $0.15056 \mathrm{~nm}$ ). The machine was calibrated prior the analysis by using quartz sample. The analysis of the XRD diffractogram was accomplished by using special built in software which enable to identify the major diffraction peaks, intensity and related angle. After all the peaks were located, the process of sample identification was done by using online database: Powder Diffraction File 1 (PDF 1).

A scanning electron microscope (SEM Zeiss Supra 35, Carl Zeiss AG, Oberkochen, Germany) was utilized to study the surface microstructure of the samples. The SEM imaging enable to provide surface image of the samples with resolution down to several nanometers $(10-20 \mathrm{~nm})$.

Atomic force microscopy was performed by using Asylum MFP-3D AFM with symmetric taping probe (Tap190-G, resonant frequency $190 \mathrm{kHz}$ ). The AFM analysis provide high resolution 3D surface topography at nanometer and even at sub-nanometer 
scale. Sensing layer surface morphology and surface roughness is an important parameter that was directly measured by using the AFM.

A JEOL 1400Plus transmission electron microscope (TEM) was utilized in our research in order to analyzed polycrystalline thin films of MOXs and define shape, size and density of noble metal nanoparticles. In TEM analysis an electron beam is transmitted through the material which is supported by a very thin carbon film sitting on a $3 \mathrm{~mm}$ diameter gold grid (Carbon Type-B, 200 mesh TH, Gold, part number 01808G ). The best resolution routinely obtained by using the TEM is less than $1 \mathrm{~nm}$. The preparation of TEM samples were synchronized with actual sensor fabrication with simultaneous deposition over the sensing element area and the TEM grid following by annealing process in the same chamber.

In this work, UV-Vis-NIR versatile fiber-optic spectrometer (Avantes AVASPEC 2048-L) with a broad usable range $200-1100 \mathrm{~nm}$ and the resolution of $3 \mathrm{~nm}$ was used in combination with a deuterium - halogen light source, (AvaLight-DHc Full-range Compact Light Source, $200-2500 \mathrm{~nm}$ ) for calculation of optical band gap of $\mathrm{SnO}_{2}$ and $\mathrm{TiO}_{2}$. In addition, during the experiment, a special cuvette sample holder (Avantes CUV-UV/VIS) was utilized in order to prevent the ambient light from entering the light path. During the experiment, dark spectrum of the background was first collected. The spectroscopic data was then collected for transparent glass slide ( $1 \mathrm{x} 1 \mathrm{inch})$. Finally, the UV-Vis spectroscopy of a glass slides with a thin $(30 \mathrm{~nm})$ film of semiconducting material $\left(\mathrm{SnO}_{2}\right.$ and $\left.\mathrm{TiO}_{2}\right)$ was obtained. The absorption coefficient alpha $(\alpha)$ for specific photon energy (hv) was then calculated for both semiconductors $\left(\mathrm{SnO}_{2}\right.$ and $\left.\mathrm{TiO}_{2}\right)$ by using the intensity of the incident light $\left(\mathrm{I}_{0}\right)$ and the transmitted light spectrum (I). Optical band gap of $\mathrm{SnO}_{2}$ and $\mathrm{TiO}_{2}$ for 
both direct and indirect allowed transitions was approximated by using the Tauc plot method.

\subsection{Experimental techniques}

The experimental techniques for study conductometric gas sensors can be divided into two main categories: electrical measurements and spectroscopic experiments. The study of MOX surface states (active sites) as well as direct investigation of chemical reactions on the surface of semiconductors can be investigated by using photo-electron spectroscopy. However, spectroscopic studies of the surface catalytic reactions by utilizing simplified samples (thin films only) might be different from the reactions on the surface of actual device due to sensing layer polarization and effect of metal contacts. The main focus of this work is to investigate the chemisorption processes and surface-gas interference based on phenomenological experimental techniques such as relative change in conductance of the sensing layer on the surface of actual device rather than simplified thin film samples.

Conductance/resistance measurement is the main instrument in this work to characterize sensing performance of the device. However, electrical measurements of MOXs is not that simple. The device morphology, the electronic contacts, the amplitude of applied voltage, the lead resistance $\left(\mathrm{R}_{\text {lead }}\right)$ during the experiment are important parameters that can potentially affect the resistance measurement. The four probe resistance measurement method is one of the most useful techniques that eliminates lead resistance and thus obtain a much more accurate result (Figure 2.12a) [164]. In this work, four probe resistance measurement was obtained by using high performance digital multi-meter (Keithley 3706A). The low current option of this device $(0.64 \mu \mathrm{A})$ let us obtain a precise 
resistance measurement up to $2 \mathrm{M} \Omega$ without any polarization effects. For sensing element resistances higher than $2 \mathrm{M} \Omega$, an ultra-low current source (Keithley 6221) and high precision DC voltmeter (Keithley 2010) were used in conjunction with a four probe measurement circuit under low polarization voltage $(<1 \mathrm{~V})$.

In addition, the influence of electrical contact resistance (end resistance) between the sensing layer (MOX) and metal electrodes (Pt) has been studied by using the transmission line measurement (TLM) technique [165]. The TLM method is a very useful tool to obtain the contribution of "end resistance" to the total resistance of the sensing element by running the experiments with different geometries (Figure 2.12b). The total resistance between platinum electrodes was obtained by using four probe resistance measurement technique utilizing the low DC current source (Keithley 6221) and DC multimeter (Keithley 2010). During the experiment the current was kept constant at $0.5 \mu \mathrm{A}$ and the voltage was recorded to calculate the total resistance for different geometries.

Finally, the polarization effect on MOX semiconductors was investigated under different bias voltage conditions in the range between 0.1 and $10 \mathrm{~V}$. During the experiment the bias voltage across the platinum interdigitated contacts (distance $d=25 \mu \mathrm{m}$ ) was adjusted to specific values $(0.1,0.2,0.4,0.8,1.6,3.2,5$ and $10 \mathrm{~V})$ by using variable DC voltage source (Keithley 487) and DC voltmeter (Keithley 2010). The current in the circuit was then recorded for each bias voltage by using high precision ammeter (Keithley 487) (Figure 2.12c). The resistance of the sensing layer was then calculated under different polarization conditions. 
(a) Four wire resistance measurement

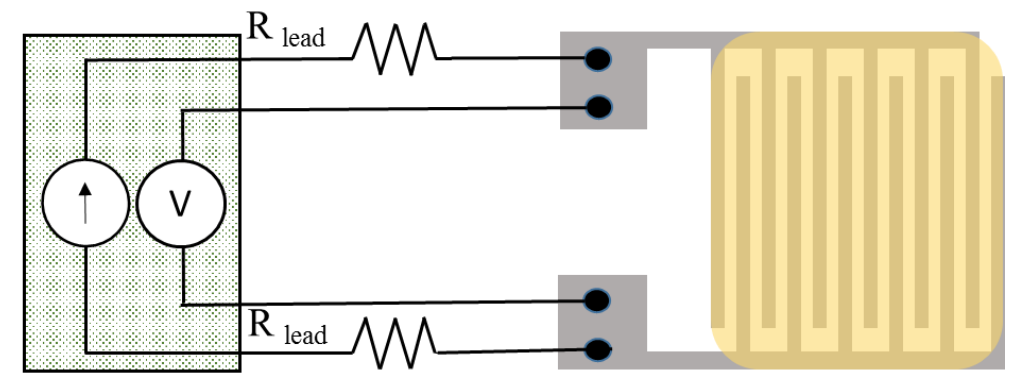

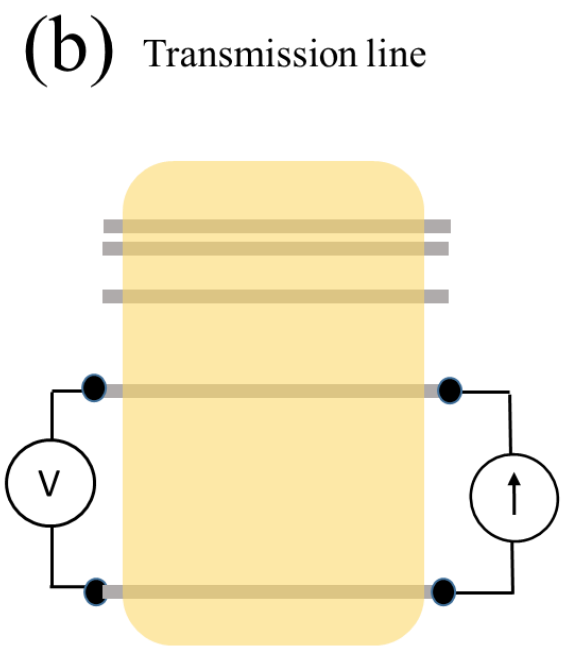

Metal oxide sensing layer
(C) V-I characteristics

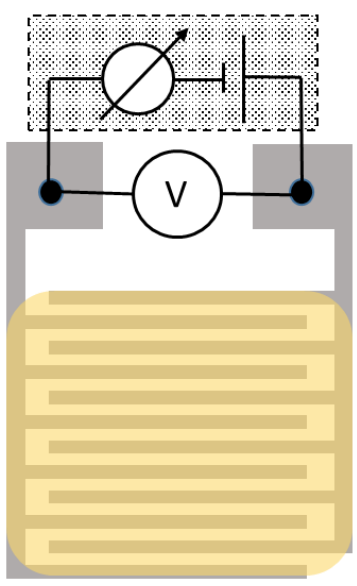

Metal electrodes

Figure 2.12 Schematics diagrams of (a) four probe resistance measurement, (b) transmission line measurement, and (c) V-I characteristics of the sensing element.

\subsection{Gas sampling and delivery systems}

\subsubsection{Multi-channel gas mixing system}

A multi-channel gas mixing system was utilized for evaluation of sensors' performance (Figure 2.13a). The gas mixing part of the system (Figure 2.13b) is capable of producing small concentrations of different gases by diluting the commercially available pre-mixed gases of known concentrations into ultra-zero-grade air. The flow rate from a single gas input was measured by a thermal mass flow meter and controlled by an integrated mass flow controller (MKS 1179A) with an accuracy of $+/-1 \%$ within a full 
scale range from 0.2 to $10 \mathrm{sccm}$. Also, a gas pre-mixing chamber with a total volume of 5 $\mathrm{cm}^{3}$ was added to the system prior the detector in order to produce a uniform concentration of deliverable gases even at sub ppm level. During the analysis, the total flow rate through the detector and the detector's volume were kept constant at $10 \mathrm{sccm}$ and $1 \mathrm{~cm}^{3}$ respectively. The multi-channel gas mixing system was controlled via LabVIEW software and NI PCI 6259 hardware. The gas detector (Figure 2.13c) was connected to the output of the gas mixing system to provide accurate response to different gas concentrations. The four probe DC resistance measurement of the sensing element was conducted by using a Keithley 3700A high performance DMM. The resistance of each sensing element was measured with a sampling rate of $10 \mathrm{~Hz}$.
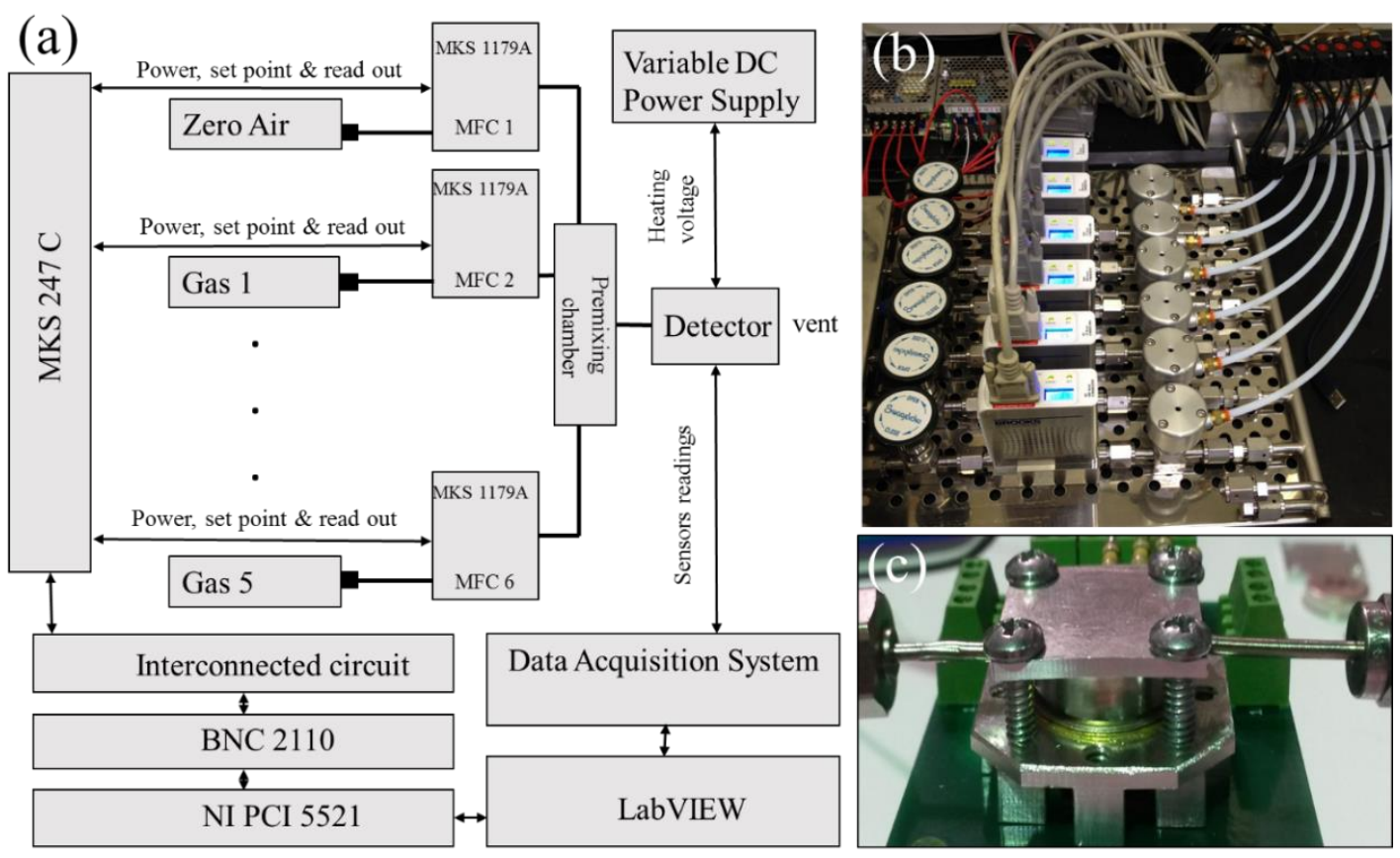

Figure 2.13 A schematic diagram of (a) multi-channel gas mixing system with (b) total six different gases and (c) detector's chamber. 


\subsubsection{Portable gas chromatograph}

A portable GC analyzer (Figure 2.14) was used for the analysis of complex gas mixtures. The GC unit was equipped with a Restek MXT WAX (30 m) column internal diameter (ID) with $0.53 \mathrm{~mm}$ and coating layer thickness $\left(\mathrm{d}_{\mathrm{f}}\right)$ of $2 \mu \mathrm{m}$. The flow rate and column temperature were held constant at $10 \mathrm{sccm}$ and $55{ }^{\circ} \mathrm{C}$, respectively. The major device settings such as temperature, pressure, and different time cycles as well as data acquisition parameters for analysis of gas mixtures were defined and upload to GC firmware prior the detection.

The GC operating cycle includes three main steps: sampling, gas mixture separation, and detection. During the first step, the gas sample was injected into the system. The sample volume of $50 \mathrm{ml}$ was kept constant for all of the experiments. It is important to note that in contrast to the straight gas sample injection into the GC column when utilizing a classical table top GC, the portable GC unit was equipped with a sample preconcentrator. The gas mixture components are absorbed by the pre-concentrator under room temperature during the sampling step and then instantly injected into the GC column by rapidly increasing the temperature of the pre-concentrator. During the second step, the gas mixture components were separated inside the capillary column by differences in molecular weight, polarity, and chemical composition. Finally, the detection of gas components was performed by the detector (Figure 2.14b). The data acquisition, signal processing and data analysis were performed by on board microprocessor. After the analysis, the purging and cleaning cycle was applied to the system to remove the leftover contaminants. The device also equipped with RS-232 communication port for real time data acquisition by using a laptop. 


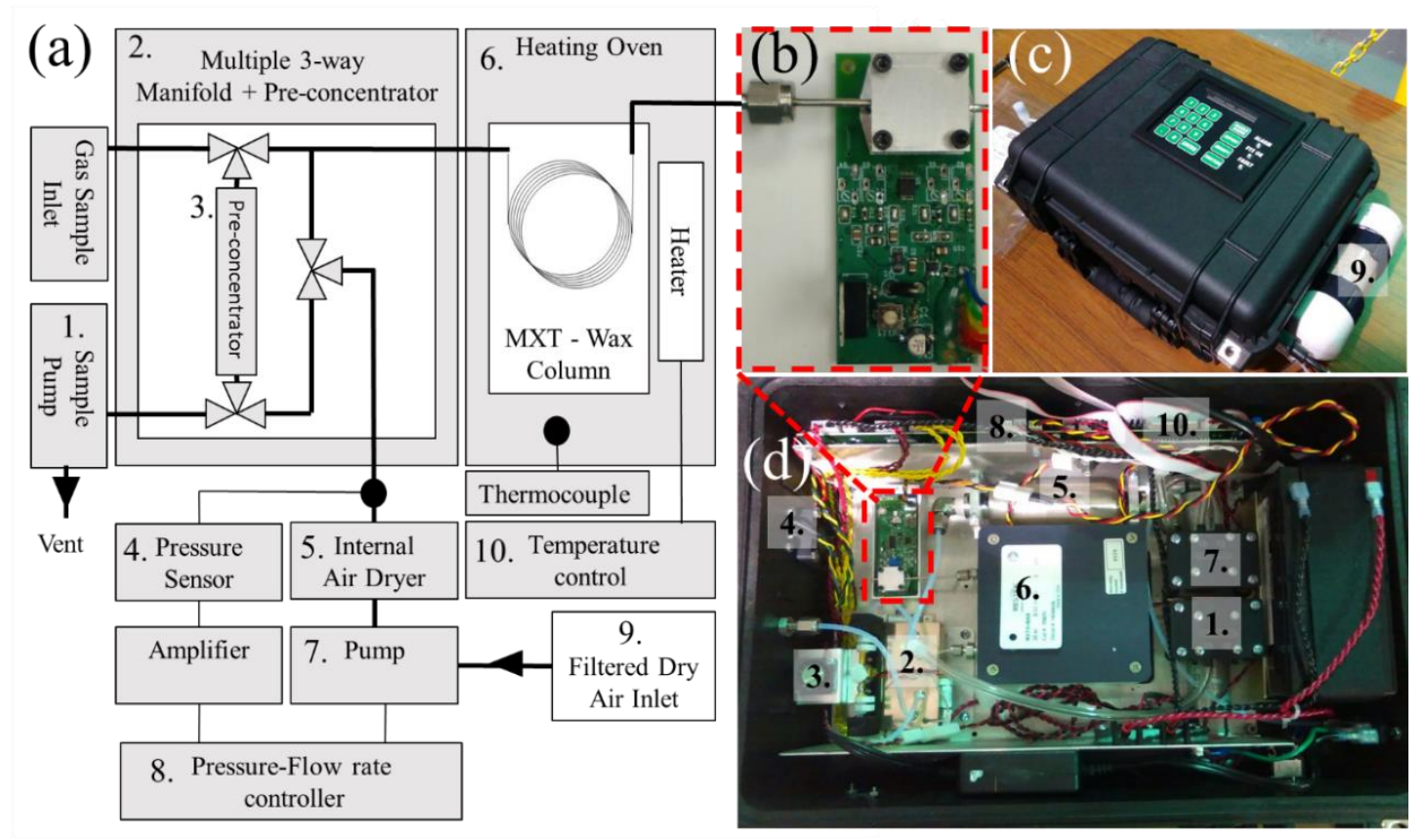

Figure 2.14 A schematic diagram of (a) portable GC unit with optical images of the (b) detector, (c) GC protection case, and (c) internal architecture of the unit.

\subsection{Gases and concentrations}

Different concentrations of complex gas mixtures were prepared by using premixed calibration gases (Table 2.5), ultra-zero grade air and a sample bag (SamplePro FlexFilm, 1L). Ultra-low concentrations of gas analytes at ppb and sub-ppb level was achieved with precise control over the injected volume $(1 \mu \mathrm{l}-20 \mathrm{ml})$ for each gas utilizing Hamilton syringes. 
Table 2.5 Gases, vapors and concentrations.

\begin{tabular}{cccc}
\hline Gases \& Vapors & Molecular Formula & $\begin{array}{c}\text { Concentration } \\
(\mathrm{ppm})\end{array}$ & Vendor in USA \\
\hline 1. Carbon monoxide & $\mathrm{CO}$ & 300 & ShopCross \\
2. Hydrogen Sulfide & $\mathrm{H}_{2} \mathrm{~S}$ & 20 & ShopCross \\
3. Ethyl-Mercaptan & $\mathrm{C}_{2} \mathrm{H}_{6} \mathrm{~S}$ & 10 & Casco \\
4. Isopropyl alcohol & $\mathrm{C}_{3} \mathrm{H}_{8} \mathrm{O}$ & 400 & Casco \\
5. Methanol & $\mathrm{CH}_{3} \mathrm{OH}$ & 10 & Casco \\
6. Ethanol & $\mathrm{C}_{2} \mathrm{H}_{6} \mathrm{O}$ & 126.5 & Cal-Gas \\
7. Acetone & $\left(\mathrm{CH}_{3}\right)_{2} \mathrm{CO}$ & 20 & Casco \\
8. Methane & $\mathrm{CH}_{4}$ & $99.9 \%$ & Cal-Gas \\
9. Benzene & $\mathrm{C}_{6} \mathrm{H}_{6}$ & 5 & Mesa \\
10. Toluene & $\mathrm{C}_{7} \mathrm{H}_{8}$ & 5 & Mesa \\
11. Ethylbenzene & $\mathrm{C}_{6} \mathrm{H}_{5} \mathrm{C}_{2} \mathrm{H}_{5}$ & 5 & Mesa \\
12. O-Xylene & $\mathrm{C}_{6} \mathrm{H}_{4}\left(\mathrm{CH}_{3}\right)_{2}$ & 5 & Mesa \\
\hline
\end{tabular}

2.8 Limit of detection

The limit of detection (LOD) of a sensor was determined based on sensors' baseline signal under clean dry air and the response of the sensor to different concentrations of detectable gases. The data for the LOD analysis was collected over the period of one week. After the data was collected, the distribution of the sensor's noise was determined based on average baseline signal $S_{\text {avg }}^{\text {air }}$, and the standard deviation of the signal $\sigma^{\text {air }}$ under ultrazero grade air. The distribution of sensor's signal under low concentrations of detectable gases was then determined by the average sensor's response $S_{\text {avg }}^{\text {gas }}$ and standard deviation of the response $\sigma^{g a s}$. The distance of 3 times the standard deviation from the mean value corresponds to $99.74 \%$ of the area under the normal distribution curve. Hence, the choice of parameters will assure that the signal can be distinguished from the noise with the 99.74\% probability. The limit of detection is the smallest gas concentration under which the sensor's signal can be distinguished from the sensor's noise (Figure 2.15). 


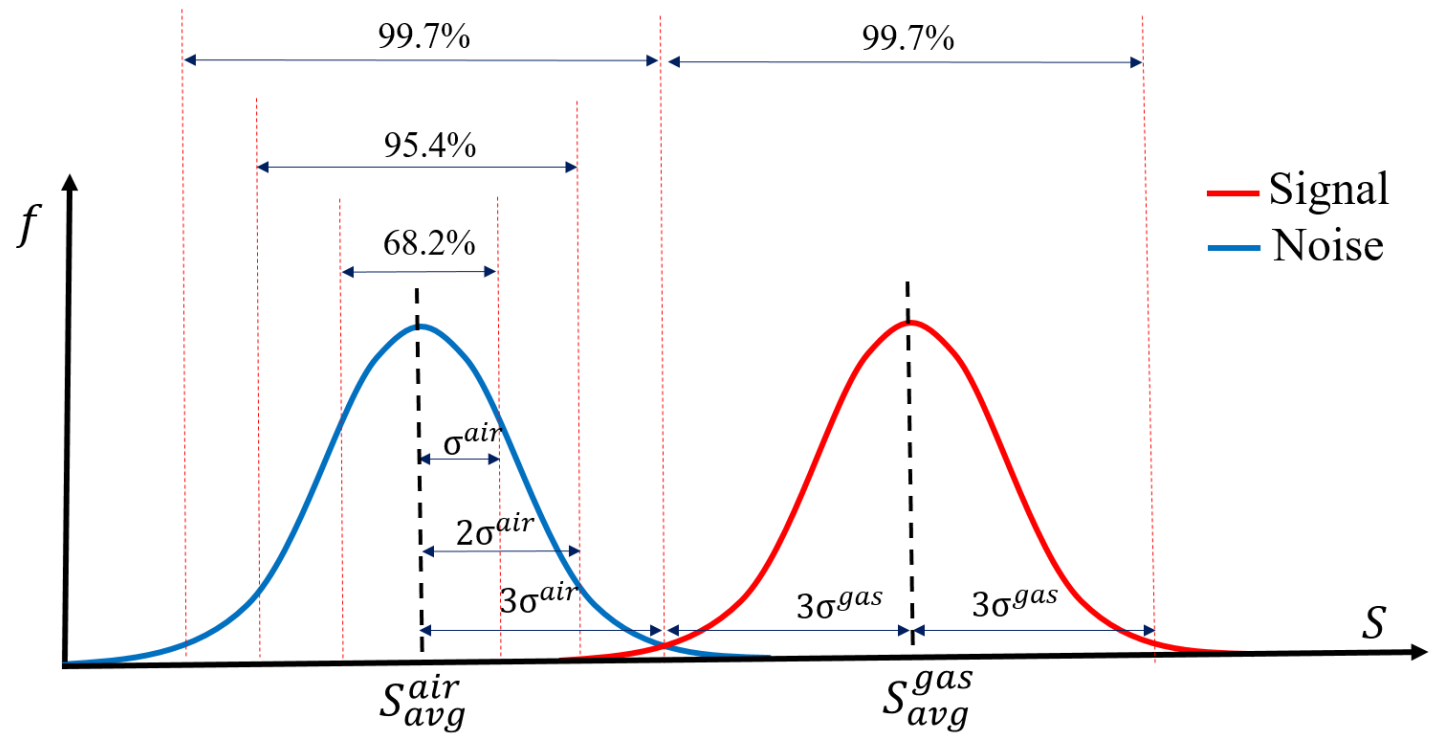

Figure 2.15 The schematic diagram of the detection limit with sensor's noise (blue) and minimum detectable sensor's signal (red). 


\section{CHAPTER 3: RESULTS AND DISCUSSION}

\subsection{Thermo-electric characteristics of the detector}

The thermo-electric characteristics of the multi-sensor MOX detector were obtained by using high precision Quantum Focus Instrument (QFI) thermal imaging system which is able to capture thermal images of the platform featuring $0.1{ }^{\circ} \mathrm{C}$ temperature and 5 um spatial resolutions. In order to minimize the uncertainty during the thermal analysis, a precise thermographic calibration and measurement procedure was applied to each sample prior the actual data collection. The thermal camera was first calibrated under constant temperature condition when the image of the detector's surface was obtained under 60 degrees $\left({ }^{\circ} \mathrm{C}\right)$ and the emissivity coefficients were calculated for each material at the surface of the device. The thermal images of the device surface were then obtained at elevated temperature by heating the detectors surface with the on board micro-heater. The thermal images of the device were obtained for three different temperature regions such as low (150 $\left.{ }^{\circ} \mathrm{C}\right)$, medium $\left(250{ }^{\circ} \mathrm{C}\right)$ and high $\left(>350{ }^{\circ} \mathrm{C}\right)$ and corresponding power dissipation across the heating element due to the Joule heating was recorded (Figure 3.1a-e) (Table 3.1). 


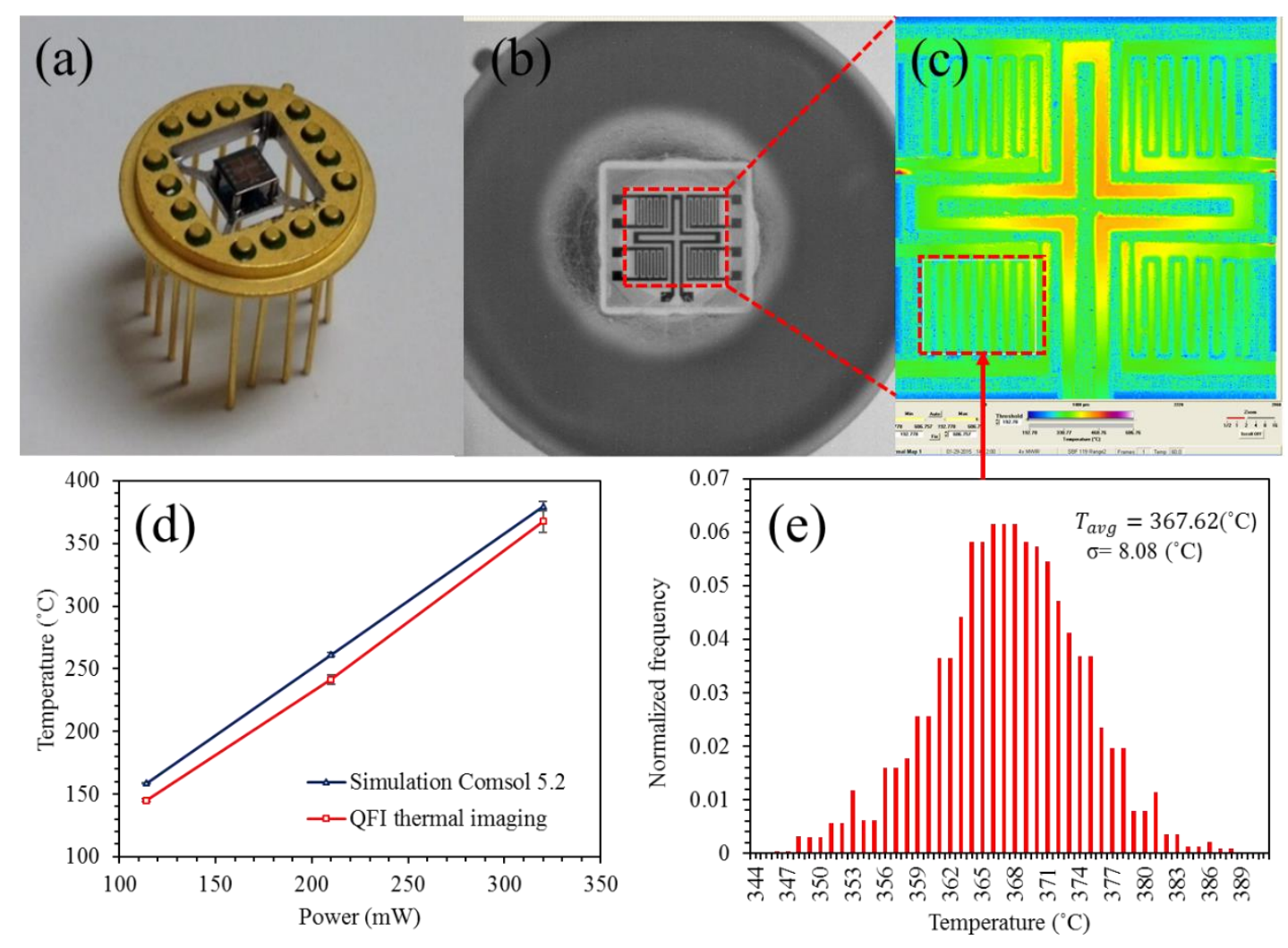

Figure 3.1 (a,b) Optical images of the detector, (c) a temperature profile obtained with QFI thermal imaging station, (d) corresponding relation between average surface temperature of a sensing element and the total power dissipation across the micro-heater for both simulated and actual device and (e) the temperature distribution across a single sensing element at high temperature $>350{ }^{\circ} \mathrm{C}$ and.

Table 3.1 Thermo-electric characteristics of the detector

\begin{tabular}{ccccccc}
\hline \multirow{2}{*}{$\begin{array}{c}\text { Voltage } \\
(\mathrm{V})\end{array}$} & $\begin{array}{c}\text { Current } \\
(\mathrm{mA})\end{array}$ & $\begin{array}{c}\text { Power } \\
(\mathrm{mW})\end{array}$ & \multicolumn{2}{c}{ Simulation } & \multicolumn{2}{c}{ Experimental } \\
\cline { 5 - 7 } & 57 & 114 & 158.61 & 0.64 & 145.11 & 2.4 \\
\hline 3 & 71 & 210 & 261.36 & 3.11 & 241.43 & 3.9 \\
4 & 82 & 320 & 379.71 & 7.52 & 367.62 & 17.6 \\
\hline
\end{tabular}

\subsection{Material analysis}

\subsection{1 $\mathrm{SnO}_{2}, \mathrm{SnO}_{2}-\mathrm{TiO}_{2}$ and $\mathrm{TiO}_{2}$}

The morphology of the $30 \mathrm{~nm} \mathrm{SnO}_{2}$ layer (S.1.0) was first investigated by SEM imaging technique. The SEM analysis revealed its porous and polycrystalline structure with a uniform coating (Figure 3.2a). In addition to high porosity of the sample, no high 
agglomeration of the nanocrystals was observed. It is important to note that ultra-thin films with thickness less or equal to $30 \mathrm{~nm}$ have an advantage over the thick films due to the combination of high porosity and low agglomeration of nanocrystals (5-10 $\mathrm{nm}$ in diameter). This feature of ultra-thin films allowed for combining high sensitivity and fast response of the sensor at the same time. The size of $\mathrm{SnO}_{2}$ crystal was further determined by TEM analysis to be in the range between 7 and $10 \mathrm{~nm}$ (Figure 3.2b). High surface roughness of the sample S.1.0 was measured by using AFM analysis (Figure 3.2c). The average roughness of the sample surface was determined to be $6.7 \mathrm{~nm}$.
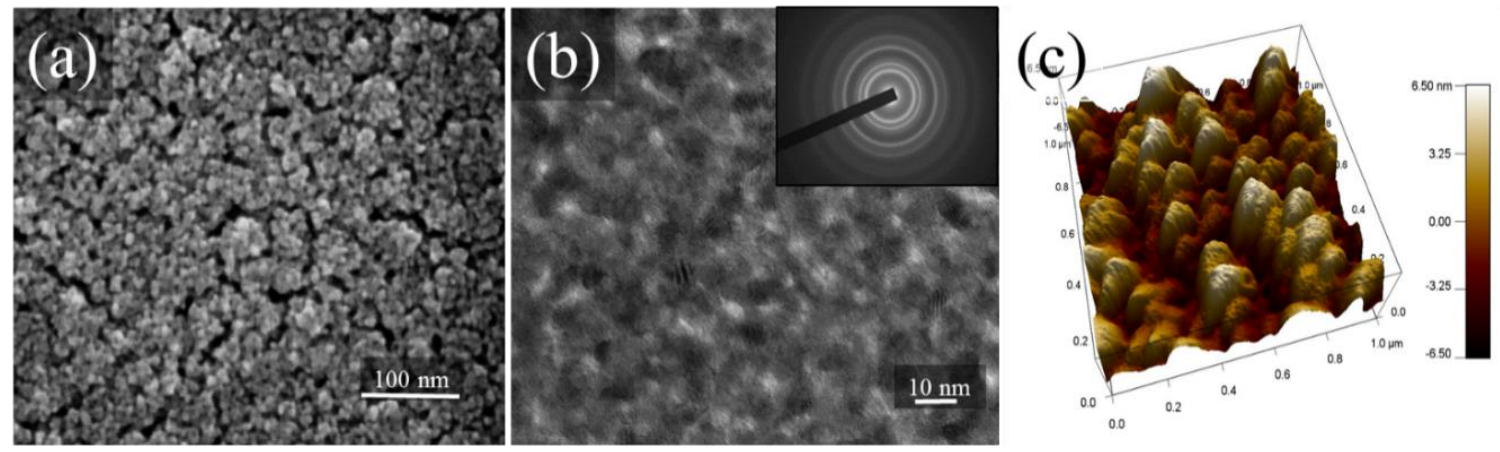

Figure 3.2 (a) SEM, (b) TEM and (c) AFM analysis of $\mathrm{SnO}_{2}$ thin film.

Different types of crystal planes and average sizes of $\mathrm{SnO}_{2}$ nanocrystals were finally characterized by X-ray diffractometer with $\mathrm{Cu} \mathrm{K \alpha}(\lambda=1.5056 \AA)$, which operated at $30 \mathrm{kV}$ and $20 \mathrm{~mA}$. The X-Ray diffraction patterns for the sample were obtained with a scan rate of $0.02 \%$ over the range of $20^{\circ}-60^{\circ}$ (Figure 3.3). The peak with the highest intensity was obtained at $2 \theta=26.92^{\circ}$ which corresponds to the most stable (110) plane of the $\mathrm{SnO}_{2}$. In addition, some other crystallographic planes (101), (200) and (211) with different structural and electronic configurations were formed at $2 \theta=34.22^{\circ}, 38.21^{\circ}$, and $52.17^{\circ}$ respectively. Finally, as a result of the XRD analysis, the average crystalline size among 
all the crystal planes of $\mathrm{SnO}_{2}$ was calculated to be $7.9 \mathrm{~nm}$ from Scherrer equation [166, 167]:

$$
D=\frac{K \lambda}{\beta \cos (\theta)}
$$

where $K$ is the shape factor, which usually has a value $0.9, \lambda$ is the $\mathrm{X}$-ray wavelength, $\theta$ is the Bragg angle and $\beta$ gives the full width of the half maxima (FWHM).

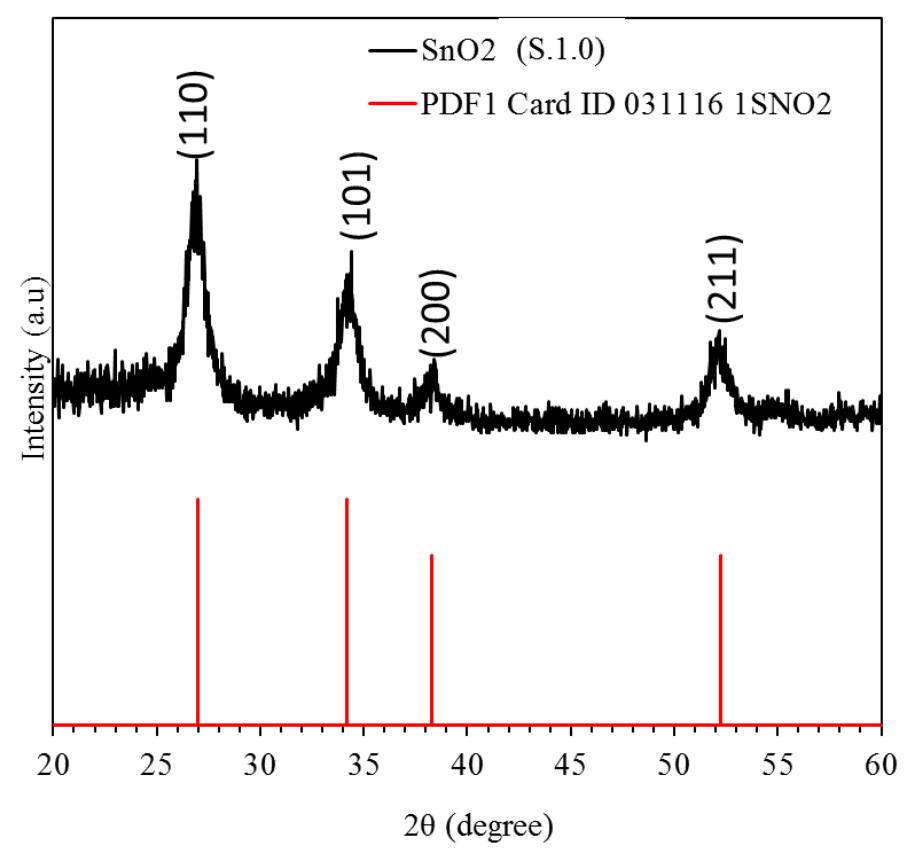

Figure 3.3 XRD analysis of $\mathrm{SnO}_{2}$ thin film.

The morphology of the samples S.1.1-S.1.6 was first investigated by using SEM analysis (Zeiss Supra 35) (Figure 3.4). All the samples except S.1.3 indicated rough and porous polycrystalline structure with short neck like interconnections between the nanocrystals. It can be noted that the porosity of the samples S.1.0 - S.1.3 decreased with increasing $\mathrm{TiO}_{2}$ coating layer. The $\mathrm{SnO}_{2}-\mathrm{TiO}_{2}$ (S.1.4-S.1.6) composite structure also showed a slightly decrease in porosity with increasing the amount of $\mathrm{TiO}_{2}$ from $5 \mathrm{vol} \%$ to $20 \mathrm{vol} \%$. It seems like that sample S.1.4 has more uniform grain size distribution and the 
higher porosity in comparison to the rest of the samples. It is important to be noted that smaller grain like structure of the samples S.1.4, S.1.5 and S.1.6 in combination with high porosity of the samples are produced high surface area for catalytic reaction.

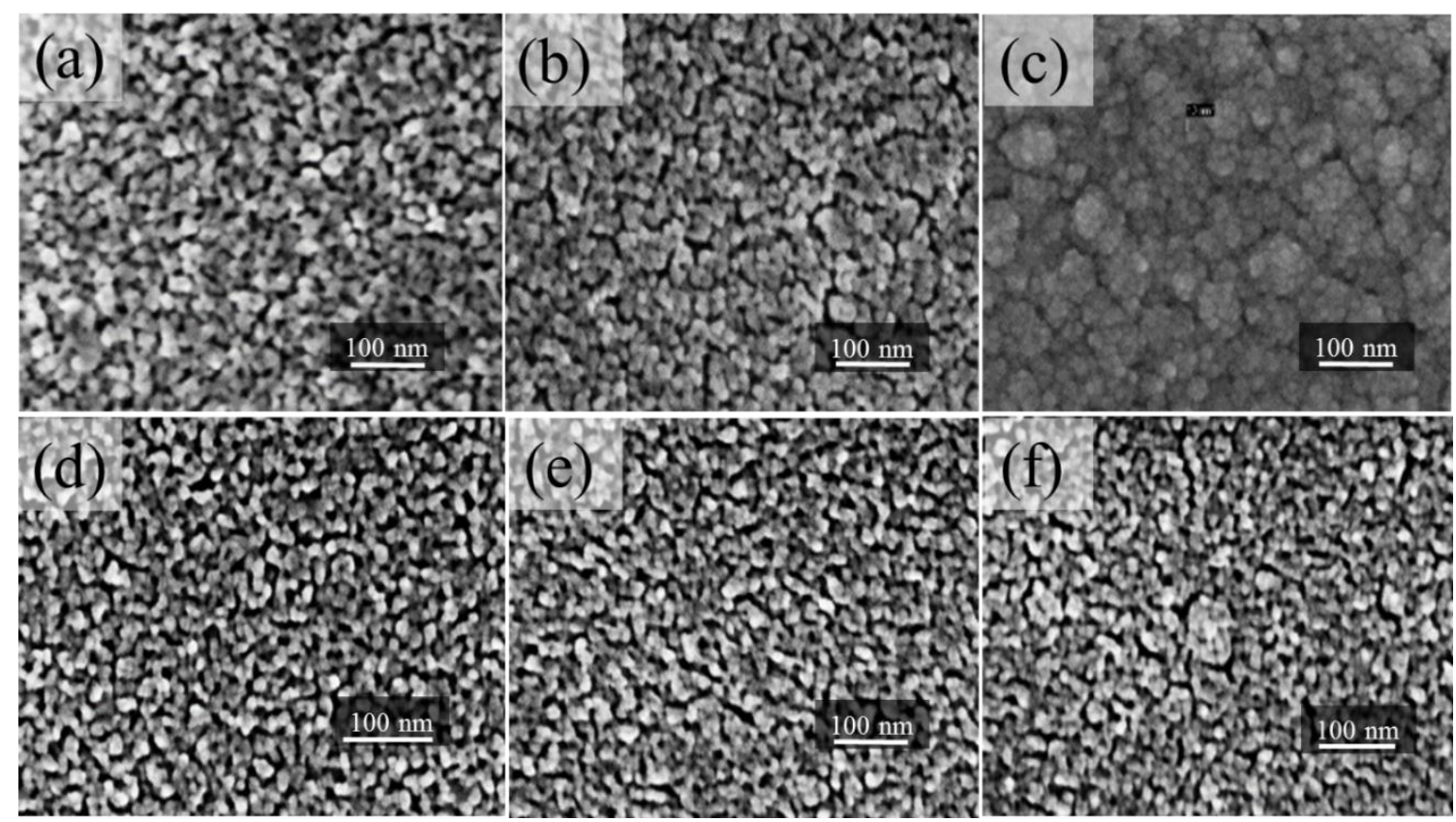

Figure 3.4 SEM images of the samples S.1.1-S.1.6: (a) $\mathrm{SnO}_{2} / \mathrm{TiO}_{2}$ bilayer structure $30 \mathrm{~nm}+5 \mathrm{~nm}$ (S.1.1), (b) $\mathrm{SnO}_{2} / \mathrm{TiO}_{2}$ bilayer structure $30 \mathrm{~nm}+10 \mathrm{~nm}(\mathrm{~S} .1 .2)$, (c) $\mathrm{SnO}_{2} / \mathrm{TiO}_{2}$ bilayer structure $30 \mathrm{~nm}+20 \mathrm{~nm}$ (S.1.3), (d) $\mathrm{SnO}_{2} / \mathrm{TiO}_{2}$ multilayer $5 \mathrm{vol} \%$ of $\mathrm{TiO}_{2}$ (S.1.4), (e) $\mathrm{SnO}_{2} / \mathrm{TiO}_{2}$ multilayer $20 \mathrm{vol} \%$ of $\mathrm{TiO}_{2}$ (S.1.5), (f) $\mathrm{SnO}_{2} / \mathrm{TiO}_{2}$ multilayer $50 \mathrm{vol} \%$ of $\mathrm{TiO}_{2}$ (S.1.6).

The XRD analysis of the bilayer samples S.1.1, S.1.2 and S.1.3 showed diffraction peaks similar to $\mathrm{SnO}_{2}$ rutile crystal structure with additional peak at $2 \theta=25.4^{\circ}$ corresponding to (101) crystal faces of anatase structure of $\mathrm{TiO}_{2}$ was detected for the samples S.1.2 and S.1.3 (Figure 3.5a). The position of the major diffraction peak of multilayer oxides shifts slightly from $2 \theta=26.78^{\circ}$ (S.1.6) to $2 \theta=26.87^{\circ}$ (S.1.5) and $2 \theta=26.91^{\circ}$ (S.1.4) with decreasing $\%$ vol of $\mathrm{TiO}_{2}$ (Figure 3.5b). In addition, the average crystal size of all the samples based on the major diffraction peak was calculated by using the Scherrer formula. The characteristic size of nanocrystals for a multilayer $\mathrm{SnO}_{2} / \mathrm{TiO}_{2}$ structure was determined to be smaller, compared to pure $\mathrm{SnO} 2: \mathrm{d}=4.87 \mathrm{~nm}$ (S.1.4), d=4.54 
$\mathrm{nm}$ (S.1.5) and $\mathrm{d}=4.09 \mathrm{~nm}$ (S.1.6). The smaller grain size of the composite oxides (S.1.4S.1.6) could be the advantage for gas sensing properties. During the XRD analysis of the samples S.1.4-S.1.6, the specific peaks of $\mathrm{TiO}_{2}$ crystal structure were not found. However, a noticeable asymmetry as well as the slight shift in the major peak of the multilayer structure may be attributed to the overlap of $\mathrm{TiO}_{2}$ and $\mathrm{SnO}_{2}$ peaks, caused by the small $\mathrm{TiO}_{2}$ nanocrystals present in the layer.
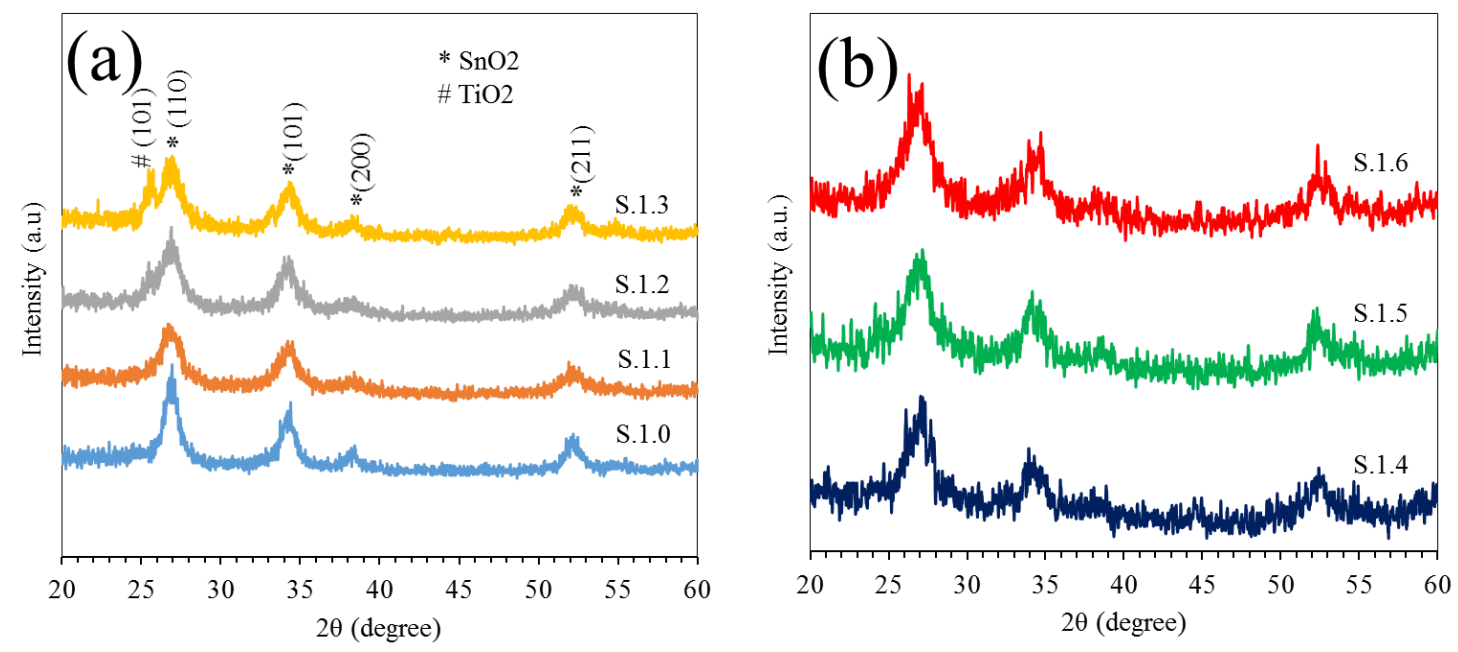

Figure 3.5 XRD analysis of (a) the samples S.1.0 - S.1.3 and (b) samples S.1.4 - S.1.6.

The morphology of pure $\mathrm{TiO}_{2}$ (S.1.7) layer was first analyzed by using electron microscopy technique. According to the SEM analysis the layer of $\mathrm{TiO}_{2}$ was much more compact compared to the porous structure of $\mathrm{SnO}_{2}$ layer (Figure 3.6a). Even distribution of the sensing material across the sensing area was confirmed without noticeable agglomeration. Further analysis of the sample with TEM revealed polycrystalline structure of $\mathrm{TiO} 2$ layer. Small nanocrystals of $\mathrm{TiO}_{2}$ in the range between $2-4 \mathrm{~nm}$ were determined by analyzing the sample S.1.7 (Figure 3.6b). Finally, the roughness of the $\mathrm{TiO}_{2}$ film was determined by using AFM data (Figure 3.6c). These results indicate that the surface of $\mathrm{TiO} 2$ is much smoother compare to the $\mathrm{SnO}_{2}$ layer of the same thickness. 

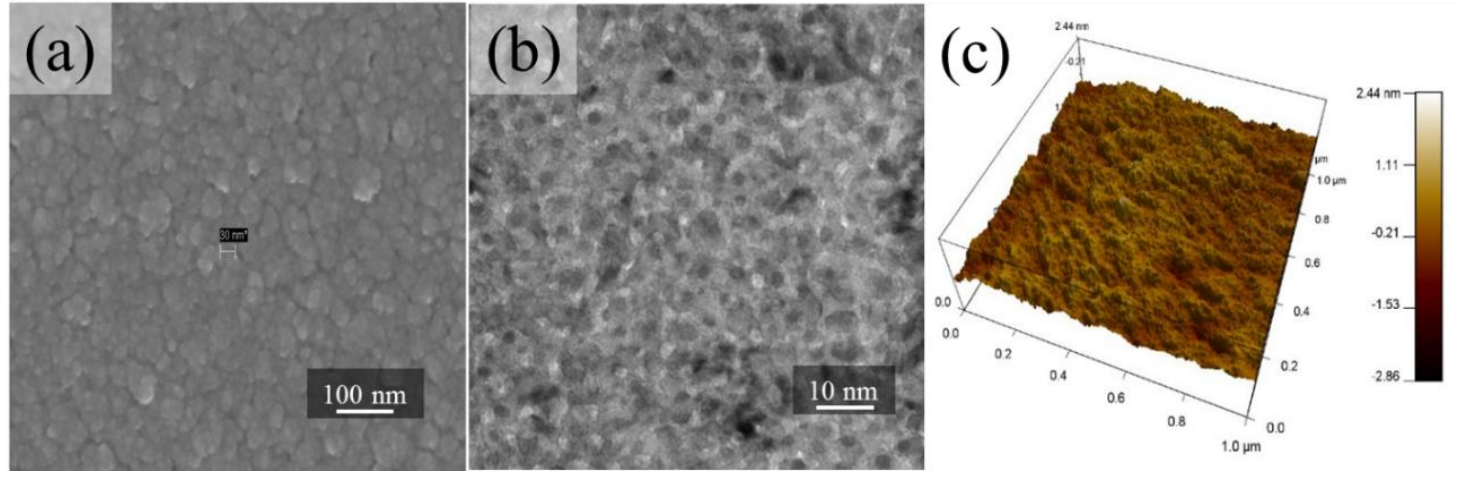

Figure 3.6 (a) SEM, (b) TEM and (c) AFM analysis of $\mathrm{TiO}_{2}$ thin film.

In addition to the microscopic investigation, the internal crystal structure of $\mathrm{TiO}_{2}$ thin film was analyzed by X-ray diffractometer ( $\mathrm{Cu} \mathrm{K \alpha}(\lambda=1.5056 \AA), 30 \mathrm{kV}$ and $20 \mathrm{~mA})$. As a result of the XRD analysis, the type of crystal structure and average size of the $\mathrm{TiO}_{2}$ were investigated. The X-Ray diffraction pattern for the sample was obtained with a scan rate of $0.02 \%$ over the range of $20^{\circ}-60^{\circ}$ (Figure 3.7). The anatase structure of $\mathrm{TiO}_{2}$ was identified according to the major diffraction peaks at $2 \theta=25.43,36.28$, and $47.86^{\circ}$ and the average crystal size of the $\mathrm{TiO}_{2}(\mathrm{~S} .1 .7)$ was calculated to be $4.21 \mathrm{~nm}$.

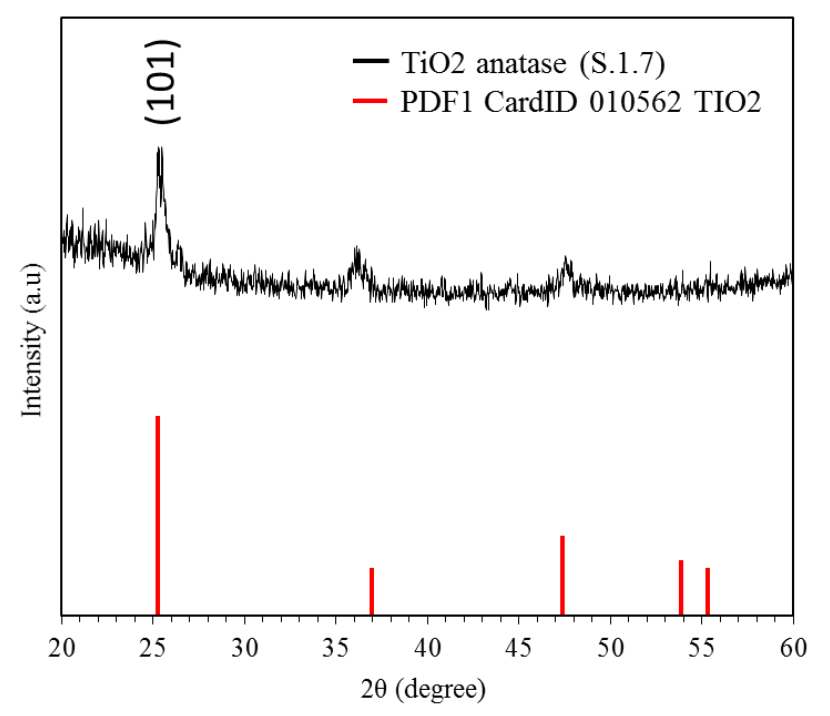

Figure 3.7 XRD analysis of $\mathrm{TiO}_{2}$ thin film. 


\subsubsection{Pt@ $\mathrm{SnO}_{2}, \mathrm{Au} @ \mathrm{SnO}_{2}, \mathrm{Pd} @ \mathrm{SnO}_{2}$, and $\mathrm{Au} / \mathrm{Pd} @ \mathrm{SnO}_{2}$}

Morphologies of the samples S.2.0-S.2.3 were investigated by using SEM and TEM analysis (Figure 3.8). SEM analysis of the sensors S.2.0 and S.2.3 indicated formation of spherical metal nanoclusters of $3-10 \mathrm{~nm}$ in diameter on the surface of $\mathrm{SnO}_{2}$ layer during the calcination process (Figure 3.8a, d and j). Also, the magnified surface images of the sensors S.2.0, S.2.1 and S.2.3 revealed an even distribution of metal nanoclusters across the sensing element and no agglomeration of metal nanoclusters was identified. In the case of a $\mathrm{SnO}_{2}$ surface functionalized with $\mathrm{Pd}$ (S.2.2), no visible metal nanoparticles were observed by SEM analysis (Figure 3.8g). The overall SEM pictures of the samples S.2.0S.2.3 exhibit a uniform distribution of the sensing material across the sensing area. A more precise analysis of the surface morphology of the samples S.2.0-S.2.3 was then accomplished by utilizing transmission electron microscopy (TEM) (Figure 3.8b, e, h and k). The higher resolution ability of the TEM analysis made it possible to describe the shape, average size, particle agglomeration, as well as the density and size distribution of metal nanoclusters. Equal distributions of $\mathrm{Pt}, \mathrm{Au}$ and $\mathrm{Au} / \mathrm{Pd}$ spherical shape nanoparticles across the $\mathrm{SnO}_{2}$ surface was determined to be in a good agreement with SEM analysis for the samples S.2.0, S.2.1 and S.2.3 respectively and no particle agglomeration into bigger clusters was observed. Very small Pd nanoclusters of 2-4 nm in diameter were seen while analyzing the sample S.2.2 by TEM. According to TEM image (Figure 3.8h), Pd nanoparticles have a tendency to agglomerate into bigger clusters, which makes it difficult to conduct a uniform surface modification of $\mathrm{SnO}_{2}$ layer. Further analysis of the TEM images of the samples S.2.0-S.2.3 by utilizing LabVIEW vision module was used to 
determine the particle size distribution (Figure 3.8c, f, i and 1) and the density of the nanoparticles per unit area (Table 3).

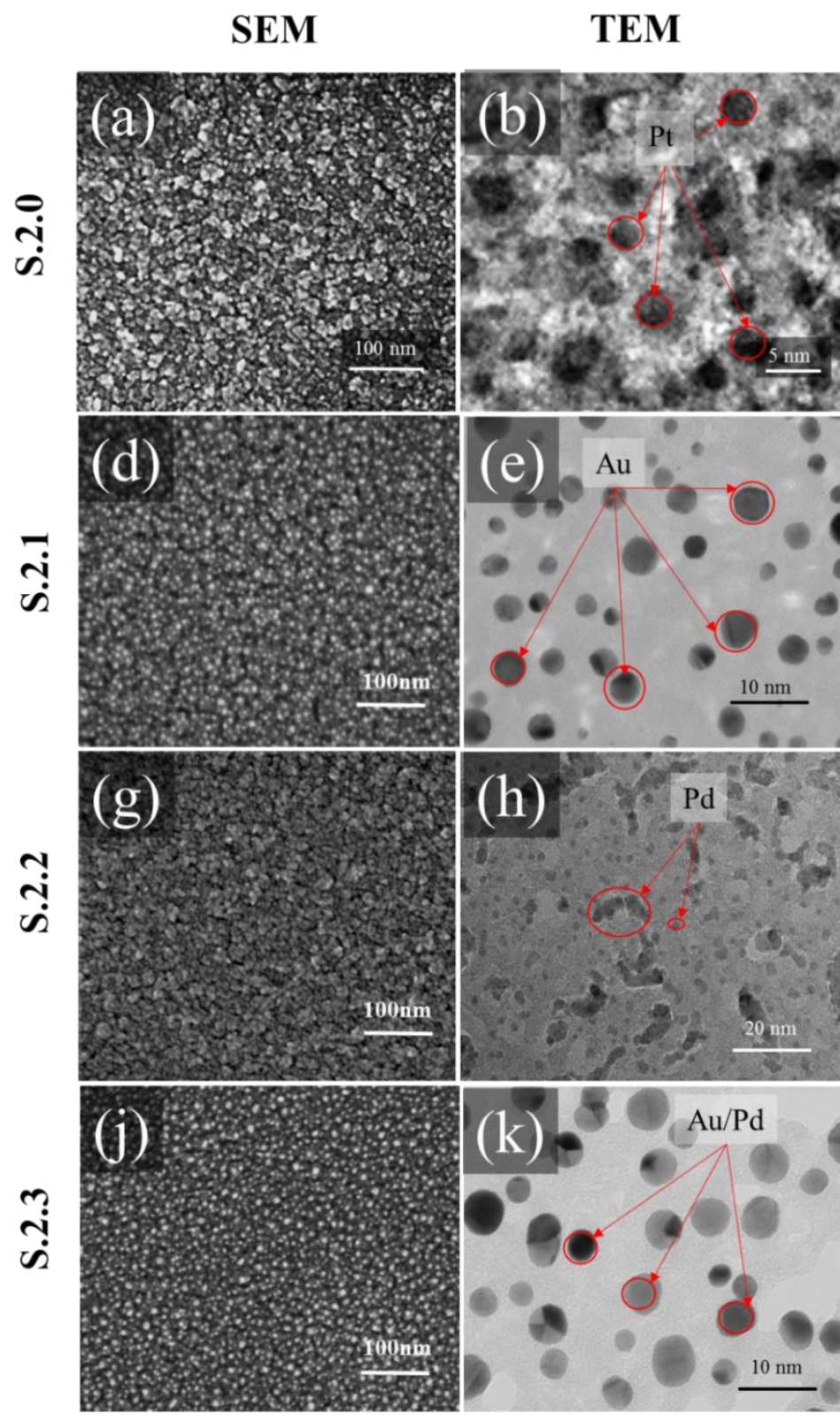

\section{Particle size distribution}
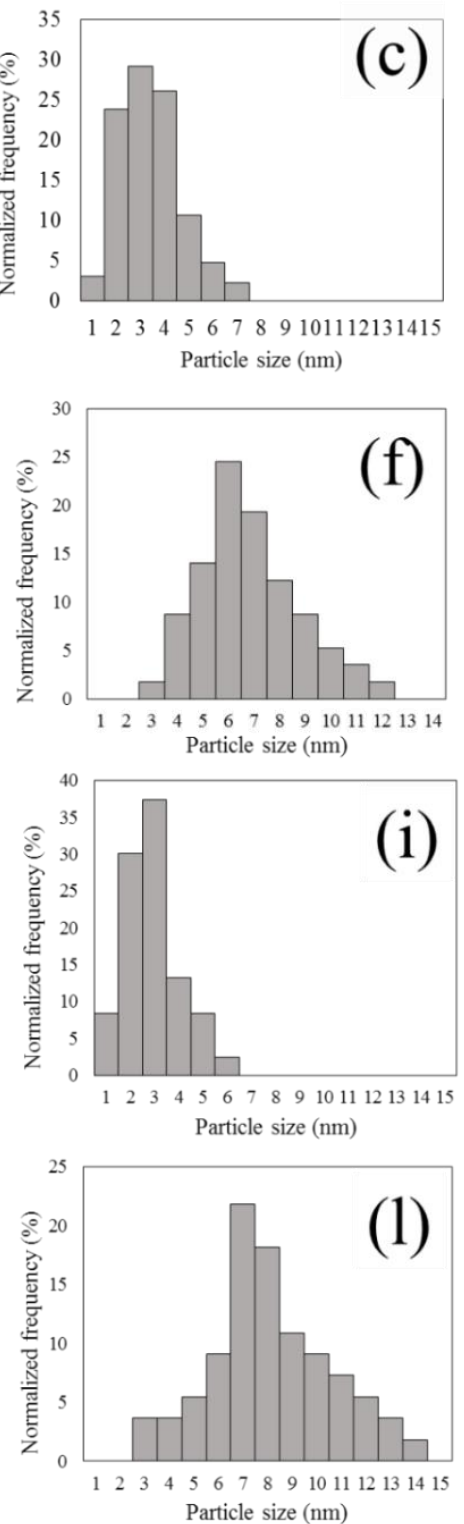

Figure 3.8 (a, d, g and j) SEM surface images of the samples S.2.0 - S.2.3, (b, e, h and k) TEM images of the simplified samples S.2.0 - S.2.3, and (c, $\mathrm{f}, \mathrm{i}$ and $\mathrm{l}$ ) nanoparticle size distribution calculated from the TEM analysis. 
Table 3.2 Some important characteristics of the metal nanoparticles.

\begin{tabular}{ccccc}
\hline Sensor's & \multicolumn{2}{c}{ Nanoparticle size distribution } & $\begin{array}{c}\text { Density of } \\
\text { Nanoparticles } \\
\left(10^{10} / \mathrm{cm}^{2}\right)\end{array}$ & Agglomeration of \\
\cline { 2 - 3 }$\#$ & Mean $(\mathrm{nm})$ & FWHM $(\mathrm{nm})$ & 113 & Nanoparticles \\
\hline $\mathrm{Pt} @ \mathrm{SnO}_{2}(\mathrm{~S} .2 .0)$ & 3.15 & 3.12 & 31 & No \\
$\mathrm{Au} @ \mathrm{SnO}_{2}$ (S.2.1) & 6.42 & 4.63 & 141 & Yes \\
$\mathrm{Pd@SnO}$ (S.2.2) & 2.68 & 2.72 & 25 & No \\
$\mathrm{Au} / \mathrm{Pd} @ \mathrm{SnO}_{2}$ & 7.63 & 4.21 & & \\
$(\mathrm{~S} .2 .3)$ & & & & \\
\hline
\end{tabular}

\subsection{Electrical characteristics}

\subsubsection{Optical band gap of $\mathrm{SnO}_{2}$ and $\mathrm{TiO}_{2}$}

The UV-Visible spectrometry was used in this work to determine the optical band gap of $\mathrm{SnO}_{2}$ and $\mathrm{TiO}_{2}$. Simplified samples were prepared by depositing a thin layer of $\mathrm{SnO}_{2}$ $(30 \mathrm{~nm})$ and $\mathrm{TiO}_{2}(30 \mathrm{~nm})$ on the surface of 1 x 1-inch glass slides. Several spectrums including dark spectrum, spectrum of the glass slide with no coating, spectrum of the glass slide with $\mathrm{SnO}_{2}$, and the spectrum of the glass slide with $\mathrm{TiO}_{2}$ were then collected (Figure 3.9a). After the dark spectrum was subtracted the absorption coefficient ( $\alpha$ ) was calculated for both $\mathrm{SnO}_{2}$ and $\mathrm{TiO}_{2}$ by using the intensity of the incident light $\left(I_{0}\right)$ from the glass slide with no coating. The optical band gap of $\mathrm{SnO}_{2}$ and $\mathrm{TiO}_{2}$ for direct allowed transitions was then calculated (Table 3.3) from a Tauc plot (Figure 3.9b) by using extrapolation method [168]:

$$
(\alpha h v)=A\left(h v-E_{g}\right)^{1 / 2}
$$

where A is a proportionality constant, $\mathrm{h}$ is Planck's constant, $v$ is photon's frequency, and $E_{g}$ is a band gap for direct allowed transitions. 

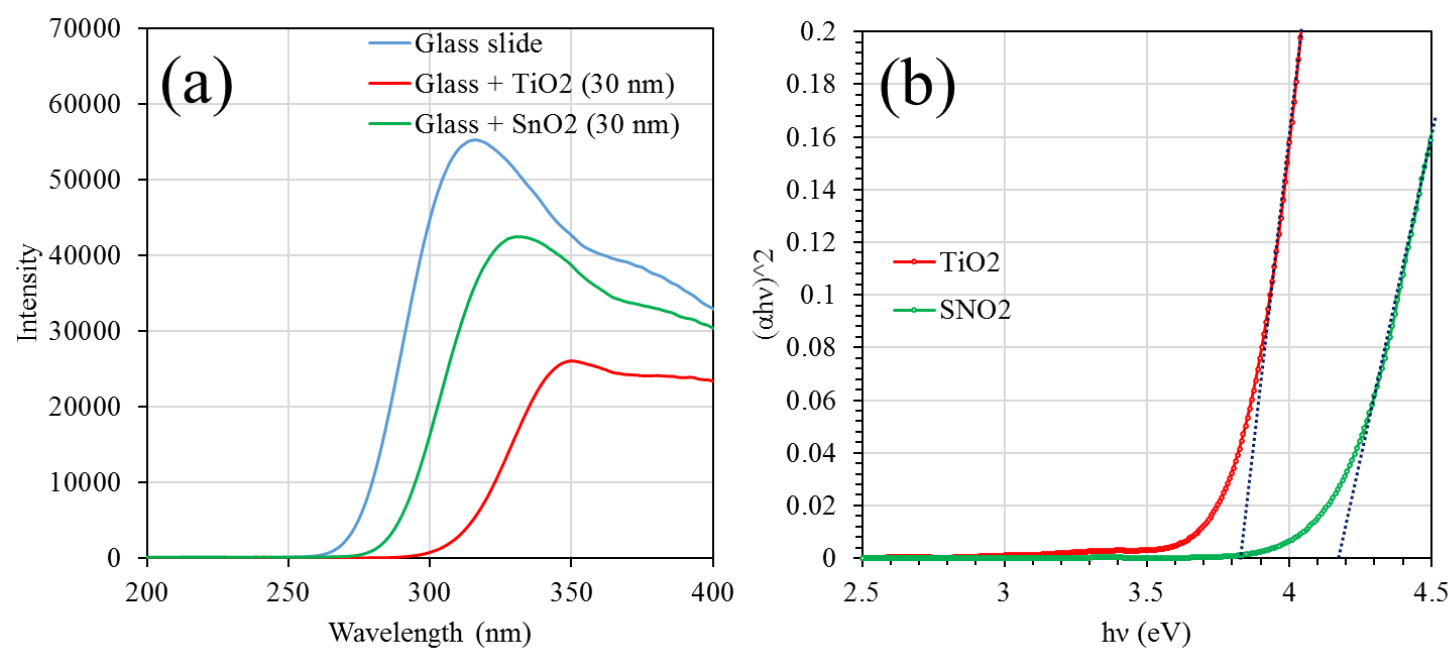

Figure 3.9 (a) UV-Vis spectroscopy of $\mathrm{SnO}_{2}, \mathrm{TiO}_{2}$ thin films and intensity of incoming light (blue) with no coating, (b) the calculated Tauc plot for the thin films with direct allowed transitions.

A schematic diagram of direct allowed transition between two direct valleys with energy conservation is presented in Figure 3.10a. When transition requires a change in both energy and momentum a two - step process is required. The conservation of momentum via an additional phonon interaction is illustrated in Figure 3.10b [169].
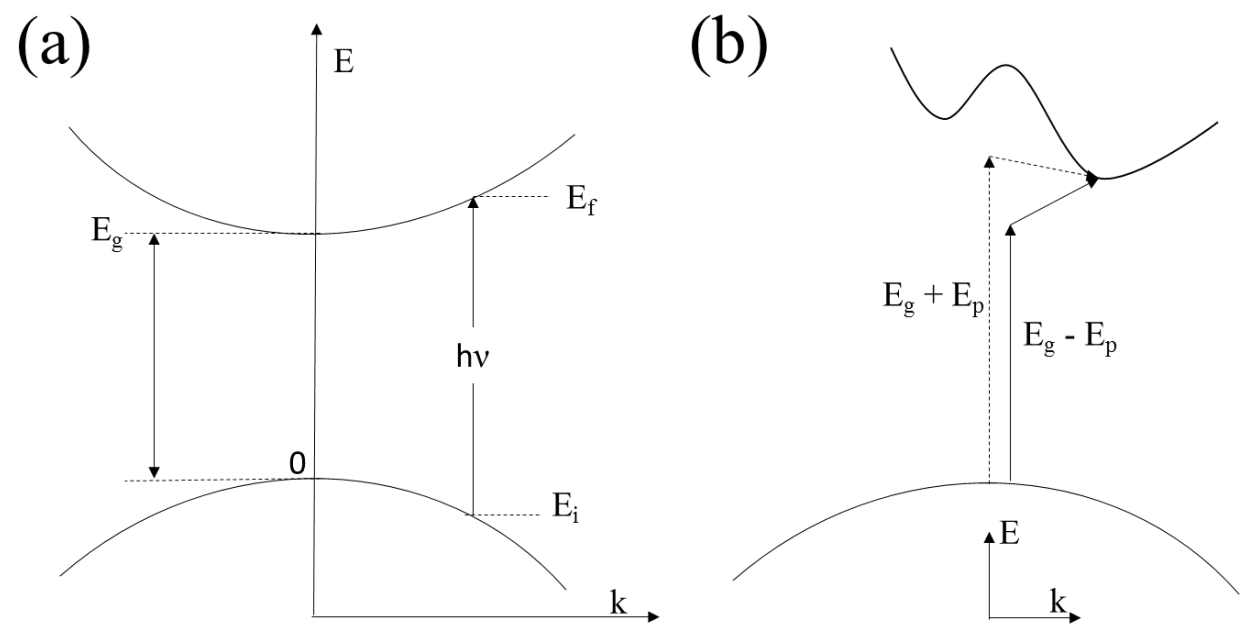

Figure 3.10 A schematic representation of the process for (a) direct and (b) indirect allowed transitions inside semiconductors by using energy-momentum diagram, where $E_{p}$ is the energy of a phonon and $E_{g}$ is the band gap energy.

The absorption coefficient for the indirect allowed transition with a phonon absorption is

$$
\alpha_{a}(h v)=\frac{A\left(h v-E_{g}+E_{p}\right)^{2}}{\exp \left(\frac{E_{p}}{k T}\right)-1}
$$


for $h v>E_{g}-E_{p}$ and the absorption coefficient for indirect transition with phonon emission is

$$
\alpha_{e}(h v)=\frac{A\left(h v-E_{g}-E_{p}\right)^{2}}{1-\exp \left(-\frac{E_{p}}{k T}\right)}
$$

for $h v>E_{g}+E_{p}$. The absorption coefficient for $h v>E_{g}+E_{p}$ can be calculated according to equation 3.5 .

$$
\alpha(h v)=\alpha_{a}(h v)+\alpha_{e}(h v)
$$

According to the equations (3.3-3.4) there is a temperature dependence for indirect allowed transitions. At low temperature $\sim 0 \mathrm{~K}, \alpha_{a}(h v)$ is small. However, at elevated temperature the probability of indirect allowed transition with phonon absorption is increasing. Both values of $\mathrm{E}_{\mathrm{g}}+\mathrm{E}_{\mathrm{p}}$ and $\mathrm{E}_{\mathrm{g}}-\mathrm{E}_{\mathrm{p}}$ for $\mathrm{SnO}_{2}$ and $\mathrm{TiO}_{2}$ under room temperature $\sim 300 \mathrm{~K}$ can be experimentally approximated by linear extrapolation method by plotting $(\alpha h v)^{1 / 2}$ vs (hv) (Figure 3.11a and b) [169].
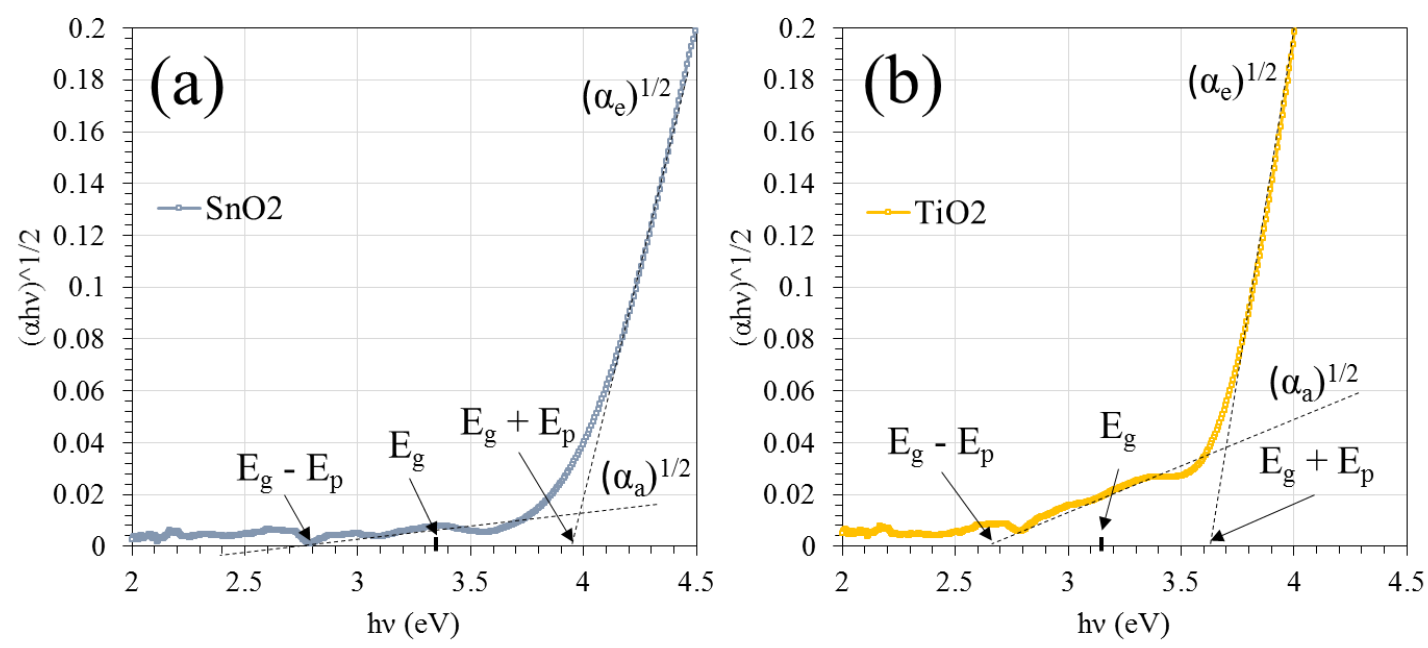

Figure 3.11 Tauc plots of (a) $\mathrm{SnO}_{2}$ and (b) $\mathrm{TiO}_{2}$ thin films for indirect allowed transitions 
The approximated values for direct and indirect allowed transitions of polycrystalline films of $\mathrm{SnO}_{2}$ and $\mathrm{TiO}_{2}$ can be found in Table 3.3.

Table 3.3 Optical band gap characteristics of $\mathrm{SnO}_{2}$ and $\mathrm{TiO}_{2}$.

\begin{tabular}{ccc}
\hline $\begin{array}{c}\text { Sample } \\
\#\end{array}$ & $\begin{array}{c}\text { Direct allowed transition } \\
(\mathrm{eV})\end{array}$ & $\begin{array}{c}\text { Indirect allowed transition } \\
(\mathrm{eV})\end{array}$ \\
\hline $\mathrm{SnO}_{2}$ & $4.17+/-0.2$ & $3.35+/-0.2$ \\
$\mathrm{TiO}_{2}$ & $3.84+/-0.2$ & $3.15+/-0.2$ \\
\hline
\end{tabular}

\subsubsection{Polarization effect}

Highly nonlinear current-voltage characteristics of $\mathrm{SnO}_{2}$ varistors (voltagedependent resistors) were previously reported by other groups [170-172]. They also indicated that the free carrier activation energy inside the $\mathrm{SnO}_{2}$ crystals is weak when electric field is small and strong increase in conductivity was noticed in a case of high electric field. In our work, the V-I characteristic of polycrystalline $\mathrm{SnO}_{2}$ film $(30 \mathrm{~nm})$ was investigated (Figure 3.12a) and the resistance of the film was calculated under different polarization voltages (Figure 3.12b). It was determined that the resistance of the thin film of $\mathrm{SnO}_{2}$ depends not only on ambient test conditions, but also on applied bias voltage across the interdigitated platinum contacts. 

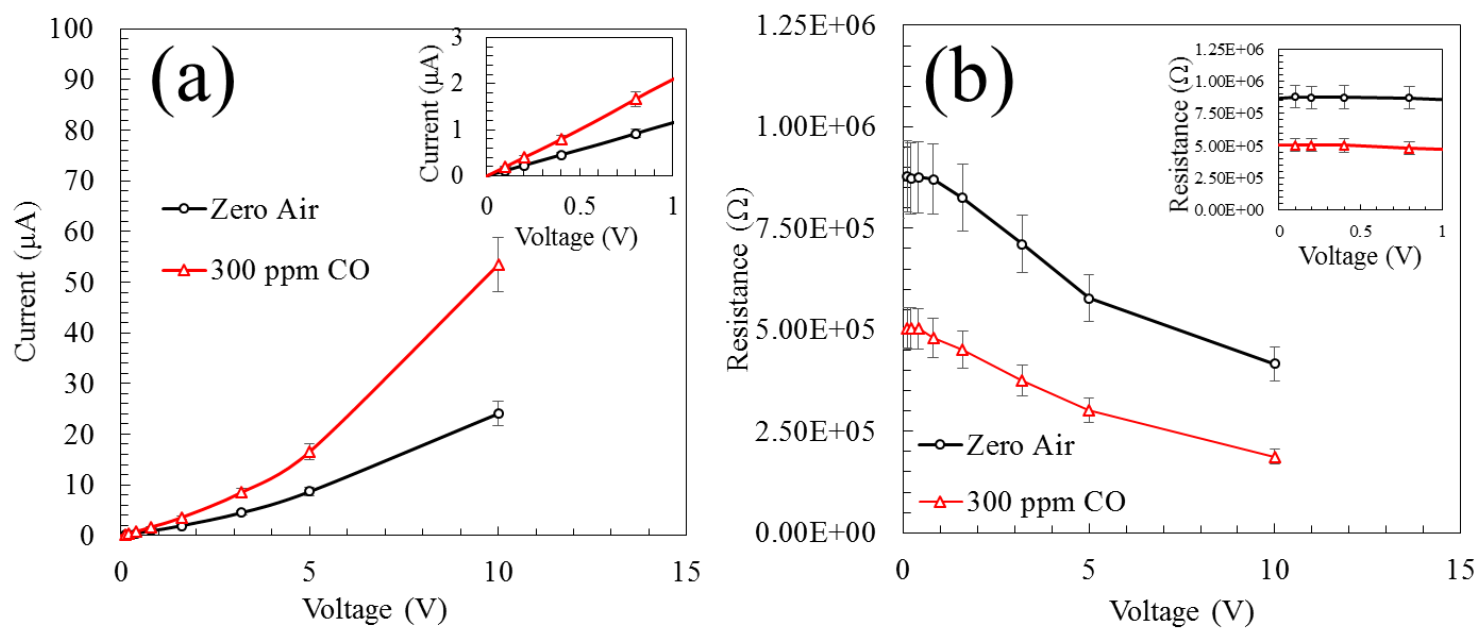

Figure 3.12 (a) V-I characteristics of thin $\mathrm{SnO}_{2}$ film at $300{ }^{\circ} \mathrm{C}$ and (b) resistance of the sensor as a function of polarization voltage across the platinum contacts under zero grade air and $300 \mathrm{ppm}$ of $\mathrm{CO}$.

In order to minimize the polarization effect on the sensor's resistance measurement one can identify an appropriate voltage range between 0 and $1 \mathrm{~V}$, where effect of polarization become negligible. It is important to note that the appropriate polarization voltage range for resistance measurements was determined for specific device with known geometry of metallic electrodes and the distance between them.

\subsubsection{Effect of electrical contact}

The contribution of electrical resistance between metal $(\mathrm{Pt})$ electrodes and $\mathrm{SnO}_{2}$ sensing layer was investigated by using transmission line measurement (TLM) technique. The overall resistance of $\mathrm{SnO}_{2}$ sensing layer was obtained for several electrode geometries under ambient air and $300 \mathrm{ppm}$ of $\mathrm{CO}$. The dependence of the sensor resistance was plotted as a function of the distance $(10-80 \mu \mathrm{m})$ between electronic contacts (Figure 3.13). 

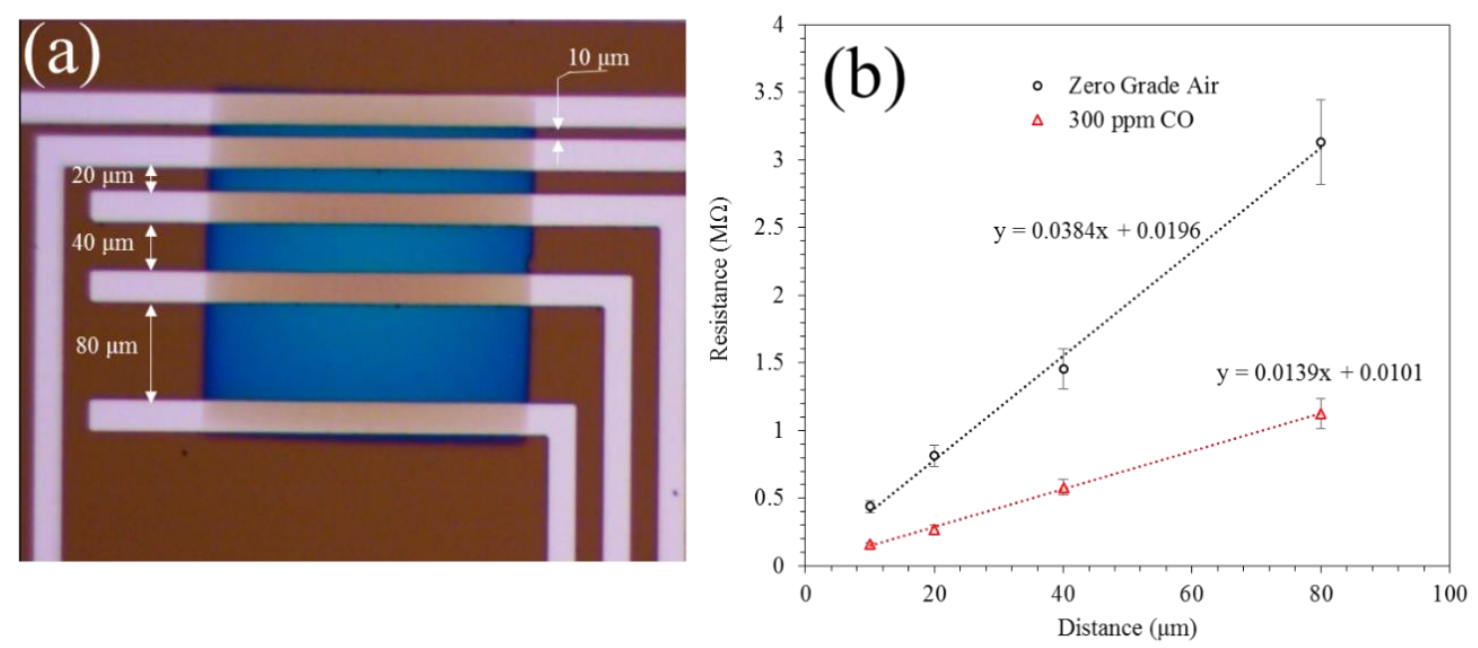

Figure 3.13 (a) An image of fabricated device for TLM experiment and (b) $\mathrm{SnO}_{2}$ film resistance at $300{ }^{\circ} \mathrm{C}$ as a function of the distance between electronic contacts under zero grade air and $300 \mathrm{ppm}$ of CO.

According to the TLM analysis, the contribution of metal (Pt) -semiconductor $\left(\mathrm{SnO}_{2}\right)$ contact $\left(\mathrm{R}_{\mathrm{c}}\right)$ was calculated to be less than $10 \mathrm{k} \Omega$. The obtained result can be justified based on polycrystalline and porous structure of $\mathrm{SnO}_{2}$ layer, where the major part of the resistance under elevated temperature and ambient air, coming from the large number of $\mathrm{SnO}_{2}$ grain-grain boundaries. In a case of $\mathrm{SnO}_{2}$ based nanocomposite materials $\left(\mathrm{SnO}_{2}-\mathrm{TiO}_{2}, \mathrm{Au} @ \mathrm{SnO}_{2}, \mathrm{Pd} @ \mathrm{SnO}_{2}, \mathrm{Pt} @ \mathrm{SnO}_{2}\right)$, the internal resistance of the sensing layer was observed to be even higher due to additional n-n heterojunctions between different oxides $\left(\mathrm{SnO}_{2}\right.$ and $\left.\mathrm{TiO}_{2}\right)$ or nano size Schotky contacts between noble metal nanoparticles and thin film of $\mathrm{SnO}_{2}$.

\subsection{Gas sensing characteristics}

After all the sensors were fabricated, characterization of sensing material was done, and electrical characteristics of the sensors were obtained under zero grade air, a series of experiments were conducted for further investigation of gas sensing characteristics of the sensors. 


\subsection{1 $\mathrm{H}_{2} \mathrm{~S}$ detection with $\mathrm{SnO}_{2}, \mathrm{TiO}_{2}$ and $\mathrm{SnO}_{2}-\mathrm{TiO}_{2}$ gas sensors}

The performance of sensors (S.1.0-S.1.7) were first investigated over a wide temperature range between 100 and $350^{\circ} \mathrm{C}$ upon exposures to $10 \mathrm{ppm}$ of $\mathrm{H}_{2} \mathrm{~S}$ in zero grade air (Figure 3.14a-c). The optimized temperature conditions for detection of $\mathrm{H}_{2} \mathrm{~S}$ were determined for each sensing layer (Table 3.4). The thin film of $\mathrm{TiO}_{2}$ (S.1.7) did not show any noticeable response to $10 \mathrm{ppm}$ of $\mathrm{H}_{2} \mathrm{~S}$ over the temperature range between 100 and 350 ${ }^{\circ} \mathrm{C}$. Also, the extremely large resistance of $\mathrm{TiO}_{2}$ thin film (> $100 \mathrm{M} \Omega$ ) makes it complicated to measure the resistance of the sensing layer. In our analysis, we compare the ratio of the sensor's resistance in the presence of detectable gasses to the resistance of the sensor under clean ambient air at a given sensor temperature; a ratio hereafter referred to as the "resistance ratio" or more compactly, $\mathrm{R}_{\text {air }} / \mathrm{R}$ gas . The bilayer $\mathrm{SnO}_{2} / \mathrm{TiO}_{2}$ structure (S.1.2) at $200{ }^{\circ} \mathrm{C}$ exhibited higher resistance change under exposure to $10 \mathrm{ppm}$ of $\mathrm{H}_{2} \mathrm{~S}$ compared to pure $\mathrm{SnO}_{2}$ (S.1.0) sensor at $225^{\circ} \mathrm{C}$. The highest change in resistance ratio ( $\mathrm{R}$ air $/ \mathrm{R}$ gas $\left.=1.06 \times 10^{4}\right)$ was obtained for multilayer $\mathrm{SnO}_{2} / \mathrm{TiO}_{2}(\mathrm{~S} .1 .5)$ at $150{ }^{\circ} \mathrm{C}$. Thus a multilayer material has superior sensitivity toward $\mathrm{H}_{2} \mathrm{~S}$ gas and lower activation temperatures.
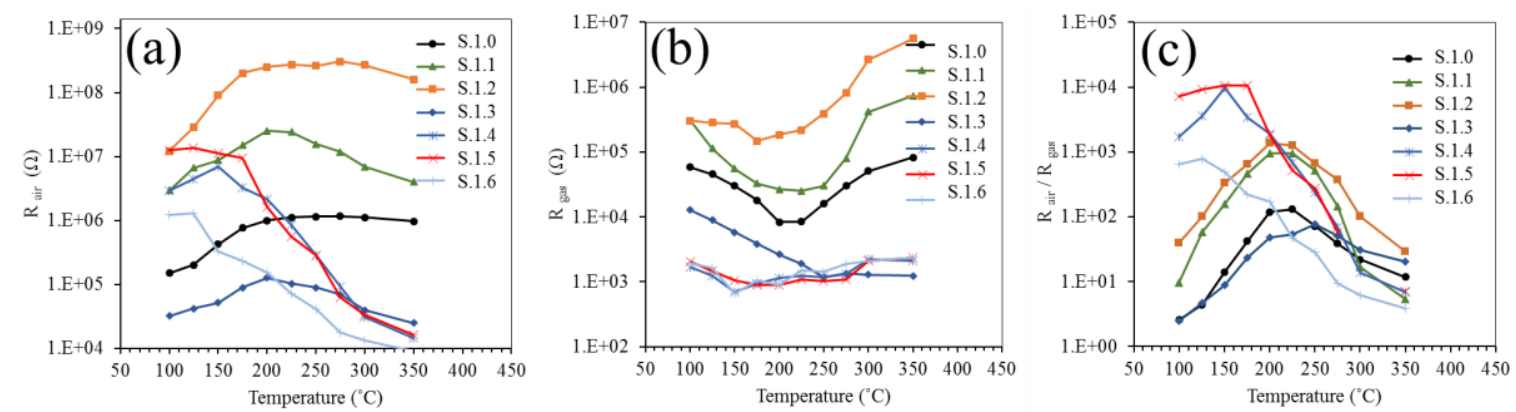

Figure 3.14 (a) Sensors resistance (zero grade air) under different temperature conditions 100-350 ${ }^{\circ} \mathrm{C}$, (b) resistance of the sensors in the present of $10 \mathrm{ppm}$ of $\mathrm{H}_{2} \mathrm{~S}$ as a function of temperature and (c) various response of the sensors toward $10 \mathrm{ppm}$ of $\mathrm{H}_{2} \mathrm{~S}$ over the temperature range.

The content of $\mathrm{TiO}_{2}$ in the hybrid structure was determined to be very important parameter that affects the performance of the sensor for detection of $\mathrm{H}_{2} \mathrm{~S}$. Both types of 
hybrid oxide structures (bilayer and multilayer) exhibited a decline in sensitivity when the $\mathrm{TiO}_{2}$ content in the layer was high. Even at temperatures as high as $300^{\circ} \mathrm{C}$, a thick $(20 \mathrm{~nm})$ compact layer of $\mathrm{TiO}_{2}$ deposited over $\mathrm{SnO}_{2}$ (S.1.3) affected the layer porosity and caused the decrease in sensor's response. The bilayer structure of $\mathrm{SnO}_{2}$ with a $20 \mathrm{~nm}$ thickness of $\mathrm{TiO}_{2}$ measured very low resistance over the temperature range $100-350{ }^{\circ} \mathrm{C}$, compared to the other bilayer samples with thinner $\mathrm{TiO}_{2}$ coating. Increasing the content of $\mathrm{TiO}_{2}$ within the multilayer structure (S.1.6) from 10 to $20 \mathrm{vol} \%$ also decreased the sensitivity of the sensor. The sensor S.1.6 with $20 \mathrm{vol} \%$ of $\mathrm{TiO}_{2}$ exhibited low resistance over the temperature range between 100 and $350{ }^{\circ} \mathrm{C}$ and lower sensitivity compare to the other nanocomposite oxides with lower $\mathrm{TiO}_{2}$ concentration. Table 3.4 summarizes these results.

Table 3.4 Optimal operational temperature of the sensors S.1.0-S.1.6

\begin{tabular}{ccccc}
\hline Sample \# & $\mathrm{R}_{\text {air }}(\Omega)$ & $\mathrm{R}_{\text {gas }}(\Omega)$ & $\mathrm{R}_{\text {air }} / \mathrm{R}_{\text {gas }}$ & Temperature $\left({ }^{\circ} \mathrm{C}\right)$ \\
\hline S.1.0 & $1.10 \times 10^{6}$ & $8.43 \times 10^{3}$ & $1.31 \times 10^{2}$ & 225 \\
S.1.1 & $2.53 \times 10^{7}$ & $2.64 \times 10^{4}$ & $9.55 \times 10^{2}$ & 200 \\
S.1.2 & $2.50 \times 10^{8}$ & $1.85 \times 10^{5}$ & $1.88 \times 10^{3}$ & 200 \\
S.1.3 & $8.93 \times 10^{4}$ & $1.17 \times 10^{3}$ & $7.60 \times 10^{1}$ & 250 \\
S.1.4 & $6.90 \times 10^{6}$ & $6.99 \times 10^{2}$ & $9.87 \times 10^{3}$ & 150 \\
S.1.5 & $9.39 \times 10^{6}$ & $8.82 \times 10^{2}$ & $1.06 \times 10^{4}$ & 150 \\
S.1.6 & $3.21 \times 10^{5}$ & $6.65 \times 10^{2}$ & $4.83 \times 10^{2}$ & 150 \\
\hline
\end{tabular}

Sensors S.1.2 (bilayer) and S.1.5 (multilayer) were measured to have the highest sensitivity to $\mathrm{H}_{2} \mathrm{~S}$ in their groups due to the optimized content of $\mathrm{TiO}_{2}$. The bilayer sensor (S.1.2) exhibited the highest resistance for this concentration of gas among all the sensors (S.1.0-S.1.6), which is an indication of the maximum depletion of carriers in the catalytic layer. The superior response of the multilayer oxide sensors (S.1.4 and S.1.5) compared to the rest of the sensors, is attributed to the optimal content of $\mathrm{TiO}_{2}$ uniformly distributed through the volume of the catalytic layers affecting the morphological, electrical and 
catalytic properties of the sensor. The multilayer structures have smaller average crystal size after the annealing, higher porosity for 5 and $10 \%$ volume of $\mathrm{TiO}_{2}$ and the highest surface roughness.

Also, the response and recovery time upon exposure to $10 \mathrm{ppm}$ of $\mathrm{H}_{2} \mathrm{~S}$ were determined under optimal temperature conditions for each sensor (Table 3.5). Sensors S.1.2 and S.1.5 were measured to have the shortest time for the sensors' resistance to reach $90 \%$ of its steady state value under exposure to $\mathrm{H}_{2} \mathrm{~S}$. It is important to note that time related experiments were conducted by using ultra-small detector's volume less than $1 \mathrm{~cm}^{3}$ to produce almost instant change in concentration.

Table 3.5 Response and recovery time of the sensors S.1.0-S.1.6.

\begin{tabular}{ccccc}
\hline $\begin{array}{c}\text { Sample } \\
\text { number }\end{array}$ & $\begin{array}{c}\text { Response time } \\
\mathrm{T}_{90}(\mathrm{sec})\end{array}$ & $\begin{array}{c}\text { Recovery time } \\
\mathrm{T}_{90}(\mathrm{sec})\end{array}$ & $\begin{array}{c}\text { Concentration of } \\
\mathrm{H}_{2} \mathrm{~S}(\mathrm{ppm})\end{array}$ & $\begin{array}{c}\text { Temperature } \\
\left({ }^{\circ} \mathrm{C}\right)\end{array}$ \\
\hline S.1.0 & 3.7 & 5.6 & 10 & 225 \\
S.1.1 & 3.5 & 2.8 & 10 & 200 \\
S.1.2 & 3.3 & 2.5 & 10 & 200 \\
S.1.3 & 3.7 & 2.9 & 10 & 250 \\
S.1.4 & 3.0 & 2.4 & 10 & 150 \\
S.1.5 & 3.2 & 2.4 & 10 & 150 \\
S.1.6 & 3.9 & 2.7 & 10 & 150 \\
\hline
\end{tabular}

Furthermore, the calibration curves for the sensors S.1.0-S.1.6 were obtained (Figure 3.15a-c) upon exposure to different concentrations (2-20 ppm) of $\mathrm{H}_{2} \mathrm{~S}$. It was observed that all the sensors exhibited nonlinear behavior for the given gas concentration range. 

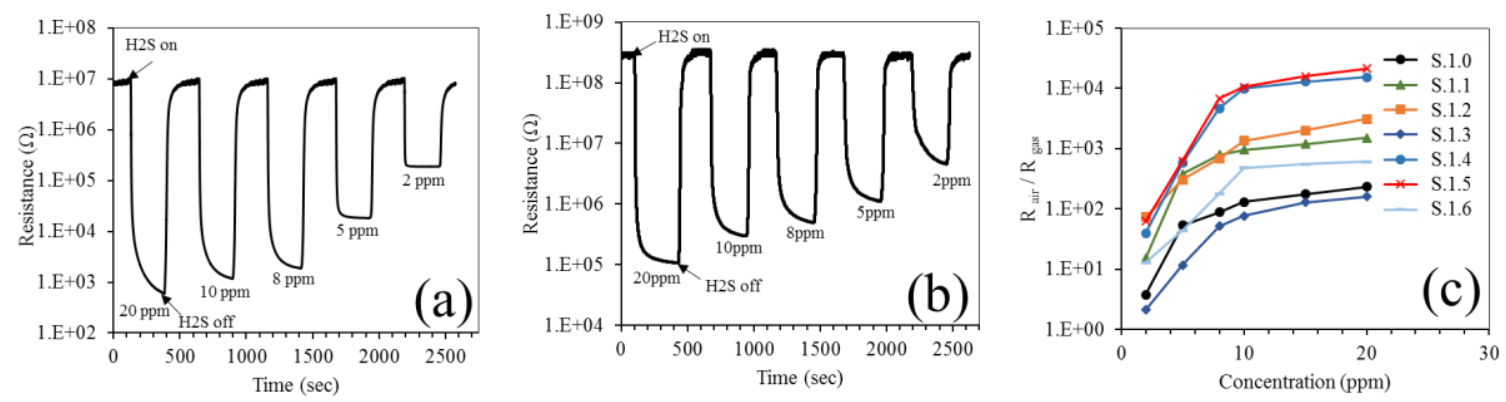

Figure 3.15 (a) A response of the sensor (a) (S.1.5) multilayer and (b) (S.1.2) bilayer structure to different concentrations of $\mathrm{H}_{2} \mathrm{~S}(2-20 \mathrm{ppm})$ and (c) sensor response vs. concentration for all the sensors.

Besides excellent sensitivity, quick response and recovery time, hybrid sensors also show superior selectivity to $\mathrm{H}_{2} \mathrm{~S}$. In our experiments, hybrid sensors were capable of detecting $\mathrm{H}_{2} \mathrm{~S}$ in complex gas mixtures, such as natural gas, which is not typical for MOX sensors. The illustration of cross-sensitivity studies on hybrid sensors is shown in the figure 3.16(a). The figure 3.16(a) shows the amplitude response of the sensors S.1.5 (multilayer structure) and S.1.2 (bilayer structure) to various gases at different concentrations. The figure 3.16(b) shows the response of sensor S.1.5 to sub-ppm concentrations of $\mathrm{H}_{2} \mathrm{~S}$ diluted in pure methane. We attribute this remarkable selectivity of hybrid layers to high catalytic activity of $\mathrm{SnO}_{2} / \mathrm{TiO}_{2}$ hybrid structures relative to $\mathrm{H}_{2} \mathrm{~S}$ at relatively low temperatures. Maximum sensor response for bilayer and multilayer structures was achieved at $200{ }^{\circ} \mathrm{C}$ and $150{ }^{\circ} \mathrm{C}$ respectively, which is substantially lower than the optimum activation temperature of pure $\mathrm{SnO}_{2}$ sensor $\left(300{ }^{\circ} \mathrm{C}\right)$. It is related to a lower activation temperature for oxidation of hybrid catalyst, compared to $\mathrm{SnO}_{2}$. Because of that, the energy of active sites on the surface is not enough to overcome the activation barrier of combustibles, ethanol and carbon dioxide, which provides a natural cut-off for all the catalytic reactions except for the $\mathrm{H}_{2} \mathrm{~S}$ oxidation. 

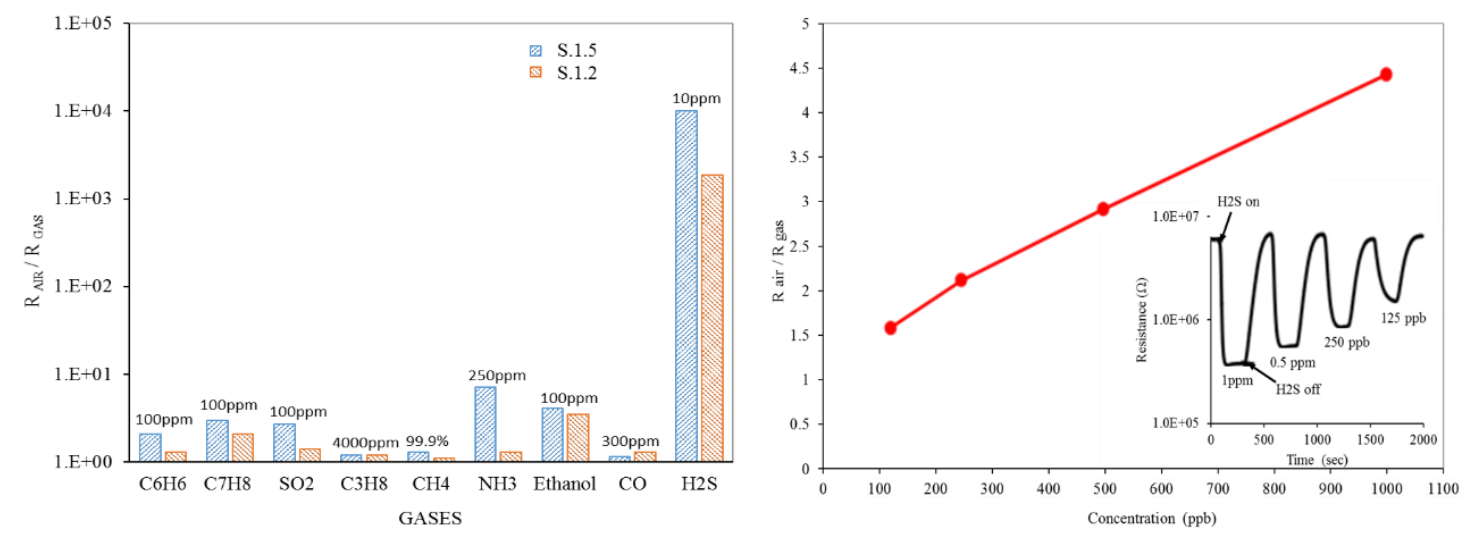

Figure 3.16 A response of the sensor (a) S.1.5 (multilayer structure) and S.1.2 (bilayer structure) to various gases and (b) response of sensor S.1.5 to sub-ppm concentrations of $\mathrm{H}_{2} \mathrm{~S}$ diluted in pure methane.

Finally, the overall gas sensing performance of $\mathrm{SnO}_{2}$ based sensor with $10 \%$ vol. of $\mathrm{TiO}_{2}$ (S.1.5) was evaluated with respect to previously reported $\mathrm{H}_{2} \mathrm{~S}$ sensors based on different materials, morphology and fabrication methods (Table 3.6).

Table 3.6 Some important reports on $\mathrm{SnO} 2$ and $\mathrm{SnO} 2$ doped MOX gas sensors for detection of $\mathrm{H}_{2} \mathrm{~S}$.

\begin{tabular}{|c|c|c|c|c|c|}
\hline $\begin{array}{l}\text { Material and } \\
\text { structure }\end{array}$ & $\begin{array}{l}\text { Deposition } \\
\text { technique }\end{array}$ & $\begin{array}{l}\text { Concentration } \\
(\mathrm{ppm})\end{array}$ & $\begin{array}{l}\text { Sensitivity } \\
\left(\mathrm{R}_{\text {air }} / \mathrm{R}_{\text {gas }}\right)\end{array}$ & $\begin{array}{c}\text { Temperature } \\
\left({ }^{\circ} \mathrm{C}\right)\end{array}$ & References \\
\hline $\begin{array}{c}\mathrm{SnO}_{2} \\
\text { (porous thick film) }\end{array}$ & Sol gel method & 13.7 & 58.057 & 60 & [173] \\
\hline $\begin{array}{c}\mathrm{Sb}_{-} \mathrm{SnO}_{2} \\
\text { (nanoribbons) }\end{array}$ & $\begin{array}{c}\text { Thermal } \\
\text { evaporation }\end{array}$ & 0.1 & 10 & 150 & [174] \\
\hline $\begin{array}{c}\mathrm{Ag}-\mathrm{SnO}_{2} \\
\text { (nanocolumns) }\end{array}$ & $\begin{array}{l}\text { Glacncing } \\
\text { Angle } \\
\text { Deposition } \\
\text { Glacncing }\end{array}$ & 5 & 66 & 300 & [175] \\
\hline $\begin{array}{c}\mathrm{Au}-\mathrm{SnO}_{2} \\
\text { (nanocolumns) }\end{array}$ & $\begin{array}{c}\text { Angle } \\
\text { Deposition }\end{array}$ & 5 & 111 & 300 & [175] \\
\hline $\begin{array}{c}\mathrm{Ag}_{2} \mathrm{O}-\mathrm{SnO}_{2} \\
\text { (mesoporous) }\end{array}$ & Nanocasting & 0.3 & 5,7 & 100 & [176] \\
\hline $\begin{array}{c}\mathrm{Fe}-\mathrm{SnO}_{2} \\
\text { (nanoparticles) }\end{array}$ & Pechini method & 200 & 100 & 25 & [177] \\
\hline $\begin{array}{l}\mathrm{In}_{2} \mathrm{O}_{3}-\mathrm{SnO}_{2} \\
\text { (thick film) }\end{array}$ & Screen printing & 100 & 1481 & 25 & [178] \\
\hline $\begin{array}{l}\mathrm{SnO}_{2}-\mathrm{ZnO} 2 \mathrm{D} \\
\quad \text { (thin film) }\end{array}$ & Sputtering & 0.01 & 5 & 100 & [179] \\
\hline $\begin{array}{r}\mathrm{CuO}-\mathrm{SnO}_{2} \\
\text { (thin film) }\end{array}$ & $\begin{array}{c}\text { Magnetron } \\
\text { sputtering }\end{array}$ & 100 & $1.6 \times 10^{4}$ & 170 & [180] \\
\hline $\begin{array}{r}\mathrm{CuO}-\mathrm{SnO}_{2} \\
\text { (thick film) }\end{array}$ & Screen printing & 1 & $8 \times 10^{3}$ & 50 & [181] \\
\hline $\begin{array}{c}\mathrm{CuO}-\mathrm{SnO}_{2} \\
\text { (thin film bi-layer) }\end{array}$ & $\begin{array}{l}\text { Reactive } \\
\text { sputtering }\end{array}$ & 20 & $7.4 \times 10^{3}$ & 150 & [182] \\
\hline
\end{tabular}




\begin{tabular}{cccccc} 
SnO2-TiO2 & $\begin{array}{c}\text { Multi-source } \\
\text { magnetron } \\
\text { sputtering }\end{array}$ & 10 & $1.06 \times 10^{4}$ & 150 & This work \\
\hline
\end{tabular}

\subsubsection{Detection of BTEX compounds with $\mathrm{Au}, \mathrm{Pd}$ and $\mathrm{Au} / \mathrm{Pd}$-doped $\mathrm{SnO}_{2}$ gas sensors}

A comparative analysis of the sensors (S.1.0 and S.2.1-S.2.3) was accomplished by utilizing a multi-channel gas mixing system for sensor exposure to different concentrations of benzene (12.5-500 ppb) and toluene (12.5-500 ppb). Important sensors' characteristics were measured: the optimal operational temperature, the sensors response (as expressed as $\mathrm{R}_{\text {air }} / \mathrm{R}_{\text {gas }}$ ), the time of response, as well as the LOD upon steady state exposure to low concentrations of benzene and toluene. The operation of sensors in different humidity levels was also studied along with the effect of oxygen ion sorption.

The effect of temperature on the conductance of ultra-thin MOX films is significantly different relative to bulk MOX due to high surface to volume ratio. Heating bulk MOX excites free carriers, which produces a drop in resistance. However, for ultrathin films, there are two competing processes: thermal generation of free carriers (decreasing the resistance) and trapping of free electrons by ionized oxygen at the surface (increasing the resistance). The heating profile for all four sensor S.1.0 and S.2.1 - S.2.3 (Figure $3.17 \mathrm{a}$ ) shows that for specific temperature range between $150-300{ }^{\circ} \mathrm{C}$ the layer depletion by the adsorbed oxygen dominates, which is sufficient for high sensitivity. At the same time, for a comparative analysis of sensors' ability to ionize the atmospheric oxygen, this profile is insufficient. In Figure 3.17, three out of four layers are functionalized with metal nanoparticles. Such a functionalization affects both competing temperaturerelated effects: the carrier density in the oxide layer and the ion sorption of oxygen on its 
surface. In order to evaluate the catalytic activity of the layers and their ability to activate the atmospheric oxygen, these competing effects need to be decoupled. In order to accomplish that, the experiment was repeated in the inert nitrogen atmosphere, where the effect of oxygen was eliminated (Figure 3.17b). After that the heating profile in oxygen was divided by the heating profile in nitrogen, generating the relative change attributed to the ion sorption of oxygen only (Figure 3.17c). The results revealed the highest ion sorption of oxygen by gold-coated sample, followed by bi-metal gold-palladium, bare $\mathrm{SnO}_{2}$ and palladium modified $\mathrm{SnO}_{2}$ respectively.
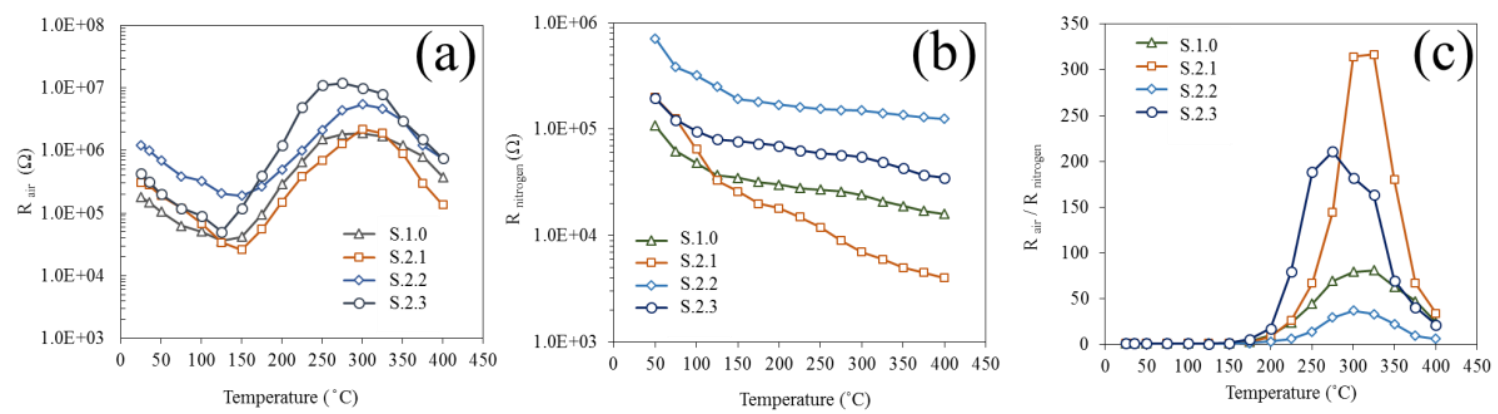

Figure 3.17 (a) Baseline resistance of the sensors S.1.0, S.2.1-S.2.3 in ultra-zero grade air, (b) the corresponding resistance of the sensors in pure nitrogen, and (c) calculated response of the sensors to presence of oxygen over the temperature range from 25 to $400{ }^{\circ} \mathrm{C}$.

The surface density of adsorbed oxygen ions in combination with optimal temperature for the catalytic reaction between the oxygen and reductive gas species at the surface of MOX, determine the rate of the surface catalytic reaction and as a result of that the overall sensor's response.

The optimum operational temperature of the sensors S.1.0 and S.2.1-S.2.3 for detection of low concentrations of benzene and toluene was then determined by using a multi-channel gas mixing system. During the experiment, the baseline resistance was measured in ultra-zero grade air (Figure 3.17a) under different temperature conditions in a range from 25 to $400{ }^{\circ} \mathrm{C}$ and the sensors' resistance was then recorded upon steady state 
exposure to $0.5 \mathrm{ppm}$ of benzene (Figure $3.18 \mathrm{a}$ ). The quantity $\mathrm{R}_{\text {air }} / \mathrm{R}$ gas was then calculated for each temperature condition and the optimum temperature with a corresponding maximum sensor performance was determined for all four sensors (S.1.0, and S.2.1-S.1.3) (Figure 3.18b). It was observed that when the target gas was switched from benzene to toluene of the same concentration, the same result for the optimum operating temperature was obtained. The pure $\mathrm{SnO}_{2}$ sensor had very poor sensitivity and a high operational temperature of $325{ }^{\circ} \mathrm{C}$. Surface modification of the $\mathrm{SnO}_{2}$ layer with gold and palladium nanoparticles slightly decreased the operational temperature of sensors S1 and S2 to 300 ${ }^{\circ} \mathrm{C}$ and $275{ }^{\circ} \mathrm{C}$, respectively. At the same time, a significant increase in sensitivity of nanoparticle-functionalized sensors was observed in comparison with the pure $\mathrm{SnO}_{2}$ sensor (S.1.0). It is important to notice that the sensor S.2.2 functionalized with palladium exhibited higher baseline resistance compared to the sensor S.2.1 functionalized with Au nanoparticles. Such a dramatic difference under identical conditions reveals a potentially different mechanism of interaction between $\mathrm{SnO}_{2}$ nanocrystals and palladium nanoparticles compared to $\mathrm{SnO}_{2}$ interaction with nanoscale gold. The highest baseline resistance as well as the highest response was observed for the $\mathrm{SnO}_{2}$ functionalized with bimetal $\mathrm{Au} / \mathrm{Pd}$ alloy nanoparticles (S.2.3). The lowest operational temperature of $250{ }^{\circ} \mathrm{C}$ was also observed for the same sensor S.2.3. 

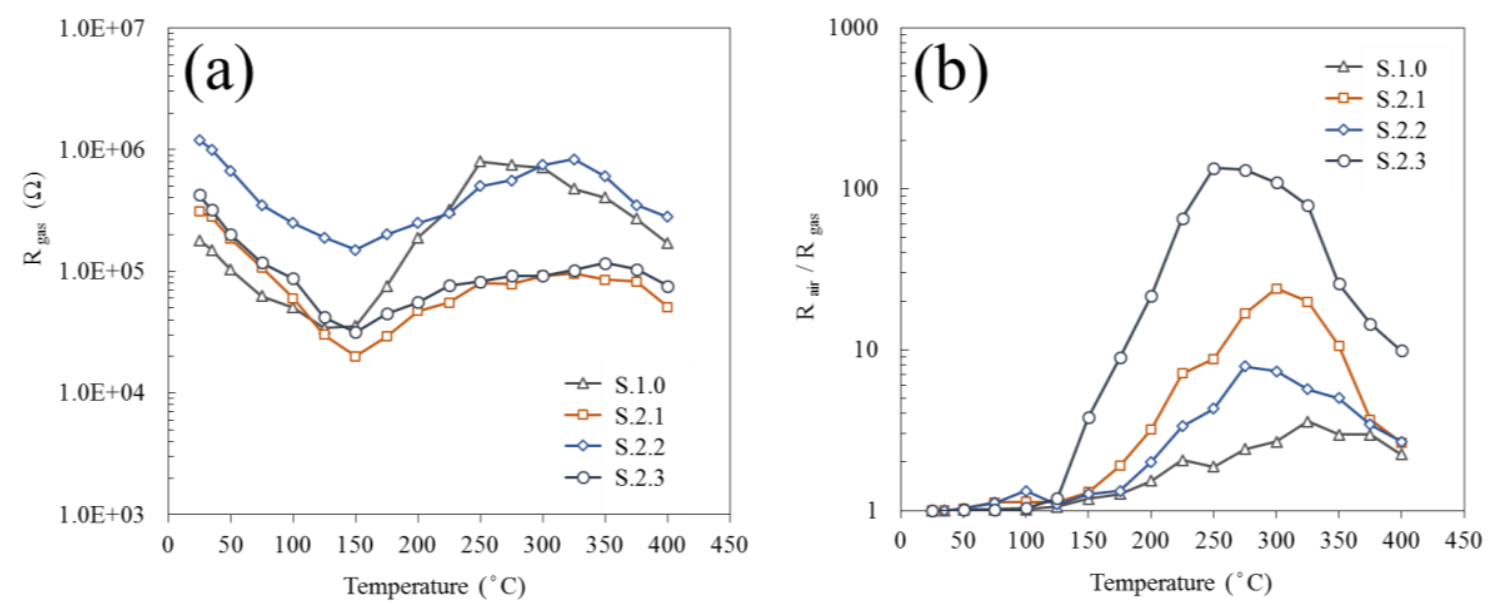

Figure 3.18 (a) The resistance of sensors S.1.0, S.2.1-S.2.3 in the presence of $0.5 \mathrm{ppm}$ of benzene, and (b) the calculated response of sensors S.1.0, S.2.1-S.2.3 to $0.5 \mathrm{ppm}$ of benzene over the temperature range from 25 to $400{ }^{\circ} \mathrm{C}$.

After the optimum operational temperature was determined, the sensors' responses to different concentrations of benzene and toluene in a range between 12.5 and $500 \mathrm{ppb}$ was obtained (Figure 3.19a, b). All of the sensors S.1.0 and S.2.1-S.2.3 show linear behavior upon exposure to low concentrations (10-100 ppb) of benzene and toluene and slightly saturated behavior in the case of higher concentrations (>100 ppb). It was determined that the functionalization of sensors with metal nanoparticles $(\mathrm{Au}, \mathrm{Pd}, \mathrm{Au} / \mathrm{Pd})$ increases the sensitivity of the sensors S.2.1-S.2.3 compared to pure $\mathrm{SnO}_{2}$ sensor (S.1.0). Sensor S.2.3 was measured to have the highest sensitivity toward the low concentrations of benzene and toluene. 

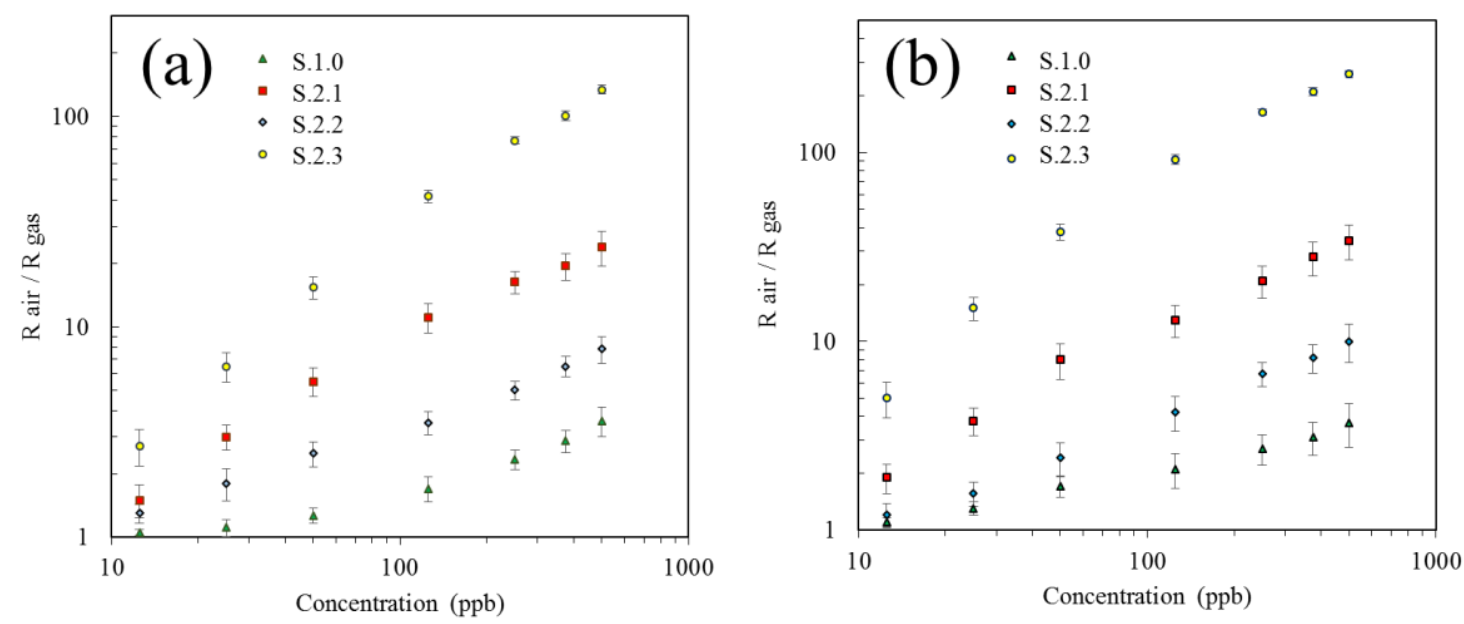

Figure 3.19 The average response of the sensors S.1.0, S.2.1-S.2.3 to different concentrations of (a) benzene and (b) toluene in a range between 12.5 and $500 \mathrm{ppb}$ under optimal operational temperature conditions (Table 3.6) were obtain from multiple experiments over a two week period. The error bars on the graphs correspond to statistical errors equal to three times the standard deviation.

Another important parameter for sensor characterization such as time of response was determined to be the time of exposure of the sensors to $500 \mathrm{ppb}$ of benzene and toluene (Table 3.7). During the experiment, a near-instantaneous change in gas concentration was achieved by reducing the detector volume to $0.5 \mathrm{~cm}^{3}$ and utilizing a premixed benzene bottle with concentration of $500 \mathrm{ppb}$. It was determined that the response time was improved significantly by coating the surface of $\mathrm{SnO}_{2}$ with metal nanoparticles. The fastest response time measured was sensor S.2.3, functionalized with bimetal ( $\mathrm{Au} / \mathrm{Pd})$ nanoparticles. It should be noted that the sensor S.2.2 modified with Pd nanoparticles have a faster response time compared to the sensor S.2.1 modified with gold nanoclusters. The detection limits of the sensors S.1.0 and S.2.1-S.2.3 for benzene and toluene are also included in the Table 3.7. 
Table 3.7 Performance characteristics of the sensors S.1.0, S.2.1-S.2.3 under detection of benzene and toluene

\begin{tabular}{ccccccc}
\hline $\begin{array}{c}\text { Sensors } \\
\#\end{array}$ & $\begin{array}{c}\text { Operational } \\
\text { temperature } \\
\left({ }^{\circ} \mathrm{C}\right)\end{array}$ & $\begin{array}{c}\text { Time of response } \\
\mathrm{T}_{90}(\mathrm{sec}) *\end{array}$ & $\begin{array}{c}\text { Limit of } \\
\text { Detection } \\
(\mathrm{LOD})(\mathrm{ppb})\end{array}$ & $\begin{array}{c}\text { Operational } \\
\text { temperature } \\
\left({ }^{\circ} \mathrm{C}\right)\end{array}$ & $\begin{array}{c}\text { Time of response } \\
\mathrm{T}_{90}(\mathrm{sec})^{*}\end{array}$ & $\begin{array}{c}\text { Limit of } \\
\text { Detection } \\
(\mathrm{LOD})(\mathrm{ppb})\end{array}$ \\
\hline S.1.0 & 325 & 4.9 & 250 & 325 & 4.7 & 125 \\
$\mathrm{~S} .2 .1$ & 300 & 4.3 & 25 & 300 & 4.2 & 25 \\
$\mathrm{~S} .2 .2$ & 275 & 3.7 & 25 & 275 & 3.5 & 50 \\
$\mathrm{~S} .2 .3$ & 250 & 3.3 & $<12.5$ & 250 & 3.1 & $<12.5$ \\
\hline * & & & &
\end{tabular}

Also, a comparative analysis of the sensors' performance at different humidity levels as well as the response of sensors to $0.5 \mathrm{ppm}$ of benzene under different humidity conditions was investigated. The baseline resistance of sensors S.1.0 and S.2.1-S.2.3 was recorded upon exposing them to ultra-zero grade air and the corresponding humidity level inside the detector's chamber was determined to be less than $5 \%$. The response of each sensor upon increasing the relative humidity to 25,60 and $90 \%$ was then calculated (Figure 3.20a). It was determined that all of the sensors S.1.0 and S.2.1-S.2.3 are responsive to the humidity change. Sensor S.2.1, modified with Au nanoparticles, exhibited the highest drift in the sensor's baseline under high (40-90\%) relative humidity conditions and a moderate baseline drift was recorded for sensors S.1.0, S.2.2 and S.2.3. The responses of sensors S.1.0 and S.2.1-S.2.3 upon exposure to $0.5 \mathrm{ppm}$ of benzene were collected under different humidity conditions (Figure 3.20b). It was determined that the responses were affected by the humidity level. The highest (> 6 times) change in response was recorded for sensor functionalized with Au nanoparticles (S.2.1). 

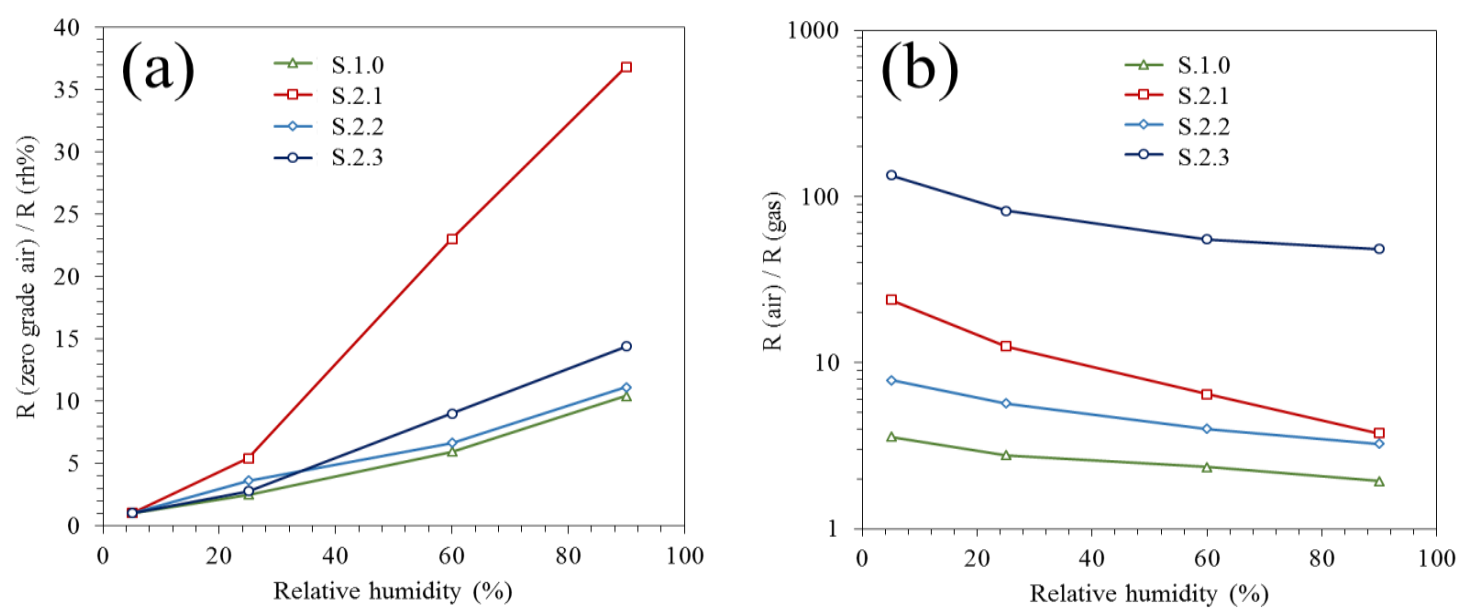

Figure 3.20 (a) A response of sensors S.1.0, S.2.1-S.2.3 to different relative humidity levels and (b) the response of the sensors to $0.5 \mathrm{ppb}$ of benzene under different humidity conditions.

The selectivity of the sensors S.1.0 and S.2.1-S.2.3 was studied under exposure it to different gases and vapors $\left(\mathrm{CO}, \mathrm{H}_{2} \mathrm{~S}\right.$, acetone, ethanol, benzene and toluene) of the same concentration $(0.5 \mathrm{ppm})$. The sensor's signal was recorded after 10 min of being constantly exposed to the gas and corresponding sensors response was calculated for each sensor under different gas environments (Figure 3.21a). The absolute sensor's response was then normalized with respect to the total response of a sensor to all the gases (Figure 3.21b). The selective analysis of the sensors S.1.0 and S.2.1-S.2.3 indicated that while all the sensors were determined to be highly sensitive to $\mathrm{H}_{2} \mathrm{~S}$, acetone and ethanol, the advanced sensitivity toward heavy hydrocarbons (benzene and toluene) was determined only in case of the sensors S.2.1 and S.2.3. It should also be noted that the response of the sensor S.2.3 constantly increased under detection of heavier gas molecules. This, in fact, might lead one to the conclusion that higher order of oxidation with more surface oxygen involved is a key feature of $\mathrm{Au} / \mathrm{Pd} @ \mathrm{SnO} 2$ sensor that increase its sensitivity to heavy hydrocarbons. 

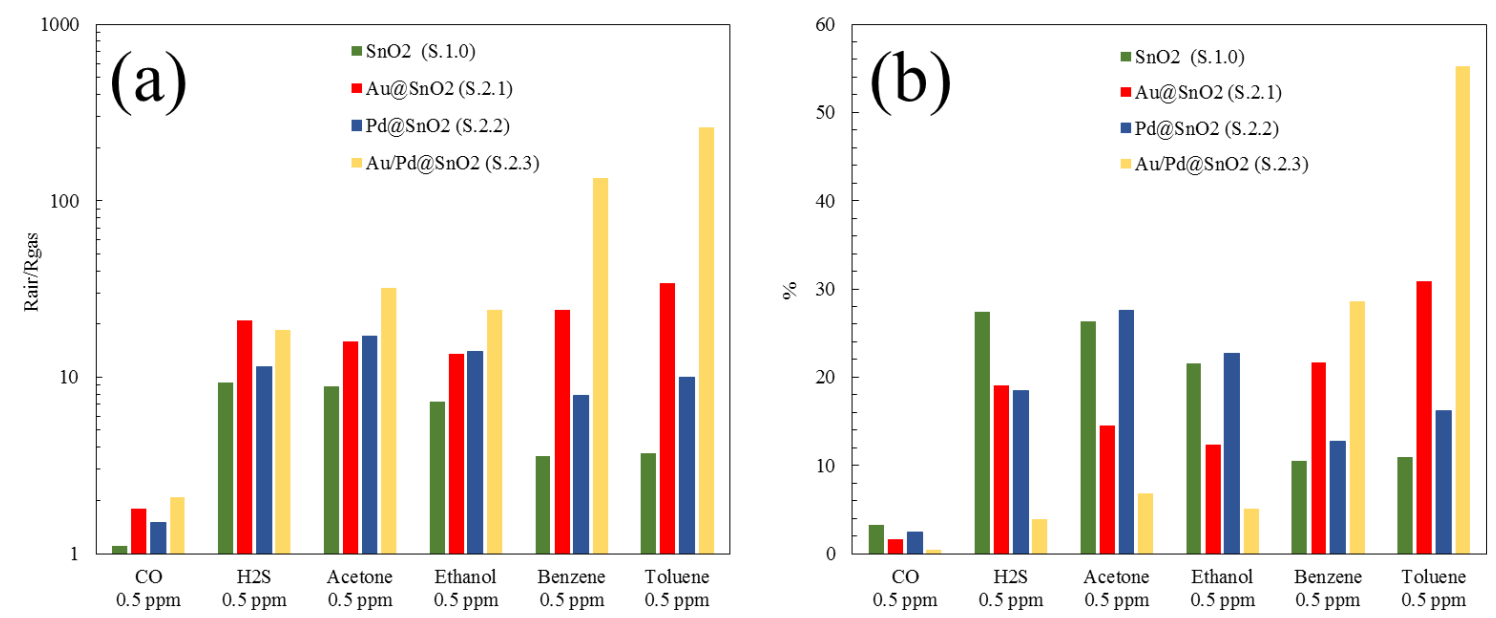

Figure 3.21 (a) A response of the sensors S.1.0 and S.2.1-S.2.3 to 0.5 ppm of CO, $\mathrm{H}_{2} \mathrm{~S}$, acetone, ethanol, benzene and toluene, and (b) normalized response of the sensors.

The comparative analysis of the sensors S.1.0 and S.2.1-S.2.2 in terms of their optimal operational temperature, time of response, lowest detection limit, selectivity and performance under different humidity conditions revealed the superiority of sensor S.2.3. This sensor with bimetal $\mathrm{Au} / \mathrm{Pd}$ nanoparticles exhibited the lowest operational temperature, the highest response to low concentrations of benzene and toluene as well as the fastest response time, compared to the rest of the sensors (S.1.0, S.2.1 and S.2.2). The sensor's signal was not highly affected by the change in relative humidity of the carrier gas and the sensitivity of the sensor stayed high even under $90 \%$ humidity level. Due to its superior properties, sensor S.2.3 was further used for detection of ppb and sub-ppb level of BTEX components by utilizing a portable GC analyzer.

A drastic difference in sensors' response to low concentrations of BTEX components is related to different surface dopant of $\mathrm{SnO}_{2}$. In order to explain the superiority of S.2.3 sensor functionalized with $\mathrm{Au} / \mathrm{Pd}(9: 1)$ nanoparticles, the origin of the conduction mechanism for all of the samples has to be identified as well as catalytic properties of each sample. 
The size of noble metal nanoparticles is one of the important factors that influence their catalytic properties $[183,184]$. Small $(2-3 \mathrm{~nm})$ noble metal nanoclusters have the highest catalytic activity. However, high thermal instability of ultra-small gold clusters makes them hard to utilize in thermally activated MOX sensors at temperatures $\sim 200$ $400{ }^{\circ} \mathrm{C}$ [185]. Instead, the bigger size gold nanoparticles with diameters between 5 to 10 $\mathrm{nm}$ were determined to be very stable over long term. On the other side, palladium nanoclusters $(2-5 \mathrm{~nm})$ were ascertained to be more thermally stable and no particles growth was observed over time. However, some partial particle agglomeration into bigger clusters was observed on the surface of the sample S.2.2. At the same time, the sensitivity of the sensor S.2.2 with ultra-small Pd nanoclusters toward detection of BTEX components was determined to be much lower compared to the result obtained from the sensor S.2.1 with bigger $(5-10 \mathrm{~nm})$ Au nanoparticles. Furthermore, the biggest Au/Pd nanoclusters with the average size of $7.63 \mathrm{~nm}$ were determined to have the highest performance for detection of BTEX components. This in fact provides a clear demonstration that not only the size but the chemical composition of metal nanoclusters as well has a strong influence on the surface catalytic activity. The superiority of Au/Pd (9:1) nanoparticles should be further discussed in combination with $\mathrm{MOX}\left(\mathrm{SnO}_{2}\right)$ support layer.

\subsubsection{Multi-component analysis of complex gas mixtures}

The multi-component analysis of complex gas mixtures was accomplished by using novel multisensory detector in combination with portable GC unit. Four different sensing elements $\mathrm{SnO}_{2}$ (S.1.0), $\mathrm{TiO}_{2}-\mathrm{SnO}_{2}$ (S.1.5), $\mathrm{Au} / \mathrm{Pd} @ \mathrm{SnO}_{2}$ (S.2.3), and $\mathrm{Pt} @ \mathrm{SnO}_{2}$ (S.2.0) were fabricated on the same platform for quantitative detection of sulfur compounds $\left(\mathrm{H}_{2} \mathrm{~S}\right.$ and mercaptans), alcohols (propanol, methanol and ethanol), ketones (acetone), 
hydrocarbons (methane and BTEX) and CO. During the analysis the operational temperature of the detector was kept at $250{ }^{\circ} \mathrm{C}$. The separation of gas species inside the GC column was accomplished under $55^{\circ} \mathrm{C}$ and $14 \mathrm{sccm}$. The analysis of several gas mixtures (Table 3.8) was done during the experiment.

Table 3.8 Gas mixtures and concentrations.

\begin{tabular}{|c|c|c|c|}
\hline Mix. \# & Gases and Concentrations & Possible applications & Ref. \\
\hline 1 & $\begin{array}{ll}1 . & \mathrm{H}_{2} \mathrm{~S}(100 \mathrm{ppb}) \\
\text { 2. } & \text { Mercaptans }(50 \mathrm{ppb}), \\
\text { 3. } & \text { Benzene }(10 \mathrm{ppb}) \\
\text { 4. } & \text { Toluene }(10 \mathrm{ppb}) \\
5 . & \text { Ethylbenzene }(10 \mathrm{ppb}) \\
6 . & \text { O-Xylene }(10 \mathrm{ppb}) \\
\end{array}$ & Indoor air quality control & [186-191] \\
\hline 2 & $\begin{array}{ll}\text { 1. } & \text { Methane }(99.99 \%) \\
\text { 2. } & \mathrm{H}_{2} \mathrm{~S}(100 \mathrm{ppb}) \\
\text { 3. } & \text { Mercaptans }(50 \mathrm{ppb}) \\
\text { 4. } & \text { Benzene }(10 \mathrm{ppb}) \\
\text { 5. } & \text { Toluene }(10 \mathrm{ppb}) \\
\text { 6. } & \text { Ethylbenzene }(10 \mathrm{ppb}) \\
& \text { O-Xylene }(10 \mathrm{ppb}) \\
\end{array}$ & Natural gas analysis & [192-194] \\
\hline 3 & $\begin{array}{ll}\text { 1. } & \mathrm{CO}(10 \mathrm{ppm}) \\
\text { 2. } & \mathrm{H}_{2} \mathrm{~S}(100 \mathrm{ppb}) \\
\text { 3. } & \text { Ethyl-Mercaptan }(50 \mathrm{ppb}) \\
\text { 4. } & \text { Acetone }(50 \mathrm{ppb}) \\
\text { 5. } & \text { Ethanol }(50 \mathrm{ppb}) \\
\text { 6. } & \text { Benzene }(10 \mathrm{ppb}) \\
\text { 7. } & \text { Toluene }(10 \mathrm{ppb}) \\
\text { 8. } & \text { Ethylbenzene }(10 \mathrm{ppb}) \\
\text { 9. } & \text { O-Xylene ( } 10 \mathrm{ppb}) \\
\end{array}$ & Breath analysis & {$[195-200]$} \\
\hline
\end{tabular}

The detection of low concentrations of $\mathrm{H}_{2} \mathrm{~S}$, ethyl-mercaptan and BTEX compounds was ascertained to be very important for indoor air quality monitoring. All the gas compounds from Mix.1 were diluted in 1 liter of zero grade air and small sample volume of $50 \mathrm{ml}$ was then analyzed. As the result of the analysis, the chromatogram of the gas mixture (Mix.1) was obtained by using multi-sensor MOX detector. After the device background was subtracted, seven major peaks were detected (Fig. 22a-b). The identification of each compound was accomplished according to specific retention time for each gas. 


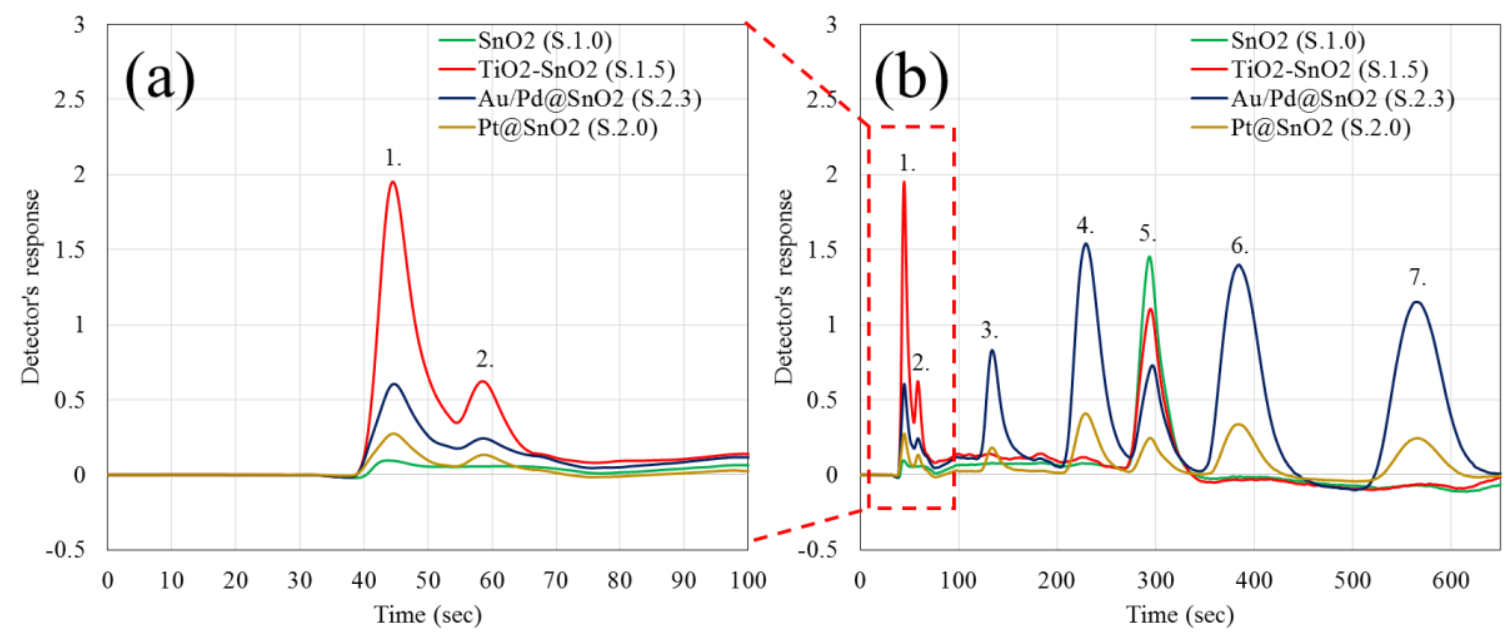

Figure 3.22 Gas chromatogram of Mix. 1: (a) zoomed image of light compounds and (b) the full gas chromatogram.

(1. $\mathrm{H}_{2} \mathrm{~S} 100 \mathrm{ppb}, 2$. Ethyl-Mercaptan $50 \mathrm{ppb}, 3$. Benzene $10 \mathrm{ppb}$, 4. Toluene $10 \mathrm{ppb}, 5$. Water, 6.

Ethylbenzene $10 \mathrm{ppb}, 7$. O-Xylene $10 \mathrm{ppb}$ ).

In this work, the specific gas pre-concentrator (10 mg of Carbopack B, 60/80 mesh from Supelco No. 20273) inside the portable GC was designed specifically for heavy hydrocarbons (BTEX). This feature in combination with highly sensitive detector allowed to achieve a sub-ppb level of detection (Figure 3.23a). In the process, the background signal from the GC was recorded upon analyzing zero grade air samples. It was determined that the integrated response of $\mathrm{Au} / \mathrm{Pd} @ \mathrm{SnO}_{2}$ sensor to $0.5 \mathrm{ppb}$ of BTEX was higher than the background signal of the portable GC for all the BTEX components with a confidence level of $99.74 \%$ (Figure 3.23b). The sub-ppb level of detection of the sensor S.2.3 makes it possible to utilize it for real time indoor air quality monitoring. It is worth noting that the fast response and recovery time of the detector, upon exposure to reducing gases, substantially increases the GC selective ability of the device and improves the air sample analysis in the case of complex contaminated backgrounds or high humidity conditions. 

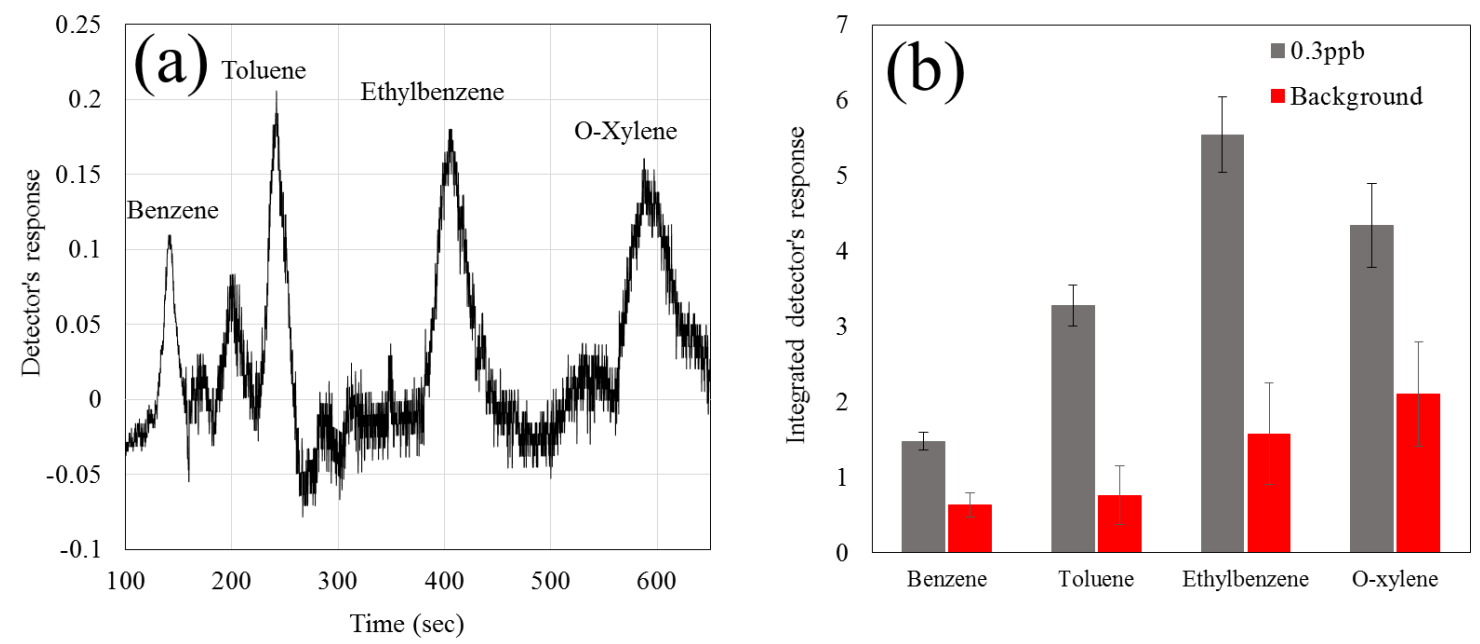

Figure 3.23 (a) Gas chromatogram of $0.3 \mathrm{ppb}$ of BTEX mixture, (b) integrated detector's response to $0.3 \mathrm{ppb}$ of BTEX mixture and integrated GC background signal.

Furthermore, the ability of the system to analyze the gas samples with more complex background, different than air, was confirmed. The detection of ultra-low concentrations of gas impurities $\left(\mathrm{H}_{2} \mathrm{~S}\right.$, ethyl-mercaptan, benzene, toluene, ethylbenzene and o-xylene) in pure methane (99.99\%) was accomplished and all the gas components were identified (Figure 3.24a and b). The specific selectivity of the sensors S.1.5 and S.2.3 to $\mathrm{H}_{2} \mathrm{~S}$ and hydrocarbons respectively, helps to separate different chemicals within very short time interval $(<20 \mathrm{sec}$.). The experiment with methane as a background gas, confirms the advantage of multi-dimensional chromatography by using an array of sensors instead of a single non selective detector. This advantage can be utilized in the area of fast portable natural gas analysis by using a single GC column under constant temperature. 


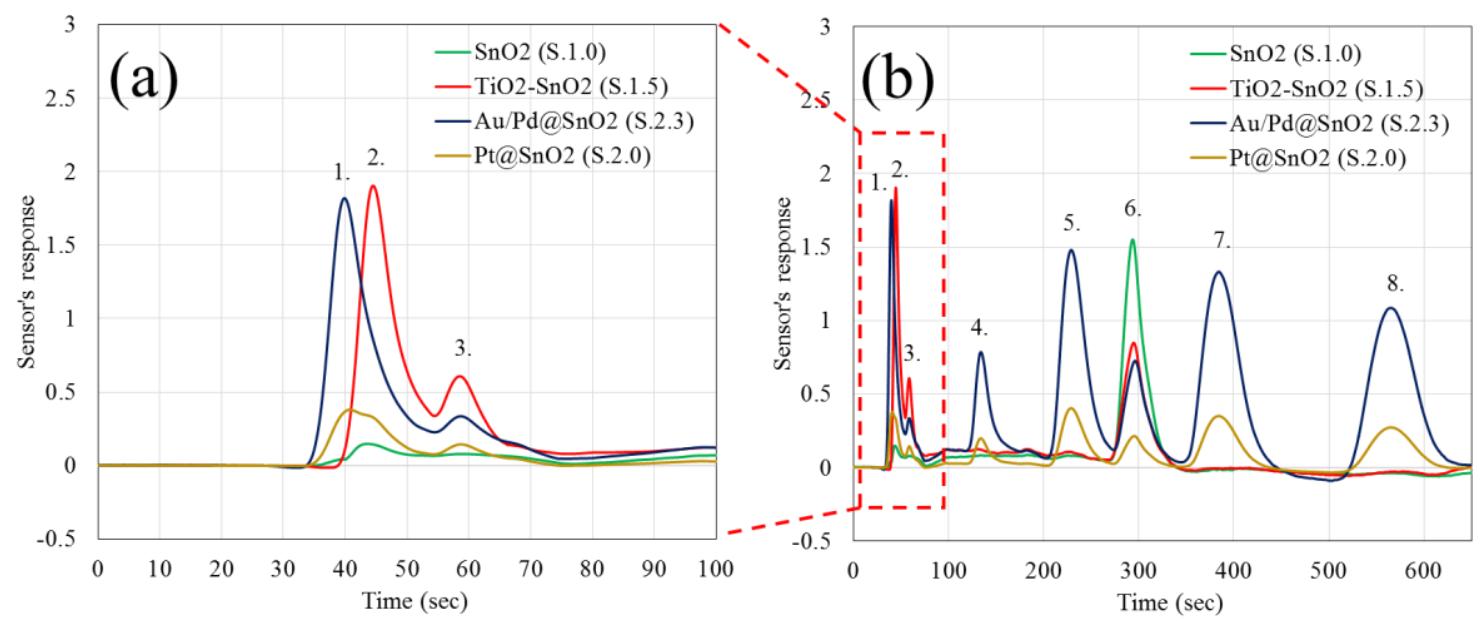

Figure 3.24 Gas chromatogram of Mix. 2: (a) zoomed image of light compounds and (b) the full gas chromatogram. (1. Methane 99.99\%, 2. $\mathrm{H}_{2} \mathrm{~S} 100 \mathrm{ppb}, 3$. Ethyl-Mercaptan $50 \mathrm{ppb}$, 4. Benzene 10 ppb, 5. Toluene $10 \mathrm{ppb}, 6$. Water, 7. Ethylbenzene $10 \mathrm{ppb}, 8$. O-Xylene $10 \mathrm{ppb}$ ).

Finally, the analysis of the third gas mixture (Mix. 3) was done in order to demonstrate the ability of the instrument to analyze very complex gas samples similar to a human breath with 10 or more gases from different chemical groups (hydrocarbons, ketones, alcohols, sulfur compounds, and $\mathrm{CO}$ ). It was determined that some biomarkers in human breath like acetone, ammonia, $\mathrm{CO}$, hydrogen sulfide, mercaptans, and BTEX can be used for disease diagnostic as well as monitoring the exposure to toxics via breath samples. It was ascertained that, conventional MOX detector (Figaro TGS 2602) with a single sensing element does not provide necessary selectivity to identify all the gases present in the sample (Figure 3.25a and b). 


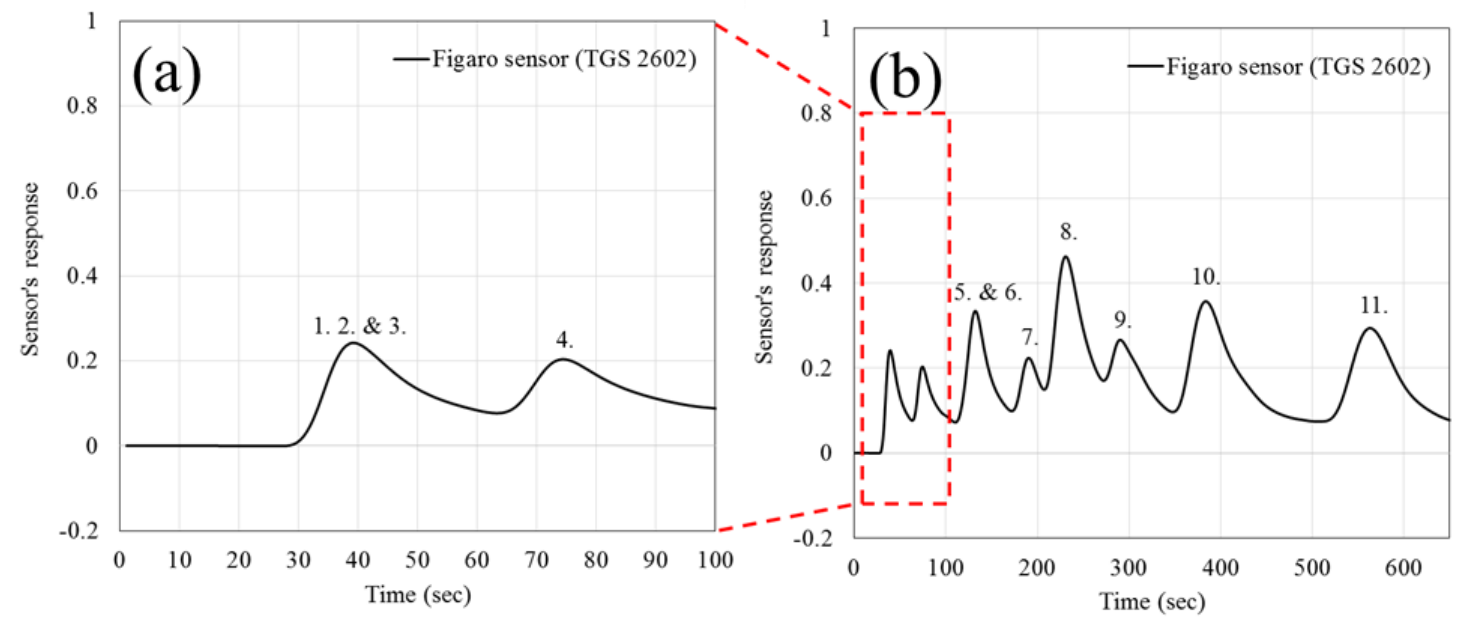

Figure 3.25 Gas chromatogram of Mix. 3 by using conventional non selective MOX detector (a) zoomed image of light compounds and (b) the full gas chromatogram. (1. CO $10 \mathrm{ppm}, 2 . \mathrm{H}_{2} \mathrm{~S} 100 \mathrm{ppb}$, 3. EthylMercaptan $50 \mathrm{ppb}, 4$. Acetone $50 \mathrm{ppb}$, 5. Ethanol $50 \mathrm{ppb}, 6$. Benzene $10 \mathrm{ppb}, 7$. Unknown, 8. Toluene 10 ppb, 9. Water, 10. Ethylbenzene $10 \mathrm{ppb}, 11$. O-Xylene $10 \mathrm{ppb}$ ).

The slow time of response and recovery, the low sensitivity and the poor selectivity of conventional MOX detectors based on thick films limits their utility in GC analysis of complex gas mixtures.

However, novel thin film nanocomposite sensing materials that were developed in this dissertation research allow multi-dimensional analysis of gas mixtures utilizing an integrated sensor array e.g. the analysis of the Mix. 3 was accomplished by using four sensor array. All the known gases in the mixture were detected and identified (Figure 3.26). Fast response and recovery time of the thin film sensors increases the time resolution of the device. Also, the separation of the chemicals with almost the same retention time such as $\mathrm{CO}$ and $\mathrm{H}_{2} \mathrm{~S}$, benzene and toluene was significantly improved by using an array of selective sensors. 


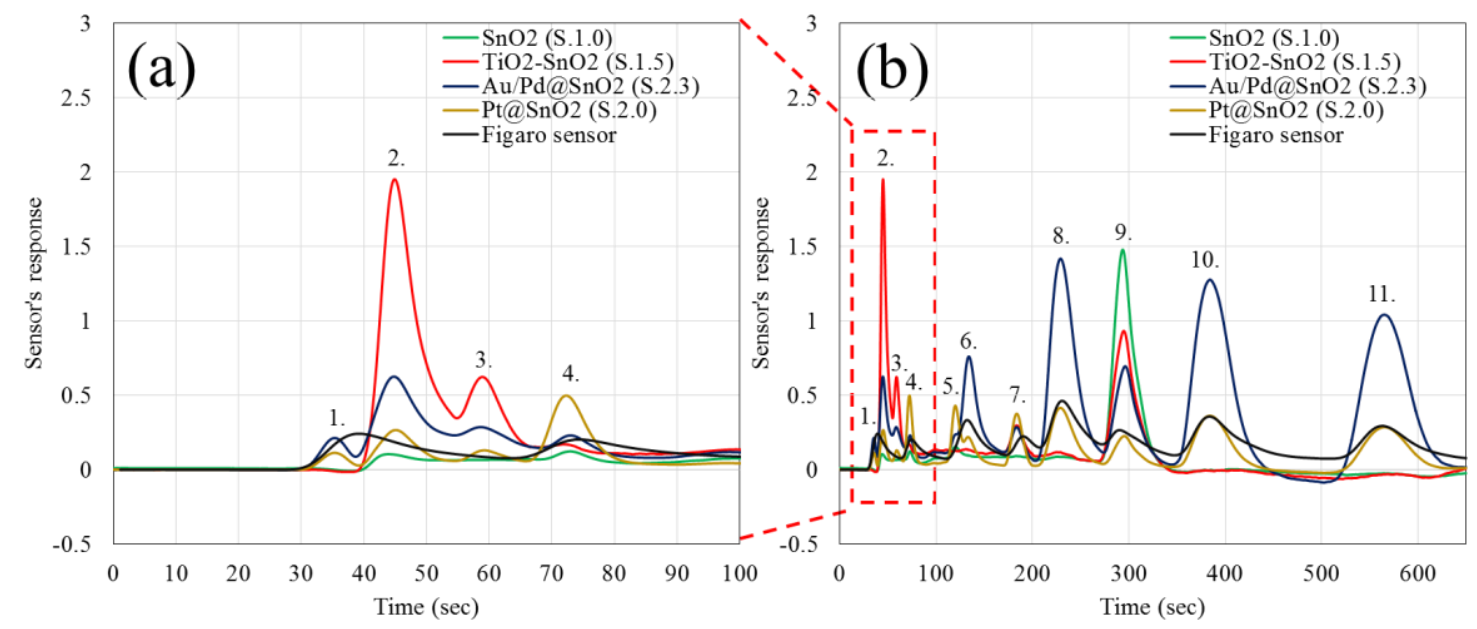

Figure 3.26 Gas chromatogram of Mix. 3: (a) zoomed image of light compounds and (b) the full gas chromatogram. (1. CO $10 \mathrm{ppm}, 2 . \mathrm{H}_{2} \mathrm{~S} 100 \mathrm{ppb}$, 3. Ethyl-Mercaptan $50 \mathrm{ppb}$, 4. Acetone $50 \mathrm{ppb}, 5$. Ethanol $50 \mathrm{ppb}, 6$. Benzene $10 \mathrm{ppb}, 7$. Unknown, 8. Toluene $10 \mathrm{ppb}, 9$. Water, 10. Ethylbenzene $10 \mathrm{ppb}, 11$. OXylene $10 \mathrm{ppb})$.

In addition to qualitative analysis of gas mixtures and component identification, a quantitative analysis of each component in the mixtures was proposed by calibrating the device for different concentrations of the same gas. The standard approach for GC signal evaluation is based on calculating the area under the curve for each peak detected. In this work, the integrated detector's response was calculated by integrating the area under the curve over the time interval for each gas.

The detector's performance was evaluated over a period of 10 days. During this time, the response of the detector was monitored upon exposure to different concentrations of detectable gases: $\mathrm{H}_{2} \mathrm{~S}$ (10-500 ppb), ethyl-mercaptan (10-500 ppb), acetone (10-500 $\mathrm{ppb})$, ethanol (10-500 ppb) and BTEX (10-500 ppb). Finally, the calibration curves for the concentration of various gases for all four sensors were obtained based on average sensors' response (Figure 27a-d). All four sensors exhibited non-linear behavior for detection of various gases in the concentration range between 10 and $500 \mathrm{ppb}$. It was once again shown that pure $\mathrm{SnO}_{2}$ have very low sensitivity at ppb level and poor selectivity (Figure 3.27a). 
The $\mathrm{TiO}_{2}-\mathrm{SnO}_{2}$ sensor which was specifically designed for detection of $\mathrm{H}_{2} \mathrm{~S}$, also displayed high response to ethyl-mercaptan (Figure 3.27b). The $\mathrm{SnO}_{2}$ films modified with $\mathrm{Au} / \mathrm{Pd}$ bimetal nanoparticles provide an opportunity for selective detection of heavy (BTEX) hydrocarbons at ultralow concentrations (Figure 3.27c). Finally, the highest sensitivity to ethanol and acetone was obtained by using $\mathrm{SnO}_{2}$ film modified with $\mathrm{Pt}$ nanoparticles (Figure 3.27d).
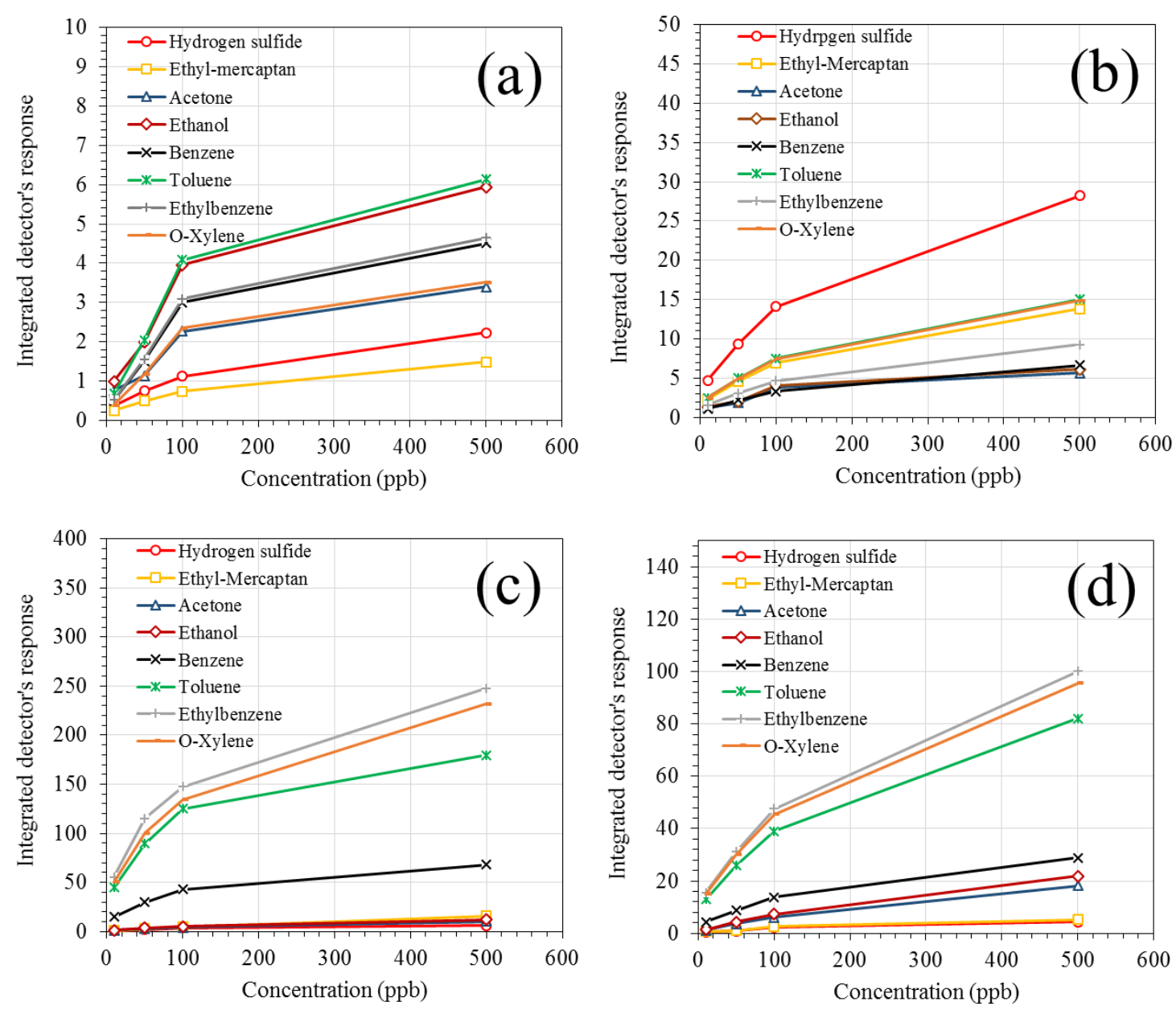

Figure 3.27 The calibration curves for (a) $\mathrm{SnO}_{2}$, (b) $\mathrm{TiO} 2-\mathrm{SnO}_{2}$, (c) $\mathrm{Au} / \mathrm{Pd} @ \mathrm{SnO}_{2}$ and (d) $\mathrm{Pt} @ \mathrm{SnO}_{2}$ obtained by integrating the total area under the sensor's response curve over specific time interval.

In this work we established and confirmed a method for the quantitative and the qualitative analysis of gas mixtures by using an array of selective sensors. All the gases in the analyzing mixtures were easily separated by the GC column or by selective sensor's 
array. It is important to note that the performance of the multi-dimensional GC analysis by using an array of MOX sensors can be significantly improved by calculating first and second derivative of the original signal. In addition to the amplitude analysis of the detector's signal, which represents the absolute rate of surface catalytic reaction, the first derivative is representing the rate of change in the reaction and can be very useful for close peak separation.

Data analysis algorithms for multi-dimensional gas chromatography including signal detection, peak identification, and background analysis are important parts of multicomponent analysis of gas mixtures. However, this material is beyond the scope of this dissertation project and will not be further discussed but rather noting that there is significant and sufficient material for future work in these areas.

\subsection{Discussion}

For the gas sensing materials based on MOX semiconductors the conduction path inside the sensing layer is extremely important because it has great influence on the magnitude of the sensor's response. Based on this assumption, thin porous polycrystalline films are the best type of gas sensing material where electrons are passing from one MOX grain to another. The grain-grain boundary with Schottky contact approximation is greatly influenced by the ambient conditions as discussed above. At the same time, the height of the barrier controls the concentration of free charge carriers passing through it.

\subsubsection{Gas sensing mechanism of polycrystalline $\mathrm{SnO}_{2}$}

Recently, new theoretical and experimental evidence of the conduction mechanism in polycrystalline $\mathrm{SnO}_{2}$ films was investigated in detail and revised by N. Barzan et. al. [201]. In Barzan's paper, the simultaneous measurement of DC electrical resistance and 
the work function of porous $\mathrm{SnO}_{2}$ film was conducted under different concentrations of reducing gases such as $\mathrm{H}_{2}$ and $\mathrm{CO}$ in the absence of oxygen and under different concentrations of oxygen in nitrogen. It was shown that the change in conductivity of $\mathrm{SnO}_{2}$ polycrystalline film is controlled by the potential barrier $\mathrm{qV}_{\mathrm{s}}$ at the surface of $\mathrm{SnO}_{2}$ grains upon exposure to reducing or oxidizing gases. Different conduction mechanisms by using depletion and accumulation layer models were investigated as well as a flat band condition under inert nitrogen gas. In the case of the upward band bending due to oxygen ion sorption at the surface of the grains (Figure 3.28a), the relative change of the surface potential barrier upon exposure to reducing gases can be directly calculated from the change in resistance (equation 3.6):

$$
q \Delta V_{s}=-k T \cdot \ln \left(\frac{R_{0}}{R_{g a s}}\right)
$$

Band bending at the grain surfaces decreases with the decrease of adsorbed oxygen species. The flat band situation with no oxygen traps at the grain surfaces can be achieved in dry nitrogen whenever the barrier height becomes comparable to $k T$ (Figure 3.28b). Futhermore, the surface of the grains becomes an accumulation layer under different concentrations of reducing gases in nitrogen (Figure 3.28c) and the relationship between change in resistance and band bending becomes:

$$
q \Delta V_{s}=-2 k T \cdot \ln \left(\frac{R_{0}}{R_{\text {gas }}}\right)
$$

Boltzmann statistics for electron energy distribution can be applied to the accumulation layer model only in cases when the band edges are far enough $(>2 k T)$ from the Fermi-level. A more general approach to electron density calculation by using density of states in the conduction band and the Fermi-Dirac probability distribution function can be used in a case when the band bending is close to the Fermi-level [201]. 


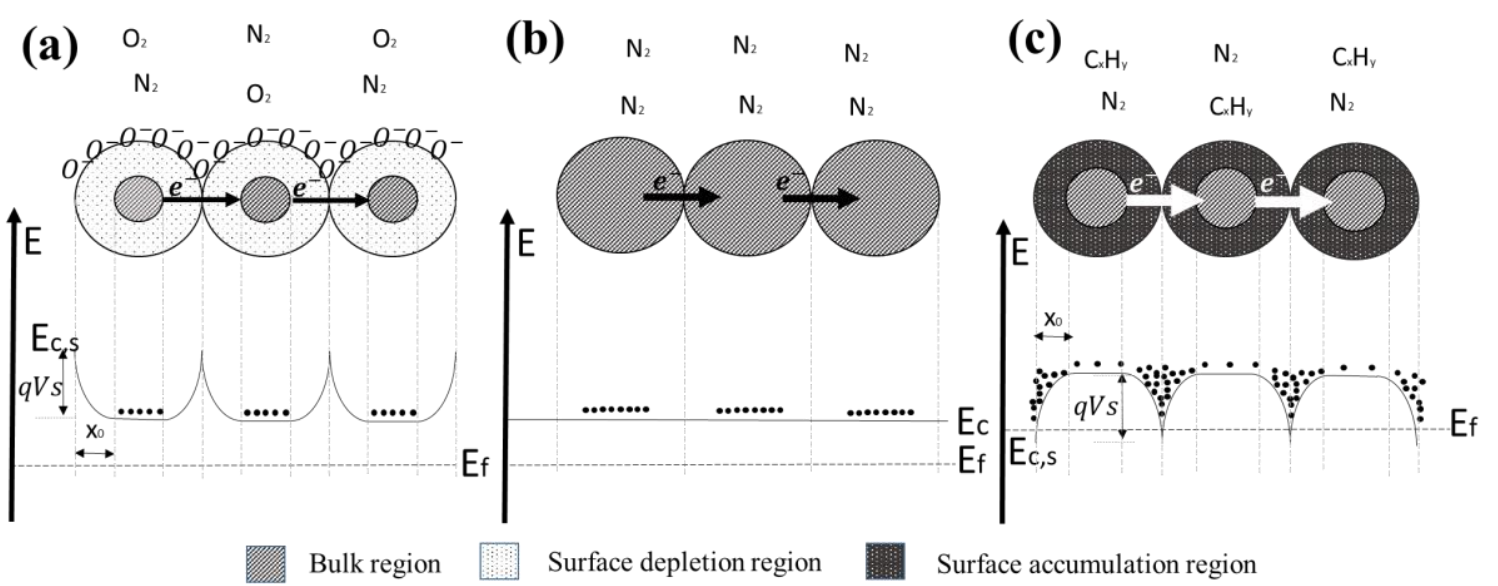

Figure 3.28 A simplified diagram of the conduction mechanism in polycrystalline $\mathrm{SnO}_{2}$ in the case of (a) depletion layer, (b) flat band, and (c) accumulation layer model.

\subsubsection{Gas sensing mechanism of $\mathrm{TiO}_{2}-\mathrm{SnO}_{2}$ hybrid sensor}

Based on the main theory of conduction mechanism of polycrystalline $\mathrm{SnO}_{2}$ film, the poor response of bare $\mathrm{SnO}_{2}$ sensor can be amplified by tuning the grain-grain surface potential $\left(\mathrm{V}_{\mathrm{s}}\right)$ and by increasing the catalytic activity on the surface of the grains. Nanocomposite gas sensing materials based on two or more MOXs is one of the ways to tune the barrier $\left(\mathrm{V}_{\mathrm{s}}\right)$ height. In addition to the surface potential barriers between the grains created by the ion sorption of oxygen from ambient air, the contribution of heterojunction barrier at the boundary of two different oxides can be very significant even with no oxygen present. The enhanced gas sensing ability of $\mathrm{SnO}_{2} / \mathrm{TiO}_{2}$ thin films deposited over $\mathrm{SiO}_{2}$ and Corning 1737 glass substrates was previously reported by Lee and Hwang [202]. In our research, the resistance of $\mathrm{TiO}_{2}-\mathrm{SnO}_{2}$ hybrid sensors was determined to be much higher than the resistance of bare $\mathrm{SnO}_{2}$ film under ambient air conditions. On the other hand, in the presence of reductive gas species $\left(\mathrm{H}_{2} \mathrm{~S}\right)$, an exceptional sensitivity (increase in conductance) based on high catalytic activity of hybrid $\mathrm{TiO}_{2}-\mathrm{SnO}_{2}$ gas sensing material 
was shown. This in fact might lead one to the conclusion that electrical and catalytic properties of the hybrid oxide are closely connected.

First of all, the titanium dioxide powder is a very reactive catalyst that is used in the Clauss process for sulfur production. It's much more catalytically active for sulfur oxidation than $\mathrm{SnO}_{2}$. Some recent reports indicated outstanding catalytic properties of $\mathrm{TiO}_{2}$ nanoparticles in the range between 2 and $5 \mathrm{~nm}$ [203-205]. This catalytic activity is related to the high surface to volume ratio of the nanoscale material and large amount of surface active sites (oxygen vacancies) for chemisorption. Due to high thermal and mechanical stability, the $\mathrm{TiO}_{2}$ is also used as a catalyst support material [206]. However, the thin films of $\mathrm{TiO}_{2}$ (S.1.7) fabricated by using magnetron sputtering technique appeared to be extremely dense with low active surface area. At the same time, high resistivity of $\mathrm{TiO}_{2}$ makes it very difficult to utilize the material for gas sensing applications [207, 208]. Conversely, pure $\mathrm{SnO}_{2}$ (S.1.0) sensor exhibits moderate sensitivity to hydrogen sulfide at low ppm level. Also, no selectivity of $\mathrm{SnO}_{2}$ sensor for detection of $\mathrm{H}_{2} \mathrm{~S}$ was determined. In addition to that, a long time of recovery upon exposure to $\mathrm{H}_{2} \mathrm{~S}$ gas revealed two potential problems such as poisoning effect and low catalytic activity of the surface even at elevated temperature $\sim 300{ }^{\circ} \mathrm{C}$.

In our experiments the nanocomposite structure of $\mathrm{TiO}_{2}-\mathrm{SnO}_{2}$ showed enhanced sensing properties for detection of $\mathrm{H}_{2} \mathrm{~S}$. Both double layer (S.1.1-S.1.3) and multilayertype sensors (S.1.4-S.1.6) demonstrated maximum performance at optimum volume concentration of titanium dioxide in the sensing layer. For particular concentration of $\mathrm{TiO}_{2}$ in $\mathrm{SnO}_{2}$, the sensitivity of the hybrid structure as well as the time of response and recovery upon exposure to low concentrations $\mathrm{H}_{2} \mathrm{~S}$ were improved dramatically with respect to bare 
$\mathrm{SnO}_{2}$. The sensor (S.1.5) exhibits the highest sensitivity and the fastest recovery time at $10 \%$ vol. of $\mathrm{TiO}_{2}$. The decline in sensor performance was noticed with further increase in $\mathrm{TiO}_{2}$ concentration. This effect can be related to decrease in porosity of the samples with high content of $\mathrm{TiO}_{2}$. Also, the agglomeration of $\mathrm{TiO}_{2}$ particles into a bigger clusters reduce the catalytic activity and the total active area of the sensor. In particular, significant increase in $\mathrm{TiO}_{2}$ coating of the sensor S.1.3 overcoming its percolation threshold and forming a continuous layer of dense and extremely inert film with low catalytic activity and poor electrical conductance.

The advanced sensitivity of the hybrid type $\mathrm{SnO}_{2}-\mathrm{TiO}_{2}$ sensor is also mainly related to specific charge transfer and heterojunction formation between the grains of two different oxides. The electronic structure of $\mathrm{SnO}_{2}$ and $\mathrm{TiO}_{2}$ oxide including band gap, work function and electron affinity was determined to be different (Figure 3.29a). The band gap of polycrystalline $\mathrm{SnO}_{2}$ for direct $(4.17 \mathrm{eV})$ and indirect $(3.35 \mathrm{eV})$ allowed transitions by using UV-Vis spectrometry (Tauc plot) was measured larger than the optical band gap of $\mathrm{TiO}_{2}$ with $3.84 \mathrm{eV}$ and $3.15 \mathrm{eV}$ for direct and indirect allowed transitions correspondingly. The result obtained from our optical band gap measurement agrees with values previously reported by other research groups for polycrystalline $\mathrm{SnO}_{2}$ with rutile crystal structure (3.5 - $4.0 \mathrm{eV})[92,209-211]$ and polycrystalline $\mathrm{TiO} 2$ with anatase crystal structure (3.2 - 3.6 eV) $[207,211-215]$. Also, the work function of polycrystalline rutile $\mathrm{SnO}_{2}[210,216]$ was reported to be larger than the work function and electron affinity of polycrystalline anatase $\mathrm{TiO}_{2}[215,217,218]$ by approximately $0.3-0.5 \mathrm{eV}$. As a result of different band energy structures, a type two heterojunction is formed between $\mathrm{SnO}_{2}$ and $\mathrm{TiO}_{2}$ nanocrystals with valence and conduction band misalignment and bending at the crystals interface (Figure 
3.29b) $[209,214,219,220]$. The important work on $\mathrm{TiO}_{2}-\mathrm{SnO}_{2}$ heterojunction was previously accomplished by Vagner et al [211]. The research in Reference 205 has shown that the heterojunction is growing even in the case of anatase $\mathrm{TiO}_{2}$ and rutile $\mathrm{SnO}_{2}$ crystals with slightly different lattice parameters. The formation of the heterojunction leads to a discontinuity in the conduction band and formation of the energy barrier at the interface due to the electrons transfer. The electron transfer from the conduction band of $\mathrm{TiO}_{2}$ to the conduction band of $\mathrm{SnO}_{2}$ is primarily determined by the position of the Fermi energy level of $\mathrm{TiO}_{2}$ which is higher with respect to $\mathrm{SnO}_{2}$ Fermi level.
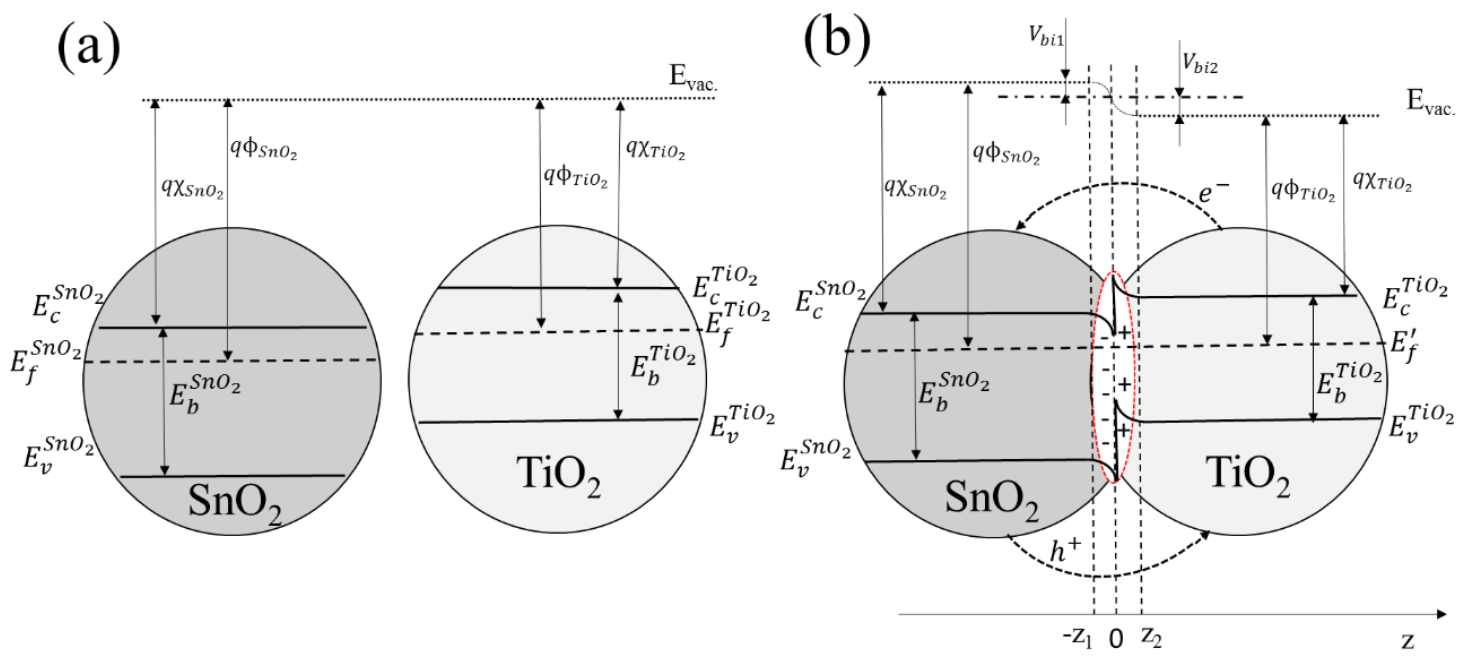

Figure 3.29 A schematic diagrams of flat energy band approximation of (a) $\mathrm{SnO}_{2}$ and $\mathrm{TiO}_{2}$ and (b) the $\mathrm{TiO}_{2}$ $\mathrm{SnO}_{2}$ heterojunction in vacuum.

The total build in voltage $\mathrm{V}_{\mathrm{bi}}$ of the heterojunction is given by the equation 2 [221].

$$
V_{b i}=\phi_{\mathrm{SnO}_{2}}-\phi_{\mathrm{TiO}_{2}}=V_{b i_{1}}+V_{b i_{2}}
$$

where $q \phi_{\mathrm{SnO}_{2}}$ is the work function of $\mathrm{SnO}_{2}, q \phi_{\mathrm{TiO}_{2}}$ is the work function of $\mathrm{TiO}_{2}, q V_{b i_{1}}$ is the band curvature in $\mathrm{SnO}_{2}$ and $q V_{b i_{2}}$ is the band curvature in $\mathrm{TiO}_{2}$ due to the charge transfer. Two potential drops from each semiconductor can be determined by solving the Poisson equation with specific boundary conditions for the region of interest. The solution 
for the depletion region of the heterojunction in a case of fully ionized impurities $\left(\rho(z)=N_{d}\right)$ was described in Chapter 1 and expression for the surface potential becomes:

$$
V_{b i_{2}}=\frac{q N_{d_{2}} z_{2}^{2}}{2 \varepsilon_{2}}
$$

where $q$ is the magnitude of electronic charge, $\varepsilon_{2}$ is semiconductor $\left(\mathrm{TiO}_{2}\right)$ permittivity, $N_{d 2}$ is donor concentration in $\mathrm{TiO}_{2}, V_{b i 2}$ is built-in potential barrier at the surface of the depletion region and $z_{2}$ the width of the depletion region. The solution for the potential drop on another side of the junction $V_{b i l}$ is more complicated due to the additional concentration of free carriers $\mathrm{n}(\mathrm{z})$ inside the region but can be numerically calculated. An important theoretical work on $\mathrm{TiO}_{2}-\mathrm{SnO}_{2}$ heterojunction was done by E. Floriano [222] where the electronic properties of $\mathrm{SnO}_{2}$ and $\mathrm{TiO}_{2}$ were calculated by using density functional theory-Becke, three-parameter, Lee-Yang-Parr (DFT/B3LYP) and an enhanced $\mathrm{TiO} 2 / \mathrm{SnO} 2$ heterostructure was proposed to increase the gas detection efficiency of MOX sensors.

The effect of charge transfer and heterojunction formation on the gas sensitization mechanism of nanocomposite $\mathrm{SnO}_{2} / \mathrm{TiO}_{2}$ is shown in Figure 3.30 has three components. First, the transfer of free carriers from $\mathrm{TiO}_{2}$ crystal leads to the increase of incomplete bonding in $\mathrm{TiO}_{2}$ crystals. Second, the comparably high electron affinity of $\mathrm{TiO}_{2}$ define the adsorption of reductive gases in the form of negative ions at the $\mathrm{TiO}_{2}$ surface. Third, the formation of an electron-enriched zone at the $\mathrm{SnO}_{2}$ side of the interface amplifies oxygen adsorption in this region $[223,224]$, under standard ambient air conditions. Trapping of free electrons at the surface of the electron enriched region increase the depletion depth $(\mathrm{z})$ and reduce the conductance of the $\mathrm{TiO}_{2}-\mathrm{SnO}_{2}$ layer compared to the conductance of polycrystalline $\mathrm{SnO}_{2}$ (Figure 3.30a). From our experiments, not only does the resistance 
increase for the $\mathrm{TiO}_{2}-\mathrm{SnO}_{2}$ hybrid sensors under ultra-zero grade air conditions, but also, much more significantly, the $\mathrm{R}_{\text {air }} / \mathrm{R}_{\text {gas }}$ was detected upon exposure to low concentrations of $\mathrm{H}_{2} \mathrm{~S}$ compared to a single-oxide homogeneous system. This is because hybrid $\mathrm{TiO}_{2}$ $\mathrm{SnO}_{2}$ sensors have more active oxygen resulting in a high catalytic oxidation of $\mathrm{H}_{2} \mathrm{~S}$ to water and sulfur dioxide which is related to increase in free carrier concentration in the bulk and an overall increase in conductance compared to the same reaction at the surface of polycrystalline $\mathrm{SnO}_{2}[173]$.

$$
\mathrm{H}_{2} \mathrm{~S}+3 \mathrm{O}^{-} \stackrel{\mathrm{SnO}_{2}\left(\mathrm{Temp} \sim 150-200^{\circ} \mathrm{C}\right)}{\longrightarrow} \mathrm{H}_{2} \mathrm{O}+\mathrm{SO}_{2}+3 e^{-}
$$

At the same time, the direct oxidation of $\mathrm{H}_{2} \mathrm{~S}$ to elemental sulfur with stoichiometric amount of oxygen at the surface of $\mathrm{TiO}_{2}$ crystal is mainly described by MODOP (mobile direct oxidation process) [203].

$$
\mathrm{H}_{2} \mathrm{~S}+2 \mathrm{O}^{-} \stackrel{\mathrm{TiO}_{2}\left(\mathrm{Temp} \sim 150-200^{\circ} \mathrm{C}\right)}{\longrightarrow} \mathrm{H}_{2} \mathrm{O}+\frac{2}{n} S_{n}+2 e^{-}
$$

It is important to note that other oxidation reactions between $\mathrm{H}_{2} \mathrm{~S}$ and ionized surface oxygen at the surface of $\mathrm{TiO}_{2}$ crystals are also possible and not restricted. The enhanced catalytic activity of both oxides together with amplified resistance changes due to charge transfer effects (bulk - surface and oxide-oxide) make the hybrid $\mathrm{TiO}_{2}-\mathrm{SnO}_{2}$ sensor superior to single-oxide $\left(\mathrm{SnO}_{2}\right.$ or $\left.\mathrm{TiO}_{2}\right)$ sensors (Figure 3.30b). 

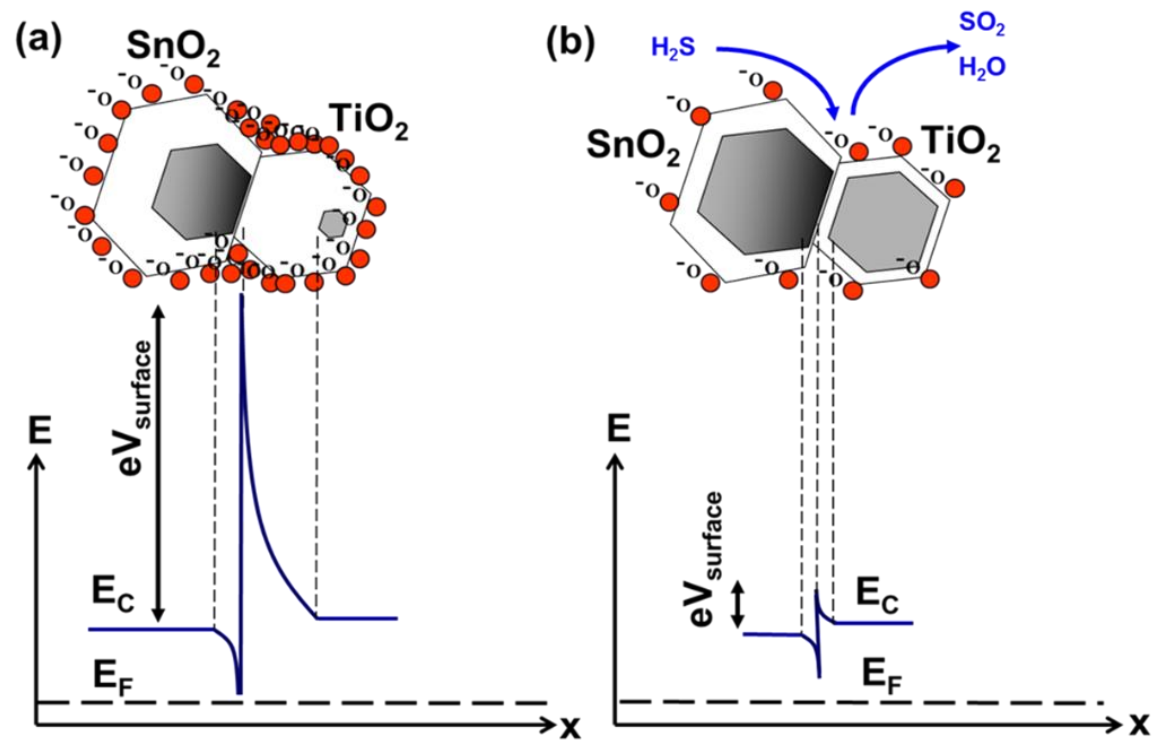

Figure 3.30 (a) Electronic grain structure of a hybrid $\mathrm{SnO} 2 / \mathrm{TiO} 2$ layer in ambient atmosphere and (b) upon exposure to $\mathrm{H}_{2} \mathrm{~S}$.

Unfortunately, an analytical model of the change in the heterojunction barrier height under different ambient air conditions is hard to obtain due to unknown geometry of the heterojunction and the complicated kinetics of gas adsorption - desorption process at its surface.

3.5.3 Noble metal nanoparticles and gas sensing mechanism of $\mathrm{Pt}, \mathrm{Au}, \mathrm{Pd}$ and $\mathrm{Au} / \mathrm{Pd}-$ doped $\mathrm{SnO}_{2}$ gas sensors

The modification of $\mathrm{SnO}_{2}$ with noble metal nanoparticles was determined to be very effective for analysis of VOCs compounds. In our research we utilized $\mathrm{Au}, \mathrm{Pt}$ and $\mathrm{Pd}$ monometallic nanoparticles to enhance the sensing performance of pure $\mathrm{SnO}_{2}$ based on advanced catalytic and electrical properties of noble nanoparticles. Furthermore, sensing materials based on $\mathrm{SnO}_{2}$ and bimetal nanostructure such as $\mathrm{Au} / \mathrm{Pd}$ were heavily investigated. 
According to the conduction mechanism theory of bare $\mathrm{SnO}_{2}$, the response of $\mathrm{MOX}$ gas sensors can be significantly improved by increasing the concentration of active oxygen ions $\left(\mathrm{O}^{-}, \mathrm{O}^{2-}\right)$ at the surface. Based on the results from our experiments, small additives of noble metal ( $\mathrm{Au}, \mathrm{Pd}$, and $\mathrm{Pt}$ ) nanoparticles to $\mathrm{SnO}_{2}$, substantially increase the response of the $\mathrm{SnO}_{2}$ modified sensors to low concentrations of BTEX components. The enhanced performance of $\mathrm{SnO}_{2}$ gas sensor modified with gold nanoparticles was previously reported by other research groups $[127,225]$. The advanced gas sensitivity of the Au-doped $\mathrm{SnO}_{2}$ is mainly related to the outstanding catalytic properties of Au nanoclusters. For example, low temperature oxidation of benzene and toluene over 5-10 $\mathrm{nm}$ gold nanoparticles suspended at different catalyst support was previously shown [226, 227]. However, deep understanding of the sensing mechanism of the Au-doped $\mathrm{SnO}_{2}$ is necessary to explain the advanced properties of the sensing material. An important work on explanation of the sensing mechanism of Au-doped $\mathrm{SnO}_{2}$ gas sensors was done by Hubner et. al. [228]. In this work, the simultaneous measurement of DC resistance and the work function of $\mathrm{SnO}_{2}$ and $\mathrm{Au}$-doped $\mathrm{SnO}_{2}$ in inert gas environment $\left(\mathrm{N}_{2}\right)$ showed that gold nanoclusters have no noticeable impact on the bulk or surface electronic properties of $\mathrm{SnO}_{2}$ nanocrystals. The absence of upper band bending in $\mathrm{SnO}_{2}$ nanocrystals, means that no electron trapping by $\mathrm{Au}$ nanoclusters is present. Conversely, the higher base line resistance of $\mathrm{Au}$-doped $\mathrm{SnO}_{2}$ sensor in the oxygen reach atmosphere and significantly higher sensor's response to reductive gases may lead one to the conclusion that "chemical" type of gas sensitization (Figure 3.31a) is predominant in the case of $\mathrm{Au}$ nanoclusters. In this case, the major function of the gold nanoclusters is assigned to the "spillover effect". The theoretical background of the "spillover effect" is based on the proposed idea that the special role of 
electronically independent and catalytically active metal clusters attributes to gas activation and dissociation function follow by adsorption on the main oxide. For example, the special role of $\mathrm{Au}$ nanoclusters is to enrich the surface of $\mathrm{SnO}_{2}$ with oxygen ions under ambient clean air conditions and dissociate or activate the detectable gas molecules prior the reaction at the $\mathrm{SnO}_{2}$ surface. Absence of the common Fermi level between the gold nanoparticles and the $\mathrm{SnO}_{2}$ nanocrystals makes it difficult to monitor the direct chemical reaction on the surface of gold nanoclusters and convert it to the electrical signal. The change in the sensing layer conductivity during the catalytic reaction between the detectable gases and the ionized oxygen is mainly attributed to the charge transfer from the surface of MOX back to the bulk and decrease the depletion region of $\mathrm{SnO}_{2}$ nanocrystals. As a result of high catalytic activity of Au nanoclusters and the "spill-over effect", the optimal operational temperature of Au-doped $\mathrm{SnO}_{2}$ sensors for detection BTEX components was slightly decreased compared to the $\mathrm{SnO}_{2}$ sensor.

The conduction mechanism of $\mathrm{Pt}$ and $\mathrm{Pd}$-doped $\mathrm{SnO}_{2}$ samples was determined to be different from Au-doped $\mathrm{SnO}_{2}$. Both, $\mathrm{Pt}$ and $\mathrm{Pd}$ doped samples exhibited much higher based line resistance in the ambient air and in nitrogen compared to the Au-doped $\mathrm{SnO}_{2}$ sensors. An additional, resistance inside the sensing layer was built due to nano-Schotky contact between the $\mathrm{SnO}_{2}$ crystals and the metal ( $\mathrm{Pt}$ and $\mathrm{Pd}$ ) nanoparticles, which is not related to the oxygen ionosorption. As a result of the nano-Schotky contacts and transfer conduction electrons from $\mathrm{SnO}_{2}$ to the $\mathrm{Pd}$ and $\mathrm{Pt}$ nanoparticles, the depletion region of the $\mathrm{SnO}_{2}$ grains increase and the total conductance of the sensing layer drops. Hubner et al. [229] also performed important work on the investigation of the sensing mechanism of Pt and Pd-doped $\mathrm{SnO}_{2}$ where simultaneous measurements of the sensing layer resistance and 
its work function $(\phi)$, under different ambient conditions. These measurements exhibited significant surface band bending for Pd-doped $\mathrm{SnO} 2$ and slightly less change in the surface energy banding of Pt-doped $\mathrm{SnO}_{2}$ in pure nitrogen wherein there is an absence of oxidized gas species. Based on our experiments with $\mathrm{Au}, \mathrm{Pt}$, and $\mathrm{Pd}$-doped $\mathrm{SnO}_{2}$ in pure nitrogen and ambient air under different temperature conditions and the results obtained by Hubner [228, 229], one can conclude that the conduction mechanism in $\mathrm{Pt}$ and $\mathrm{Pd}$-doped $\mathrm{SnO} 2$ sensor is different from "chemical" sensitization mechanism of Au-doped $\mathrm{SnO}_{2}$. It was also shown that the "spillover effect" on the surface of Pt and Pd clusters is less pronounce compared to the Au nanoclusters [230-232]. High surface oxidation in combination with lower oxygen mobility at the surface of Pd and Pt clusters are the main factors that limiting the "spillover effect" compared to the gold nanoclusters. Poor "spillover effect" produced by Pd and Pt nanoclusters on one side and common Fermi level position between Pd or Pt nanoparticles and the tin oxide nanocrystals on another, leads to the conclusion that "electronic type" of gas sensitization is dominating in a case of $\mathrm{Pd}$ and $\mathrm{Pt}$-doped $\mathrm{SnO}_{2}$. The "electronic type" (Fermi-level control) of gas sensitization mechanism is based on the reversible transfer of free charge carriers in and out of electrochemical/stoichiometric state inside the Pt or Pd metal nanoclusters upon exposure to oxidizing or reductive gases, which affects the overall Fermi level position and change the conductivity of the sensor (Figure 3.31b). Common Fermi level position between the metal nanoclusters and the MOX in combination with high catalytically active surface of noble metals improved the sensitivity of the $\mathrm{Pd}$ and $\mathrm{Pt}$-modified $\mathrm{SnO}_{2}$ and reduced the activation temperature of the nanocomposite material for detection of common VOCs compounds. 
(a)

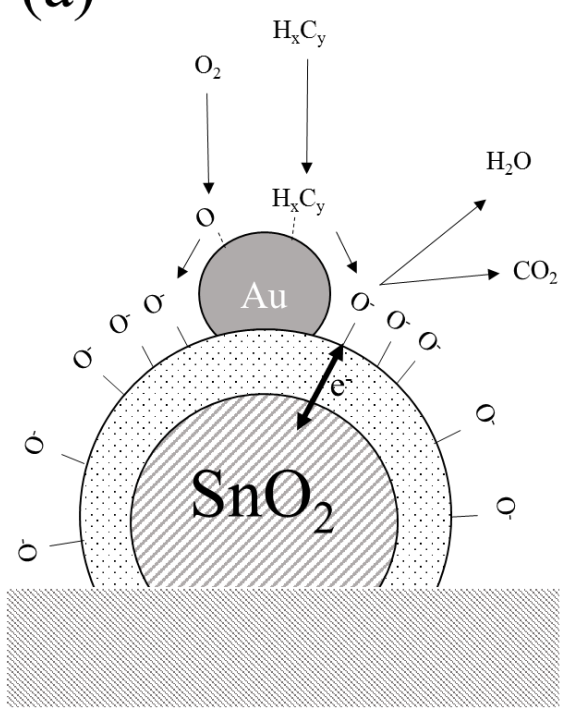

(b)

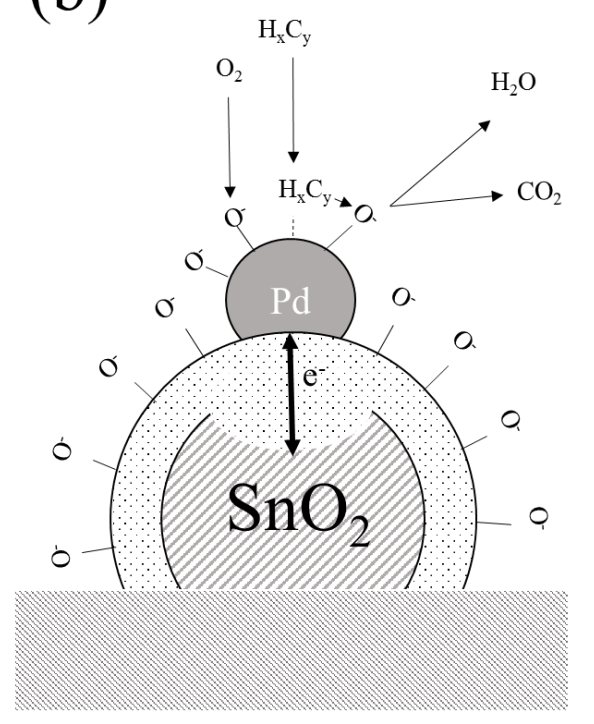

$\mathrm{Au}, \mathrm{Pd}$ nanoparticles $\mathrm{SnO}_{2}$ surface depletion region

$\mathrm{SnO}_{2}$ bulk $\mathrm{SiO}_{2}$ support

Figure 3.31 A schematic diagram of the gas sensing mechanism of polycrystalline $\mathrm{SnO}_{2}$ functionalized with (a) gold nanoparticles with the primarily chemical (spill-over) type of sensitization, and (b) palladium nanoparticles with the primarily electric (Fermi level) sensitization type.

The effect of mono-metal nanoparticles was determined to be have significant impact on the sensor performance. At the same time, it was shown that different metal doping (Au vs. Pd) might have different effect on conductivity of the main oxide $\left(\mathrm{SnO}_{2}\right)$ and sensing mechanism. In our work we developed a novel $\mathrm{SnO} 2$ gas sensors based on $\mathrm{Au} / \mathrm{Pd}$ bimetal nanoparticles by combining the best theories and observations reported by different research groups over the years. In the proposed design, the main function of the ultrathin $(30 \mathrm{~nm})$ tin oxide layer is to be a catalyst support material for bimetal nanoparticles that can be easily depleted or enriched with free carriers from gas species or from the bimetal nanoparticles and provide the electrical signal based on the ambient air conditions. The catalytic activity of pure $\mathrm{SnO}_{2}$ crystals (far from the metal-semiconductor junction) is its secondary function, based on much higher catalytic activity of noble metal nanoparticles under low activation temperature $\left(200^{\circ} \mathrm{C}\right)$. The performance of $\mathrm{SnO}_{2}$ layer functionalized 
with monometallic nanoparticles was determined to have its natural limitations due to the specific properties of the metals (Au or Pd). Pure gold nanoparticles have extremely high catalytic and dissociative activity that allowed to enrich the surface of $\mathrm{SnO}_{2}$ around the metal clusters with activated oxidizing or reductive gas species and as a result of that, amplified the catalytic reaction at the surface of $\mathrm{SnO}_{2}$ nanocrystals. However, the formation of metal-semiconductor junction between the gold nanoparticles and the $\mathrm{SnO}_{2}$ crystals was not been observed. In contrast to the Au metal clusters, the Pd nanoparticles create an excellent electronic junction with $\mathrm{SnO}_{2}$ nanocrystals which is very important for efficient charge transfer between the surface of Pd or Pt metal nanoparticles and the bulk of the MOX. However, Pt and Pd nanoparticles are less efficient in terms of mobile oxygen dissociation and gas spillover effect.

Synthesis of bi-metal nanoparticles combining the best characteristics of both metals including small particle size, thermal and mechanical stability, catalytically active surface and electronic exchange between the metal nanoparticles and the MOX layer is the one of the original ideas in this work. In particular, $\mathrm{Au} / \mathrm{Pd}$ bi-metal nanoparticles were synthesize to improve the catalytic (chemical) activity of metal nanoclusters, and provide stable electronic interaction between $\mathrm{Au} / \mathrm{Pd}$ nanoparticles and the support layer (Figure 3.32). 


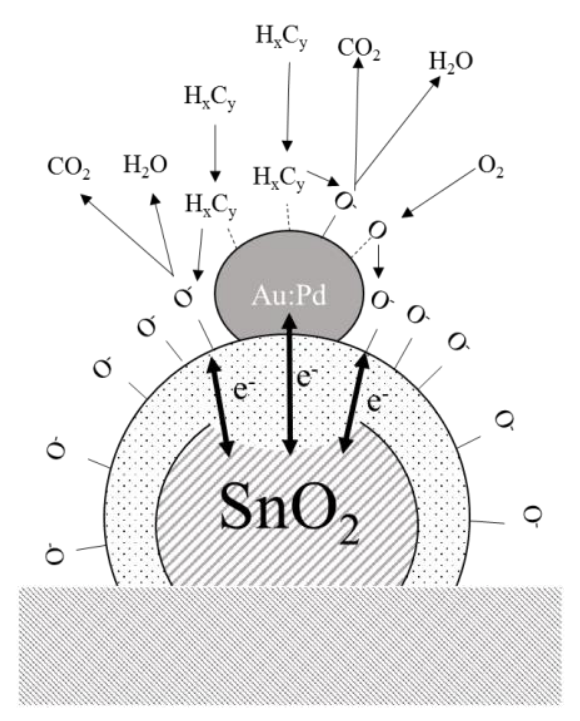

$\mathrm{Au} / \mathrm{Pd}$ nanoparticles

$\mathrm{SnO}_{2}$ surface depletion region

$\mathrm{SnO}_{2}$ bulk

$\mathrm{SiO}_{2}$ support

Figure 3.32 A schematic diagram of the gas sensing mechanism of polycrystalline $\mathrm{SnO}_{2}$ functionalized with bimetal nanoparticles with a hybrid sensitization type, when spill-over and electric mechanisms complement and amplify each other.

The catalytic activity of $\mathrm{Au} / \mathrm{Pd}$ of bimetal nanoparticles, according to the recent reports is extremely sensitive to the molar ratio of the two metals. Silva et. al. [131] reports that the bimetal $\mathrm{Au} / \mathrm{Pd}$ nanoparticles exhibited their maximum performance for oxidation of alcohols when the molar ratio of palladium in gold was equals 1:10. Silva's group proposed that the key to increased catalytic activity of the $\mathrm{Au} / \mathrm{Pd}$ nanoparticles derives from the balance between the number of active sites and the ease of product desorption. Based on DFT calculations conducted by Silva et. al., both parameters are extremely sensitive to the Pd content. It was shown that a composition of $\mathrm{Au}: \mathrm{Pd}(10: 1)$ corresponds to the amount of Pd necessary to cover the existing Au cores with a monolayer of Pd as a full-shell cluster. Another work which displayed the high catalytic activity of Au:Pd nanoparticles with the molar ratio of 9:1 was performed by Wang et. al. [233] for selective oxidation of glycerol to glyceric acid. Based on the experimental evidence and theoretical calculations, the high catalytic activity of the Au:Pd nanoparticles with a molar ratio of 9:1 
toward BTEX components can be justified. In order to support dual type ("chemical" and “electronic") of gas sensitization mechanism by $\mathrm{Au} / \mathrm{Pd} @ \mathrm{SnO}_{2}$, more experimental evidence is needed based on real time simultaneous measurements of the sensor's work function and corresponding conductivity change at different ambient conditions. Based on our phenomenological data of the sensors response in oxygen free environment and under zero grade air $\mathrm{Au} / \mathrm{Pd} @ \mathrm{SnO}_{2}$ we strongly believe that both types "chemical" and "electronic" are present. 


\section{CHAPTER 4: SUMMARY AND OUTLOOK}

The overview of gas analytical instrumentation for quantitative and qualitative gas mixture analysis was presented in this work. The increasing demand on portable gas analytical instrumentation was supported by the data from recent reports on gas analysis. The comparative analysis of different gas sensors and detectors based on different physical principles confirmed the strengths of MOX sensors. In this work we presented a novel method for gas mixture analysis based on portable gas chromatography and highly integrated multi-sensor MOX detector. High performance of the portable gas analyzer for selective detection of specific gasses inside complex gas mixtures was demonstrated. Furthermore, the advantage of gas mixture analysis with highly integrated multi-sensor MOX detector was shown in comparison to a single, non-selective, commercial MOX detector.

The analysis of gas sensing performance of nanocomposite thin films based on $\mathrm{SnO}_{2}$ including $\mathrm{TiO}_{2}-\mathrm{SnO}_{2}, \mathrm{Pt} @ \mathrm{SnO}_{2}, \quad \mathrm{Pd} @ \mathrm{SnO}_{2}, \quad \mathrm{Au} @ \mathrm{SnO}_{2}$, and $\mathrm{Au} / \mathrm{Pd} @ \mathrm{SnO}_{2}$ demonstrated the ability of MOX sensors to be utilized in gas analytical instrumentations providing both: high sensitivity down to sub-ppb level and high stability over an extensive period of time. A promising result for detection of common VOC compounds was obtained by using thin $\mathrm{SnO}_{2}$ films modified with noble metal nanoparticles such as $\mathrm{Au}, \mathrm{Pt}$, and $\mathrm{Pd}$. At the same time, the outstanding gas sensing performance of $\mathrm{SnO}_{2}$ modified with bimetal Au:Pd (9:1) nanoclusters was closely investigated in this work. High thermal stability, excellent catalytic activity, and electronic interconnection between the bimetal nanocluster 
and the main oxide layer makes the Au:Pd bimetal nanostructure extremely useful for detection of very small concentrations of VOCs. Also, by controlling content of palladium in gold, it is conceivable to "tune" the selectivity of bi-metal nanoclusters to specific chemical reactions and thus to specific gases.

The outlook on the sensing technology based on $\mathrm{SnO}_{2}$ nanocomposite materials looks very promising. The performance of $\mathrm{SnO}_{2}$ modified with other bi-metal nanoclusters such as $\mathrm{Pt}-\mathrm{Au}, \mathrm{Cu}-\mathrm{Au}, \mathrm{Ag}-\mathrm{Au}$ needs investigation. Also, the synthesis of tri-metal nanoparticles is a goal for the future research.

The study of novel materials with unknown properties requires more preparation in order to collect reliable experimental data. It is important to note, that novel nanocomposite gas sensors cannot be studied separately from the actual device. It was observed that, the effect of electrical contacts, different insulating and support materials, temperature profile, sensing layer synthesis and transfer procedure have a big impact on the final properties of micro and nanoscale devices. 


\section{REFERENCES}

1. Mullen, P.W., Modern gas analysis. Interscience manuals, 6. 1955, New York: Interscience Publishers.

2. Mandayo, G.G., et al., System to control indoor air quality in energy efficient buildings. Urban Climate, 2015. 14: p. 475-485.

3. National Institute for Occupational, S., Health, and H. United States. Public Health Service. Division of Occupational, The industrial environment--its evaluation \& control. [3d ed.]. ed. 1973, Washington;: for sale by the Supt. of Docs., U.S. Govt. Print. Off.

4. Bielecki, Z., et al., Sensors and Systems for the Detection of Explosive Devices An Overview, in Metrology and Measurement Systems. 2012. p. 3.

5. Miekisch, W., J.K. Schubert, and G.F.E. Noeldge-Schomburg, Diagnostic potential of breath analysis - focus on volatile organic compounds. Clinica Chimica Acta, 2004. 347(1): p. 25-39.

6. Megson, D., et al., A review of the determination of persistent organic pollutants for environmental forensics investigations. Analytica Chimica Acta, 2016. 941(7): p. 10-25.

7. Brown, A.S., et al., Analysis of natural gas by gas chromatography. Journal of Chromatography A, 2004. 1040(2): p. 215-225.

8. Handbook of environmental analysis: chemical pollutants in air, water, soil, and solid wastes. Choice Reviews Online, 1997. 35(02): p. 35-0932.

9. Brattoli, M., et al., Gas Chromatography Analysis with Olfactometric Detection (GC-O) as a Useful Methodology for Chemical Characterization of Odorous Compounds. Sensors (Basel, Switzerland), 2013. 13(12): p. 16759-16800.

10. Funazaki, N., et al., Application of semiconductor gas sensor to quality control of meat freshness in food industry. Sensors \& Actuators: B. Chemical, 1995. 25(1): p. 797-800.

11. Quantitative gas chromotography for laboratory analyses and on-line process control :by G. Guiochon and C.L. Guillemin, Elsevier, Amsterdam, Oxford, New York, Tokyo, 1988, XII + 793 pp., price Dfl. 315.00 US\$ 165.75, ISBN 0-44442857-7. Journal of Chromatography A, 1988. 455: p. 445-445.

12. Arnold, P. and K.B. Floor. Integrating process gas analysis and production control. in IEEE-IAS/PCA 2001 Cement Industry Technical Conference. Conference Record (Cat. No.01CH37150). 2001.

13. Shabtai, Y. and C. Mandel, Control of ethanol production and monitoring of membrane performance by mass-spectrometric gas analysis in the coupled fermentation-pervaporation of whey permeate. Applied Microbiology and Biotechnology, 1993. 40(4): p. 470-476.

14. Sacher, F., S. Lenz, and H.-J. Brauch, Analysis of primary and secondary aliphatic amines in waste water and surface water by gas chromatography-mass spectrometry after derivatization with 2,4-dinitrofluorobenzene or benzenesulfonyl chloride. Journal of Chromatography A, 1997. 764(1): p. 85-93.

15. Pijolat, C., et al., Gas detection for automotive pollution control. Sensors \& Actuators: B. Chemical, 1999. 59(2): p. 195-202. 
16. Frost\&Sullivan, Analysis of the Global Gas Sensors, Detectors, and Analyzers Market, NF77-33, Editor. 2015.

17. Baker, C., W. Laminack, and J.L. Gole, Sensitive and selective detection of H2S and application in the presence of toluene, benzene, and xylene. Sensors and Actuators B: Chemical, 2015. 212(Suppl. 17): p. 28-34.

18. Panda, D., et al., Selective detection of carbon monoxide (CO) gas by reduced graphene oxide (rGO) at room temperature. RSC Adv., 2016. 6(53): p. 4733747348.

19. Sekhar, P.K. and F. Wignes, Trace detection of research department explosive (RDX) using electrochemical gas sensor. Sensors \& Actuators: B. Chemical, 2016. 227: p. 185-190.

20. Hong, H.S., et al., Suppression of $\mathrm{NO}$ and SO2 cross-sensitivity in electrochemical CO2 sensors with filter layers. Sensors \& Actuators: B. Chemical, 2006. 113(1): p. 71-79.

21. Razali, M., et al., Simulation and measurement of carbon dioxide exhaust emissions using an optical-fibre-based mid-infrared point sensor. Journal of Optics A: Pure and Applied Optics, 2009. 11(5).

22. Eckenrode, B.A., Environmental and Forensic applications of field-portable GCMS: An overview. Journal of the American Society for Mass Spectrometry, 2001. 12(6): p. 683-693.

23. Wright, R.S., G.B. Howe, and R.K. Jayanty, Evaluation of a Portable Fourier Transform Infrared Gas Analyzer for Measurements of Air Toxics in Pollution Prevention Research. Journal of the Air \& Waste Management Association (1995), 1998. 48(11): p. 1077-1084.

24. Gałuszka, A., Z.M. Migaszewski, and J. Namieśnik, Moving your laboratories to the field - Advantages and limitations of the use of field portable instruments in environmental sample analysis. Environmental Research, 2015. 140: p. 593-603.

25. Lenz, C., et al., Development and Characterization of a Miniaturized Flame Ionization Detector in Ceramic Multilayer Technology for Field Applications. Procedia Engineering, 2016. 168: p. 1378-1381.

26. Nasreddine, R., et al., Development of a novel portable miniaturized GC for near real-time low level detection of BTEX. Sensors and Actuators B: Chemical, 2016. 224: p. 159-169.

27. Garg, A., et al., Zebra GC: A mini gas chromatography system for trace-level determination of hazardous air pollutants. Sensors \& Actuators: B. Chemical, 2015. 212: p. 145-154.

28. Meciarova, L., et al., Measurement of VOCs with a portable GC/SAW detector. Chemical Engineering Transactions, 2014. 40(Special Issue): p. 283-288.

29. Iglesias, R.A., et al., Hybrid separation and detection device for analysis of benzene, toluene, ethylbenzene, and xylenes in complex samples. Analytical chemistry, 2009. 81(21): p. 8930-5.

30. Zampolli, S., et al., Real-time monitoring of sub-ppb concentrations of aromatic volatiles with a MEMS-enabled miniaturized gas-chromatograph. Sensors \& Actuators: B. Chemical, 2009. 141(1): p. 322-328. 
31. Korotcenkov, G. and B.K. Cho, Metal oxide composites in conductometric gas sensors: Achievements and challenges. Sensors \& Actuators: B. Chemical, 2017. 244: p. 182-210.

32. Yamazoe, N., Y. Kurokawa, and T. Seiyama, Effects of additives on semiconductor gas sensors. Sensors and Actuators, 1983. 4: p. 283-289.

33. Rumyantseva, M. and A. Gas'kov, Chemical modification of nanocrystalline metal oxides: effect of the real structure and surface chemistry on the sensor properties. Russian Chemical Bulletin, 2008. 57(6): p. 1106-1125.

34. Wan, Q. and T. Wang, Single-crystalline Sb-doped SnO 2 nanowires: synthesis and gas sensor application. Chemical Communications, 2005(30): p. 3841-3843.

35. Korotcenkov, G., V. Brinzari, and B. Cho, In2O3-and SnO2-Based Thin Film Ozone Sensors: Fundamentals. Journal of Sensors, 2016. 2016.

36. Ishihara, T. and S. Matsubara, Capacitive Type Gas Sensors. Journal of Electroceramics, 1998. 2(4): p. 215-228.

37. Zamani, C., K. Shimanoe, and N. Yamazoe, Capacitive-type gas sensors combining silicon semiconductor and NaNO2-based solid electrolyte for $\mathrm{NO} 2$ detection. Sensors and Actuators B: Chemical, 2005. 109(2): p. 300-306.

38. Park, C.O., et al., Solid-state electrochemical gas sensors. Ionics, 2009. 15(3): p. 261-284.

39. Möbius, H.-H. and R. Hartung, Solid-state potentiometric gas sensors-a supplement. Journal of Solid State Electrochemistry, 2010. 14(4): p. 669-673.

40. Pasierb, P. and M. Rekas, Solid-state potentiometric gas sensors-current status and future trends. Journal of Solid State Electrochemistry, 2009. 13(1): p. 3-25.

41. Stetter, J.R. and L. Jing, Amperometric Gas Sensors-A Review. Chemical Reviews, 2008. 108(2).

42. Xiong, L. and R.G. Compton, Amperometric gas detection: A review. International Journal of Electrochemical Science, 2014. 9(12): p. 7152-7181.

43. Jane, H. and P.T. Ralph, Optical gas sensing: a review. Measurement Science and Technology, 2013. 24(1): p. 012004.

44. Eguchi, K., Optical Gas Sensors, in Gas Sensors: Principles, Operation and Developments, G. Sberveglieri, Editor. 1992, Springer Netherlands: Dordrecht. p. 307-328.

45. Kuang, S., et al., Differential Absorption Lidar to measure subhourly variation of tropospheric ozone profiles. IEEE Transactions on Geoscience and Remote Sensing, 2011. 49(1 PART 2): p. 557-571.

46. Refaat, T.F., et al., Backscatter 2-\{m Lidar Validation for Atmospheric \{CO 2 Differential Absorption Lidar Applications. IEEE Transactions on Geoscience and Remote Sensing, 2011. 49(1).

47. Yi, W., et al. Measurement of CH4 by differential infrared optical absorption spectroscopy. in 2009 9th International Conference on Electronic Measurement \& Instruments. 2009.

48. Miya, H., et al., Compact Raman lidar for hydrogen gas leak detection. Pacific Rim Conference on Lasers and Electro-Optics, CLEO - Technical Digest, 2009.

49. Lawrence Livermore National, L., et al., Photonic MEMS for NIR in-situ. 2007, United States. Dept. of Energy ; 
Distributed by the Office of Scientific and Technical Information, U.S. Dept. of Energy: Washington, D.C. :

Oak Ridge, Tenn. :

50. Liu, K., et al., Investigation of wavelength modulation and wavelength sweep techniques in intracavity fiber laser for gas detection. Journal of Lightwave Technology, 2011. 29(1): p. 15-21.

51. Liu, K., et al., Wavelength Sweep of Intracavity Fiber Laser for Low Concentration Gas Detection. IEEE Photonics Technology Letters, 2008. 20(18): p. $1515-1517$.

52. McNaghten, E.D., et al., Detection of trace concentrations of helium and argon in gas mixtures by laser-induced breakdown spectroscopy. Spectrochimica Acta Part B: Atomic Spectroscopy, 2009. 64(10): p. 1111-1118.

53. Rubio, R., et al., Non-selective NDIR array for gas detection. Sensors \& Actuators: B. Chemical, 2007. 127(1): p. 69-73.

54. Verner, P., Photoionization detection and its application in gas chromatography. Journal of Chromatography A, 1984. 300: p. 249-264.

55. Zhang, L., et al., Recent Progress in Chemiluminescence for Gas Analysis. Applied Spectroscopy Reviews, 2010. 45(6): p. 474-489.

56. Cheeke, J.D.N. and Z. Wang, Acoustic wave gas sensors. Sensors \& Actuators: B. Chemical, 1999. 59(2): p. 146-153.

57. Hök, B., A. Blückert, and J. Löfving, Acoustic gas sensor with ppm resolution. Sensor Review, 2000. 20(2): p. 139.

58. Petculescu, A., et al., A prototype acoustic gas sensor based on attenuation. Journal of the Acoustical Society of America, 2006. 120(4).

59. Granstedt, F., et al., Modelling of an electroacoustic gas sensor. Sensors \& Actuators: B. Chemical, 2005. 104(2): p. 308-311.

60. Nawaz, F. and V. Jeoti, SAW sensor read range limitations and perspectives. Wireless Networks : The Journal of Mobile Communication, Computation and Information, 2014. 20(8): p. 2581-2587.

61. Ralib, A.A.M., et al., Piezoelectric thin films for double electrode CMOS MEMS surface acoustic wave (SAW) resonator. Microsystem Technologies : Micro- and NanosystemsInformation Storage and Processing Systems, 2015. 21(9): p. 19311940.

62. Feng, L., et al., Colorimetric sensor array for determination and identification of toxic industrial chemicals. Analytical chemistry, 2010. 82(22): p. 9433-9440.

63. Janzen, M.C., et al., Colorimetric sensor arrays for volatile organic compounds. Analytical chemistry, 2006. 78(11): p. 3591-3600.

64. Caucheteur, C., et al., Catalytic fiber Bragg grating sensor for hydrogen leak detection in air. IEEE Photonics Technology Letters, 2008. 20(2): p. 96-98.

65. Tardy, P., et al., Dynamic thermal conductivity sensor for gas detection. Sensors and Actuators B: Chemical, 2004. 98(1): p. 63-68.

66. Van Herwaarden, A. and P. Sarro, Thermal sensors based on the Seebeck effect. Sensors and Actuators, 1986. 10(3-4): p. 321-346.

67. Han, C.-H., et al., Synthesis of Pd or Pt/titanate nanotube and its application to catalytic type hydrogen gas sensor. Sensors and Actuators B: Chemical, 2007. 128(1): p. 320-325. 
68. Yamazoe, N., G. Sakai, and K. Shimanoe, Oxide semiconductor gas sensors. Catalysis Surveys from Asia, 2003. 7(1): p. 63-75.

69. Yamazoe, N., New approaches for improving semiconductor gas sensors. Sensors and Actuators B: Chemical, 1991. 5(1-4): p. 7-19.

70. Morrison, S.R., Semiconductor gas sensors. Sensors and Actuators, 1981. 2: p. 329-341.

71. Neri, G., First fifty years of chemoresistive gas sensors. Chemosensors, 2015. 3(1): p. 1-20.

72. Fine, G.F., et al., Metal oxide semi-conductor gas sensors in environmental monitoring. Sensors, 2010. 10(6): p. 5469-5502.

73. Capone, S., et al., Solid state gas sensors: state of the art and future activities. Journal of Optoelectronics and Advanced Materials, 2003. 5(5): p. 1335-1348.

74. Wolkenstein, T., Electronic processes on semiconductor surfaces during chemisorption. 2012: Springer Science \& Business Media.

75. Rhoderick, E.H., Metal-semiconductor contacts. Monographs in electrical and electronic engineering; Monographs in electrical and electronic engineering. 1978, Oxford :: Clarendon Press.

76. Sze, S.M., Physics of semiconductor devices. 2nd ed. ed. 1981, New York :: Wiley.

77. Assaid, E.M., et al. Finite difference numerical solution of Poisson equation in a Schottky barrier diode using maple. in Faible Tension Faible Consommation (FTFC), 2011. 2011. IEEE.

78. John, D., et al., Electrostatics of coaxial Schottky-barrier nanotube field-effect transistors. IEEE Transactions on Nanotechnology, 2003. 2(3): p. 175-180.

79. Malagu, C., et al., Model for Schottky barrier and surface states in nanostructured n-type semiconductors. Journal of Applied Physics, 2002. 91(2): p. 808-814.

80. Barsan, N. and U. Weimar, Conduction model of metal oxide gas sensors. Journal of Electroceramics, 2001. 7(3): p. 143-167.

81. Korotcenkov, G., Metal oxides for solid-state gas sensors: What determines our choice? Materials Science and Engineering: B, 2007. 139(1): p. 1-23.

82. Wang, C., et al., Metal oxide gas sensors: sensitivity and influencing factors. Sensors, 2010. 10(3): p. 2088-2106.

83. Barsan, N., M. Schweizer-Berberich, and W. Göpel, Fundamental and practical aspects in the design of nanoscaled $\mathrm{SnO} 2$ gas sensors: a status report. Fresenius' journal of analytical chemistry, 1999. 365(4): p. 287-304.

84. Fioravanti, A., et al. Enhanced Gas Sensing Properties of Different ZnO 3D Hierarchical Structures. in Advances in Science and Technology. 2017. Trans Tech Publ.

85. Deng, S., et al., A highly sensitive VOC gas sensor using p-type mesoporous Co 3 $O 4$ nanosheets prepared by a facile chemical coprecipitation method. Sensors and Actuators B: Chemical, 2016. 233: p. 615-623.

86. Šutka, A., et al., Orthorhombic CaFe 2 O 4: A promising p-type gas sensor. Sensors and Actuators B: Chemical, 2016. 224: p. 260-265. 
87. Lupan, O., et al., Single and networked $\mathrm{CuO}$ nanowires for highly sensitive p-type semiconductor gas sensor applications. physica status solidi (RRL)-Rapid Research Letters, 2016. 10(3): p. 260-266.

88. Barsan, N. and U. Weimar, Understanding the fundamental principles of metal oxide based gas sensors; the example of $\mathrm{CO}$ sensing with $\mathrm{SnO} 2$ sensors in the presence of humidity. Journal of Physics: Condensed Matter, 2003. 15(20): p. R813.

89. Dieguez, A., et al., Morphological analysis of nanocrystalline SnO2 for gas sensor applications. Sensors and Actuators B: Chemical, 1996. 31(1-2): p. 1-8.

90. Göpel, W. and K.D. Schierbaum, SnO2 sensors: current status and future prospects. Sensors and Actuators B: Chemical, 1995. 26(1-3): p. 1-12.

91. Sberveglieri, G., Classical and novel techniques for the preparation of $\mathrm{SnO} 2$ thinfilm gas sensors. Sensors and Actuators B: Chemical, 1992. 6(1-3): p. 239-247.

92. Das, S. and V. Jayaraman, SnO 2: a comprehensive review on structures and gas sensors. Progress in Materials Science, 2014. 66: p. 112-255.

93. Ulatowska, A., et al., Advantages of sol-gel technologies for biomedical applications. Optical and Imaging Techniques for Biomonitoring IV, 1999: p. 5058.

94. Rella, R., et al., Tin oxide-based gas sensors prepared by the sol-gel process. Sensors and Actuators B: Chemical, 1997. 44(1): p. 462-467.

95. Sung, J.-H., et al., Sensing characteristics of tin dioxide/gold sensor prepared by coprecipitation method. Sensors and Actuators B: Chemical, 2000. 66(1): p. 149152.

96. Gyger, F., et al., Nanoscale SnO2 hollow spheres and their application as a gassensing material. Chemistry of Materials, 2010. 22(16): p. 4821-4827.

97. Liu, Y., E. Koep, and M. Liu, A highly sensitive and fast-responding SnO2 sensor fabricated by combustion chemical vapor deposition. Chemistry of materials, 2005. 17(15): p. 3997-4000.

98. Kim, K.H. and C.G. Park, Electrical Properties and Gas-Sensing Behavior of $\mathrm{SnO} 2$ Films Prepared by Chemical Vapor Deposition. Journal of The Electrochemical Society, 1991. 138(8): p. 2408-2412.

99. Serrini, P., et al., Chemical composition and crystalline structure of SnO2 thin films used as gas sensors. Thin solid films, 1997. 304(1-2): p. 113-122.

100. Katti, V., et al., Mechanism of drifts in $\mathrm{H} 2 \mathrm{~S}$ sensing properties of $\mathrm{SnO} 2$ : $\mathrm{CuO}$ composite thin film sensors prepared by thermal evaporation. Sensors and Actuators B: Chemical, 2003. 96(1): p. 245-252.

101. Niinistö, L., et al., Advanced electronic and optoelectronic materials by Atomic Layer Deposition: An overview with special emphasis on recent progress in processing of high $-k$ dielectrics and other oxide materials. physica status solidi (a), 2004. 201(7): p. 1443-1452.

102. Wang, B., et al., Fabrication of a SnO2 nanowire gas sensor and sensor performance for hydrogen. The Journal of Physical Chemistry C, 2008. 112(17): p. 6643-6647.

103. Yang, D.J., et al., Ultrasensitive and highly selective gas sensors based on electrospun SnO2 nanofibers modified by Pd loading. Advanced Functional Materials, 2010. 20(24): p. 4258-4264. 
104. Choi, Y.-J., et al., Novel fabrication of an SnO2 nanowire gas sensor with high sensitivity. Nanotechnology, 2008. 19(9): p. 095508.

105. Ying, Z., et al., SnO2 nanowhiskers and their ethanol sensing characteristics. Nanotechnology, 2004. 15(11): p. 1682.

106. Tricoli, A., M. Graf, and S.E. Pratsinis, Optimal doping for enhanced SnO2 sensitivity and thermal stability. Advanced Functional Materials, 2008. 18(13): p. 1969-1976.

107. Korotcenkov, G. and S. Do Han, $(\mathrm{Cu}, \mathrm{Fe}$, Co, or Ni)-doped tin dioxide films deposited by spray pyrolysis: Doping influence on thermal stability of the film structure. Materials Chemistry and Physics, 2009. 113(2): p. 756-763.

108. $\mathrm{Xu}, \mathrm{C}$., et al., Promoting effects of additives on thermal stability of tin oxide (IV) fine particles. Journal of materials science letters, 1989. 8(9): p. 1092-1094.

109. Morimitsu, M., et al., Effects of surface modification with platinum and ruthenium on temperature and humidity dependence of $\mathrm{SnO}$ 2-based $\mathrm{CO}$ gas sensors. Sensors and Actuators B: Chemical, 2000. 67(1): p. 184-188.

110. Matsushima, S., et al., Electronic interaction between metal additives and tin dioxide in tin dioxide-based gas sensors. Japanese journal of applied physics, 1988. 27(10R): p. 1798.

111. Cuenya, B.R., Synthesis and catalytic properties of metal nanoparticles: Size, shape, support, composition, and oxidation state effects. Thin Solid Films, 2010. 518(12): p. 3127-3150.

112. Valden, M., X. Lai, and D.W. Goodman, Onset of catalytic activity of gold clusters on titania with the appearance of nonmetallic properties. science, 1998. 281(5383): p. 1647-1650.

113. Bell, A.T., The impact of nanoscience on heterogeneous catalysis. Science, 2003. 299(5613): p. 1688-1691.

114. Murdoch, M., et al., The effect of gold loading and particle size on photocatalytic hydrogen production from ethanol over Au/TiO2 nanoparticles. Nature Chemistry, 2011. 3(6): p. 489-492.

115. Haruta, M. and M. Daté, Advances in the catalysis of Au nanoparticles. Applied Catalysis A: General, 2001. 222(1): p. 427-437.

116. Najim, A.A., S.S. Shaker, and M.A. Muhi, Room temperature NO2 gas sensor based on SnO2-WO3 thin films. Plasmonics, 2017. 12(4): p. 1051-1055.

117. Tamaki, J., et al., $\mathrm{CuO}-\mathrm{SnO} 2$ element for highly sensitive and selective detection of H2S. Sensors and Actuators B: Chemical, 1992. 9(3): p. 197-203.

118. Khanna, A., R. Kumar, and S. Bhatti, CuO-doped $\mathrm{SnO} 2$ thin films as hydrogen sulfide gas sensor. Applied physics letters, 2003. 82(24): p. 4388-4390.

119. Verma, M.K. and V. Gupta, A highly sensitive SnO 2-CuO multilayered sensor structure for detection of H 2 S gas. Sensors and Actuators B: Chemical, 2012. 166: p. 378-385.

120. Reghu, A., et al., 5.3. 2 WO3 sensor for ppb detection of ammonia. Proceedings IMCS 2012, 2012: p. 457-460.

121. Tyagi, P., et al., SnO 2 thin film sensor having NiO catalyst for detection of SO 2 gas with improved response characteristics. Sensors and Actuators B: Chemical, 2017. 248: p. 998-1005. 
122. Chen, Y.-J., et al., Synthesis and enhanced ethanol sensing characteristics of $\alpha$ Fe2O3/SnO2 core-shell nanorods. Nanotechnology, 2008. 20(4): p. 045502.

123. Li, Y., et al., A high performance methanol gas sensor based on palladiumplatinum-In 2 O 3 composited nanocrystalline SnO 2. Sensors and Actuators B: Chemical, 2016. 237: p. 133-141.

124. Li, M., et al., Ultrasensitive and highly selective detection of methoxy propanol based on Ag-decorated SnO 2 hollow nanospheres. Sensors and Actuators B: Chemical, 2016. 232: p. 545-556.

125. Yu, J., et al., Study on RuO2/SnO2: novel and active catalysts for $\mathrm{CO}$ and $\mathrm{CH} 4$ oxidation. ChemCatChem, 2012. 4(8): p. 1122-1132.

126. Oliaee, S., et al., Highly selective Pt/SnO 2 sensor to propane or methane in presence of $\mathrm{CO}$ and ethanol, using gold nanoparticles on $\mathrm{Fe} 2 \mathrm{O} 3$ catalytic filter. Sensors and Actuators B: Chemical, 2010. 147(2): p. 400-405.

127. Kim, J.-H., et al., Highly selective sensing of CO, C6H6, and C7H8 gases by catalytic functionalization with metal nanoparticles. ACS applied materials \& interfaces, 2016. 8(11): p. 7173-7183.

128. Menini, P., et al., CO response of a nanostructured SnO 2 gas sensor doped with palladium and platinum. Sensors and Actuators B: Chemical, 2004. 103(1): p. 111-114.

129. Toshima, N. and T. Yonezawa, Bimetallic nanoparticles-novel materials for chemical and physical applications. New Journal of Chemistry, 1998. 22(11): p. 1179-1201.

130. Hou, W., N.A. Dehm, and R.W. Scott, Alcohol oxidations in aqueous solutions using $A u, P d$, and bimetallic AuPd nanoparticle catalysts. Journal of Catalysis, 2008. 253(1): p. 22-27.

131. Silva, T.A., et al., Volcano-like behavior of Au-Pd core-shell nanoparticles in the selective oxidation of alcohols. Scientific reports, 2014. 4.

132. Liu, X., et al., Synthesis of thermally stable and highly active bimetallic $\mathrm{Au}-\mathrm{Ag}$ nanoparticles on inert supports. Chemistry of Materials, 2008. 21(2): p. 410-418.

133. Huang, R., et al., Pt-Pd bimetallic catalysts: structural and thermal stabilities of core-shell and alloyed nanoparticles. The Journal of Physical Chemistry C, 2012. 116(15): p. 8664-8671.

134. Young, R.C., et al., Electronic nose for space program applications. Sensors and Actuators B: Chemical, 2003. 93(1): p. 7-16.

135. Sysoev, V.V., et al., Temperature gradient effect on gas discrimination power of a metal-oxide thin-film sensor microarray. Sensors, 2004. 4(4): p. 37-46.

136. Briand, D., et al., A low-power micromachined MOSFET gas sensor. Journal of microelectromechanical systems, 2000. 9(3): p. 303-308.

137. Steiner, F.-P., et al. Polymer coated capacitive microintegrated gas sensor. in Solid-State Sensors and Actuators, 1995 and Eurosensors IX.. Transducers' 95. The 8th International Conference on. 1995. IEEE.

138. Suehle, J.S., et al., Tin oxide gas sensor fabricated using CMOS micro-hotplates and in-situ processing. IEEE Electron Device Letters, 1993. 14(3): p. 118-120.

139. Savage, N.O., et al., Thermolithographic Patterning of Sol-Gel Metal Oxides on Micro Hot Plate Sensing Arrays Using Organosilanes. Analytical chemistry, 2003. 75(17): p. 4360-4367. 
140. Semancik, S., et al., Microhotplate platforms for chemical sensor research. Sensors and Actuators B: Chemical, 2001. 77(1): p. 579-591.

141. Chen, P.-C., G. Shen, and C. Zhou, Chemical sensors and electronic noses based on 1-D metal oxide nanostructures. IEEE Transactions on Nanotechnology, 2008. 7(6): p. 668-682.

142. Chen, P.-C., et al., A nanoelectronic nose: a hybrid nanowire/carbon nanotube sensor array with integrated micromachined hotplates for sensitive gas discrimination. Nanotechnology, 2009. 20(12): p. 125503.

143. MAX-R, R. and R. BASELINE, The Cyranose. Sensors, 2000.

144. Ryan, M.A. and M.L. Homer, JPL Electronic Nose. 2009.

145. Wilson, A.D. and M. Baietto, Applications and advances in electronic-nose technologies. Sensors, 2009. 9(7): p. 5099-5148.

146. Cuevas-Glory, L.F., et al., A review of volatile analytical methods for determining the botanical origin of honey. Food Chemistry, 2007. 103(3): p. 1032-1043.

147. Barrettino, D., et al., CMOS monolithic metal-oxide gas sensor microsystems. IEEE Sensors Journal, 2006. 6(2): p. 276-286.

148. Mo, Y., et al., Micro-machined gas sensor array based on metal film microheater. Sensors and Actuators B: Chemical, 2001. 79(2): p. 175-181.

149. Sheng, L.-y., et al., A low-power CMOS compatible integrated gas sensor using maskless tin oxide sputtering. Sensors and Actuators B: Chemical, 1998. 49(1): p. 81-87.

150. Zhou, Q., et al., Fast response integrated MEMS microheaters for ultra low power gas detection. Sensors and Actuators A: Physical, 2015. 223: p. 67-75.

151. Belmonte, J.C., et al., High-temperature low-power performing micromachined suspended micro-hotplate for gas sensing applications. Sensors and Actuators B: Chemical, 2006. 114(2): p. 826-835.

152. Chung, W.-Y., et al., Thermal and gas-sensing properties of planar-type micro gas sensor. Sensors and Actuators B: Chemical, 2000. 64(1): p. 118-123.

153. Andio, M.A., et al., Comparison of gas sensor performance of SnO 2 nanostructures on microhotplate platforms. Sensors and Actuators B: Chemical, 2012. 165(1): p. 13-18.

154. Vasiliev, A., et al., Non-silicon MEMS platforms for gas sensors. Sensors and Actuators B: Chemical, 2016. 224: p. 700-713.

155. Lombardi, A., et al., A CMOS integrated interface circuit for metal-oxide gas sensors. Sensors and Actuators B: Chemical, 2009. 142(1): p. 82-89.

156. Ferri, G., et al., A single-chip integrated interfacing circuit for wide-range resistive gas sensor arrays. Sensors and Actuators B: Chemical, 2009. 143(1): p. 218-225.

157. Tsamis, C., A. Nassiopoulou, and A. Tserepi, Thermal properties of suspended porous silicon micro-hotplates for sensor applications. Sensors and Actuators B: Chemical, 2003. 95(1): p. 78-82.

158. Aslam, M., C. Gregory, and J. Hatfield, Polyimide membrane for micro-heated gas sensor array. Sensors and Actuators B: Chemical, 2004. 103(1): p. 153-157.

159. Briand, D., et al., Micro-hotplates on polyimide for sensors and actuators. Sensors and Actuators A: Physical, 2006. 132(1): p. 317-324. 
160. Chen, L. and M. Mehregany. Exploring silicon carbide for thermal infrared radiators. in Sensors, 2007 IEEE. 2007. IEEE.

161. Das, N., et al. Low power polysilicon sources for IR applications. in Solid-State and Integrated Circuit Technology, 1998. Proceedings. 1998 5th International Conference on. 1998. IEEE.

162. Kimura, M. and K. Komatsuzaki, Microheater made of heavily boron doped single crystal silicon beam. MRS Online Proceedings Library Archive, 1992. 276.

163. Creemer, J., et al., Microhotplates with TiN heaters. Sensors and Actuators A: Physical, 2008. 148(2): p. 416-421.

164. Janesch, J., two-Wire vs. Four-Wire Resistance Measurements: Which Configuration Makes sense for Your Application? no. May, 2013: p. 2-4.

165. Reeves, G. and H. Harrison, Obtaining the specific contact resistance from transmission line model measurements. IEEE Electron device letters, 1982. 3(5): p. 111-113.

166. Monshi, A., M.R. Foroughi, and M.R. Monshi, Modified Scherrer equation to estimate more accurately nano-crystallite size using XRD. World Journal of Nano Science and Engineering, 2012. 2(3): p. 154-160.

167. Langford, J.I. and A. Wilson, Scherrer after sixty years: a survey and some new results in the determination of crystallite size. Journal of Applied Crystallography, 1978. 11(2): p. 102-113.

168. Viezbicke, B.D., et al., Evaluation of the Tauc method for optical absorption edge determination: ZnO thin films as a model system. physica status solidi (b), 2015. 252(8): p. 1700-1710.

169. Pankove, J.I., Optical processes in semiconductors. 2012: Courier Corporation.

170. Bueno, P.R., J.A. Varela, and E. Longo, $\mathrm{SnO} 2$, $\mathrm{ZnO}$ and related polycrystalline compound semiconductors: an overview and review on the voltage-dependent resistance (non-ohmic) feature. Journal of the European Ceramic Society, 2008. 28(3): p. 505-529.

171. Glot, A., A. Gaponov, and A. Sandoval-García, Electrical conduction in SnO 2 varistors. Physica B: Condensed Matter, 2010. 405(2): p. 705-711.

172. Pianaro, S., et al., A new SnO2-based varistor system. Journal of materials science letters, 1995. 14(10): p. 692-694.

173. Mei, L., Y. Chen, and J. Ma, Gas sensing of SnO2 nanocrystals revisited: developing ultra-sensitive sensors for detecting the H2S leakage of biogas. Scientific reports, 2014. 4.

174. Ma, J., et al., Room temperature ppb level H2S detection of a single Sb-doped SnO2 nanoribbon device. Sensors \& Actuators: B. Chemical, 2015. 216: p. 72-79.

175. Yoo, K.S., et al., Highly Sensitive H2S Sensor Based on the Metal-Catalyzed SnO2 Nanocolumns Fabricated by Glancing Angle Deposition. Sensors (Basel, Switzerland), 2015. 15(7): p. 15468-77.

176. Yang, T., et al., A pulse-driven sensor based on ordered mesoporous Ag2O/SnO2 with improved H2S-sensing performance. Sensors \& Actuators: B. Chemical, 2016. 228: p. 529-538.

177. Sun, H., et al., Fe/SnO2 Composite Sensors Prepared from Oxalate Precursors for the Detection of H2S. Journal of Dispersion Science and Technology, 2009. 31(1): p. 124-128. 
178. Liu, H., et al., Nanocrystalline In2O3-SnO2 thick films for low-temperature hydrogen sulfide detection. Ceramics International, 2011. 37(6): p. 1889-1894.

179. Fu, D., et al., Two-dimensional net-like SnO 2/ZnO heteronanostructures for high-performance H 2 S gas sensor. Journal of Materials Chemistry A, 2016. 4(4): p. 1390-1398.

180. Vasiliev, R., et al., $\mathrm{CuO} / \mathrm{SnO} 2$ thin film heterostructures as chemical sensors to $\mathrm{H}$ 2 S. Sensors and Actuators B: Chemical, 1998. 50(3): p. 186-193.

181. Patil, L. and D. Patil, Heterocontact type CuO-modified $\mathrm{SnO} 2$ sensor for the detection of a ppm level H $2 S$ gas at room temperature. Sensors and Actuators B: Chemical, 2006. 120(1): p. 316-323.

182. Chowdhuri, A., et al., Contribution of adsorbed oxygen and interfacial space charge for enhanced response of $\mathrm{SnO} 2$ sensors having $\mathrm{CuO}$ catalyst for $\mathrm{H} 2 \mathrm{~S}$ gas. Sensors and Actuators B: Chemical, 2010. 145(1): p. 155-166.

183. O'Dell, D., P. Schein, and D. Erickson, Simultaneous Characterization of Nanoparticle Size and Particle-Surface Interactions with Three-Dimensional Nanophotonic Force Microscopy. Physical Review Applied, 2016. 6(3).

184. Moshfegh, A.Z., Nanoparticle catalysts. Journal of Physics D: Applied Physics, 2009. 42(23).

185. Cao, A., R. Lu, and G. Veser, Stabilizing metal nanoparticles for heterogeneous catalysis. Physical Chemistry Chemical Physics, 2010. 12(41): p. 13499-13510.

186. Stranger, M., S. Potgieter-Vermaak, and R. Van Grieken, Characterization of indoor air quality in primary schools in Antwerp, Belgium. Indoor air, 2008. 18(6): p. 454-463.

187. Hulin, M., D. Caillaud, and I. Annesi-Maesano, Indoor air pollution and childhood asthma: variations between urban and rural areas. Indoor air, 2010. 20(6): p. 502-514.

188. Darlington, A.B., J.F. Dat, and M.A. Dixon, The biofiltration of indoor air: air flux and temperature influences the removal of toluene, ethylbenzene, and xylene. Environmental science \& technology, 2001. 35(1): p. 240-246.

189. Guo, H., et al., Source characterization of BTEX in indoor microenvironments in Hong Kong. Atmospheric Environment, 2003. 37(1): p. 73-82.

190. Reynolds, S.J., et al., Air quality assessments in the vicinity of swine production facilities. Journal of Agromedicine, 1997. 4(1-2): p. 37-45.

191. Godish, T., W.T. Davis, and J.S. Fu, Air quality. 2014: CRC Press.

192. Kidnay, A.J., W.R. Parrish, and D.G. McCartney, Fundamentals of natural gas processing. Vol. 218. 2011: CRC Press.

193. Al-Juaied, M. and W. Koros, Performance of natural gas membranes in the presence of heavy hydrocarbons. Journal of Membrane Science, 2006. 274(1): p. 227-243.

194. Papadias, D.D., S. Ahmed, and R. Kumar, Fuel quality issues with biogas energyAn economic analysis for a stationary fuel cell system. Energy, 2012. 44(1): p. 257-277.

195. Hill, D. and R. Binions, Breath Analysis for Medical Diagnosis. International Journal on Smart Sensing \& Intelligent Systems, 2012. 5(2).

196. Manolis, A., The diagnostic potential of breath analysis. Clinical chemistry, 1983. 29(1): p. 5-15. 
197. Dweik, R.A. and A. Amann, Exhaled breath analysis: the new frontier in medical testing. Journal of breath research, 2008. 2(3): p. 030301.

198. Peng, G., et al., Diagnosing lung cancer in exhaled breath using gold nanoparticles. Nature nanotechnology, 2009. 4(10): p. 669-673.

199. Phillips, M., et al., Breath biomarkers of active pulmonary tuberculosis. Tuberculosis, 2010. 90(2): p. 145-151.

200. Amorim, L.C.A. and Z.d.L. Cardeal, Breath air analysis and its use as a biomarker in biological monitoring of occupational and environmental exposure to chemical agents. Journal of Chromatography B, 2007. 853(1): p. 1-9.

201. Bârsan, N., M. Hübner, and U. Weimar, Conduction mechanisms in SnO 2 based polycrystalline thick film gas sensors exposed to $\mathrm{CO}$ and $\mathrm{H} 2$ in different oxygen backgrounds. Sensors and Actuators B: Chemical, 2011. 157(2): p. 510-517.

202. Lee, H.-C. and W.-S. Hwang, Substrate effects on the oxygen gas sensing properties of $\mathrm{SnO}$ 2/TiO 2 thin films. Applied Surface Science, 2006. 253(4): p. 1889-1897.

203. Chun, S.W., et al., Selective oxidation of H $2 \mathrm{~S}$ to elemental sulfur over $\mathrm{TiO} 2 / \mathrm{SiO}$ 2 catalysts. Applied Catalysis B: Environmental, 1998. 16(3): p. 235-243.

204. Rezaee, M., et al., Preparation and evaluation of new nanocatalysts for selective oxidation of $\mathrm{H} 2 \mathrm{~S}$ to sulfur. World Academy of Science, Engineering and Technology, 2012. 6: p. 621-626.

205. Shahzad, N., S.T. Hussain, and M.A. Baig, $H^{\wedge}$ sub $2^{\wedge} S$ EMISSIONS CONTROL IN INDUSTRIAL EXHAUSTS USING TIO^ sub $2^{\wedge}$ NANOPARTICLES. Academic Research International, 2011. 1(2): p. 70.

206. Zhang, X., et al., H2S-selective catalytic oxidation: catalysts and processes. ACS catalysis, 2015. 5(2): p. 1053-1067.

207. Tang, H., et al., Electrical and optical properties of TiO2 anatase thin films. Journal of applied physics, 1994. 75(4): p. 2042-2047.

208. Yildiz, A., et al., Electrical properties of TiO 2 thin films. Journal of NonCrystalline Solids, 2008. 354(45): p. 4944-4947.

209. Siedl, N., et al., Particle networks from powder mixtures: generation of TiO2$\mathrm{SnO} 2$ heterojunctions via surface charge-induced heteroaggregation. The Journal of Physical Chemistry C, 2012. 116(43): p. 22967-22973.

210. Varela, J.A., et al., Sintering of tin oxide and its applications in electronics and processing of high purity optical glasses. Cerâmica, 2001. 47(302): p. 117-123.

211. de Mendonça, V.R., et al., Heterostructure formation from hydrothermal annealing of preformed nanocrystals. Journal of Materials Chemistry A, 2015. 3(5): p. 2216-2225.

212. Scanlon, D.O., et al., Band alignment of rutile and anatase TiO2. Nature materials, 2013. 12(9): p. 798-801.

213. Dang, V.S., et al., Electrical and optical properties of TiO2 thin films prepared by plasma-enhanced atomic layer deposition. physica status solidi (a), 2014. 211(2): p. 416-424.

214. Bedja, I. and P.V. Kamat, Capped semiconductor colloids. Synthesis and photoelectrochemical behavior of TiO2 capped $\mathrm{SnO} 2$ nanocrystallites. The Journal of Physical Chemistry, 1995. 99(22): p. 9182-9188. 
215. Liu, G., et al., XPS and UPS characterization of the TiO2/ZnPcGly heterointerface: alignment of energy levels. The Journal of Physical Chemistry B, 2002. 106(23): p. 5814-5819.

216. Kwoka, M., L. Ottaviano, and J. Szuber, Photoemission studies of the surface electronic properties of L-CVD SnO 2 ultra thin films. Applied Surface Science, 2012. 258(21): p. 8425-8429.

217. Imanishi, A., E. Tsuji, and Y. Nakato, Dependence of the work function of TiO2 (Rutile) on crystal faces, studied by a scanning auger microprobe. The Journal of Physical Chemistry C, 2007. 111(5): p. 2128-2132.

218. Xiong, G., et al., Photoemission electron microscopy of TiO2 anatase films embedded with rutile nanocrystals. Advanced Functional Materials, 2007. 17(13): p. 2133-2138.

219. Li, H., et al., Characterization of Incidental Photon-to-electron Conversion Efficiency (IPCE) of porous $\mathrm{TiO} 2 / \mathrm{SnO} 2$ composite film. Journal of Alloys and Compounds, 2013. 569: p. 88-94.

220. Cahen, D., et al., Nature of photovoltaic action in dye-sensitized solar cells. The Journal of Physical Chemistry B, 2000. 104(9): p. 2053-2059.

221. Colinge, J.-P. and C.A. Colinge, Physics of semiconductor devices. 2005: Springer Science \& Business Media.

222. Floriano, E.A., et al., Preparation of TiO2/SnO2 Thin Films by Sol-Gel Method and Periodic B3LYP Simulations. The Journal of Physical Chemistry A, 2014. 118(31): p. 5857-5865.

223. Trakhtenberg, L., et al., Gas semiconducting sensors based on metal oxide nanocomposites. Journal of Materials Science Research, 2012. 1(2): p. 56.

224. Suchorska-Woźniak, P., et al., Analysis of SnO2| WO3 heterocontact properties during the detection of hydrogen sulphide. Sensors, 2014. 14(11): p. 2048020499.

225. Korotcenkov, G., et al., The influence of gold nanoparticles on the conductivity response of $\mathrm{SnO}$ 2-based thin film gas sensors. Applied Surface Science, 2015. 353: p. 793-803.

226. Chlala, D., et al., Toluene total oxidation over Pd and Au nanoparticles supported on hydroxyapatite. Comptes Rendus Chimie, 2016. 19(4): p. 525-537.

227. Tabakova, T., et al., Complete benzene oxidation over mono and bimetallic AuPd catalysts supported on Fe-modified ceria. Chemical Engineering Journal, 2015. 260: p. 133-141.

228. Hübner, M., et al., An Au clusters related spill-over sensitization mechanism in $\mathrm{SnO}$ 2-based gas sensors identified by operando HERFD-XAS, work function changes, DC resistance and catalytic conversion studies. Physical Chemistry Chemical Physics, 2012. 14(38): p. 13249-13254.

229. Hübner, M., N. Bârsan, and U. Weimar, Influences of Al, Pd and Pt additives on the conduction mechanism as well as the surface and bulk properties of $\mathrm{SnO} 2$ based polycrystalline thick film gas sensors. Sensors and Actuators B: Chemical, 2012. 171: p. 172-180.

230. Marikutsa, A.V., et al., Role of $\mathrm{PdO} x$ and RuO y clusters in oxygen exchange between nanocrystalline tin dioxide and the gas phase. The Journal of Physical Chemistry C, 2013. 117(45): p. 23858-23867. 
231. Liu, C., et al., The effect of noble metal ( $A u, P d$ and Pt) nanoparticles on the gas sensing performance of $\mathrm{SnO} 2$-based sensors: A case study on the $\{221\}$ highindex faceted SnO 2 octahedra. CrystEngComm, 2015. 17(33): p. 6308-6313.

232. Hvolbæk, B., et al., Catalytic activity of Au nanoparticles. Nano Today, 2007. 2(4): p. 14-18.

233. Wang, D., et al., Bimetallic gold/palladium catalysts: Correlation between nanostructure and synergistic effects. The Journal of Physical Chemistry C, 2008. 112(23): p. 8617-8622. 


\section{CURRICULUM VITAE}

NAME: $\quad$ Alexander Larin

ADDRESS: Department of Physics and Astronomy

102 Natural Science Building

University of Louisville

Louisville KY 40292

EDUCATION \& EXPERTISE:

Ph.D., Physics

University of Louisville (UofL)

$2013-2017$

B.Sc., Physics

Western Kentucky University

$2008-2012$

REFEREED JOURNALS:

- Sensors and Actuators B (Chemical)

- Journal of Applied Physics

- Sensors

PROFESSIONAL ASSOCIATIONS:

- Member of American Physical Society (APS)

- Member of American Vacuum Society (AVS)

PUBLICATIONS:

Papers published in peer-reviewed journals:

- $\quad$ Alexander Larin, Phillip C. Womble and Vladimir Dobrokhotov, Novel highly-integrated MEMS based solid state detectors for analytical gas chromatography, Sensors and Actuators B (Chemical), (2017) (In Press) 
(Available online)

http://authors.elsevier.com/sd/article/S0925400517319445.

- Alexander Larin, Phillip C. Womble and Vladimir Dobrokhotov, Hybrid SnO2/TiO2 Nanocomposites for Selective Detection of UltraLow Hydrogen Sulfide Concentrations in Complex Backgrounds, Sensors 16(9), 1373 (2016).

- B-A. F. Kengne, S. Karmakar, M. Kaura, G. Corti, V. V. R. Sai, I. B. Niraula, A. Larin, J. Hall, D. Sowell, P. J. Hrdlicka, V. Dobrokhotov and D. N. Mcllroy. Self-assembled monolayers of thiols adsorbed on $\mathrm{Au} / \mathrm{ZnO}$-functionalized silica nanosprings: Photoelectron spectroscopy-analysis and detection of vaporized explosives, ACS Appl. Mater. Interfaces 6 (16) 13355-13366 (2014).

- Vladimir Dobrokhotov, Alexander Larin and Dewayne Sowell, Vapor Trace Recognition Using a Single Nonspecific Chemiresistor, Sensors 13 9016-9028 (2013).

- Vladimir Dobrokhotov, Landon Oakes, Dewayne Sowell, Alexander Larin, Alex Kengne, Pavel Bakharev, Giancarlo Corti, Timothy Cantrell, Tej Prakash, Joseph Williams and D. N. McIlroy, ZnO Coated Nanospring-Based Chemiresistors, Journal of Applied Physics 111 044311 (2012).

- Vladimir Dobrokhotov, Landon Oakes, Dewayne Sowell, Alexander Larin, Alex Kengne, Pavel Bakharev, Giancarlo Corti, Timothy Cantrell, Tej Prakash, Joseph Williams and D. N. McIlroy, Towards the 
Nanospring-Based Artificial Olfactory System for Trace-Detection of Flammablell and Explosive Vapors, Sensors and Actuators B 168 138148 (2012).

- Vladimir Dobrokhotov, Landon Oakes, Dewayne Sowell, Alexander Larin, Alex Kengne, Pavel Bakharev, Giancarlo Corti, Timothy Cantrell, Tej Prakash, Joseph Williams and D. N. McIlroy, Thermal and Optical Activation Mechanisms of the Nanospring-Based Chemiresistors, Sensors 12 5608-5622 (2012).

Book chapters:

- Vladimir Dobrokhotov, Alexander Larin, Victor Sysoev and Andrey Lashkov, chapter Integrated Platforms for Artificial Olfactory Systems in the book Advances in Nanotechnology and Applications Volume V, Informa Healthcare USA, Inc. (2013)

PRESENTATIONS:

- Alexander Larin and Vladimir Dobrokhotov, Intelligent MultiFunctional Artificial Olfactory System, 43rd Annual WKU Student Research Conference, March 2013, Bowling Green KY.

- Alexander Larin and Vladimir Dobrokhotov, Application of Spectral Analysis for the Processing of Signals from Metal Oxide Sensors, Kentucky NanoSymposium, August 16-17, 2013, Louisville, KY. 